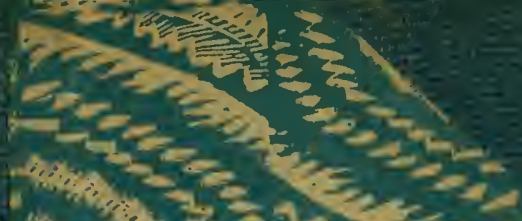

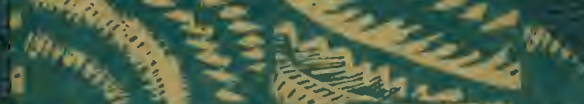

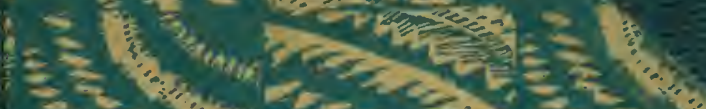

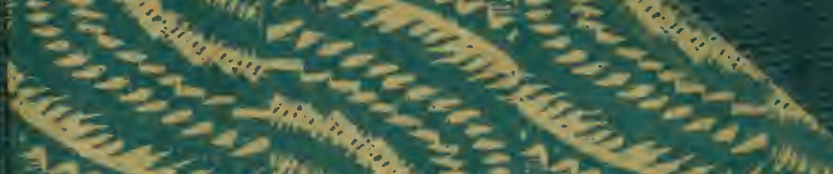

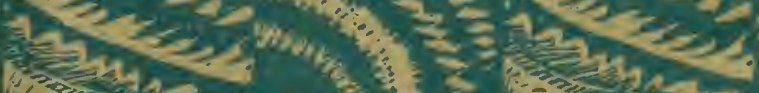
100 ,

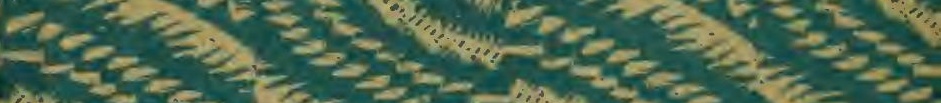

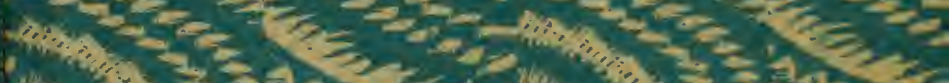

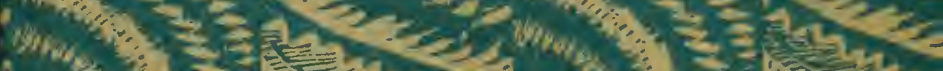

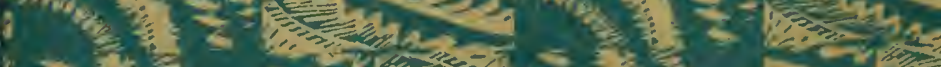

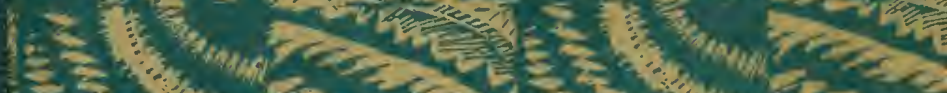

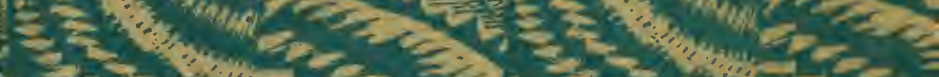

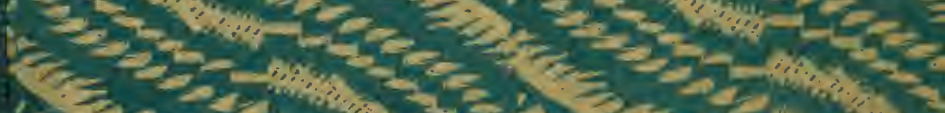

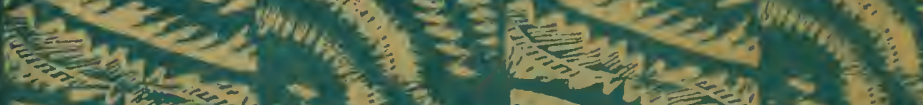

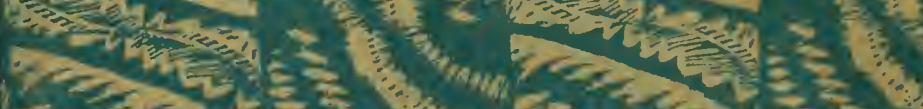

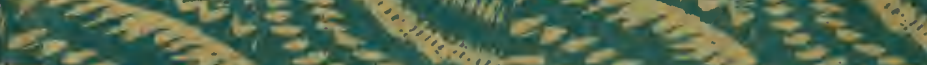

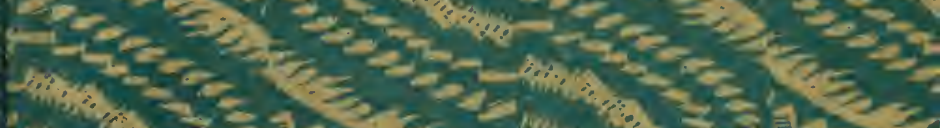

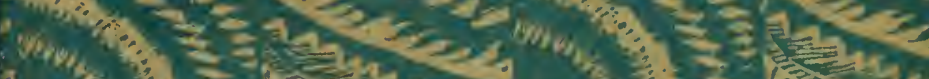
I.

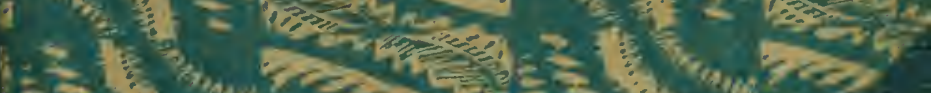

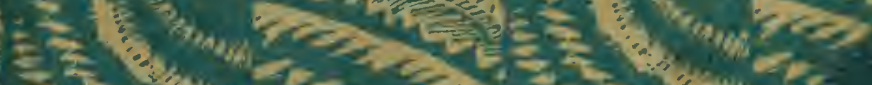

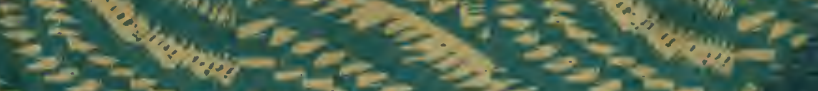

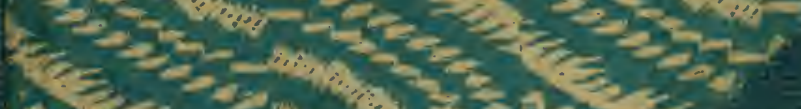

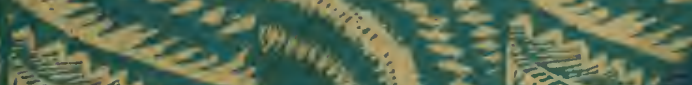

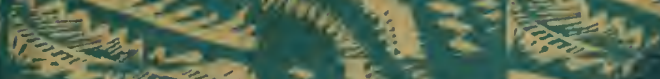

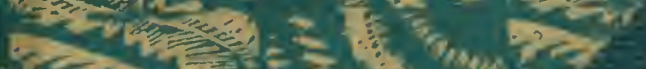

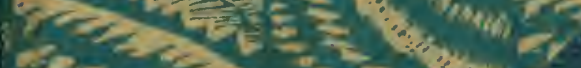

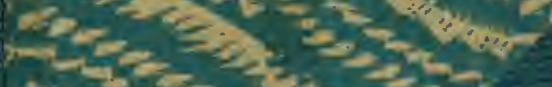
$6,2 e^{2}=25$

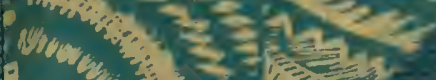

.

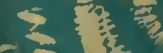




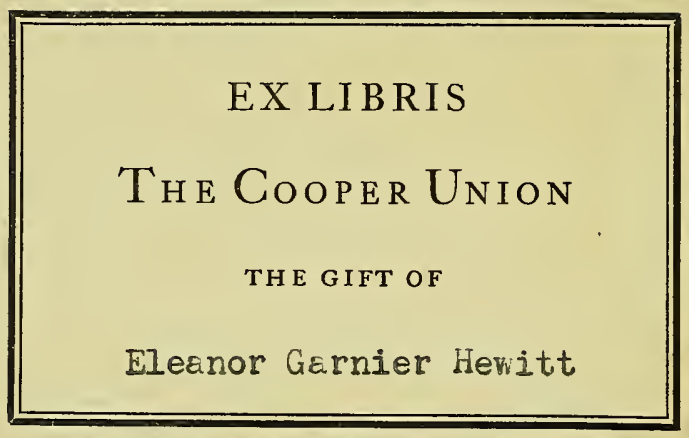


- 









\section{E \\ UUSEE HISTORIQUE}

DES TISSUS 



\section{LE \\ MUSÉE HISTORIQUE \\ DES TISSUS}

DE LA CHAMBRE DE GOMMERCE

\section{DE LYON}

I'RÉCIS HISTORJQUE DE L'ART UE UÉCORER LES ÉTOFFES

ET CATALOGUE SOMNAIRE

PAI

RAYMOND COX

Altaché au Musée

Chargé du cours de décoration des étolfes.

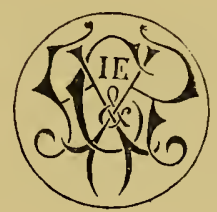

LYON

A. REY ET Cie, IMPRIMEURS-ÉDITEURS

$\{$, HEE GEXTIL; 4

1902 


$$
\begin{aligned}
& \text { NK } \\
& 8806 \\
& 292
\end{aligned}
$$

347
29910 


\section{MEMIRRES DE IA GHAMBRE DE COMMERGE}

MM. ED. AYNARD, O. 絭, A., Président d'honneur.

A. ISAAC, Président.

J. COIGNET, Vice-Président.

P. VINDRY, 粪, Secrétaire.

G. CHAMBEYRON, 袁, Trésorier.

En. PAYEN, $¥$, Administrateur-Délégué de la Condition des soies.

MM. J. CARRET, 絭.

I. CIIAVENT,

F. FAVRE, 管 I.

J. GILLET, 米.

F. GUERIN.

A. LIGNON.

G. LYONNET.

F.MANGINI, O. I.
MIM. M. PAUFIQUE.

L. PERMEZEL, O. *

U. PIL $\Lambda, O$, 并.

F. RICARD, 画.

E. RICHARD.

A. TESTE

E. TESTENOIRE

\section{GOMMisSION DU MUSÉE}

\section{LE BUREAU DE LA CIIAMBRE.}

MM. CHAVENT, FAVRE, GILLET, GUERIN, PERMEZEL, RICHARD.

A. TERME, Directeur du Musée. 



\section{INTRODUCTION}

Le 24 janvier $\mathbf{8 5 6}$, la Chambre de commerce de Lyon discutait pour la première fois l'opportunité de la création d'un musée d'art décoratif.

Fạisaient alors partie de la Chambre: MIM. Brosset, président; Arlès-Dufolr, Tardi, Jaye, P. Memnier, B. Faure ainé, Fougasse ainé, Desgrand, A. Micuel, Bonyardel, H. Arnard, Brisson, Grodon, O. Galline, A. Monterrad.

Après un rapport de son président, M. Brosset, parlant au nom de la Commission des manufactures, etaprès discussion, la Chambre de commerce de Lyon prenait à l'unanimité la délibération suivante :

"Considérant :

"Que l'établissement d'un musée industriel de produits tissés offrira des avantages considérables à l"industrie des soieries, en mettant à la disposition des manufacturiers et des dessinateurs des spécimens et 


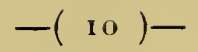

des matériaux qui, éparpillés dans des collections particulières, ne peuvent être consultés qu'avec beaucoup de peine et d'une manière incomplète, soit en aidant à l'achèvement de l'instruction des élères qui suivent les cours de la Martinière ou de l'Ecole des Beaux-Arts, soit enfin en propageant la connaissance pratique du dessin, les notions du goût, et le sentiment de l'art appliqué ì l'industrie,

" La Chambre de commerce délibère ce qui suit:

" Un musée industriel destiné à recevoir des colleetions d'échantillons de dessins, et autres objets utiles à lindustrie lyonnaise, sera établi dans le palais du commerce actuellement en construction.

"Le musée restera placé sous la direction de lit Chambre qui seule le gérera et l'administrera...

"La Commission des manufactures reste chargée de tout ce qui concerne l'organisation de eet établissement. Elle proposera à la Chambre toutes les mesures qu'elle jugera utiles, soit pour provoquer les donations, soit pour l'acquisition et le classement des matériaux. Elle sera libre de s'adjoindre toutes personnes étrangères à la Chambre, même salariées, sauf à en référer à la Chambre... »

(Extrait du rapport de la séance du 24 janvier ı 856.)

Consécutivement ì cette délibération, M. Natalis Rondot fut chargé d'une mission ‘̀ l'étranger. Il alli 
en Angleterre, en Belgique et en Prusse étudier les musées industriels et toutes les questions qui s'y rattachaient. En séance du 9 août $18 \check{7}$, il rendait compte de sa mission avec sa conscience habituelle de statisticien érudit.

Quelque temps après, la Chambre de commerce déléguait deux de ses membres, MM. Arlès-Dufour et Mernier, à l'Exposition des trésor's de l'art, ouverte a Manchester. MM. Bonnefond, directeur de l'Ecole des Beaux-Arts de Lyon, et Jean Tisseur, secrétaire de la Chambre de commerce, leur araient été adjoints. Cette mission donna lieu à différents rapports confirmant la nécessité de créer à Lyon un musée d'art et d'industrie. Toutefois, si l'on s'était mis d'accord sur l'ensemble du projet, on l'était moins sur le caractère particulier et sur le mode d'organisation à donner à la nouvelle institution. M. Natalis Rondot, de nouveau appelé, fut chargé d'exposer et de fixer le plan général définitif.

Il se mit au travail, fit un second royage à Londres et présenta à la Chambre de commerce un rapport qui fut lu dans la séance du 27 septembre 1858 . Ce rapport contenait un projet de musée destiné à représenter toutes les manifestations de l'art et comprenant trois divisions: le département de l'art, composé de tableaux, de fleurs et d'ornements, de moulages, de photographies, de reproductions en 
galvanoplastie, etc.; le département de l'industrie réservé aux matières premières, aux tissus, au matériel de fabrication; le département historique contenant des dessins d'anciens maîtres lyonnais, des dessins ou des modèles de métiers anciens...

Une bibliothèque technique d'ouvrages d'art devait être jointe au musée.

Le rapport de M. Natalis Rondot concluait en ces termes :

" La patrie de Philibert Delorme, de Jacques Stella, de Coysevox, des Coustou, de Gérard Audran, de Philippe de la Salle et de Jacquard a dans son sein les éléments de tous les progrès. Le génie de lïnvention y est sans cesse en éveil ; la distinction et la perfection du travail ne s'y sont jamais démenties. L'imagination des dessinateurs et la science des fabricants ne le cèdent ni à l'esprit ardent d'entreprise des commerçants, ni à l'habileté réfléchie des ouvriers. L'intelligence, l'activité et la prohité sont des vertus communes, et par les grandes manufactures qui ont résolu, avec les métiers mécaniques, le problème d'allier l'exécution correcte au bon marché, Lyon peut soutenir victorieusement la lutte pour la fabrication courante avec l'industrie étrangère. La mode, cette impérieuse maîtresse, n'a jamais trouvé Lyon soumis servilement à ses caprices; elle reçoit, dans ce milieu artiste, pour les 
étoffes de soie, comme à Paris pour les objets de toilette, de fantaisie et de luxe, ces corrections habiles qui tempèrent ses extravagances et donnent un cachet d'élégance, même à des bizarreries fugitives. A tant d'heureux dons, à des traditions, et à des conquêtes par le succès, il faut ajouter des moyens nouveaux : le musée d'art et d'industrie est un de ces moyens. Mais le système de la grande industrie, l'enseignement élevé et varié de l'art et de la science, l'étude des beautés éternelles de la création, le constant effort vers le goût plus pur et un plus noble idéal, voili les meilleures armes pour fortifier et défendre une position que trois siècles de suprématie ont rendue glorieuse. "

La lecture de ce rapport par M. Natalis Rondot fut entendue par la Chambre avec le plus vif intérêt, et la création d'un musée d'art et d'industrie fut rotée. La Chambre décida également que le rapport serait imprimé à ses frais et l'impression confiée à Louis Perrin. Ce travail, dans lequel Natalis Rondot avait mis un peu de son âme, et tant de science et de lumineux aperçus, montrait tout son attachement it sa patrie d'élection (Natalis Rondot était de SaintQuentin). A peine sorti du collège, il s'était passionné pour les questions économiques et statistiques. En 1848, il écrivait à M. Horace Say, vice-président de la Chambre de commerce de Paris, lui soumettant un 


\section{$-(14)-$}

ouvrage sur la statistique industriclle de Paris. Ce projet, il l'exécuta avec la collaboration du jeune Léon Say, auquel il était lié d'étroite amitié depuis l'enfance.

Nous avons pris ees détails dans la belle étude que M. Léon Galle a fait paraître sur Natalis Rondot. Nous devions dire ici quelle fut la part glorieuse prise par lui, lors de la fondation du musée.

En ı86r, M. Jourdeuil en fut nommé conservateur, MM. Brossard et Guillot lui étaient adjoints, et nous sommes heureux de compter encore parmi nous ce dernier, toujours vaillant et fidèle à son poste. Pendant trois ans, leur rôle consista à rassembler les matériaux qui devaient ètre l'embryon des collections.

Le 6 mars ı 86 4, on inaugurait enfin le Musée d'art et d"industrie de la Chambre de commeree de Lyon.

Faisaient alors partie de la Chambre de commerce :

MM. Brosset, président; Arlès-Dufolr, P. Mexnier, B. Falre, Folgasse aîné, A. Michel, H. Aynard, O. Galline, A. Monterrad, P. Desgrayd, C. Lyonnet, L. Guérin, J. Bonnet, A. Vachon, H. Jame, secrétairetrésorier.

En ı 866, M. Brossard succédait comme conservateur à M. Jourdeuil décédé.

A sa fondation, le Musée comprenait non seulement 
des échantillons de soieries, mais toute espèce de matériaux pouvant servir l̈inspiration des dessinateurs industriels et des fabricants.

Trois grandes galeries avaient été aménagées :

Dans la première (façade occidentale) étaient exposés :

Des moulages en plâtre, des terres cuites, des bois et ivoires sculptés, des serrureries anciennes, des orfèvreries, bronzes, objets en fer ciselé, des cuirs et enfin 'des tissus anciens et modernes.

Dans la seconde (façade méridionale) étaient exposés :

Des dessins originaux et reproductions photographiques des dessins des principaux maitres italiens, allemands, flamands, espagnols, français; des peintures décoratives, tableaux de fleurs, fruits et ornements; des esquisses, dessins et peintures de l'école lyonnaise. On y voyait également une collection de modèles de métiers, représentant l'histoire de la mécanique des tissus depuis les temps les plus reculés jusqu'ì nos jours.

Dans la troisième galerie (façade orientale) étaient exposés :

Lhistoire des tissus en général, et particulièrement l'histoire des produits de la fabrique lyonnaise depuis son origine jusqu $\ddot{i}$ nos jours.

Deux vestibules contenaient: l'un des écliantillons 
de l'industrie des papiers peints, l'autre des accessoires du mécanisme du tissage et des spécimens de matière première. Une bibliothèque, enfin, complétait l'ensemble de l'institution.

Nous ne saurions omettre ici de rappeler la part prise par M. Pariset, alors membre de la Chambre de commerce, à cette première organisation du Musée. Sa compétence éclairée fut précieuse, et son nom doit rester intimement lié à ceux des premiers ouvriers de l'œuvre.

En 1885, au décès de M. Brossard, M. Antonin Terme voulut bien accepter, sur les sollicitations pressantes de M. Ed. Aynard, la direction du Musée. La profonde expérience des choses d'art du nouveau directeur devait donner un intérêt tout particulier à une organisation plus savante des collections. Avec un pareil collaborateur la Chambre de commerce de Lyon put songer à transformer le Musée. Elle n'avait pas tardé, en effet, à s'apercevoir que les ressources et surtout les locaux dont elle disposait ne pouvaient pas répondre au programme séduisant, mais trop vaste, qu'elle avait primitivement adopté. Elle résolut de spécialiser l'institution. Elle l'appliqua à un but unique : la collection des tissus, afin d'en faire, ce à quoi elle a réussi, le premier musée du monde en ce genre. Des travaux considérables furent décidés en 189 o. Après une fermeture de plus de neuf mois, on 
inaugurait solennellement les nouvelles salles. L'institution eut alors sa forme définitive, sous le nom de Musée historique des tissus de la Chambre de commerce de Lyon.

Faisaient partie de la Chambre de commerce en I 890 :

MM. Sevene, président d'honneur ; Ed. Arrard, président; Dec, A. Gourd, L. Chavext, J. Caliret, S. Causse, L. Couturier, de la Pochette, J. Gillet, F. Guerix, J. Guinet, A. Jaceuand, S. Lilienthal, C.-L. Mulaton, Ed. Paten, L. Peruezel, U. Pila.

Il ne peut nous appartenir d'apprécier comme il conviendrait le dévouement et la hauteur de vues de ceux qui conçurent et réalisèrent la belle œuvre du Musée. Nous n'hésitons pas toutefois à rappeler ici combien M. Ed. Aynard contribua au développement de l'institution. Avec sa vision très nette du beau et du grand, avec son autorité savante et respectée, il servit, plus que tout autre, sa grandeur et sa richesse. Sous sa présidence, les collections s'accrurent considérablement, et, grâce à sa conviction entraînante, de monuments incomparables, dont le prix parfois élevé aurait pu faire hésiter une prudence moins éclairée. Il ne se contente pas dailleurs de donner ses peines ; son initiative est généreuse et se manifeste aussi par des dons. Le Musée lui doit quelques spécimens de grande valeur. 
M. Ed. Aynard n'est pas non plus seulement un connaisseur aimant les arts pour les jouissances qu'ils procurent ; pour lui, de la collection doit se dégager l'enseignement. A ce point de vue, proclamons bien haut la complète réalisation de son rêve d'économiste.

Les collections ont été classées avec un parti pris savant de chronologie rationnelle. Aussi, une visite attentive du Musée, pour qui sait et veut voir, est du plus haut intérêt, tant au point de vue artistique et industriel qu'au point de vue historique. Jusqu'ici, malgré les trésors accumulés, en France et ì l'étranger, l'histoire de la décoration des tissus n'avait pas été faite. Toutefois, disons-le, d'érudits travailleurs avaient rassemblé les éléments qui devaient aider à la formuler. Les ouvrages qui traitent ce sujet sont de deux sortes: les premiers sont de consciencieux travaux de compilation de textes de tous les pays et de toutes les époques; l'intérêt s'y corse souvent de discussions curieuses sur les origines ou l'authenticité des documents étudiés. Les seconds sont des albums où sont représentés plus ou moins de spécimens, en général sans classement méthodique et surtout sans l'expression d'une théorie didactique pouvant servir directement l'enseignement de la décoration des tissus. Ce sera le mérite incliscutable et personnel de M. Ant. Terme d'en avoir établi le prin- 
cipe. Gràce à son intuition, à sa profonde science, il a su dégager des travaux déjà parus et des richesses accumulées au Musée la première théorie historique complète. Nous sommes heureux d'en fixer la tradition dans ce livre publié par la Chambre de commerce, à l'occasion du bicentenaire de sa fondation.

Les Lyonnais ont le droit d'être fiers de leur Musée; mais ce serait singuliẻrement méconnaître sa valeur que d'y voir seulement la coquetterie d'un joyau; c'est aussi un merveilleux instrument de travail, et la révélation de ce coin imparfaitement exploré jusqu'ici de l'histoire des arts décoratifs. Il appartenait ì Lyon d'en écrire la page qui est celle de la glorieuse industrie qu'elle a faite sienne et prépondérante sans conteste depuis trois siècles.

Il pourrait paraitre étonnant qu'un tel travail n'ait pas tenté les spécialistes de l'histoire des arts. Souvent nous les voyons appuyer leurs discussions de documents tissés, mais aucun n'a songé à se servir d'eux comme point de départ et pourtant... 



\section{PRÉCIS HISTORIQUE}

\section{DE L'ART DE DÉCORER LES TISSUS}

L'art de décorer les tissus est peut-être de tous les arts celui qui permet le mieux de suivre les différentes évolutions de la décoration. Plus que tout autre, il reflète les esprits et les temps, étant par excellence art intime ct utile. Chaque race y laisse l'empreinte de son génie, chaque civilisation la trace de ses efforts et de ses aspirations. Soit que l'impulsion vienne d'un conquérant heureux, soit que le goût s'affine dans une nation prospère, à même de jouir des bienfaits de la paix, chaque civilisation entraîne, correspondant à ses besoins particuliers, des manifestations nouvelles, caractéristiques de son art. Un courant se crée qui, dans la suite des temps, prend une forme spéciale, expression des tendances contemporaines, et ainsi s'échelonnent à travers les âges les différents arts, les différents styles.

Bien loin de se chasser mutuellement, ils se pénètrent, évoluant sans secousses, insensiblement modifiés par des causes multiples : changement dans la compréhension du 
goût, déplacement de la production et de la consommation, pénétration des races, développement des ressources industrielles, etc.

Il s'en faut que chaque étape marque un réel progrès ; souvent le goût s'égare, et, si l'on étudie sa transformation à de longs interralles, il est facile de constater ses fluctuations, dont les hauts et les bas accompagnent d'ailleurs les phases d'enfance, de prospérité et de décadence des civilisations correspondantes. Au Musée historique des tissus, le classement méthodique des collections permet justement de suivre ces évolutions successives depuis les premiers siècles de notre ère jusqu à nos jours. "Chacun de ces documents réunis devient un fait, indique une action, précise une époque et démontre le degré de civilisation, de progrès ou de décadence de la contrée productrice. " (A. Terme, inauguration du cours d'art décoratif des tissus, ir janvier ryor.)

Ainsi M. Terme lui-même nous dit en quelques mots quel a été son but, quelle fut sa constante préoccupation lors de l'arrangement des vitrines. Sans heurt, les arts, les styles nous y paraissent sortir les uns des autres.

Pour l'étude de l'art décoratif, les monuments tissés sont d'ailleurs incomparablement plus nombreux que les spécimens de toute autre branche de la décoration. Le musée n'en possède-t-il pas à lui seul plusieurs centaines de mille? Un tel trésor a permis, au moment de l'organisation, une sélection de modèles plus caractéristiques, et l'ensemble raconte presque sans lacune la suite des différentes évolutions de la décoration. 
Nous ajouterons que les tissus anciens ont l'avantage de nous parvenir sans altérations mensongères; tout maquillage de restauration y est impossible à dissimuler; le temps lui-même, tout en leur ajoutant, ce qui est incontestable, le charme de sa patine, ne nous cache rien de leur technique et de leur exécution. Pourrait-on dire la même chose d'aucune autre industrie artistique? Nous ne le croyons pas. En tête de ce catalogue sommaire des trésors de la Chambre de commerce, nous avons donc pensé qu'il était intéressant de dégager, pour en mieux faire sentir toute la valeur, un résumé chronologique pouvant aider les curieux, les industriels et les artistes intéressés, dans leurs recherches. Le cadre de cette étude est forcément restreint: nous nous bornons ì présenter de grandes lignes tout en jalonnant notre précis, pour expliquer les érolutions artistiques, de quelques détails historiques importants leur ayant servi de point de départ.

Nous ne nous occuperons pas de l'antiquité. Les documents de ces temps reculés sont trop rares pour qu'il soit possible de le faire. Il n'en est pas ainsi ì partir du commencement de notre ère, grâce aux fouilles d'Egypte, dont les hypogées nous ont livré une moisson d'échantillons suffisante pour pouroir entreprendre l'étude de leur technique, tant au point de vue artistique qu'au point de rue industriel.

Au cours de notre ère, nous constatons cinq cirilisations 


\section{$-(24)-$}

principales: la civilisation byzantine, suite de l'antique civilisation romaine; la civilisation musulmane; la Renaissance italienne; la glorieuse période française des $\mathrm{xvul}^{\mathrm{e}}$ et xvul $^{\circ}$ siècles; le monde nouveau enfin, préparé par l'esprit philosophique du xwñe siècle, et issu de la Révolution qui transforme les conditions du travail et de la consommation.

De même que les civilisations nouvelles ont leur enfance, leur période éducative, avant d'arriver à leur période d'autonomie et de production géniale, l'art de ces civilisations passe par deux phases distinctes: phase de préparation, d'adaptation des formules artistiques de la civilisation rivale à sa période descendante, et phase créatrice affranchie de toute influence directe du passé.

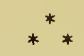

Avant d'entreprendre l'esquisse historique de ces périodes, il nous paraît nécessaire de présenter au lecteur quelques observations, d'un caractère d'ailleurs très général, qui aideront à expliquer les causes qui président aux différentes évolutions. En premier lieu, nous parlerons du génie particulier des principales races.

La caractéristique du génie occidental nous est révélée par les Grecs.Leur art, plein de bon sens pratique, cherchait avant tout la proportion harmonieuse des lignes. Chez eux, l'ornement toujours légitimé par la destination n'apparaît que pour embellir l'utile. La clarté dans la composition, l'affirmation de la forme et la liaison architectonique entre les éléments décoratifs, telles sont les règles primordiales 
qui président ici aux manifestations artistiques, et que nous retrourons a toutes les grandes époques d'art en occident.

L'art musulman nous donnera la note précise du génie oriental. Il dissimule la forme sous l'abondance du détail, les différents motifs s'enchevêtrent les uns dans les autres avec un parti pris savant qui rend souvent difficile à résoudre le problème de leur construction; le modèle nature y est interprété au point de devenir parfois méconnaissable.

Si nous choisissons, pour étudier le grénie oriental, la période arabe, c'est que, pour les tissus principalement, elle nous fournit de multiples exemples; mais nous retrouyerions les mêmes tendances, en étudiant les monuments de l'antique assyrien et égyptien.

Dépassant encore la fantaisie orientale, la conception ornementale de l'Extrême Orient arrive à l'impréru et au mystère. Ici plus de forme intelligible : l'artiste semble viser à la surprise au point de n'être compréhensible que pour un très petit nombre d'initiés. Par ailleurs, son initiative est subordonnée à un formalisme rituel rigoureux. Toutefois, dans son expression, l'art d'Extrême Orient dénote une observation pénétrante de la nature.

En résumé, les caractéristiques de ces différents génies sont: pour l'Occident, la clarté et l'affirmation de la forme; pour l'Orient, la fantaisie et la dissimulation de la forme; pour l'Extrême Orient, l'imprévu et le mystère. Souvent, déjà dans l'histoire des temps, ces différents génies, mis en contact par les efforts de la conquête ou de l'extension 
commerciale, se sont mutuellement influencés. Ils furent alors le principe de nouvelles méthodes décoratives.

L'Occidental a cherché à se vêtir et à s'abriter d'abord, l'ornement est venu après, et ce n'est pas là seulement une question de climat; son instinct le pousse à raisonner indéfiniment son sort, dans l'espoir de l'améliorer.

L'Oriental, fataliste par nature, l'accepte sans le discuter. Le premier craint la mort, le second la méprise. On peut dire que l'Occidental est actif, que l'Oriental est fataliste, que le Chinois est passif. J'Occidental tend constamment au progrès avec la recherche, non d'une lorme définitive, mais du mieux indéfini. L'Oriental, après des efforts considérables, subira pendant des siècles la décadence, sans chercher à réagir, attendant tout du hasard. En Extrême Orient, tout s'est immobilisé depuis des siècles, tout tend à l'isolement pour rester dans l'immobilité des choses réglées, jadis, par le génie de législateurs ayant trouvé la forme correspondant à la nature de la race. Nous allons successivement étudier la composition décorative en Occident, en Orient et en Extrême Orient.

Quelle idée préside en Occident à toute manifestation artistique? L'embellissement raisonné de l'utile. L'utile en art est évidemment tout ce qui tient à l'architecture et au costume, et, puisque pour nous les Grecs sont l'expression la plus parfaite du génie occidental, voyons comment ils comprenaient l'architecture et le costume.

En architecture tout détail répond à un besoin et est subordonné à la destination. A l'origine, seuls les éléments essentiels de la construction apparaissent, et le premier 
soin du Grec, dans son besoin d'harmonie, fut d'en déterminer les proportions.

Du tâtonnement des artistes, naquirent alors des règles bientôt inmuables et basées sur l'expérience. L'ensemble de ces règles constitue ce qu'on a appelé les ordres d'architecture : le Dorique, l'Ionique, le Corinthien, auxquels nous pouvons ajouter le Composite, chacun étant un progrès d'élégance et de richesse sur le précédent. Ces règles sont rassemblées dans un livre : le Vignol, qui est la base de l'enseignement en architecture. Si l'expérience et le talent peuvent plus tard en faire s'affranchir les artistes, ils trouvent du moins là à leurs débuts un résumé de l'expérience de l'antiquité, c'est-à-dire de l'expression la plus complète d'un art qui fut merveilleux et reste le grand modèle. Nous n'avons pas à nous étendre plus longuement sur l'architecture des Grecs, nous ajouterons seulement ceci : c'est que l'art antique à l'époque romaine, s'il se complique, n'en reste pas moins fidèle à ces règles initiales. Il superposera des ordres, il introduira le plein cintre remplaçant la plate-bande, uniquement employée par les Grecs, qui se contentaient de monuments de proportions restreintes; à Rome au contraire les dimensions deviennent énormes, et l'art de l'architecture se marie à l'art de l'ingénieur; et, nous sommes bien là en face d'un exemple typique de cette préoccupation du progrès raisonné de l'utile.

Quant au costume, il est d'une simplicité comparable à celle de l'architecture primitive : il se compose presque exclusivement d'une tunique plus ou moins longue et 
d'un manteau, le péplum ou la toge. La suprême élégance consistera à draper cette toge, de façon à faire ressortir la beauté du nu ou à en corriger les imperfections, suivant le grand principe des Grecs : l'affirmation de la forme. A peine se permettra-t-on une bordure d'ornement, qui ondulera sur le corps, précisant la forme du vêtement lui-même.

Pour le détail décoratif, l'Olympe antique en fournira la majeure partie. Pas une idée, même abstraite, qui n'y soit représentée; à tel point qu'on a pu dire que la mythologie des Grecs fut mère de leur art. Sans recourir au dieu lui-même, la plante, l'animal, les différents accessoires qui lui étaient consacrés, étaient autant de ressources ornementales pour l'artiste, ayant à exprimer l'idée à laquelle le dieu présidait. Le culte particulier à chacun de ces dieux était une mine inépuisable, dont les livres d'iconographie antique nous fournissent d'abondants exemples.

Les Grecs se servent simultanément de l'ornement conventionnel et d'ornements nature plus ou moins stylisés. Les premiers sont du domaine de la géométrie artistique, le plus souvent symétriques, toujours très simples et se réduisant d'ailleurs à quelques types principaux.

La flore est ou interprétée ou nature. L'animal est surtout nature, représenté, en général, sous une forme d'activité, sans accessoires dissimulant le détail anatomique, dont la perfection est une des recherches les plus chères aux Grecs. Cheveux, barbe, poils, conservent leur 
ondulation naturelle, enveloppant la forme rraie. Si la figure est habillée, elle le sera de façon que les plis du costume révèlent les points principaux de nu, précisant le geste, affirmant le mourement.

Etudions maintenantl'art oriental. Ici, l'architecture n'est qu'un support à l'ornement ; parfois le costume lui-même n'existe pas, tandis que l'ornement subsiste. De grandes surfaces de murailles seront dressées dans le but d'y accrocher la décoration, qui n'aura aucun rapport souvent avec la forme et la destination de l'édifice; au point que celuici paraîtra édifié seulement en vue de ce revêtement décoratif. La construction disparaît sous l'abondance de détails que rien ne légitime, pour arriver à un charme chatoyant incontestable, mais qui nous étonne toujours, nous, les Occidentaux. L'élément architectonique n'existe plus. Les arabesques, les complications inextricables de lignes géométriques, placées là comme elles pourraient l'être ailleurs, ont plutôt l'air de n'avoir d'autre principe que la fantaisie.

La flore sera de la plus extrême interprétation, ne rappelant que de très loin le modèle nature, réduite parfois à un schéma de la plus grande simplicité, compliquée parfois aussi d'une infinité de détails.

L'animal, juste de silhouette, s'habille d'ornements; tout détail anatomique devient motif à rinceaux, à volutes, dissimulant la forme vraie. Le poil, la plume s'échafaudent en savantes combinaisons ornementales, et nous dirons la même chose pour la barbe et les cheveux des figures. Quand celles-ci sont habillées, le costume les enveloppe sans rien rappeler du nu. Les animaux domestiques sont le 
plus souvent couverts de toutes sortes de harnachements, de banderoles plissées, flottant au vent, et, si nous retournous en arrière chez les ancêtres des peuples de l'Islam, nous retrouvons les mêmes complications décoratives. Telles, par exemple, les lionnes du palais de Darius; elles sont tout aussi pures de dessin que les chevaux du Parthénon, mais l'artiste les a habillées d'émail. Il semblerait qu'au lieu d'être impressionné comme le Grec par la forme anatomique raisonnée, le Perse ait surtout cherché à interpréter les fugitifs effets de la lumière se jouant sur le poil luisant des bêtes.

La fantaisie dans l'expression n'exclut ni la forme, ni l'idée. Presque tous ces ornements sont construits sur un canevas géométrique destiné à disparaitre. Généralement aussi, ils expriment un symbole, soit que l'inspiration en vienne de dogmes, soit que, dans son langage imagé, l'Oriental prenne l'allure extérieure des choses et des êtres pour évoquer une idée. Quelques-uns de ces emblèmes sont faciles à expliquer; d'autres, venant de rites anciens, demandent une initiation préalable. Il dérive de cette représentation symbolique que les figures animées, particulièrement, n'ont plus la forme d'activité qu'elles avaient dans l'antique grec, mais la forme hiératique. L'art héraldique du moyen âge en dérivera.

La Chine nous fournit la troisième formule décorative. Depuis des siècles l'art s'y est immobilisé, réglementé par la législation rigoureuse des rites. Le Chinois, de nature passive, a ascepté ces règles étroites et routinières; son art est figé, répétant avec une exactitude machinale des types 


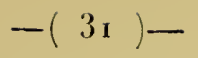

immuablement arrêtés. Six siècles avant notre ère, Confucius détermina ces traditions. Vers le $\mathrm{I}^{\mathrm{er}}$ siècle, le bouddhisme apportera quelques formules nouvelles que les Chinois adaptent rapidement à leur compréhension artistique spéciale. Aux xur" et xive siècles, lors des invasions mongoles, c'est en vain qu'à la cour de Pékin se réuniront des philosophes, des savants, des religieux de tous les pays du monde; de leurs discussions ne sortira pas le moindre progrès. Les types établis suffisent à cette race fermée à laquelle l'avenir importe peu.

Plus de deux mille ans avant notre ère, la technique artistique était déjà perfectionnée en Chine; depuis, les progrès sont pour ainsi dire nuls. La création originale de l'art chinois est le monstre, correspondant aux plus affreuses visions du rêve : tel le dragon, symbole de l'Orient et du printemps, emblème aussi de la puissance impériale; la licorne, incarnation des cinq éléments; le phénix, emblème des impératrices, dont l'apparition annonçait, en outre, l'apparition d'hommes d'état vertueux; la tortue, emblème de la force. Tous ces emblèmes ne rappellent guère lidée que leur image évoque; c'est bien lá le mystère dont la tradition se perd dans la nuit des temps et qui reste incompréhensible pour la masse. Avec le bouddhisme naît un monde de dieux; mais, à la représentation hiératique de l'Inde, le Chinois substituera une représentation grimaçante et terrible. A côté de ces éléments principaux, indéfiniment replacés par des ouvriers plutôt que par des artistes, certains ornements conventionnels définis dont la compréhension est toujours plus ou moins mysté- 


\section{$-(32)-$}

rieuse, même pour les initiés, certains ornements, disonsnous, augmentent encore les ressources décoratives.

Mais si l'idée qu'éroquent ces monstres et ces symboles est de fantaisie troublante, leur exécution, dans le détail, s'inspire étrangement de la nature. Si les figures grimacent, leurs grimaces sont curieusement expressives. Dans les figures, les plis du costume s'accentuent jusqu'à l'exagération, pour mieux préciser la monstruosité de la forme ou du mouvement.

Il n'y aurait pas pour nous grand'chose à retenir de cet art chinois, si les Japonais ne l'avaient fait dévier de son immobilité stagnante. Au vil ${ }^{\mathrm{e}}$ siècle, des relations s'étant établies entre la Chine et le Japon, l'art pénètre dans la grande île. Ses premières manifestations artistiques sont identiques à celles cle sa puissante voisine; transplanté chez les Japonais, l'art chinois évolue. Comme son voisin, le Japonais est matériel, mais cette matérialité, au lieu d'être morose, est gaie et aimable. Son art est essentiellement pittoresque, de beauté calme et primesautière. Le Japonais est d'une extraordinaire habileté de main : aussi, dans sa peinture principalement, il conserve tout le charme de l'esquisse la plus habile ou bien parachève jusqu'au trompe-l'œil. Ces deux qualités qui, au premier abord, paraissent se contredire, sont pourtant également caractéristiques de cet art dont les manifestations restent toujours petites de dimension.

Autres observations :

A l'origine, l'ornement est presque toujours symbolique. Peu à peu, s'éloignant de son point de départ, cet orne- 


\section{$-(33)-$}

ment devient courant; il tombe dans le domaine commun; il n'a plus sa signification première ; sa forme ellemême se dénature. C'est ce qui nous explique comment nous retrouvons loin du pays qui les a conçus, et longtemps après leurs premières manifestations, des motifs décoratifs que nous pourrons imputer à l'art d'une époque bien antérieure à celie de leur exécution.

Autrefois, en Orient, comme en Occident, les artistes étaient des croyants; de plus, ils travaillaient dans un but bien défini et d'après des programmes imposés. Aujourd'hui, l'invention décorative relève du producteur seul : il faut qu'il impose son ceuvre. C'est dans les besoins de ses contemporains qu'il devra chercher le principe de ses conceptions; dans l'art industriel surtout, la destination devra préoccuper sa pensée. L’inspiration symbolique ayant abandonné l'artiste, l'étude constante de la nature fera sa force; mais ce serait folie de sa part de se refuser le bénéfice de l'expérience des siècles. Aussi, est-il indispensable qu'il approfondisse les beaux exemples que lui ont légués ses devanciers. Leur connáissance sera son plus merveilleux outil, qu'il s'agisse de la composition ou de l'exécution de ses créations.

Au cours de ce précis historique, nous serons amené à étudier tous les genres de tissus. Par une fortune bizarre, il est impossible de les désigner par leur nom; et pourtant, nous connaissons beaucoup de ces noms. Dans un travail remarquable, Francisque Michel passe en revue les documents les plus divers: inventaires, chansons de gestes, lois somptuaires, romans, etc., de toutes les époques et de 
tous les pays. L'auteur donne une suite interminable de dénominations de tissus précieux (dénominations le plus souvent dues à la fantaisie d'un moment), sans pouvoir déterminer ceux auxquels elles se rapportent. Il est fort probable qu'il en sera longtemps ainsi. Même pour les tissus modernes, il est bien difficile de se renseigner d'une façon précise, à plus forte raison pour les anciens. MM. Rondot et Pariset constatent le même fait.

Pour l'art de décorer les tissus, nous diviserons notre ère en cinq grandes périodes : période byzantine, période arabe, période italienne, période française et enfin nos contemporains.

\section{PÉRIODE BYZANTINE}

Cette période comprend environ les huit premiers siècles de notre ère. Pour l'étudier, nous avons les précieux échantillons trouvés dans les sépultures coptes.

Voyons d'abord quel était le monde connu à l'origine de cette période dite byzantine. C'était presque exclusivement l'empire romain. Quels étaient alors les pays producteurs?

Rome elle-même n'était pas industrielle. La plus raffinée de ses provinces, la Grèce, la fournissait de tous les produits d'art el d'industrie dont elle avait besoin. Byzance, 
par sa situation aux portes de l'Orient, était le grand entrepôt, le port d'importation et d'exportation par excellence. Là arrivaient les navires de cette fameuse Phénicie, dont Auguste avait fait une province romaine et dont l'activité commerciale avait fait l'étonnement de toute l'antiquité. Ses hardis navigateurs couvraient la Méditerranée de leurs vaisseaux. Non contents de parcourir la Palestine, la Syrie, l'Arabie, I'Assyrie, la Babylonie, la Perse, l'Egypte et toute la côte méditerranéenne, les Phéniciens s'étaient ouvert, par la mer Rouge, le chemin des còtes orientales de l'Afrique et, par le golfe Persique, celui de l'Inde. Ils trouvaient ainsi à s'approvisionner de tous les produits que l'Europe a de tout temps demandés à ces contrées lointaines.

Leur industrie était aussi considérable que leur marine. Homère parle des teinturiers de Sidon. On sait que la pourpre de Tyr fut un des principaux objets de luxe chez les anciens. (Par pourpre ne pas entendre seulement le rouge violet, mais un genre particulier de teinture organique provenant du suc de certaines plantes, de certains coquillages, et donnant de nombreuses colorations diffé rentes.)

Les Phéniciens n'excellent pas moins dans l'art de tisser les étolfes, dans les ouvrages de verrerie dont on leur attribue l'invention, dans la fabrication des armes, des bijoux, etc., etc. La Bible et les plus anciens documents énumèrent une suite interminable de produits sortis de leurs fabriques.

A Babylone, à Memphis, à Suse, à Ninive, dans tous les 
grands centres, des quartiers entiers leur étaient réservés pour exercer leurs industries et leur commerce. La Crète, Chypre, Rhodes furent colonies phéniciennes. Partout, les Phéniciens avaient initié les peuples à leurs industries, et tous ces peuples étaient devenus colonies romaines sans rien perdre de leur activité, grâce d'ailleurs au système de colonisation des Romains. Ceux-ci ne ménageaient pas les encouragements; ils respectaient toutes les coulumes, ne froissaient aucun sentiment chez lespeuples conquis. Ils ne changeaient rien à leur organisation in térieure. Non seulement ils favorisaient leurs institutions, protégeaient leurs coutumes, mais ils allaient jusqu'ì adopter leurs croyances religieuses. Leur habileté consistait alors à rapprocher des leurs tout ce qui pouvait avoir quelques points communs. Leur Olympe était élastique, déjà si encombré, que peu leur importaient quelques dieux de plus ou de moins. A Rome même, il était de bon ton d'avoir un culte spécial pour ces dieux étrangers, comme celui d'Isis entre autres.

De leur côté, pour plaire aux conquérants, qui étaient en même temps de si bons clients, les peuples soumis s'empressaient de confondre tout ce qui pouvait se mélanger dans leurs dogmes réciproques.

Nous ne parlons pas de la Chine restée fermée et mystérieuse, grâce à sa constitution et aussi grâce aux Parthes qui en fermaient soigneusement la route pour se réserver le bénéfice des transactions commerciales.

En somme, les grands foyers industriels sont au commencement de notre ère : la Grèce, l'Asie Mineure et l'Egypte. 
Le sol de l'Egypte, sablonneux et très sec, conserve merveilleusement tout ce qu'on lui confie. Sous les Ptolémées, l'usage de l'embaumement des corps avait peu ì peu disparu. Les cadavres, ensevelis dans de riches costumes, étaient simplement déposés à tleur de terre ( 1 ou 2 mètres) dans des réduits maçonnés en briques crues ou dans des auges en pierre, quand le mort était romain.

Des découvertes récentes nous ont livré quelques secrets de l'ancienne splendeur de l'Egypte. Dans les tombeaux ouverts, on a trouvé, entre autres documents, les spécimens si intéressants de tissus que depuis quelques années on est convenu d'appeler gobelins coptes. En voici la raison : 1I. Gerspach, alors directeur de notre grande manufacture de tapisseries, eut l'idée de faire copier par ses ourriers, quelques-uns de ces spécimens d'étoffe, et les résultats obtenus l'amenèrent à conclure qu'ils avaient été fabriqués sur des métiers analogues à ceux encore employés de nos jours par les ouvriers de haute et de basse lisse; de là le nom de gobelins coptes.

Cette conservation des sépultures coptes est d'autant plus heureuse pour l'histoire de l'art que l'époque grecque, pas plus que l'époque romaine, n'a laissé de traces en Egypte en tant que grands monuments. Il n'en est plus ainsi, pour les arts de détail, tels que celui que nous étudions spécialement, l'art de décorer les tissus.

Les Coptes sont les descendants plus ou moins directs des Egyptiens. Leur habileté comme tisserands était légendaire, aussi fournissaient-ils en grande partie l'empire romain de tissus sortis de leurs fabriques. Ces tissus pas- 
saient par Byzance et Alexandrie qui les exportaient ensuite.

Disons avant tout que, jusqu'au vile siècle, les tissus coptes ne contiennent pas de soie. En réalité, le précieux textile était connu, mais la Chine, seule, possédait le secret de son origine. Nous voulons dire par là que l'Occident ignorait l'élevage domestique du ver à soie, du mûrier et, le dévidage du cocon. La soie sauvage de certains bombyx était connue. Les Parthes, pour lesquels le commerce des soieries était une source considérable de revenus, fermaient soigneusement la route du Céleste Empire. Dans la seconde moitié du $\mathrm{n}^{\mathrm{e}}$ siècle pourtant, une mission partit de Rome en ambassade, passa par les ports de sa colonie égyptienne et le golfe Persique, longea les côtes de l'Inde, pénétra daus les mers de Chine, et des relations directes s'établirent entre les deux grands empires.

Les Chinois expédiaient la soie à l'état de tissu uni. Le prix élevé de la matière première fit que l'on parfilait ces tissus pour en fabriquer d'autres, extrêmement légers, dans le genre de ces lameuses étoffes transparentes appelées byssus. Quelques fils aussi étaient employés pour rehausser l'éclat de certaines broderies.

M. de liémusat raconte que, vers le $11^{\mathrm{e}}$ ou le $\mathrm{III}^{\mathrm{\theta}}$ siècle, une princesse chinoise fiancée à un roi du Khotan, apporta par fraude, dans sa nouvelle patrie, des eufs de vers à soie du mûrier. Est-ce bien de l'histoire? Nous devions du moins signaler la légende.

Ce que nous savons de plus certain sur l'introduction de la sériciculture en Occident, c'est que, sous Justinien, au 


\section{$-(39)-$}

$\mathrm{ri}^{\mathrm{e}}$ siècle, Constantinople apprenait son secrel de deux religieux, moines ou bonzes, qui apportèrent la précieuse graine dans des bâtons creux, des bambous.

Les Coptes avaient incontestablement un art particulier, art surtout géométrique à combinaisons de lignes, d'entrelacs et de fleurs très stylisées. Jusqu“à la fin du moyen âge nous le retrouvons isolé ou uni aux arts des pays consommateurs et conquérants. Colonie greeque au moment du dénombrement de l'empire d'Alexandre, l'Egypte est colonie romaine au commencement de notre ère. Il était naturel que les Coptes se préoccupassent des goûts de la métropole, sa riche cliente ; aussi, l'art antique jusqu'à la fin du $11^{\mathrm{e}}$ siècle, l'art byzantin à partir $\mathrm{du} \mathrm{r}^{\mathrm{e}}$, apparaissent dans leurs compositions.

Sous la dynastie sassanide, les Perses rivalisaient de luxe avec leurs voisins de l'Inde et de l'empire romain; travaillant pour eux, les Coptes s inspirent également de lcur art particulier, comme de l'art arabe, au moment du triomphe de l'Islam.

Aussi nous diviserons l'étude de ces tissus coptes en cinq parties : art copte proprement dit; inspiration antique; inspiration byzantine, inspiration sassanide et inspiration arabe.

Pour la période dite byzantine, lart eopte à inspiration antique $\left(\mathrm{I}^{\mathrm{er}}, \mathrm{II}^{\mathrm{e}}\right.$ et $\mathrm{II}^{\mathrm{e}}$ siècles) sert de préparation à la phase qui comprendra les $\mathrm{r}^{\mathrm{e}}, \mathrm{v}^{\mathrm{e}}, \mathrm{r}^{\mathrm{e}}$ et $\mathrm{r}^{\mathrm{e}} \mathrm{e}^{\mathrm{e}}$ siècles, l'inspiration 
sassanide faisant, au contraire, partie de l'évolution qui nous amènera à la période arabe.

Quelle est la forme de la composition pendant la période byzantine? En général le sujet principal, qui varie suivant les époques, est renfermé dans une forme géométrique, carré, cercle, losange, etc., donnant lieu elle-même à un encadrement architectonique plus ou moins décoré. Evidemment, les proportions de cette disposition seront d'autant plus harmonieuses qu'elles seront plus près de l'antique, toujours si merveilleux de pondération.

Avant d'entrer dans le détail, disons un mot de l'utilisation des tissus décorés que nous avons à notre disposition pour étudier l'art copte. Ils proviennent des fouilles faites en Egypte dans les hypogées. Ce sont, ou des pièces de costume, ou des coussins funéraires (sur ces coussins on plaçait la tête et parfois les pieds du mort). Le costume se compose d'une tunique qui reçoit différents ornements que nous allons indiquer: des galons au cou et aux manches, les paragaudes (la paragaude est un souvenir du costume militaire, c’est la chaînette ou la courroie qui maintenait la cuirasse; s'allongeant de plus en plus, la paragaude deviendra l'orfroi des vêtements liturgiques); les tabulæx (tablettes, petits tableaux); les clavi (clous, ornements en forme de tête de clou). Suivant le grade et suivant l'époque, ces différents ornements changent. La tunique s'arrêtait un peu au-dessus du genoux; les femmes en portaient en dessous une seconde qui descendait jusqu'aux pieds.

Par-dessus la tunique, un manteau plus ou moins long, 
pièce d'étoffe carrée, dérivée de l'ancienne chlamyde grecque. Ce manteau s'attachait sur l'épaule droite au moyen d'agrafes ou de fibules plus ou moins riches; il laissait le bras droit libre, l'autre étant caché sous la draperie.

Comme dans tous les tissus exécutés sur le métier de tapissier, on trouve dans les tissus dits gobelins coptes des relais et des liures. Le relai est cette solution de continuité de la trame nécessitée par certains changements de couleurs ou certains contours verticaux. La liure est un croisement de fils de trame destiné justement à rattacher les relais. Souvent le dessin est obtenu par un fil plus fin que les autres se détachant sur le fond; des expériences faites par M. Gerspach, il résulte que nous sommes en présence de véritables ressauts, c'est-à-dire d'une exécution obtenue à la broche volante, passée en mêne temps que le reste de la trame et non au moyen d'une aiguille brodant aprés coup sur le fond, ainsi qu'on l'avait cru d'abord. La paletle, au commencement de notre ère, ne comprend guère que la couleur écrue et la gamme des pourpres plus ou moins foncés, variant suivant la mode du moment : «Pendant ma jeunesse, dit Cornélius Nepos, le pourpre violet était en vogue, bientôt on lui préféra le pourpre rouge de Tarente, et ensuite le double pourpre de Tyr. »

Peu à peu on introduira des bleus, des jaunes, des verts, en tout une douzaine de tons. Les couleurs coptes sont d'une résistance très remarquable. Malgré leur exposition au soleil ardent de l'Egypte, la différence entre l'endroit 
et l'envers des tissus est insensible; leur long enfouissement n'en a pas davantage altéré l'éclat.

Jusqu'au $\mathbf{v}^{e}$ siècle, le fond de la tunique el du manteau est le plus souvent uni; après, il sera décoré d'un jeu de fond.

Une tunique de chevalier byzantin avait parfois cinq ou six cents figures tissées ou brodées.

Art copte proprement dit. - L'art personnel des Coptes apparaît dans ces compositions très simples de coloration où, sur un fond de laine brune, noire ou pourpre, un fil écru trace des zigzags capricieux d'entrelacs, faits à la broche volante. Ces compositions, à dessius géométriques, sont d'une fantaisie et d'une variété infinies, et offrent au dessinateur des ressources inépuisables. Peut-être fautil voir, dans ces dessins géomélriques, l'ancien art phénicien. On les rencontre, en effet, beaucoup dans leur antique décoration. Celte même formule fera le fond de la première ornementation arabe, quand les musulmans rejetteront de parti pris tout ce qui leur rappellera l'art des pays restés chrétiens. Ceci tendrait à nous prouver que nous sommes bien en présence d'un art indigène spécial à la race.

La flore et la faune sont également employées par les Coptes. La flore est trés stylisée et comme aplatie. Elle se présente plutôt à l'état d'ornement foliacé. La faune fournit quelques animaux : le lièvre, le guêpard, le lion, le dauphin, la colombe, etc. Toutefois, devrions-nous peutêtre voir, dans ces manifestations animées, une réminis- 
cence, une conséquence plus ou moins directe des arts dont les Coptes s'inspirent .

Inspiration antiqne. - Quand les Coptes s'inspirent de l'antique, l'ensemble de la composition est beaucoup plus correct de dessin el d'une grande sobriété de coloration. Dans les plus anciens ( $\mathrm{r}^{\text {er }}$ el $\mathrm{Il}^{\mathrm{e}}$ siècles), le décor s'enlève en clair sur le fond foncé. Le motif décoratif évoque celui des vases gréco-romains toujours ton sur ton. Le sujet rappelle les jeux du cirque, la chasse, la guerre, ou bien est emprunté à l'inépuisable iconographie de la mythologie païenne. Ia technique des tissus coptes de cette phase a inspiration antique est supérieure; certains spécimens sont d'une si précieuse exécution qu'on pourrail les croire tissés de soie; ils sont pourtanl de laine ${ }^{2}$.

Dès le $11^{\mathrm{e}}$ siècle, la richesse tendra vers la couleur, très sobrement d'abord, par taches épisodiques de bleu, de jaune, de rouge, introduites dans l'ensemble comme des gemmes, le reste étant traité en pourpre foncé sur fond écru. Les animaux et les figures sont trailés comme nous l'avons indiqué dans nos observations générales. Tant que l'inspiration reste antique,les différentes taches de la composition se pondèrent sans répétition symétrique. Le motif principal lui-même rentre dans le genre de composition dite pittoresque ${ }^{3}$.

1 Voir dans notre ourrage, l'Arl de décorer les tissus, pl. III, tous les numéros moins le 6 et le is (Paris, P. Mouillot, imprimeur-éditeur; Lyon, A. Rey et Cic éditeurs, 4, rue Gentil, un volume grand in-folio, aree planches en couleurs. publié sous le patronage de la Chambre de commerce de L,yon).

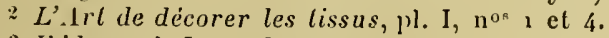

3 Ibidem. pl. I, nos 3 et 5 . 
Inspiralion byzantine. - Lorsque, au rv $v^{e}$ siècle, sous Constantin, les chrétiens purent afficher leurs croyances, les symboles pieux, les sujets tirés de l'Ancien et du Nouveau Testament, apparaissent dans la composition, en même temps que quelques détails pris au pays d'où venait la religion nouvelle. L'ordonnance architecturale reste la même, mais le dessin perd de la correction qu'il devait à l'antique, tandis que le byzantin va fournir sa riche palette. En général, les différents éléments de la décoration se reproduisent symétriquement de chaque côté de l'axe. Les encadrements architecturaux s'alourdissent d'expression, divisant plutôt en compartiments, la composition. Par ailleurs dans le costume, l'usage se généralisera de plus en plus de le surcharger d'images. En vain les pères de l'Eglise s'élèveront contre cette richesse excessive, aussi loin de la simplicité antique que des aspirations vraiment chrétiennes. A mesure que nous nous éloignons de l'époque de Constantin, la richesse de la palette prend davantage d'importance, au détriment du dessin, au point que, sous Justinien, celui-ci est devenu barbare et la coloration éclatante ${ }^{1}$.

"Sous Constantin, dit Châteaubriand, prit naissance cetle monarchie religieuse, qui, tendant à se resserrer sous un seul chef, eut ses lois particulières et générales, ses conciles, sa hiérarchie, ses dignités .. Tandis qu'honorés des princes et chéris des peuples les évêques étaient élevés aux plus hauts emplois politiques, ils remplaçaient

${ }_{1} L^{\prime} A r l$ de décorer les tissus, pl. I, nos 8, 13 ; pl. XLVI, no 6. 
encore les magistrats inférieurs dans les fonctions municipales et administratives, s'emparaient par les sacrements des principaux actes de la vie civile et devenaient les législateurs et les conducteurs des nations."

Un des premiers actes de cette monarchie religieuse arait été le concile de Nicée. Les évêques y fixèrent, non seulement le symbole complet de la foi catholique, mais, pénétrant l'organisation de toutes choses, en fixèrent les lois. Les arts y furent réglementés. Au vile siècle, une interprétation fâcheuse de ce rèğlement arrête le premier essor de l'art chrétien. "La disposition des images n'est pas de l'invention des peintres, c'est une législation et une tradition approuvées par l'Eglise catholique, et cette tradition ne vient pas du peintre, la pratique seule est son affaire, mais de l'ordre et de l'invention des Saints Pères qui les ont établies. »

Par suite, l'art byzantin s'immobilisera dans un formalisme rigoureux qui trouvera un asile dans les monastères, au mont Athos particulièrement, d'où il rayonnera dans le monde chrétien pendant tout le moyen âge.

Inspiration sassanide. - Au $\mathrm{rr}^{\mathrm{e}}$ siècle, les Coptes ne produisent plus seulement pour le monde romain et byzantin, mais aussi pour cette autre civilisation parallèle, créée par la dynastie sassanide qui inaugure, pour la Perse, une nouvelle ère de splendeur. Tandis qu'elle était greeque, romaine ou parthe, la Perse avait plus ou moins adopté l'art et la religion de ses conquérants. L'avènement de la nouvelle dynastie fut le signal d'une véritable renaissance religieuse et artistique tendant à revenir au beau temps des 


\section{$-(46)-$}

Cyrus et des Cambyse. Les Perses s'emparant d'une partie de l'Egypte, les Coptes travaillent pour eux et, naturellement, empruntent aux dogmes et aux goûts de leurs nouveaux maîtres leurs formules décoratives particulières, que nous allons trouver dans les manifestations tissées, isolées ou jointes aux différents détails ornementaux de leur art proprement dit, ou de leur art mitigé de byzantin. Parmi ces formules, deux principales appelées à jouer un rôle important, non seulement dans la décoration de cette époque, mais que nous retrouverons pendant toute la période arabe: l'autel du feu ou la pyrée, l'arbre de vie ou le homa. On sait que les disciples de Zoroastre adoraient le feu ; en Perse, des tours élevées remplaçaient les temples, et à leur sommet brûlait le feu sacré entretenu par les mages. La pyrée en est le souvenir.

L'arbre de vie était pour les Perses le symbole de l'éternelle renaissance des êtres et des choses On le représentait à l'origine sous la forme d'un palmier, plus tard sous forme de végétations plus ou moins fantaisistes où paraissent toujours simultanément fleurs, feuilles et fruits. Dans la plupart des compositions coptes à inspiration sassanide, nous retrouvons le souvenir de ces deux emblèmes.

La forme architecturale de la composition reste la même, c'est toujours la division en compartiments géométriques rlans lesquels le motif décoratif, pittoresque au moment de l'inspiration antique, symétrique quand l'inspiration est byzantine, continuera à être symétrique avec l'inspiration

1 L'Art de décorer les tissus, pl. XLVI, no 8. 


\section{-( 17$)-$}

sassanide, mais les détails qui se répétent symétriquement, seront séparés par l'une ou l'autre de ces figures symboliques: le homa ou la pyrée ${ }^{1}$.

Jusqu'à la fin du vil ${ }^{\mathrm{e}}$ siècle les relations plus ou moins pacifiques des races d'Orient, d'Occident et même d'Extrême Orient feront se pénétrer les tendances des différentes compositions artistiques, qui restent dans cette forme que nous venons d'étudier, forme avant tout architecturale, dont lïnspiration première remonte à l'antique. Peu à peu le costume s'est modifié. Son ornementation n'a plus de signification aussi rigoureuse de distinction de grades et de castes, la mode veut cles tissus à fond entièrement décorés ${ }^{2}$.

Aux tabulie, aux clavi succèdent des jeux de fond. Par ailleurs, la soie, qui apparaîl couramment dans le tissu décoré, révolutionnera d'autant plus l'art des étołfes, qu'en même temps que la Chine livrait son secret du ver à soie du mûrier et du dévidage des cocons l'Occident dut connaître ces métiers perfectionnés en usage de l'autre côté de l'Himalaya où l'on fabrique des soieries depuis des milliers d'années. C'est donc en réalité de la fin $\mathrm{du} \mathrm{v}^{\mathrm{e}}$ siècle qu'on pourrait dater l'histoire des tissus décorés, toutes ces étoffes, que nous venons d'étudier, étant des tapisseries, c'est-à-dire fabriquées sur le métier de haute ou basse lisse. Puisque les deux civilisations byzantine et sassanide sont parallèles, que les Coptes fabriquent indistinctement pour

1 L'Art de décorer les tissus, pl. XLVI, n8.

2 lbidem, pl. I, $\mathrm{n}^{\circ} \mathrm{I} 3$. 


\section{$-(48)-$}

elles, s'inspirant des deux tendances et les faisant d'ailleurs indifféremment accepler des deux côtés, voyons ce que le Byzantin prendra au Perse en échange de ce que celui-ci lui empruntera.

Une des formes les plus courantes de la composition sera l'ordonnance de roues qui est évidemment d'origine byzantine. Nous la retrouvons jusqu'au xü siècle très employée surtout dans le milieu de fabrication avoisinant le Bosphore. (Cette ordonnance de roues nous l'avons retrouvée en Chine à cette même époque du vin ${ }^{\circ}$ siècle). Ces roues sont tangentes ou isolées ${ }^{1}$.

La seconde forme de la composition, non moins exploitée au $\mathrm{vuI}^{\mathrm{e}}$ siècle, est celle à ordonnance. de lignes horizontales. Elle est d'origine sassanide; c'est la forme architecturale favorite de l'antiquité de Perse qui nous offre dans ses monuments de longues façades uniformément décorées de motifs qui se répètent indéfiniment le long de lignes horizontales ${ }^{2}$.

Le Byzantin n'hésitera pas à adopter ce genre de composition à cause de sa clarté, le détail décoratif changeant seul.

Une troisième ordonnance est celle que nous appellerons losangée, Byzantins et Sassanides s'en servent également, le Byzantin pour sa division architectonique, le Perse à cause de la répétition du motif ${ }^{3}$.

Il nous reste à parler d'une dernière disposition, cellelà tout orientale, et qui sera l'origine du semis arabe. Ici,

1 L'Art de décorer les tissus, pl. II, no 1 .

2 Ibidem, pl. IV, $\mathrm{n}^{\circ} 3$.

3 Ibidem, pl. I, no 10. 
plus de compartimente géométriques, seul le motif qui le décorait subsiste simplement juxtaposé, répété en semis ${ }^{1}$.

Souvent nous retrouvons dans le même tissu l'alliance du semis et de l'ordonnance de lignes horizontales. En dehors du homa et de la pyrée, les Sassanides se servent de différents détails ornementaux dont la chasse et la guerre fournissent de nombreux éléments. Guerriers, chasseurs, animaux domestiques ou sauvages se reproduisent alors symétriquement de chaque côté d'un homa ou d'une pyrée. Souvent, dansle décor, l'animal n'a plus la formed'activité que lui prêtait le Byzantin: il devient hiératique. Affrontés ou adossés de chaque côté de homas ou de pyrées, ces bêtes semblent les gardiens de ces symboles.

La flore est très stylisée. Nous arrivons d'ailleurs ici à un moment où la fantaisie arabe va s'affirmer, au moment du triomphe de l'Islam qui imposera son art en même temps que son dogme.

\section{PÉRIODE ARABE}

La période arabe commence au vill siècle. Son histoire est celle de l'art de la brillante civilisation musulmane. Quelque mystérieuse que soit cette époque du haut moyen âge, aucune n'est plus riche en invention décorative. $\mathrm{Si}$ d'épaisses ténèbres en enveloppent encore la politique, il n'en est pas ainsi pour l'art quand nous considérons l'abondance de preuves exhumées. Elles nous dévoilent

${ }_{1}$ L'Art de décorer les tissus, pl. V, $\mathrm{n}^{0} 2$. 
le secrel d'une société merveilleusement douée; si riche même sera l'enseignement qui s'en dégage, que nous y trouverons le principe de presque toules les formules décoratives qui suirront. La lueur émanée nous éclairera nous-mêmes dans nos recherches, longlemps, toujours peut-être.

Ce sont encore les nécropoles qui nous ont aidé à soulever le voile de ce passé. Ce n'est plus seulement en Egyple que les savants vont fouiller les tombeaus, mais un peu partout. Il ne faudrait pas trop insister sur ces curiosités de nos érudits, leur ardeur travailleuse est leur excuse, les services qu'ils rendent à l’art, aux sciences, à l’industrie, légitiment à peu près cetle violation du repos des morts. L'usage s'élait généralisé d'ensevelir les cadavres dans de riches suaires, de les recouvrir de tissus précieux. Ce luxe funéraire atteint même de telles proportions que sans cesse nous voyons les législateurs s'élever contre celte prodigalité ruineuse. L histoire du moins y gagne. Nos musées recueillent ces reliques, les installent dans des palais somptueux, tirant de l'oubli ces vestiges de l'orgueil humain. Peut-être celui-ci y trouve-t-il son compte après tout! Quelque Thaïs ou quelque Pétrone auraient probablement accepté, avec une certaine satisfaction professionnelle, l'idée que leurs élégances glorieuses brilleraient encore en belle place tant de siècles après eux.

Pour l'Europe, le moyen âge est une période d'incubation, d'où sortira notre organisation moderne. Assaillie au dehors, miné au dedans, le monde romain succombe. Pour enfanter une civilisation nouvelle, il faudra à 
l'Europe dix siècles, pendant lesquels les races les plus diverses combattent entre elles. La féodalité, qui se soucie peu des arts, morcelle et rançonne partout. Charlemagne essayera bien une réaction, mais ses successcurs seront impuissants à continuer l'effort de son génie, et l'anarchie régnera de nouveau. Les lettres seépuisent en futiles discussions de mots. Pour les arts, le formalisme rituel et lintransigeance religieuse des iconoclastes font que presque toute l'œurre profane des anciens est détruite. A l'intérêt de la composition, à la noblesse et à l'exactitude du dessin on préfére l'éclat de l'or, des gemmes, des couleurs. Dépourvus des ressources de l'imagination, les artistes deviennent ourriers reproduisant partout les mêmes formules, les mêmes sujets réglementés ; il en sera ainsi jusqu'à ce que le génie de la Renaissance guidé par Dante vienne rénover les sciences, les lettres et les arts, délivrant l'Europe de sa torpeur. Mais à côté de cette décadence de l'Occident, décadence plutôt apparente, puisqu'elle préparait quand même le triomphe moderne, une civilisation 'mystérieuse, mais superbe, naît à la suite des armées du prophète.

Parti de la Mecque, l'Islam en fait le centre d'un immense empire, qui va de l'Himalaya à l'Atlantique. Sur les ruines des civilisations antiques égyptienne, assyrienne, gréco-romaine, l'art arabe s'épanouit, imprévu, fantaisiste, savant, avec une telle variété d'expression qu'il reste le grand modèle, l'inépuisable source pour les artistes. La prospérité arabe a dû être merveilleuse, à voir ses restiges, et nous comprenons, par ce qui nous 


\section{$-(52)-$}

reste, l'étonnement des croisés devant ces splendeurs, et leur impérieux besoin de jouir de ce luxe si nouveau pour eux, et leur désir de créer à leur tour une industrie similaire, après un tel enseignement.

Il était d'usage chez les principaux chefs musulmans d'entretenir dans leur palais même un hôtel du tiraz ou manufacture de soie. On y tissait des étoffes à inscriplions, à emblèmes, pour l'usage du maître et de son entourage. C'était, en général, marchandise prohibée servant parfois à faire des cadeaux diplomatiques; ainsi s'explique l'existence en Europe de ces tissus manifestement orientaux, conservés dans nos églises ou nos collections publiques. Aroun-al-Raschicl en envoya à Charlemagne parmi d'autres produits de l'industrie arabe.

A mesure que la domination musulmane s'étendit, le pouvoir se subdivisa et donna naissance à divers califats, dont les principaux sont : ceux d'Orient ou de Bagdad, d'Espagne ou de Cordoue, d'Egyple ou du Caire. Au moment même de la mort de Mahomet, une première division était née de la rivalité de deux de ses lieutenants : Omar et Ali, postulant également la succession du prophète. Le doux Ali gagna l'Orient, la Perse; il y devait même, après l'avoir amenée à l'Islam, épouser la fille de son roi Khosroë. (Il avait déjà pour femme la fille de Mahomet.) Omar, lui, farouche, intraitable, devait porter la parole du prophète du côlé de l'Occident, c'est à lui que revient la triste gloire d'avoir brûlé la bibliothèque d'Alexandrie, et c'est sa secte qui ira jusqu'en Espagne. 
Dans une aussi vaste étendue de pays, l'art forcément se modifie, et nous sommes amenés à la classification suivante: l'art d'Egypte ou du Caire; l'art de Perse ou de Bagdad, l'art d'Espagne ou de Cordoue. Nous y ajouterons une quatrième catégorie : l'art siculo-arabe, qui nous servira de transition pour arriver à la période italienne à laquelle il sert de préparation.

Les caractéristiques de la période byzantine avaient été : la division architecturale, l'affirmation de la forme et la clarté de la composition. L'art arabe tend à les supprimer. Sa fantaisie dissimulera la forme sous l'abondance du détail ; même lorsque la composition sera purement géométrique, comme chez les Maures d'Espagne, les lignes s'enchevêtreront les unes dans les autres avec un parti pris savant, dont la clef est parfois un problème difficile à résoudre.

Pendant le moyen âge, en dehors du costume et des poêles funéraires, les tissus précieux étaient encore employés pour bannières, enseignes, gonfanons, tentures, couvertures de livres, housses de chevaux, tentes de guerre ou de chasse, etc.

Les éloffes de soie et d'or faisaient partie de tous'les trésors, étaient, au même titre que le numéraire, un moyen d'échange commercial. Les empereurs grees payaient en soieries, aux églises d'Occident, certains tributs annuels. Dans les nombreux inventaires de trésors d'églises, il est question de samit de Perse, d'Egypte, d'Alexandrie, de baudequin de Bagdad, etc... Au sac d'Antioche (1098), à la prise de Constantinople (1204), à Damiette ( 1219 ), les 
croisés trouvèrent, entre autres richesses, quantité d'étoffes de soie.

"Il est probable, dit Francisque Michel, que ces étoffes élaient deslinées à l'exportation, d'autant que le Coran interdisail aux hommes l'usage de la soie; certaines sectes seulement portaient des tissus mélangés, "

Nous ferons remarquer pourtant que le Prophète autorisail la soie dans le costume de guerre, el le luxe des armées musulmanes allant au combat était inouï. Ciest sur le champ de bataille même que les croisés s'initièrent ì ces fameuses splendeurs orientales.

Nous avons déjà dit que, dans l'art du tissu décoré, il n'y a pas de transition brusque; l'évolution artistique s'effectue sans secousse. C'est peu à peu que les manifestations changent de milieu de consommation, de centre de production, abandonnant les pays en décadence pour gagner ceux en progrès. Aussi nous partirons de l'Egypte, qui nous a déjà servi à étudier la période byzantine, laissant le Nord s"immobiliser dans sa tradition et consommant d'ailleurs fort peu, el nous irons ensuite à l'Est ou à r'Ouest, sur les chemins glorieux du Croissant.

Califat du Caire. - L'art musulman en Égypte est une suite pluis directe de l'art byzantin, ayant d'ailleurs le même ourrier : le Copte, qui conservera les mêmes ordonnances du décor, telles que celles de roues tangentes ou isolées, de lignes horizontales de la disposition losangée, ordonnance enfin du semis, forme particulière de la période arabe affranchie de l'influence byzantine. 
Au vin siècle, l'Égyple est devenue musulmane. En haine des chrétiens, on y abandonnera tout ce qui, dans la composition décorative, les rappelle; par là même les Coptes, ou bien se serviront des détails sassanides, ou exploiteront ce genre d'ornementation que nous avons dit être leur art propre après avoir élé celui des Phéniciens, art qui relève de la géométrie esthétique el qui sera à l'origine la première expression de l'art arabe ${ }^{1}$. Celle intransigeance religieuse de la première heure cédera rapidement dans un pays où la tradition artistique reste vivace el s'impose. Longtemps nous verrons encore les sujets de chasse ou de guerre dont les détails se reproduisent symétriquement, mais le type le plus caractéristique jusquau xm1 siècle sera celui d'animaux à représentation hiéralique isolés, adossés ou affrontés Liartiste leur donnera une signification emblématique, ajoutant souvent, avec toute l'emphase orientale, une inscription à la louange de celui auquel le tissu étail destiné. Parfois, celle inscription est religieuse, évoquant quelque versel du Coran, ou répétant le nom du Prophète el de ses principaux lieutenants. Ces tissus à inscriptions, nous les retrouvons dans tout l'empire musulman; elles sont écrites cı caractères cuffiques (arabe littéraire); dans les plus anciens, les caractères sont anguleux. I.es lettres souples sont postérieures au $\mathrm{x}^{\mathrm{e}}$ siècle $\mathrm{e}^{2}$. Linscription constituera parfois loute la décoration. Par suite de son côté éminem-

1 L'Arl de décorer les lissus, pl. V, no:3, 12, 1. ; pl. VI, no 6.

2 Ibillem, pl. Y'Il, no 4 . 
ment ornemental, la lettre arabe apparaîtra aussi à titre purement décoratif, sans signification. Peut-être faut-il voir, dans ces tissus à inscriptions sans signification, ceux destinés à l'exportation, ayant le même aspect au point de vue du décor, sans avoir le caractère religieux des autres. Il est évident que mettre des formules sacrées sur des étoffes fabriquées pour des chrétiens aurait été considéré comme une profanation par les Musulmans.

On donne aussi une autre explication que nous livrons à titre de curiosité. Ces assemblages de lettres, où généralement la voyelle n’existe pas, seraient des espèces de devinettes religieuses où les mots d'un verset du Coran seraient mélangés, il s'agissait alors de le reconstituer ${ }^{1}$.

Galifat de Bagdad. - L'art en Perse, plus libre, sera celui qui correspondra le mieux à l'esprit oriental; la Perse semble le lieu d'origine de la vraie formule musulmane. La composition va s'y renouveler; les ornements s'enchevêtreront les uns dans les autres sans le compartiment architectural cher aux Byzantins. Comme le pays possède une tradition d'art, cette tradition servira les artistes et remplacera rapidement le parti pris géométrique des premiers temps de l'Islam. Parmi les détails les plus employés au commencement de la période arabe, et qui viennent de cette tradition, nous citerons ces guerriers et ces chasseurs montés sur des chevaux fougueux. Armés de l'arc, ils s'en servent suivant la tactique particulière

1 L'Art de décorer les tissus, pl. V, nos 1,$6 ;$ pl. VI, n०8. 
aux Scythes, tirant, non pas devant leur monture, mais derrière en se retournant. A leurs pieds, des animaux, en activité s'il s'agit de chasse, hiératiques quand c'est de guerre, ceux-ci devenant alors emblématiques des vertus et des qualités des combattants. Ces différents motifs se reproduisent symétriquement, de chaque côté de l'axe qui lui-même est affirmé par un homa ou une pyrée.

Deux phases distinctes dans l'art musulman-perse alfranchi de l'influence byzantine : la première pendant laquelle l'aspect général de la composition, quoique débarrassée du compartiment géométrique, conservera la rigidité et la symétrie $^{1}$, la seconde où tous les détails s'assouplissent et oú nous avons cru devoir reconnaitre l'influence chinoise, favorisée par les invasions mongoles des $\mathrm{x}_{11}{ }^{\mathrm{D}}$ et $\mathrm{x}^{\mathrm{r}^{\prime \prime}}$ siècles, qui met tout le pays, de l'Euphrate au Pacifique, sous la même domination ${ }^{2}$.

Dans la première phase, tout détail devient symbolique, la composition est touffue, très chargée, et d'un établissement qui paraît extrêmement compliqué par suite de la disparition de toute liaison architectonique. Elle est alors construitesur un échafaudage destiné à disparaître. Mieux que toute description, un exemple vous initiera au mode de travail de l'artiste persan. Nous prenons pour celte étude un échantillon du Musée de Lyon. Au point de vue industriel, voici d'abord ce qu'en dit M. Pariset, un maitre dont les savants travaux sur la soie ont bien souvent guidé nos recherches:

1 L'Art de décorer les tissus, pl. XX, no $\mathrm{n}$.

2 Ibidem, pl. XXIX, no 2. 
"Cette étoffe est de couleur uniformément verte avec quelques points brochés or. Elle est formée de deux chaines et de deux trames; elle a ceci de particulier qu'elle est en réalité un composé de deux tissus qui se pénètrent dans les contours du dessin, et qui laissent entre eux de véritables poches 》.

C'est un genre de fabrication spécial au $\mathrm{xm}^{\mathrm{e}}$ siècle.

Parlons maintenant de la composition elle-même : nous y voyons encore des animaux affrontés ou adossés: aigles et girafes, très fantaisistes de représentation; entre ces animaux un homa. Les points brochés or, qui sembleraient d'abord placés au hasard, sont au contraire disposés suivant un canevas que seuls ils rappellent dans le décor. Ce canevas initial est, dans la circonstance, un semis de roues, que nous indiquons, dans notre dessin, en pointillé. Sur une première roue sont placées la tête, une rosace qui fait le haut de l'aile et les pattes des aigles; sur une seconde roue: dans l'axe horizontal, les têtes des girafes avec, en haut et en bas, des fleurons faisant partie du homa; dans une troisième roue enfin, symétriquement et régulièrement apparaissent quatre points d'or dessinant les sabots des girafes. Une fois ces premiers détails déterminés, le reste de la composition devient facile à établir. L'ensemble présente des qualités de pondération, qu'une fantaisie moins raisonnée aurait difficilement pu obtenir.

Dans cette première phase de l'art persan, la stylisation, nous le répétons, est extrême; les animaux y sont représentés arec ces complications ornementales que nous avons indiquées dans nos observations générales, comme parti- 


\section{$-(59)-$}

culières à l'Orient. La flore est plutôt floraisons irréelles,

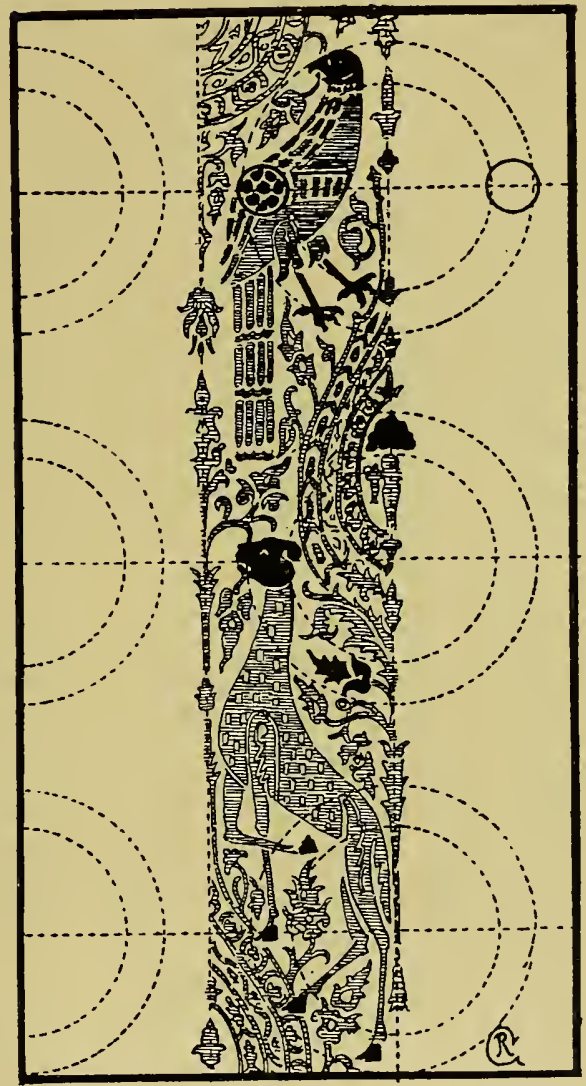

Cliché du Bulletin des Soies el des Soieries.

qui apparaissent déchiquetées, dentelées, allongées; les tiges serpentent en traits effilés. 
Un détail caractéristique de l'ornement floral sera la palmette, qui est un composé de feuillages rayonnants autour d'un noyau central généralement ovale. Nous en pouvons compter trois espèces principales : la palmette calice, la palmette couronne, la palmette éventail. Dans la palmelte calice, les feuilles, enveloppantes s'épanouissent en forme de vase; dans la palmette couronne, elles sont présentées, ainsi que leur nom l'indique, tout autour du noyau central; dans la palmette éventail, ces mêmes feuilles sont dans une disposition en éventail. L'aster est, avec les palmettes, une des floraisons courantes de l'art persan; son origine remonte à l'antique représentation du soleil, image du feu sacré. Nous ajouterons que palmettes, asters et feuillages dentelés font le fond du décor floral des fameux tapis persans.

La deuxième phase de l'école persane correspond aux invasions mongoles. La Chine si rigoureusement fermée s'ouvre momentanément. Il est probable qu'arts et indus tries livrèrent en même temps quelques-uns de leurs secrets. Dans la composition décorative, nous allons voir s'assouplir les lignes, rigides jusque-là. De même que nous avons étudié la précédente phase en nous servant d'un exemple, nous prendrons encore un modèle au Musée de Lyon pour expliquer la construction de la seconde.

L'établissement du décor repose toujours sur un échafaudage initial qui, dans ce cas, sera la combinaison des circonférences indiquées en pointillé dans notre dessin. Ces circonférences se pénètrent régulièrement et vont nous aider à construire les différents éléments de la décoration. 
Nous placerons sur les courbes les deux personnages affrontés; leur mouvements en suivent légèrement l'ondu-

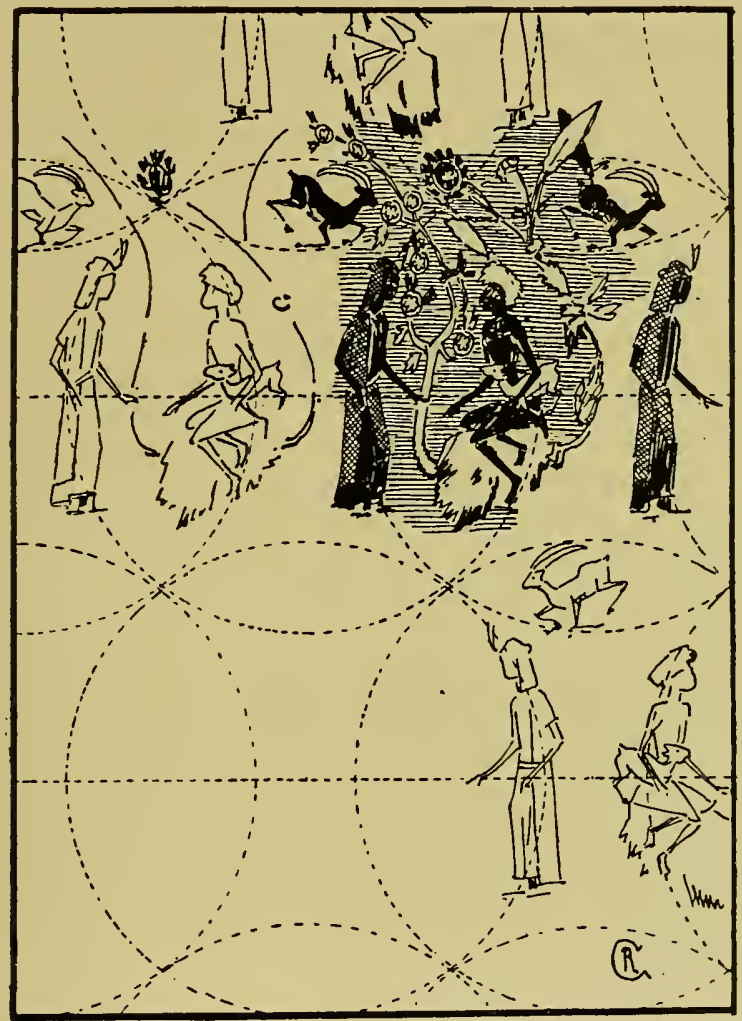

lation. Egalement les arbres qui les séparent, souvenirs évidents des homas, ondulent, se divisant en rameaux a floraisons irréelles. En dehors des personnages affrontés, 


\section{$-(62)-$}

du homa, les segments horizontaux provenant de la rencontre des circonférences déterminent la place occupée par des gazelles d'un dessin exquis. En somme, c'est le même principe de composition que celle de sa phase précédente, mais avec ce parti pris, désormais inséparable, du pittoresque, rejetant toute symétrie. Nous ajouterons que nous sommes là en présence d'un mode très typique que nous retrouvons dans de nombreux velours persans à personnages des $\mathrm{xIV}^{\mathrm{e}}$ et $\mathrm{x} \mathrm{v}^{\mathrm{e}}$ siècles ${ }^{1}$.

Dans cetle seconde phase de l'art du tissu décoré persan, nous signalerons également une innovation, dans laquelle nous n'hésitons pas à reconnaître l'influence occidentale. Au xive siècle, en effet, la consommation a considérablement augmenté en Occident, après l'initiation qu'ont été pour lui les Croisades. N'étant plus principaux consommateurs, sollicités par la clientèle qu'approvisionnent les marines italiennes, celle de Venise en particulier, les Orientaux versent forcément dans la tendance réaliste des primitifs de la Renaissance. Dans l'art de l'Islam nous voyons inaugurer une représentation plus nature de la flore, réduite, d'ailleurs, à un pelit nombre de modèles : l'œillet. la jacinthe, la tulipe, l'églantier, et nous ajouterons le pêcher. Cette nouvelle expression du dessin de la flore est surtout remarquable par sa simplicité; nul art n'a poussé aussi loin la science de l'abréviation décorative. C'est principalement dans les velours dits d'Asie Mineure ou de Venise que nous en trouvons les plus curieux exemples ${ }^{2}$. Ces

1 L'Art de décorer les tissus, pl. XXVII.

2 Ibidem, pl. XXVI, nos I et 3. 
mêmes velours nous fournissent les premiers spécimens de l'ordonnance à compartiments affirmés dont l'arc lancéolé est la base, et qui sera le point de départ d'une des formes les plus caractéristiques de l'art italien du $\mathrm{xv}^{\mathrm{e}}$ siècle. Nous ajouterons que ces velours sont tous coupés, du moins nous n'en avons jamais rencontré d'autres.

Galifat de Cordoue. - L'art hispano-mauresque est par excellence un art de revêtement; il s'inspire particulièrement de la géométrie esthétique et nous montre l'application la plus considérable qui ait été faite des formes gréométriques dans la décoration. Elle ne suppose nullement une connaissance scientifique de la géométrie mathématique; les données générales des entrelacs hispanomauresques se réduisent à quelques formes principales très simples servant à l'artiste d'échafaudage, et destinées à disparaître. Sur cet échafaudage il brodera, et c'est seulement son interprétation qui paraît compliquée.

En dehors de la ligne géométrique, deux autres éléments concourentau décor: l'arabesque, qui est une représentation de flore irréelle, et l'épigraphie, c'est-à-dire les inscriptions.

Au moment du triomphe de l'Islam, nous avons vu que l'art arabe avait déjà été tout géométrique, exploitant l'art particulier des Coptes qui sont les premiers ouvriers d'art de la religion nouvelle, commeils avaient été ceux du christianisme. Les Arabes eux-mêmes, surtout nomades, n'avaient pas d'art à eux. Avec le succès, dès la première heure, leur besoin inné d'ostentation les avait poussés 
à affirmer leur conquête par des manifestations artistiques, et ils s'étaient servis pour cela des Coptes, convertis ou non à leur doctrine. Ĺne lois leur domination définitivement établie en Egypte, leur luxe devait forcément subir l'influence d'un milieu où l'art avait de tout temps prospéré, et il en avait été de même à l'Est musulman, en Perse, comme nous venons de le voir.

Il n'en est plus ainsi à l'Ouest. Du côté de l'Espagne, l'antiquité n’a pas laissé de modèles indigènes, aussi les artistes de l'Islam trouveront-ils à y développer sans distraction leur conception première de l'art. Bien mieux, par suite de leur isolement, cette conception s'exaspère : importée géométrique simple, elle progressera dans le même sens mathématique compliqué ${ }^{1}$.

Mais cet art géométrique n'a-t-il pas les tendances générales de l'Orient: le symbolisme et l'emblème? Ce serait une grave erreur d'en douter. De tout temps l'Arabe a donné une signification aux lignes, signification dont la théorie se dégage absolument de l'ensemble de ses œuvres et correspond à cet instinct particulier des races d'Orient.

La ligne horizontale représente le calme, la méditation, l'extase ; la ligne verticale représente l'élan de l'âme dans la prière. Le minaret, où le muezzin l'annonce, en est un exemple, et nos clochers gothiques ne représentent-ils pas la même idée d'exaltation fervente? Le cyprès, si souvent employé par les musulmans, est pour eux l'image de l'âme aspirant au ciel. Les lignes obliques sont

1 L'Art de décorer les tissus, pl. XIV, nos 3 et 5 . 
également emblématiques: brisées, la pointe en haut, elles symbolisent la souffrance; la pointe en bas, la joie.

Une figure polygonal, produira diverses impressions suivant qu'elle sera régulière, symétrique ou irrégulière. Les polygones, de nombre pair de côtés, reflèteront des sentiments calmes ; les autres, par leur irrégularité, évoqueront des idées de vague, de trouble, d'incertitude. Dans leurs multiples combinaisons, le Maure d'Espagne verra le symbole de l'agitation de l'âme, sans cesse tourmenté de passions contraires, comme il verra, dans la répétition indéfinie du même motif décoratif, l'immuabilité de son dogme.

Notre cadre ne nous permet pas d'entrer dans le détail de construction des entrelacs hispano-mauresques; toute la théorie en est remarquablement expliquée dans le livre de Bourgoin intitulé : l'Art arabe, et nous y renvoyons les intéressés.

L'art siculo-arabe. - Voyons maintenant ce que ra devenir l'art arabe interprété par Palerme. Au moment du triomphe de IIslam, la Sicile est colonie byzantine; sous Justinien, en 535, Bélisaire l'avait conquise. Dès $\mathbf{6 5 2}$, les Musulmans y font leur apparition: en 829 seulement,ils s'en emparaient. L'occupation de la Sicile eut donc lieu au moment où la civilisation orientale était à son apogée, et l'île en profita. Ainsi qu'ils avaient coutume de le faire en pays conquis, les chefs sarrazins, entres autres industries, fondèrent des fabriques de soie. On y tissa des étoffes semblables à celles que nous avons étudiées en parlant du califat du Caire. 


\section{$-(66)-$}

En 10.58 apparaissent les Normands. Nous sommes à l'époque où, tout joyeux d'avoir échappé aux affres de l'an 1000 , le monde chrétien sort de sa torpeur. Dans un élan, tout de reconnaissance, des différents centres partent des pèlerins se rendant en Palestine. Les pieux voyageurs reviennent désolés d'avoir vu les lieux saints aux mains des infidèles, mais aussi, profondément suggeestionnés par les magnificences orientales. De France partira l'idée d'une guerre sainte décrétée en 1095 par le pape Úrbain VII. A la voix de Pierre l'Ermite, vilains et chevaliers se croisent et, en ro97, se trouvent rassembles sur les côtes du Bosphore; le 15 juillet 1099 Jérusalem tombait en leur pouvoir.

Jusqu'en 1270, à la mort de saint Louis sous les murs de Tunis, les Croisades se succèdent avec des fortunes diverses. Nous ne voulons en retenir que ceci : qu'elles furent, pour l'Occident, une véritable initiation. Le luxe des Orientaux l'éblouit; les croisés reviennent en Europe avec l'habitude prise de ces splendeurs, et l'impérieux besoin d'en jouir.

Les compagnons de Tancrède vont jouer un rôle particulier au point de vue de l'histoire de l'art en Sicile. En г 09o, ils finissent par en expulser complètement les envahisseurs africains. Ces Normands, devenus les farouches défenseurs de la foi et qui avaient reçu des papes la mission d'en exterminer les ennemis, trouverent en Sicile, non pas les barbares qu'ils avaient cru y rencontrer, mais les représentants d'une société merveilleuse dont l'organisation, une fois la première surprise passée, et leur domi- 
nation bien établie, leur suggéra l'impression qu ils avaient tout à gagner à entretenir avec leurs vaincus des relations courtoises. Lorsqu'en i 3 o Roger II, petit-fils de Robert Guiscard, aura formé le royaume des Deux-Siciles, par la réunion de la Pouille et du principat de Capoue à la Sicile elle-même, il attirera à sa cour, en même temps que les artistes et les savants grecs, les artistes et les savants des pays musulmans. Les monuments siciliens du xir" siècle nous offrent par là même un curieux mélange d'art, où le byzantin et l'arabe se trouvent intimement unis. A Palerme, la chapelle palatine est un précieux exemple de cette pénétration inattendue.

On conserve à Nuremberg et à Vienne différentes pièces de costumes qui remontent à cette époque. L'aube de Nuremberg est ornée autour de l'échancrure du cou, au-dessous des épaules et au bout des manches, de riches parements sur fond or. Au bas, cinq bandes ьгоdées or sur fond pourpre contiennent des inscriptions : la première et la quatrième en cuffique, presque tout effacée mais dans laquelle on distingue pourtant le nom d'Othon; la seconde et la cinquième, en latin, donnent la date de i so de notre ère, el relatent l'origine palermitaine.

Le pluvial de Vienne est en soie rouge ; ici la composition se divise en deux parties symétriques où se reproduisent de chaque côté d'un homa deux sujets semblables dans le goût oriental: un lion terrassant un chameau. Une marge inférieure porte une longue inscription cuffique datée de Palerme et de la $\tilde{J}_{2} 8^{\mathrm{e}}$ année de l'Hégire. Liinscription 


\section{$-(68)-$}

exprime des formules emphatiques de voeux en l'honneur d'un souverain, probablement le roi Roger.

Dans une paire de chausses, également conservées à Vienne, l'inscription se répète trois fois, en latin, en grec et en cuffique, indiquant la même origine palermitaine et la même époque.

La descendance mâle des princes normands s'éteignit en $18_{9}$. La fille de Roger II avait épousé Henri IV, empereur d'Allemagne; de là, ses prétentions à la couronne, revendiquée également par les papes. Cette rivalité aura pour conséquence l'élévation au trône de Sicile de Charles d'Anjou, frère de saint Louis.

Tous ces princes chrétiens s'étaient bien gardés de détruire les industries musulmanes; nous venons de voir combien, sous Roger Il, elles prospérèrent et dans quel sens. D'ailleurs, ces princes y avaient été d'autant plus incités qu'ils étaient devenus les fournisseurs naturels des croisés. Comme c'est le luxe oriental qui a donné à ceux-ci le goût des riches étoffes, ces consommateurs demandent des tissus arabes. Pour eux, Palerme en fabrique de similaires, laissant croire peut-être que tout vient des pays musulmans pour vendre plus cher.

Venise, par sa situation spéciale, prépondérante, couvre la Méditerranée de ses vaisseaux. Les Croisades, qui ruinent les pays occidentaux, sont pour elle, au contraire, une source de fortune; c'est elle qui fournira des navires et des banquiers aux croisés. Ses armateurs viennent s'approvisionner à Palerme, échangeant contre leur or les tissus précieux qu'on y fabrique et qui, 
comme nous le disions plus haul, étaient, au même titre que le numéraire, un moyen d'échange commercial.

A la première heure, les tissus palermitains sont les mêmes que ceux fabriqués dans les différents califats.

A partir du xme siècle au contraire, l'apparition de quelques signes, particuliers, aux tendances occidentales, permettra de différencier les manifestations siciliennes.

I.e type le plus caractéristique sera celui à ordonnance de lignes architectoniques horizontales plus ou moins décorées et nettement exprimées; c'est un commencement de retour à la division architecturale. Le décor de ces bandes rigides reste directement inspiré par l'art persan : des animaux s'y jouent au milieu de cette flore dentelée irréelle, spéciale aux arabesques, avec ou sans détails épigraphiques ${ }^{1}$. Dans cette disposition horizontale la bande architecturale est parfois supprimée et il ne reste plus que le motif décoratif qui se répète, mais sans que le rapport chevauche sur le voisin, comme il arrivait dans les compositions persanes ${ }^{2}$. Parfois, également, l'art palermitain conservera toute la disposition arabe en y introduisant quelques symboles chrétiens ou certaines pièces héraldiques $^{3}$ : croix, écussons, couronnes, etc. Ces mêmes détails, il les traitera aussi en semis.

On continue, bien entendu, à produire des tissus entièrement copiés de l'Orient, et dans les différentes formes. Parmi celles-ci, nous en signalons une plus intéressante à

1 L'Art de décorer les tissus, pl. VI, no ${ }_{\mathrm{t}} 3 ; \mathrm{pl}$. XV, nos I et 3.

2 Ibidem, pl. XV, n 4.

3 Ibidem, pl. VI, no 14. 
cause de l'importance qu'elle va prendre: l'ordonnance à compartiments dérivée de l'art lancéolé, de l'ogive.

A la fin du $x_{m}{ }^{e}$ et au $x_{1} r^{0}$ siècle enfin, tous les détails tendront à se rapprocher de la nature ; l'art imitatif d'Occident va remplacer l'art symbolique de l'Orient.

En r282, le sanglant épisode des Vêpres Siciliennes livre la Sicile à Pierre d'Aragon, inaugurant une période de troubles intérieurs. C'est là une date importante à retenir pour l'art de décorer les tissus. Les ouvriers, chassés de Palerme par la persécution, trouveront un asile dans différentes villes italiennes, et y créeront de nouveaux centres de production.

Lucques et Amalfi d'abord recueillent les proscrits. Pise, Gênes, Florence, Sienne, Venise les attirent également bientôt. Les tissus qu'on y fabriquera seront d'abord les mêmes que ceux de Palerme; bientôt chacun de ces centres aura une spécialité. Ce sera l'œurre du $\mathrm{xiv}^{\mathrm{\theta}}$ siècle qui sera la phase éducative de la fameuse période italienne. L Orient continuera certes à produire, mais la consommation va devenir surtout occidentale et, par là même, l'art évoluera dans le sens des aspirations particulières à l'Occident. Pour l'art musulman, il se passe au $x^{\mathrm{e}}{ }^{\mathrm{e}}$ siècle ce qui s'était passé au vili pour l'art chrétien : l'intransigeance d'un formalisme rituel en arrête l'essor.

\section{PÉRIODE ITALIENNE}

L'école palermitaine a été l'anneau de cette chaîne sans fin de l'art du tissu décoré, anneau qui aura servi de 
lien entre la période arabe et la période italienne. Après les Vêpres Siciliennes, I'Italie produit à son tour et va devenir prépondérante, pour le rester jusqu'au $x_{r u r}$ siècle. Parmi les causes qui déterminèrent cette évolution, nous avons déjà signalé les Croisades, qui initièrent l'Occident aux jouissances du luxe et consécutivement amenèrent dans son économie un changement complet de la compréhension de la vie. L'Italie, par sa situation spéciale, en bénéficie la première ; les Croisades sont pour elle l'origine de sa prospérité, entraînant la création de son commerce et de son industrie en général.

Tandis que, pour le reste de l'Europe chrétienne, les questions de castes primeront plusieurs siècles encore, les grandes familles italiennes soccupent activement de finance et de négoce. Elles protègent, par intérêt, l'organisation du travail. En France, en Allemagne, en Angleterre, les rivalités guerrières reliennent l'aristocratie chevaleresque alors toute-puissante.

Dans la confusion et les conflits de la société du moyen âge, marchands et artisans avaient senti le besoin de se grouper en corporations pour lutter contre les exactions et les violences des seigneurs féodaux ou religieux. La formation de ces corporations, correspond d'ailleurs à l'existence des premières constitutions municipales, créées dans le même but de défense ; et nous pouvons ajouter que les corps de métier composaient la principale force armée des villes, qui voulaient s'ériger en communes. La plupart des corporations datent de la seconde moitié du xue siècle, mais leur principe a toujours existé. En Italie, cette orra- 


\section{$-\left(7^{2}\right)-$}

nisation des métiers a, de bonne lieure, une importance d'autant plus considérable qu'elle correspond mieux à sa constitution en républiques et principautés différentes.

Maîtrises el jurandes recrutaient leurs adhérents suivant certaines règles rigoureuses, à l'extrême même parfois. Il fallait passer par dilférentes épreuves longues, difficiles et coûteuses pour arriver à avoir le droil d'exercer un métier à titre de maître. On assurait ainsi lá bonne façon dont toutes les corporations étaient jalouses; on retenait ainsi également l'ouvrier, désireux de profiter de droits chèrement acquis dont il n'aurait pas pu jouir en changeant de centre. L'erreur de cette organisation était d'entraver la liberté de l'ouvrier qui devait strictement s'en tenir à sa spécialité.

Disséminés clans les différentes villes du nord de l'Italie, les ouvriers de Palerme y fabriquent d'abord les mêmes tissus siculo-arabes; puis l'iniliative individuelle, l'invention de nouveaux procédés dans tel et tel milieu, confèrent à la corporation qui en a été le principe le bénéfice de ces découvertes et, d'autant plus, que les règlements sont plus sévères pour le recrutement des apprentis. Les engagements qu'on fait prendre aux nouveaux venus, les lient à leur jurande, qui garde ainsi le secret de sa spécialité. Comme conséquence, aux premiers moments de l'organisation, ces rigueurs eurent celle de localiser certaines fabrications.

Historiquement, la Renaissance date de l'apparition de la Divine Comédie de Dante (13o8). La Divine Comédie est le grand monument de l'émancipation des esprits, entravés 
jusque-là par le formalisme byzantin. La fâcheuse scholastique du moyen âge avait stérilisé l'enseignement dans ses vaines discussions de mots. Privée des ressources de l'imprimerie, par là-même des texles et de tous les moyens modernes de travail, la tâche de l'éducateur consistait alors à commenter indéfiniment la tradition; l'élève, qui parfois ne savait pas écrire, en continuait la discussion; rien ne restait de son labeur que le souvenir vague de ces discussions. Ajoutons à cela la grande importance que donnait l'extrême rareté des textes écrits à tout ce qui était écrit, les erreurs consignées auxquelles on ne pouvait toucher sans sacrilège, sans danger, à une époque où l'on ne badinait pas avec la règle, et nous pouvons nous faire une idée de ce que devait être alors l'instruction. Roger Bacon ayant osé voir dans l'autorité des textes la source de l'ignorance, ayant osé appeler à son secours les ressources des mathémathiques et de la méthode expérimentale, n'échappa pas à la persécution. Il fut condamné à la prison perpétuelle. Dante ne sera pas plus heureux, il passera pour fou, malgré l'admiration que son génie imposera à ses contemporains eux-mêmes. Boccace et Pétrarque le suivent de près. Malgré tant d'entraves, avec eux, lettres et arts vont prospérer, revenant à l'étude directe de la nature; on restaurera les études classiques en remettant en lumière les beaux modèles légués par l'antiquité, et c'est là la part qui revient sans conteste à l'Italie.

Pour l'art qui nous occupe spécialement, l'art de décorer les tissus, nous adopterons un classement correspondant à celui des arts en général pendant la Renaissance en Italie. 
Ceux qu'on a appelés les primitifs (Cimabué, Giotto, Fra Angelico, etc.) affranchissent l'art de la convention rituelle byzantine, demandant à la réalité tous leurs modèles. Leurs recherches rempliront le $x_{10}{ }^{0}$ siècle. Les préraphaéliques se passionnent à leur tour pour l'antiquité, préparant ainsi l'envolée de leurs successeurs vers la perfection de l'époque de Raphaël.

De même pour la décoration des tissus, le $x_{1}{ }^{\theta}$ siècle est l'ère du réalisme du détail ornemental ; le $\mathrm{xv}^{\mathrm{e}}$ siècle marque le retour définitif à des conceptions plus conformes au génie occidental en remettant en faveur la clarté, le bon sens et l'affirmation de la forme vraie, telle que, dans un autre ordre d'idées, l'antiquité classique gréco-romaine en avait donné l'exemple.

Il y a analogrie certaine eutre les efforts italiens de la fin du moyen âge, et nos propres elforts depuis un demi-siècle. Ici et là, toutes les tendances de progrès ont leur principe dans l'émancipation de l'individu, préparée chez nous par les philosophes du $x^{\prime} \mathrm{e}^{\mathrm{e}}$ siècle, comme elle le fut à la fin du moyen âge par cette élite glorieuse qui a à sa tête Dante, Boccace et Pétrarque. Au xwve siècle, les Républiques italiennes sont organisées; le régime démocratique favorise l'initiative individuelle. En Toscane et à Florence en particulier, se manifeste de bonne heure l'avidité ardente et fière de réputation et de groire. Florence devient le centre dirigeant pour l'art en général. Pour nos tissus, c'est aussi là que nous voyons le génie occidental se manifester d'abord franchement.

On y fabrique des damas décorés de détails à petite 
échelle, réalistes d'expression et le plus souvent ton sur ton; l'ornement s'y enlève en clair sur le fond satin avec ou sans quelques points brochés or ou couleur. Ces points sont disposés dans une ordonnance très simple de semis et sans liaison architecturale. La composition elle-même est très chargée, sans recherche symbolique. La flore, la faune et les pièces héraldiques concourent également au décor, mais ce qui caractérise surtout ces tissus florentins du xiv siècle, c'est l'interprétation très nature des floraisons et des feuillages ${ }^{1}$.

Lucques prend la spécialité d'étoffes à sujets religieux : chérubins dont les ailes rayonnent, anges portant les instruments de la Passion se détachant sur des fonds étoilés, semis de tabernacles et de reliquaires flanqués des mêmes anges ou des mêmes chérubins à ailes rayonnantes, scènes tirées surtout du Nouveau Testament, etc., etc. ${ }^{2}$.Tous ces motifs décoratifs rappellent le détail de l'ornementation peinte des primitifs. Enfin, nous signalons un détail particulier emprunté aux arts d'Extrême Orient : nous voulons parler de ce ruban dentelé, ondulant, employé par les Chinois pour figurer le ciel, et que nous retrouvons à Lucques, évoquant la même idée ${ }^{3}$.

A Sienne, on fait également des tissus à personnages, mais ces étolfes ont une destination très nette, qui est de remplacer les orfrois des vètements liturgiques. Le Nouveau Testament fournit les sujets. Jusqu'au xrrı" siècle, ces

1 L'Art de décorer les tissus, pl. XIII, nos 3, 4; pl. XX, no 3 .

2 Ibidem, pl. XVI, $\mathrm{n}^{\mathrm{os}} \mathbf{1}, 2,3$.

3 Ibidem, pl. XVI, no 4. 
mêmes tissus resteront une spécialité de Sienne. Dans les plus anciens, le dessin s'enlève en clair sur le fond généralement rouge; le plus souvent, il se détache ton sur ton, parfois il est rehaussé de taches colorées ${ }^{1}$. Plus tard, le dessin s'enlèvera en foncé sur le fond clair, et dans quelques exemples nous le trouvons en velours coupé silhouettant la forme 2 . Un motif d'architecture ou d'ornement architectonique encadre la composition, comme il arrive dans les broderies d'orfrois.

Gênes a la spécialité du velours ciselé auquel on donne son nom actuellement encore; ce nom est devenu générique à notre époque, mais au $\mathrm{xuv}^{e}$ et au $\mathrm{xv}^{\mathrm{e}}$ siècle, il indiquait réellement l'origine génoise de ce tissu particulier. Au $x^{\mathrm{e}}$ siècle, le dessin est petit de rapport et d'échelle, il s'enlève en foncé sur le fond satin. Le sujet rappelle incontestablement l'Orient : un arbre souple avec un ou deux oiseaux perchés, au pied un ou deux quadrupèdes (lions, guêpards, chiens, etc.), rampants ou passants ${ }^{3}$. La composition n'y est jamais symétrique. Le tissu est tout soie, sans métal, souvent la partie frisée clu velours est d'un autre ton que la partie coupée, souvent aussi, le même poil fait les deux effets. Nous rapprocherons de ces velours certains spécimens qui présentent quelque analogie avec eux, au point de vue de l'échelle du dessin et de l'aspect; mais leur technique artistique change: la composition y est plus ou moins symétrique; la liaison architecto-

1 L'Art de décorer les tissus, pl. XLIII, $\mathrm{n}^{\circ \mathrm{s}} 6,8$.

2 Ibidem, pl. XLIII, no $\mathbf{r}$.

3 Ibidem, pl. XXIII, nos 8, 9, 12. 


\section{$-(77)-$}

nique y apparaît (division losangée, d'arcs lancéolés, etc. ${ }^{1}$ ). Danscette catégorie, se rencontre parfois un fleuron spécial, ou plutôt ce genre de lleur de lis dite florentine. Ces velours sont, ou coupés, se détachant sur des fonds satin, ou coupés pour le dessin tandis que le fond est frisé. Peut-être sommes-nous là en présence de produits florentins et vénitiens.

Venise donne son nom au velours coupé. Au xwre siècle, grande est la prospérité de la république vénitienne; cette prospérité, elle la doit en grande partie à sa marine et à son commerce avec l'Orient. L'Asie Mineure lui fournit des tissus précieux; elle-même en fabrique dans le même goût, au point qu'il est souvent difficile de les distinguer. Nous avons vu que l'Occident n'avait pas été sans influencer la production orientale au $\mathrm{xIv}^{\mathrm{e}}$ siècle, et c'est justement cette clientèle rénitienne qui en est la cause. Les Persans deviennent plus réalistes par là même. A l'époque dont nous nous occupons, ils fabriquent ces velours à semis de tulipes, d'œillets, d'églantiers, de jacinthes ${ }^{2}$, en même temps que d'autres semis de détails plus particulièrement orientaux, tels que les asters et les différentes palmettes. Venise tisse des étoffes presque identiques ${ }^{3}$; l'aspect en est peut-être moins chatoyant. Les produits d'Asie Mineure nous semblent plus libres d'exécution, l'or y paraît quelquefois dans les fonds. A Venise, le même clécor de velours coupé se déta-

1 L'Art de décorer les tissus, pl. XXIII, nos 5,7 .

2 Ibidem, pl. XXVI, nos I, 3, 6.

3 Ibidem, pl. XXII, nos $2,4.5$. 
chera parfois sur un fond velours également coupé, parfois aussi de moindre hauteur que celui du dessin lui-même ${ }^{1}$. Pour mémoire nous répétons ici ce que nous avons dit plus haut au sujet des velours à grands meneaux et floraisons réalistes. Ils apparaissent dès la fin du xive siècle, mais c'est surtout au $\mathrm{xv}^{\mathrm{B}}$ qu'on en exploitera la formule. A la fin du xrve également Venise créera un produit original : le velours dit a ferronneries gothiques, dans lequel le dessin est satin sur un fond de velours coupé. Nous y reviendrons tout à l'heure.

Le Xve siècle. - L'art au xive siècle s'est affranchi complètement de la formule byzantine et, tout en conservant le principe de la composition arabe, il a retrempé son inspiration dans l'étude de la nature, et donné ainsi à l'ornement une expression réaliste plus conforme au génie occidental. A côté des maîtres, littérateurs et artistes, que nous avons cités comme présidant à l'éclosion de la renaissance, il convient de rappeler deux grandes figures, ou plutôt deux grands patronages, dont les influences différentes divisent les travailleurs en deux écoles: l'école franciscaine paraphrase la vie du doux Patron; son ouvre est toute de grâces naïves et émues; l'école dominicaine, elle, imprime aux recherches l'esprit doctrinal de son ordre savant et fier. L'art du $\mathrm{xv}^{\mathrm{e}}$ siècle sera le fruit de cette double éducation,

1 L'Art de décorer les tissus, pl. XXII, nº 5 . 


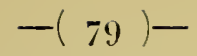

la résultante de ces deux courants différents quilui auront fourni : l'un son émotion, l'autre sa science.

A ce moment, quoique troublée, l'Italie est riche et prospère, avec une organisation sociale défnitivement établie. Sa civilisation est parvenue au plus haut degré d'activité créatrice, et celle-ci resplendit trouvant pour son expansion, le concours empressé des souverains, des princes et des papes. Jusque-là, surtout religieux et spiritualiste, son rêve va s'orienter vers les manifestations d'un luxe de plus en plus somptueux, évocateur de fètes et de plaisirs. Le costume subit des modifications profondes; de court et ajusté qu'il était, il devient ample et long. De même les proportions presque généralement restreintes du rapport des tissus du xive siècle s'agrandiront considérablement. L'école vénitienne nous en fournit l'exemple le plus typique.

Sans entrer dans des détails que notre cadre ne saurait comporter, nous avons signalé différentes causes ayant déterminé l'évolution de la période italienne; nous en étudierons rapidement une dernière, consécutive à l'archilecture spéciale qui a été une gloire toute française, mais dont les Italiens, comme les Anglais et les Allemands, d'ailleurs, ont subi l'influence; l'architecture dite gothique. La fameuse cathédrale de Milan est une preuve de cette préoccupation générale; puisque en plein centre lombard on n'hésite pas à projeter une église de style ogival à la fin du xive siècle. Ce ne fut pas, d'ailleurs, sans luttes, sans protestations patriotiques, si bien qu'au cours même de la construction, sur les réclamations expresses 
de l'opinion, on dut retourner momentanément aux formules indigènes, abandonnées de nouveau pour revenir définitivement au gothique.

L'art du gothique a son principe dans une forme arabe ; l'arc en ogive. Cette forme avait impressionné les Italiens comme les Français, mais son utilisation ici et là fut toute différente. En Italie et à Venise, en particulier, l'ogive reste avant tout du domaine de la décoration et telle que la comprenaient les Arabes. En France, au contraire, l'ogive est utilisée par l'architecture; elle y crée un mode absolument nouveau de construction des voûtes au moyen d'arcs brisés. Il en dérivera tout un style dont la science progressive révéle une conception géniale.

Dans la dernière moitié du xil ${ }^{\mathrm{e}}$ siècle, on commença à employer en France l'arc en ogive remplaçant le plein cintre exclusif du roman. On s'aperçut bientôt que ce mode de construction offrait une force supérieure de résistance: aussi, après s'en être servi seulement pour les ouvertures, portes et fenêtres, finit-on par l'appliquer également à l'ensemble des voûtes. Au xul ${ }^{\mathrm{e}}$ siècle, l'arcade est aiguë avec un rayon plus grand que la base ; la voûte s'appuie généralement sur de massives colonnes: c'est la disposition de Notre-Dame de Paris.

Au xive, l'ogive devient équilatérale, chaque cercle ayant son centre à la naissance de l'arc opposé, et la voûte repose sur un faisceau de colonnes fluettes: SaintOuen de Rouen en est un exemple.

$A u \mathrm{xv}^{\mathrm{r}}$, l'arc brisé est surbaissé, son rayon est plus court que la base, les centres sont par conséquent à l'inté- 


\section{$-(81)-$}

rieur de l'arc; de plus, les moulures de la voûte se continuent tout le long des piliers, en nervures et non plus en faisceaux de colonnes : c'est ce que nous voyons à SaintMaclou de Rouen.

A l'origine le gothique est très sobre d'ornements; le décor s'enrichira jusqu'à devenir excessif au moment du gothique flamboyant.

Les fenêtres sont trácées d'après les principes qui régissent les voûtes, mais de plus en plus elles s'agrandissent et fournissent aux peintres verriers l'occasion de manifestations qui deviendront considérables. Pour soutenir les verrières, l'architecte divise les ouvertures en multiples combinaisons, formant ces à-jour de pierre aussi utiles qu'élégants, auxquels on donne le nom de meneaux.

Ceci nous raméne au type caractéristique des tissus du $\mathrm{xv}^{\mathrm{e}}$ siècle, rappelant justement la disposition des meneaux des églises gothiques.

C'est de Venise que part cette interprétation des arcs lancéolés brisés. Nous le répétons, le principe de la forme est absolument arabe. Venise ne fait que continuer les traditions de son art toujours si préoccupé de l'Orient. Le génie occidental apparaît clans le côté architectural donné à ces meneaux de nos tissus. Au siècle précédent, quand les Musulmans et les Palermitains eux-mêmes faisaient entrer dans le décor tissé ce même arc lancéolé, ses éléments constitutifs se combinaient avec les autres détails sans faire cadre, liaison architectonique ${ }^{1}$.

1 L'Art de décorer les tissus, pl. XXI, nº I. 
Il n'en est plus ainsi au $x v^{\mathbb{e}}$ siècle; la composition nouvelle comprend alors deux parties : l'une architecturale divisant le champ en compartiments, et que nous appellerons le meneau; l'autre, décorant le vide, sera le fleuron ${ }^{1}$.

Les deux parties varient, bien entendu, tout en s'établissant d'après le même principe. Le meneau sera fait d'un ruban plus ou moins décoré, d'une ou plusieurs cordelières, de tiges foliacées, d’éléments réticulés, etc. Le fleuron de son côté empruntera à la flore divers modèles parmi lesquels la grenade et le chardon seront les plus communément employés. En tout cas, jusqu'à la fin du moyen âge, les deux parties restent distinctes, et nous ajouterons que parfois le meneau apparait seul ${ }^{2}$.

La Renaissance tendra à relier le meneau et le fleuron, et plus nous avancerons, plus ils se combineront jusqu'à se confondre dans un motif unique, pour enfin se perdre dans les complications de la décadence italienne; à la fin $d u x^{e}$ siècle, pendant la Renaissance, dans quelques exemples, le fleuron constitue seul toute la composition ${ }^{3}$.

Cette forme en meneaux et fleurons évoluera aussi d'une autre façon; l'arc tendra à se camarder, suivant cette même gradation que nous avons déjà signalée pour les différentes phases de l'architecture gothique. Au $\times \mathrm{xI}^{\mathrm{e}}$ siècle même, l'arc lancéolé arrivera à l'accolade surbaissée ${ }^{4}$; de son côté le fleuron, resté indépendant,

1 L'Art de décorer les tissus, pl. XXI, n॰ 3.

2 Ibidem, pl. XVI, nº 2.

3 Ibidem, pl. XXI, nos 8, Ir.

4 lbidem, pl. XXV, no 1 . 
s'épanouira en largeur. Toutefois, c'est surtoul dans la richesse du détail que la Renaissance affirmera ses splendeurs. Le velours ne sera plus seulement coupé, mais ciselé, l'or et l'argent viendront aussi rehausser l'éclat du tissu, lamant les fonds, bouclant les fleurons. A la virtuosité des artistes se joindra la science toujours plus grande de l'industriel.

Les velours dits à ferronnerie suivront une progression analogue. Pour mémoire nous rappelons que, dans ce genre d'étoffe, le dessin s'enlève en satin sur le fond de velours coupé. A la fin du moyen âge les lignes de ferronnerie seront plus simples ${ }^{1}$, avec un fleuron indépendant. Pendant la Renaissance au contraire, les découpures en forme de feuilles lobées se compliquent, se doublent et aussi se camardent, se silhouettant d'accolades. Le fleuron de son côté pourra se relier à la ferronnerie et s'enrichir de parties brochées d'or et d'argent ${ }^{2}$. Voyons maintenant ce que vont devenir ces deux principaux modes décoratifs à la fin du $\mathrm{xv}^{\mathrm{e}}$ siècle.

Dans la seconde moitié du $\mathrm{xv}^{\mathrm{e}}$ siècle, les artistes s'occupent avec passion de l'antiquité : Mantegna, Ghirlandajo, Lippi, Botticelli, le Perugin président à cette transformation dite préraphaélique. Nous voilà à une époque de transition. L'art du tissu décoré, toujours consécutif à l'invention en architecture, jusque-là ogivale, emprunte en même temps aux nouvelles recherches l'élément qui

1 L'Art de décorer les tissus, pl. XIX, no 4.

2 Ibidem, pl. XXXI, $\mathrm{n}^{\circ} 6$. 


\section{$-(84)-$}

constituera une des caractéristiques de la Renaissance: le rinceau. A la fin du $\mathrm{xv}^{\mathrm{e}}$ siècle les compositions dont nous parlions plus haut participeront des deux inspirations: de l'art ogival dérivé de l'art arabe, et de l'art de la Renaissance dérivé de l'antique.

Il est impossible de parler de cette époque sans dire un mot de celui qui la personnifie: Raphaël. Avec Léonard de Vinci el Michel-Ange, c'est l'incarnation même de la Renaissance. Raphaël avait vu déblayer les chambres enfouies des thermes de Titus dans lesquels on avait retrouvé, dans leur fraîcheur, les peintures et les stucs qui les décoraient. (C'est là pour l'histoire des arts un fait important à retenir.) Raphaël comprit tout le parti qu'on pouvait tirer de ces gracieux motifs; il prit pour point de départ ces fantaisies antiques el les modifia au gré de son imagination, introduisant des emblèmes, des figures délachées, une foule de petits sujets : figures mythologiques, fleurs, fruits, animaux, accessoires divers, alliant aux éléments nature l'ornement conventionnel et la liaison architecturale. C'est surtout dans ses peintures des Loges qu'apparaît l'enseignement à tirer pour nous de son œurre.

Revenons à nos tissus. A la fin du moyen âge la flore seule, plus ou moins stylisée, entrait dans le décor; à la fin du $\mathbf{x v}^{\mathrm{e}}$ siècle nous voyons reparaître les animaux, les personnages, les monstres et personnages mythologiques et l'ornement conventionnel : palmettes, grecques, volutes, etc. Une des formes les plus courantes sera le rinceau, enroulement de tiges foliacées et fleuries. 
Nous allons voir ici un exemple de cette gradation lente dans l'évolution du décor tissé. Nous avons laissé la composition divisée en meneaux et fleurons. La base du meneau se compliquera d'une volute, d'un rinceau, tandis que le haut reste silhouetté en arc lancéolé ${ }^{1}$. De même dans les velours à ferronnerie, le rinceau vient s'ajouter en broché à l'ancien décor satin.

De la composition en meneaux et fleurons dérive une infinité de combinaisons. En en conservant tout le principe, l'artiste double ou simplifie les éléments constitutifs, ou bien il supprime quelque partie, arrivant par exemple à des dispositions chevronnées, à toutes les ordonnances de semis. En dehors de ces dérivés, nous ne voyons guère à signaler qu'une forme particulière, très usitée à V'enise, surtout dans les brocarts de grande richesse. Le dessin comprend alors une large bande verticale sinueuse, sur laquelle viennent se greffer de riches ornements foliacés en velours coupé, bouclés d'or et d'argent à une ou plusieurs hauteurs.

C'est là un genre de décoration que les peintres de la Renaissance, les verriers, les tapissiers se complairont à reproduire et autant dans le costume que dans l'ameublement ${ }^{2}$.

A la fin du $x v^{e}$ siècle, la spécialisation des tissus est moins absolue. On fait un peu de tout partout. Les secrets de fabrication ont pénétré dans les différents centres, et il

1 L'Art de décorer les tissus, pl. LXVIII, nos I, 4.

2 IJidem, pl. XXI, $\mathrm{n}^{\circ \mathrm{s}} 3,4$. 
est alors bien délicat d'assigner un lieu d'origine certain à, telle ou telle étolfe. Par analogie pourtant, on peut, dans nombre de cas, réunir des indices probants.

Pour Venise, par exemple, l'influence orientale persiste, par suite de ses gros intérêts maritimes, et aussi grâce à l'influence considérable des récils du fameux Marco Polo, dont les ouvrages (publiés en français, langue de la chevalerie) entretiennent le goût des splendeurs d'Orient.

Gênes tient la première place pour les velours ciselés. Peut-être devons-nous assigner une origine florentine à quelques tissus, dans lesquels le dessin en velours coupé s'enlève sur le fond de velours frisé. Sienne continue à fabriquer ses tissus à personnages saints, destinés à remplacer les orfrois des costumes liturgiques.

L'Espagne fabrique tous les genres, soit qu'elle copie l'art italien, soit qu'elle y ajoute son cachet particulier en compliquant le décor d'arabesques. De plus, beaucoup de tissus espagnols sont reconnaissables à quelques détails héraldiques, caractérisant leur provenance ${ }^{1}$.

En Allemagne, en dehors des copies italiennes, nous n'arons à signaler comme création que les tissus de Cologne ${ }^{2}$ destinés aux costumes liturgiques, et dans lesquels certaines parties sont réservées pour recevoir un complément de broderie. Depuis l'époque carlovingienne, Cologne avait une école de broderie réputée.

Dans les dernières années du $\mathbf{x} \mathbf{v}^{\mathrm{c}}$ siècle, I'Italie intervient d'une manière décisive dans les destinées de l'art français.

! L'Art de décorer les tissus, pl. XXI, n० $9 ;$ pl. XXV, nos $2,5,8$.

2 Ibidem, pl. XL. 
Une folle entreprise, la conquête du royaume de Naples, par Charles VIII, avait mis les deux peuples en contact. Un courant de relations s'établit, sympathique ou contraire, suivant les fluctuations de la politique. Nous n'avons pas à nous occuper de lissue fâcheuse des revendications armées de Louis XII à propos du Milanais; retenons-en seulement que, lorsque nos grands seigneurs suivent, en Italie, nos aventureux monarques, ils sont éblouis de la beauté des villes italiennes, du goût somptueux des arts italiens. C'est une initiation à des théories nouvelles pour nous, que poursuivront avec ardeur François Ier et cette princesse de la maison de Médicis, élevée au trône de France.

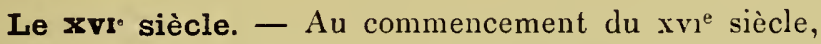
l'art en Italie resplendit merveilleusement. Son génie a su dégager lidéal du réel, avec une perfection savante comparable à la perfection antique. Ses différentes écoles atteignent les plus fiers sommets du beau. Tout y est réuni: style, originalité, abondance, impréru dans l'invention, spontanéité dans l'exécution ; et, si nous pensons que l'imprimerie est découverte, apportant à l'enseignement les ressources nouvelles de la vulgarisation didactique, il semblerait que le progrès dût être indéfini. La prestigieuse magie de cet apogée ne trouvera pas pourtant de cœur assez vaillant pour en continuer l'essor.

Pris de vertige, enivrés de savoir, les artistes versent du côté de l'habileté manuelle, deviennent de prodigieux ouvriers, dont Tiepolo sera le plus fameux représentant. 
La sagesse, la pondération, le goût ne président plus; avec le tour de force du métier on va glisser à la décadence. L'art qui nous occupe spécialement la subira, d'autant plus qu'il est moins le fruil de l'effort individuel que le reflet des tendances d'un moment.

Le décor tissé va donc se surcharger de détails superflus, il arrivera à la confusion. Il semble qu'il y eût alors obligation de répéter dans tout ce qu'on produisait tout ce qu'on avait appris, d'où celte surabondance d'ornement dans l'ornement, remplaçant la clarté et le bon sens de la période précédente.

Il suffit d'examiner une étolfe du commencement du $\mathrm{xvII}^{\mathrm{e}}$ siècle pour se rendre compte de cette outrance du détail à cette limite de la période italienne'. Au point de vue des ressources industrielles, elle dénote une incontestable supériorité. Ces complications du dessin devaient entrainer des complications de montages, bien faites pour nous surprendre, si nous songions à ce qu'étail alors le métier.

A còté de ces tissus à compositions si touffues, il apparaît dans quelques autres, comme une tendance à réagir. Nous voulons parler de ces semis de grandes floraisons très slylisées, en velours ciselés principalement, qui évoquent l'art des semis orientaux, gardant toutefois du moment l'extrême richesse d'expression ".

Dans un grand nombre de tissus de la fin $\mathrm{du} \mathbf{x v i}^{\mathrm{e}}$ siècle apparaît une particularité très caractéristique, la ligne

1 L'Art de décorer les tissus, pl. LxVIII, $\mathrm{n}^{0_{5}}$ ro, 12.

2 Ibidem, pl. LXVIII, $\mathrm{n}^{\circ \mathrm{s}} \mathrm{I}, \mathrm{I} 3$. 


\section{$-\left(8_{9}\right)$ -}

courbe y manque de souplesse, elle se brise, semblant plutôt le résultat de sections polygonales. Sommes-nous là en face d'une recherche pittoresque ou d'une insuffisance industrielle, il est assez difficile de le dire. Constatons-le seulement, tout aussi bien pour les grandes compositions que pour celles de moindres dimensions.

Notons, pour finir, que le costume au commencement $\mathrm{du} \mathrm{xvi}^{\mathrm{e}}$ siècle, change sensiblement, pour redevenir très ajusté, entrainant par là même un retour au petit décor, surtout en dehors de l'Italie.

L'activité s'y affirme d'ailleurs, et en France particulièrement. Après l'initiation de nos grands seigneurs aux splendeurs italiennes, nos rois avaient ramené d'Italie des artistes pour les mettre à la tête de nos industries de luxe : Boccador, Serlio, le Primatice, etc. François Ier mettra ces derniers à la tête de cette fameuse école de Fontainebleau dont le dernier directeur sera Philibert Delorme. Le Primatice dirigera nos beaux-arts sous quatre de nos rois: François Ier, Henri II, François II, Charles IX. Toutefois la France s'affranchit rapidement de l'influence italienne, surtout en architecture et en sculpture, avec Michel Colomb, Jean Perréal, Jean Cousin, Germain Pilon, Jean Goujon. Pour l'art du tissu décoré, l'émancipation est moins rapide. A Lyon, par exemple, on travaille, c'est certain, mais les riches tissus, particulièrement, se font sous la direction et l'inspiration d'ouvriers italiens. Nous avons vainement cherché quelque spécimen dénotant une origine franchement française du $\mathbf{x v i}^{\mathrm{e}}$ siècle. C'est ainsi que nous n’avons pas trouvé d'étoffes dans lesquelles apparaissent 


\section{$-\left(9^{0}\right)-$}

sans mélange ces deux caracléristiques de la Renaissance française, le cartouche et l'entrelacs qui pourtant faisaient le fond du décor dans le meuble et la typographie, deux arts où Lyon s'était révélé supérieur. C'est là un exemple curieux de cet orgueil professionnel de certains corps de métier, jaloux de leur autonomie, par là même se refusant l'emprunt de formes d'art, exploilées par d'autres maîtrises. Nous aurons l'occasion de revenir sur ce détail.

\section{PÉRIODE FRANÇAISE}

A partir de Louis XIV, la France devient prépondérante. Une Iongue suite d'efforts, qui représente notre éducation artistique, a préparé cette glorieuse émancipation. Nous en avons déjà signalé la trace à l'époque carlovingienne. Au moyen âge, après les angoisses de l'an mil, les phases se succèdent, dites: romane, jusqu'à la fin du xu1 ${ }^{\mathrm{e}}$ siècle, gothique jusqu'au $\mathrm{xv}^{\mathrm{e}}$ siècle. Jusque-là, la pléiade des travailleurs, le plus souvent anonymes, ne s'occupe guère que d'art religieux. Il n'en est plus ainsi à partir de François Ier, où l'art se laïcise. D'abord italienne dans ses manifestations, la Renaissance française prend rapidement un caractère qui lui est propre. C'est l'art de l'école de Fontainebleau et des châteaux de la Touraine. Il est spécialisé à l'architecture et à la sculpture. Il nous faudra attendre la fin $d_{u \times 1^{e}}$ siècle pour rencontrer dans les arls secondaires, comme ceux du domaine de la peinture, quelques personnalilés artistiques dont l'œuvre s'impose. 
A ce moment encore, l'Italie, toute décadente qu'elle soit, n'en conserve pas moins son lustre incomparable, el toutes les renommées doivent venir s'y faire consacrer. C'est le cas de Simon Voüet, qui végète en France, el qui pourlant, à peine arrivé en Italie, s'y fait rapidement connaître. Amis et protecteurs l'entourent, au point que, en 1614 , il est élu prince de l'Académie de. Saint-Luc, la plus haute distinction accordée aux artistes en Italie. Le voilà sacré maître officiellement: "Alors, dit Olivier Merson, notre regretté et vénéré ami, Louis XIII lui accorde une pension et l'appelle à Paris où il ne laisse pas de désirer revenir. Son air ouvert, l'aisance distinguée de ses manières, sa peinture agile, facile à comprendre, plaisent au roi, qui le nomme son premier peintre et le loge au Louvre. L'accueil de la reine et du cardinal de Richelieu n'est pas moins flatteur, et toute la cour renchérit, naturellement.....

"Simon Voüet n'est pas un génie, mais son rôle fut utile, son atelier fut la pépinière des peintres de l'âge suivant. Cet excellent maître était surtout fait pour développer les talents dans tous les sujets qui en renfermaient le germe. "

Ses plus fameux élèves furent Le Sueur et Le Brun. Celui-ci nous retiendra dans la suite. Parmi les autres personnalités artistiques qui vont faire consacrer leur talent en Italie, nous ne saurions omettre Nicolas Poussin, dont l'autorité embrasse la nature entière et qui tient une place sans égale parmi nos peintres. Lui aussi fait école; Jacques Stella, Gaspard Dughet, Claude Lorrain, Mignard et aussi Le Brun furent ses élères.

Nous avons cru devoir dire ces choses pour préciser 


\section{$-\left(9^{2}\right)-$}

combien l'Italie était encore prépondérante au commencement du $\mathrm{xvir}^{\theta}$ siècle; et quel rôle important elle joue au point de vue de l'éducation artistique des maîtres qui vont fonder l'école française.

Mais nous ne nous occupons que de l'art de décorer les tissus. Au point où nous en sommes, c'est-à-dire au $\mathrm{xvII}^{\mathrm{c}}$ siècle, son histoire se confond avec celle de la grande Fabrique lyonnaise. Aussi nous reviendrons encore en arrière pour rappeler rapidement les circonstances qui ont préparé sa prospérité.

Depuis longtemps, bien avant le $x v^{e}$ siècle, Lyon avait un grand marchè où accouraient les trafiquants du Sud apportant tous les produits d'Orient. Du Nord et de l'Est, on renait s'y approvisionner. Par décret du 23 novembre 1466, Louis XI décide l'établissement d'une manufacture royale de soie à Lyon, l’imposant en même temps extraordinairement. On en passa par les exigences royales dans la crainte de voir déposséder la cité, au profit de Genève, de ses quatre foires annuelles; ce qui n'empêche pas le roi de détruire lui-même l'institution qu'il a créée, en faisant transporter quatre ans plus tard, encore aux frais de Lyon, les ouvriers en soie, avec leurs métiers, dans sa bonne ville de Tours. Heureusement les foires lui restaient. La Fabrique lyonnaise, privée de la protection royale, y gagne du moins une plus complète indépendance.

Jusqu à François I ${ }^{\text {er }}$ elle luttera, mais en restant tributaire des autres centres de production tant français qu'étrangers. En I 536, une ordonnance royale affranchit de toute taille et impôts les tisseurs du royaume. Turquet et 
Naris, conseillés par un homme éminent, Mathieu Vauzelles, revendiquent le bénéfice de cette ordonnance et obtiennent des consuls lyonnais l'autorisation de monter des métiers. Déjà n'était pas tissutier qui voulait. Il fallait remplir certaines conditions et avoir fait un long apprentissage pour obtenir la maîtrise, encore était-on limité à une spécialité.

En 1540 , Lyon est déclaré entrepôt unique de toutes les soies étrangères qui entreraient en France, ce qui n'empêche pas sa Fabrique proprement dite, comme celle des autres milieux producteurs, d'être toujours aux mains d'ouvriers italiens, appelés par nos rois, ou émigrés à la suite des luttes politiques que les républiques italiennes soutenaient entre elles. Aussil'art du tissu décoré reste-t-il italien, et il en sera ainsi jusqu'au milieu du xvı ${ }^{\mathbf{e}}$ siècle.

Parallèlement à la fabrique des étoffes de soie, la prospérité de la sériciculture est assurée par les soins de Henri IV. Deux hommes de haute initiative le secondent dans cette tâche: Olivier de Serres et Laffemas. Olivier de Serres, celui-là même qu'on avait appelé le père de l'agriculture en France, s'était, entre autres choses, attaché à l'exploitation du mûrier. Sur son ordre, on en plante partout; au seul jardin des Tuileries, il n'y en a pas moins de quinze mille pieds.

L'autre collaborateur de Henri IV, Laffemas, est une curieuse figure : de petite noblesse protestante, il avait ćté obligé de prendre un métier pour vivre, et il avait choisi celui de tailleur d'habits. Au temps qu'il n'était encore que prince de Béarn, Henri IV avait été son client; devenu roi, il se l'attacha en qualité de valet de chambre. 
Sans cesser d'occuper cette charge, Laffemas se livre au commerce des tissus, particulièrement des tissus précieux ; il y amasse une fortune considérable. Un jour il présente au roi son maître, qui s'en étonne fort, un mémoire sur l'état de l'industrie en France et un règlement général: "Pour dresser des manufactures en ce royaume". On raconte que Henri IV ne put s'empêcher de dire : «Puisque mon tailleur fait des livres, il faudra que mes conseillers s'occupent de me faire des chausses. "

Le mémoire de Laffemas contenait en germe nombre de nos institutions : celle des Chambres de commerce entre autres. Nommé contrôleur du commerce, il donne une impulsion vigoureuse à l'industrie nationale, s'attache lui aussi à la culture du mûrier et à l'élevage du ver à soie. Grâce à ces efforts, la France va être en possession de la matière première. Laffemas aide ainsi Henri IV, dont l'énergique volonté s'emploie à affranchir son royaume de la dépendance étrangère.

En I6o5, un illustre enfant de Lyon, un maître ouvrier, Dangon, invente son métier à la grande tire, qui permet de porter à 2400 le nombre des cordes utilisables et, avec quatre ouvriers tireurs de lacs, de tisser de grands dessins à effets compliqués et à couleurs multiples. C'est à lui que revient, en grande partie, l'honneur de l'essor lyonnais. Henri IV lui concède le privilège de l'exploitation du métier qu'il a inventé. Praticien consommé, Dangon suscite dans les manufactures locales une direction nouvelle et féconde. C'est sur ses métiers que durent être tissées les étoffes compliquées que nous avons classées à l'époque de 
notre Louis XIII. En Italie, le dessinateur en profitera pour surcharger sa composition jusqu'à la superfétation.

Comme nous l'avons déjà dit, jusqu'à Louis XIV, les productions françaises sont surtout des productions de prix moyen, les tissus de grand luxe restant la spécialité de I'Italie. D'ailleurs, en France, le goût des tissus de soie s'était généralisé. Réservés aux grands seigneurs au moment des guerres d'Italie, ils tendent à entrer dans les habitudes de la bourgeoisie, pourvu que le prix en soit moins élevé. C'est là un problème que résoudra la recherche de compositions à pelits dessins, et peu à peu les acheteurs se déshabitueront des produits de l'Italie qui s'entête à ne fabriquer que des étoffes à grands dessins et à prix élevé.

Un homme de génie, Colbert, va rendre la France définitivement créatrice. En vain ses prédécesseurs avaient essayé de refréner le luxe, leurs édits avaient été impuissants. Colbert, lui, encourage tous les arts, toutes les industries de luxe; ainsi la prodigalité des uns servirait la fortune des autres. En réalité la noblesse s'y ruinera, mais n'était-ce pas entrer dans les vues de Louis XIV, qui cherchait à l'abaisser, dans le pays prospère?

Colbert, né à Reims en $\times 6 \mathbf{r}_{9}$, d'une famille d'industriels et d'hommes d'affaires, avait gardé, des traditions de sa race, de fortes qualités d'ordre et d'ardeur au travail. Pré-senté à Mazarin, il devient son secrétaire et, dans ce milieu dépravé, reste honnête et laborieux. Envoyé comme ambassadeur en Italie, il en profite pour étudier le commerce, les arts et l'industrie. A son retour Mazarin est mourant, il le remplace. Son premier acte est de relever les finances 
par une plus sage répartition des impôts; mais son ceuvre capitale restel'industrie française que, dans sa pensée, il ne sépare jamais de l'art et qu'il crée. Le Brun est nommé par lui à la direction de tous les travaux artistiques. On sait quelle impulsion extraordinaire il leur donna; il règle tout, non sans despotisme, mais ce despotisme même est grandement profitable. La conséquence de cette direction est l'unité du style. L'art de Louis XIV, grâce à Le Brun, est donc un art d'ensemble, essentiellement décoratif, dont tous les éléments gravitent autour de l'astre unique : le Roi, dont l'orgueil avait pris pour emblème le soleil avec la fière devise que l'on sait.

Tous les monuments sont destinés à servir de cadre à sa majesté : la colonnade du Louvre, œuvre du médecin Perrault, la porte Saint-Denis de François Blondel, l'hôtel des Invalides de Libéral Bruant avec son église de Mansart, Versailles enfin, la plus magnifique des résidences royales, sont autant d'œuvres où la préoccupation du grandiose est caractéristique du style. Tout cet art pompeux est loin des grâces élégantes de la Renaissance, mais chaque âge a son cachet particulier; les splendeurs de Louis XIV correspondent admirablement à l'idée que nous nous faisons de cette époque glorieuse.

Le Brun possédait justement, en plus d'une science réelle et d'une grande habileté d'exécution, toutes les qualités nécessaires pour satisfaire les goûts fastueux du roi Soleil : l'imagination, l'ampleur quelque peu théâtrale, avec une aisance parfaite à se tirer d'immenses travaux; ce qui ne l'empêchait pas de descendre avec la même autorité 


\section{$-(97)-$}

dans les moindres détails. Dans les dessins de Le Brun on trouve de tout : des projels d'architecture, de décors de toute sorte, des maquettes d'ameublement et des plus petits ustensiles.

Ameublements, tentures, costumes étaient alors d'un luxe et d'une profusion que les documents attestent inouis. C'est le cas de rappeler ici cette boutade de $\mathrm{M}^{\text {me }}$ de Sévigné: « M. de Langlois a donné à Mime de Maintenon une robe d'or sur or, rebrodé d'or, rebordée d'or et par-dessus un or frisé rebroché d'un or mêlé à un certain or, qui fait la plus divine étoffe qui ait jamais été imaginée. "

L'art du tissu passe par trois phases sous Louis XIV : pour la première nous n'avons rien à ajouter à ce que nous avons dit des tissus sous Louis XIII, sinon que la fabrication s'affirme chez nous plus prospère. La seconde, au contraire, bénéficiaire des institutions de Colbert, va se révéler géniale. Elle est essentiellement réaliste d'expression et d'autant plus que, grâce à Revel, un élève de Le Brun, qui avait été mis à la tête du mouvement à Lyon, on inventera une nouvelle formule dans la représentation des détails décoratifs. Jusque-là ils étaient tous rendus en à-plat, désormais l'ombre et la lumière y joueront, modelant le motif.

C'est une innovation qui révolutionne l'aspect des éloffes et dont l'usage persistera pendant les deux règnes suivants. Sous Louis XIV la flore extrêmement nature est surtout employée. On l'interprétera dans des proportions relativement énormes, plus grandes que le modèle même: de grosses fleurs, de gros fruits, isolés, réunis 


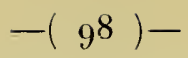

en bouquets ${ }^{1}$ ou combinés à divers détails consécutifs aux goûts du jour: tel, par exemple, celui des jardins dits à la française ${ }^{2}$, avec leurs treilles, leurs ifs, leurs caisses d'orangers, etc.; tel aussi ce goût de l'archéologie qui se manifestera par l'apparition de ruines, de fragments d'architecture ${ }^{3}$, ou bien encore la vogue des passements $^{4}$, des coquillages ${ }^{5}$, etc. Tous ces motifs deviendront éléments ornementaux associés aux mêmes grosses floraisons, aux mêmes gros fruits. Par suite de cette échelle du détail, l'étoffe est à un seul chemin, à deux au plus. Dans certaines, le décor est pittoresque, sans répétition symétrique ${ }^{6}$; dans d'autres, au contraire, il est à pointe $^{7}$; dans quelques-unes, enfin, les deux formes se présentent avec un motif pittoresque et des parties à retour ${ }^{8}$. Ces tissus sont brochés avec une profusion parfois extrême de couleurs; l'or et l'argent en rehaussent souvent la richesse. Au commencement, le sujet a plus d'importance que le fond qui est uni ${ }^{9}:$ satin ou taffetas. Le décor couvre presque toute la surface. Peu à peu, la composition s'éclaircira; le fond alors s'armure de jeux divers qui viennent concourir à la somptuosité du tout ${ }^{10}$

1 L'Art de décorer les tissus, pl. LXXVI.

2 Ibidem, pI. LXXV, $\mathrm{n}^{\circ} \mathrm{9}$.

3 Ibidem, pl. LXXX, nos 2, 3, 4 .

4 Ibidem, pl. LXXXI, no 2.

5 Ibidem, pl. LXXV, no 10.

${ }^{6}$ Ibidem, pl. LXXV, no 1 r.

7 Ibidem, pl. LXXV, $\mathrm{n}^{0} \mathrm{r} 3$.

8 Ibidem, pl. LXXVIII, $\mathrm{n}^{0} 5$.

9 Ibidem, pl. LXXV, $\mathrm{n}^{\circ} 7$.

10 Ibidem, pl. LXXIX, nos $1,6$. 
Peut-être tous ces tissus et leurs détails énormes présentent-ils, au premier abord, un aspect choquantle bon goût; mais si nous nous reportons à leur utilisation, et si, par la pensée, nous nous imaginons ce que pouvaient bien être ces cavalcades presque journalières, ces fêtes dans les jardins de Versailles, ces réceptions dans les immenses salons du palais, toute cette foule avide d'attirer un regard du mầtre, quoique souvent bien éloignée de lui par les exigences rigoureuses de la préséance, alors cette pompe particulière et magnifique nous explique l'obligation de tout faire plus grand pour être plus lisible et, par là même, plus susceptible de fixer l'attention du monarque. Alors, aussi, nous comprenons cet art de Louis XIV et sa contante recherche du cadre à sa majesté. Les jolies manifestations de l'art de Louis XVI, par exemple, eussent été perdues dans ce milieu dont on ne peut contester la grandeur et la splendeur robuste.

Dans ces monuments si variés d'expression, une chose aussi nous frappe, c'est l'apparition inconsciente de certaines formes particulières qu'exploitera le style suivant. Sous Louis XIV, elles ne sont pas encore définies; les hasards d'essai dans l'interprétation de quelques feuillages, l'imprévu de taches décoratives indéterminées nous amèneront à ce qui sera plumes, rocailles, dentelles, vingt ans plus tard.

Nous avons parlé là d'étoffes de costume; en ameublement on fait surtout des damas et des brocatelles dont le caractère spécial est facilement reconnaissable. Le plus communément, le décor est à retour ; l'ornement, en 


\section{$-($ 100 $)-$}

général, à base de larges feuillages découpés, très stylisés, se contourne avec souplesse en panache, moitié plume, moitié flore ${ }^{1}$; quelques gros fruits, quelques grosses floraisons, telles que les pivoines et grenades surtout ${ }^{2}$, accompagnent ces feuillages avec aussi des épanouissements rayonnants d'ornements conventionnels dans des dispositions qui amèneront à la coquille ${ }^{3}$.

On fait aussi des velours ciselés. Sont-ils de fabrication lyonnaise ou italienne; il serait assez malaisé de le dire. Ce qui est certain, c'est que leur décor se ressent de la suprématie, désormais assurée, du goût français ; dimensions et réalisme des détails floraux, symétrie de la composition, etc, ${ }^{4}$.

Nous signalerons, sans y insister, un genre d'étoffe fait pour le costume liturgique, étoffe de moindre valeur où le décor floral, principalement vigne et épis, toujours à retour, se rapproche davantage de l'interprétation en à-plat ${ }^{5}$.

Il est assez curieux de constater que l'école de Bérain nefournit que de très rares exemples tissés de sa formule particulière. Nous n'en avons trouvé que quelques spécimens isolés dans la profusion de la production contemporaine, et pourtant ce sera sous Napoléon III, au moment où l'on copiera le passé, ce que les marchands de meubles nous donneront comme étant du plus pur Louis XIV.

1 L'Art de décorer les tissus, pl. LXXVII.

2 Ibidem, pl. LXXVII, no 6.

3 Ibidem, pl. LXXVII, no 3 .

4 Ibidem, pl. LXXVIII.

5 Ibidem, pl. LXXXI, no 3. 


\section{$-(101)-$}

A la fin du règne, malgré la tristesse des dernières années du monarque, l'art au contraire s'égaie, devient moins solennel. Il n'y a plus alors, pour le diriger rigoureusement, l'autorité absorbante d'un Le Brun: d'où tendance à plus de fantaisie. La noblesse que le roi avait forcée à l'entourer, s'émancipe un peu de son influence unique. Tous ces grands seigneurs s'étaient fait construire de somptueuses demeures et avaient pris l'habitude de vivre à Paris ou à Versailles; ainsi s'était créé, au grand bénéfice de l'industrie nationale, un centre de luxe donnant le ton au reste $d u$ monde. La fabrique française est définitivement créée. La révocation de l'édit de Nantes, un moment, fera craindre pour sa prospérité, par suite de l'cxode de l'argent protestant. Heureusement, l'énergie nationale se relève rapidement de cet à-coup. Les revers à l'extérieur, les chagrins domestiques étaient venus, avec l'âge, assombrir l'éclat pompeux de la cour, mais le parti était pris du grand luxe. Devenu moins officiel, il prend des proportions plus gracieuses et tend à l'élégance qui aura son complet épanouissement sous Louis XV.

Louis XV. - Louis XIV mort, la noblesse se précipite a u plaisir à la suite du Régent. Une nouvelle classe de privilégiés partagera avec elle son ardente impatience de jouir. L'Écossais Law propose son systeme financier qui un moment fait croire que les finances publiques ront se relever. Grâce à lui, d'indignes intrigants font des fortunes scandaleuses et arrivent jusqu'au pouvoir. Il ne restera du 
système que la plaie de l'agiotage, et aussi cette désinvolture extrême dans la dépense, dont profiteront incontestablement les industries du luxe.

Les manifestations artistiques, servies par cette science supérieure de fabrication qu'a préparée l'école de Le Brun, vont devenir d'autant plus riches d'expression. Au point de vue de l'invention, la Régence ne nous offre pas de particularité bien saillante : c'est, avec plus de fantaisie, une suite du style précédent où l'on sent que l'initiative d'artistes de premier ordre a secoué le joug officiel. Si l'art ne rayonne plus autour d'un astre unique, il retrouve du moins en élégance ce qu'il a perdu en solennité. Par suite, nos étoffes présentent des compositions analogues à celles qui les précèdent directement, mais sensiblement plus petites d'échelle.

Avec Louis XV l'évolution s'accentue. De l'ensemble de cette nouvelle phase de la période française se dégage une idée passablement troublante de contraste. La conception qui n'a jamais été plus gracieuse, plus libre, plus dévergondée, disons-le, se jouant des formes les plus osées, s'allie à une technique incomparablement savante et pondérée. Maintenant que le temps a fait son ouvre de classement, il est facile de discerner les rapports et les concordances qui existent entre ces accouplements intimes de la méthode et du caprice; de même la puissance géniale de la philosophie contemporaine voisinait la légèreté extrême des mœurs de l'époque.

Louis XV majeur, toute sa politique consistera à laisser aller les choses à leur libre cours. D'un mot il s'est expli- 


\section{$-(103)-$}

qué lui-même. Comme on lui faisait un tableau du triste état des finances, pronostiquant la banqueroute prochaine: "Qu'importe, dit-il, après moi la fin du monde ". Après quelques années d'union heureuse avec la reine Marie Leczinska, il se laisse gouverner par ses favorites dont les plus fameuses furent $\mathrm{M}^{\text {me }}$ de Pompadour et la Dubarry. Son règne n'en est pas moins une ère de gloire au point de vue de l'esprit humain. Philosophes, littérateurs, artistes, lui donnent un éclat extraordinaire.

L'art n'a plus le côté extra-décoratif du Louis XIV ; incontestablement le Louis XV est plus pratique. C'est ainsi que les édifices de la place de la Concorde correspondent admirablement au programme imposé à l'architecte Gabriel. Leurs balcons à colonnades servent de tribunes aux invités des fêtes merveilleuses de la place alors appelée Louis XV; tandis que la colonnade du Louvre n'est qu'un cadre somptueux sans utilité. Dans le détail, toute la science du moment se plie à la réalisation d'un caprice; tout est sensuel, tout s'arrondit. Les angles des panneaux sont remplacés par des courbes, reliant les côtés qui deviennent souples et se terminent en volutes, en épanouissements fantaisistes de fleurs ou de rocailles. Des coquilles sans symétrie couronnent les encadrements d'architecture où se jouent des motifs joyeux, spirituels, pleins de mouvement et d'imprévu.

Comme sous Louis XIV la flore est le principal élément du décor tissé, mais une flore de proportions nature plutôt en dessous qu'en dessus. L'ordonnance la plus caractéristique sera celle de lignes verticales sinueuses, parallèles 
ou contrariées (auquel cas elles font compartiment), le tout semé de bouquets réalistes ${ }^{1}$. Cetle ligne verticale sinueuse, elle-même réaliste d'expression, sera passements ${ }^{2}$, dentelle ${ }^{3}$, fourrure ${ }^{4}$, ou composée également d'éléments floraux $^{5}$. Rarement la composition sera à pointe. Le fond s'éclaircit, amusé d'armures multiples, de jeux divers. Toutes les gammes de la palette la plus brillante jettent sur ces fonds leurs notes étincelantes presque toujours mêlées d'or et d'argent.

C'est pour la reine Marie Leczinska qu'on introduit la fourrure, souvenir de son pays natal. $\mathbf{M}^{\text {me }}$ de Pompadour, elle, met à la mode un autre genre de décor imité des arts d'Extrême Orient. Elle est grande actionnaire de la Compagnie des Indes, aussi aime-t-elle les chinoiseries. On en fabriquera pour la satisfaire ${ }^{6}$, interprétant d'ailleurs plutôt leur côté bizarre. Les Gillot, les Huet, les Huquier, les Pillement mettront leur fantaisie à sa dévotion, pour créer ce type particulier de composition.

Quoique de basse extraction, la Pompadour (JeanneAntoinette Poisson) reçut une éducation brillante. Ellemême avait un talent appréciable dans presque tous les arts. Aussi ne se contente-t-elle pas de commander en favorite, elle est à même de donner un conseil éclairé et,

1 L'Arl de décorer les tissus, pl. CIII, $\mathrm{n}^{0} 7$; pl. CII, $\mathrm{n}^{\circ \mathrm{s}} \mathbf{\mathrm { r }}-8$.

2 Ibidem, pl. CII, $\mathrm{n}^{0} \mathrm{x}$.

3 Ibidem, pl. CI, $\mathrm{n}^{0} 6$.

4 Ibidem, pl. CI, no 5.

5 Ibidem, pl. CI, n ${ }^{\circ}$ Ir.

${ }_{6}^{6}$ Ibidem, pl. CI, $\mathrm{n}^{0} \mathrm{r}$; pl. CII, no 5 . 


\section{$-(105)-$}

en tout cas, d'indiquer juste et sûrement ce qu'elle veut.

On évalue à une centaine de millions les prodigalités auxquelles elle entraîna Louis $\mathrm{XV}$. De toutes ces dépenses, il est resté incontestablement quelque chose, un genre particulier d'art, architecture, peinture, sculpture, ameublement, le genre Pompadour, et nous devons reconnaître qu'elle servit notre industrie artistique. Avec un goût très sûr, un amour vrai, ingénu de la beauté, elle avait l'horreur des élégances banales. Elle-même donnait souvent des modèles, et son influence est plutôt bienfaisante que néfaste. Avec elle, on ne fit plus grand, bien entendu, on fit joli. Le joli fut son but suprême. En fait de mode et d'ameublement, ses décisions faisaient loi.

A la fin du règne de Louis $\mathrm{XV}$, la composition est devenue toute florale. La ligne verticale sinueuse ellemême est constituée de branches foliacées et fleuries alternant avec les mêmes bouquets, dont le dessin est. souvent d'un art supérieur. On trouve quelques rares exemples où l'ordonnance de lignes sinueuses est horizontale. C'est sous Louis XV que la moire fait son apparition ${ }^{1}$. On emploie aussi pour la première fois la chenille; dans certaines étoffes, tout le décor en est tissé ${ }^{2}$.

Depuis un siècle, l'industrie italienne subit une véritable décadence; ou bien elle copie lourdement l'art français, ou bien quand elle-même crée, la composition rentre dans ce genre baroque dont les excentricités nous dé-

1 L'Arl de décorer les tissus, pl. CI, no 13.

2 Ibidem, pl. CIV, no 4 . 
passent. Au moment de la révocation de l'édit de Nantes, l'Allemagne et l'Angleterre, recueillant les protestants chassés du royaume, bénéficient incontestablement de la proscription, mais c'est toujours de France que part la mode. Beaucoup de tissus même, fabriqués à l'étranger et inspirés par notre goût, devront être envoyés à Lyon pour y recevoir l'estampille officielle avant d'être livrés à la consommation.

Louis XVI. - Nous avons constaté sous Louis XV un art où s'allient les contrastes : fantaisie joyeuse de la conception et perfection scientifique de l'exécution; de même qu'en littérature, la légèreté extrême avoisinait l'âpreté froide de la philosophie contemporaine. Ces contrastes s'exaspèrent encore sous Louis XVI, mais y créent deux courants absolument distincts. Deux exemples nous les indiqueront : le petit Trianon et le Panthéon. En réalité, ces deux édifices sont commencés sous Louis XV, mais MarieAntoinette, en donnant au petit Trianon son complet épanouissement, en a fait sa chose; au Panthéon, Soufflot est le précurseur des tendances qui se généraliseront avec l'école de David.

L'antithese est partout : Louis XVI, d'une intelligence moyenne, est sans prestige physique, d'un caractère indécis, brusque et timide à la fois. Au milieu de cette cour si dénuée de sens moral, la pureté de ses mours contraste étrangement. Travailleur et instruit, il s'isole à la recherche de quelque probleme, tandis que les philosophes révolutionnaires vont à la conquête des esprits. 
Profondément attaché aux traditions, il consent bien à l'adoucissement de certains abus, mais n'en veut pas l'abolition complète, et ces demi-mesures lui attirent le mécontentement général.

La reine, elle, charmante de jeunesse et d'entrain, prompte au plaisir, en recherche toutes les occasions. Cette différence des caractères éloigne les nouveaux époux. Pour cette raison et d'autres plus délicates, l'union reste stérile, ce qui n'est pas sans aigrir encore l'opinion. Enfin, après sept ans de mariage, un enfant naquit, et Marie-Antoinette prendra un peu d'influence sur le roi jusque-là si éloigné d'elle. Avec la maternité, son existence change. Désormais toute à ses devoirs de jeune mère, elle va s'enfermer à Trianon. Sa vie y tiendra, vie factice où l'étiquette est proscrite, où la cour est réduite à un petit nombre d'intimes. Là, les monarques jouent au meunier et à la meunière. Dans ce hameau de théâtre paissent des moutons enrubannés; la reine trait des vaches à cornes dorées, le roi a une houlette et le comte d'Artois est maître d'école. Toutefois, à côté de ce joujou sentimental, la reine fait aménager ce petit Trianon que Louis XVI lui a donné en propre. Elle le fait meubler au goût du jour, décorer à grand renfort de guirlandes, de pipeaux, d'accessoires lyriques et champêtres. Tout y devient exquis, c'est le bijou et l'idéal du confort féminin.

Dans le royaume, des différences extrêmes divisent les sujets : les défenseurs de l'ancienne constitution, et ceux qu'entraînent les théories nouvelles. Tous, d'ailleurs, sont mécontents du gouvernement. Les crises financières se 
sont multipliées et on accuse les prodigalités royales. Elles sont bien peu de chose, en vérité, à côté de celles de Louis XIV, des gaspillages de Louis XV et de ses ministres femelles, mais le pays est a bout et il fera payer cher aux malheureuses majestés les dépenses excessives de leurs prédécesseurs; pour le moment, c'est en les haïssant; la folie populaire en fera des martyrs.

Deux tendances sans rapports entre elles partagent les littérateurs: celle des Berquin; celle des philosophes révolutionnaires.

Les artistes suivent également deux voies opposées. L'école inaugurée par Watteau est encore représentée par des maîtres: Van Loo, La Tour, Boucher, Fragonard, Greuze, qui poussent même l'exécution décorative plus loin qu'elle ne l'a jamais été. Leur art est exquis, quoique, il faut bien le dire, un peu mince et mièvre. La rude école de David, d'autre part, est une conséquence des idées nouvelles qui poussent à l'admiration sans bornes de l'antique.

Revenons à nos tissus. Jamais la Fabrique n'a été plus habile. La verve des dessinateurs est intarissable. L'ensemble de la production donne l'impression du plus petit que nature tant pour la composition que pour les détails qui y entrent. La mode veut encore des tissus façonnés, mais les grands coûtant trop cher, on se rabat sur les petits. L'industrie s'ingénie à produire avec cette préoccupation nouvelle du bon marché, conséquence du manque d'argent dans une société qui a toujours l'impérieux besoin de jouir. 
La disposition la plus courante, et en même temps celle qui est le plus directement la suite de l'évolution, sera celle à ordonnance de lignes verticales rigides semées de fleurettes et d'accessoires de toute sorte: nœuds de rubans, pipeaux, instruments de musique et de jardinage, médaillons, corbeilles et vases fleuris, tout l'attirail de l'idylle champêtre et des mascarades du petit Trianon ${ }^{1}$. Liimportance du fond s'est encore accrue : le détail y apparaît, très lisible, jetant de ci, de là, sa note gaie et jolie, à colorations délicates, sans tomber toutefois dans cette fadeur dont on a tant abusé dans la copie.

Conséquence plus directe des exigences du bon marché, on fabrique à Lyon un nouveau genre de tissu: le droguet, dans lequel la chaîne concourt au même titreque la trame à l'ensemble du dessin. Il serait bien difficile de dire quel genre de composition on emploie dans les droguets. Au Musée de Lyon, il y en a des milliers d'échantillons tous variés, avec ou sans velours, avec ou sans métal, polychromes ou d'une seule couleur; retenons seulement que le motif décoratif $y$ est toujours de très petite dimension.

Non moins grande est la variété des velours miniature, Ceux-ci, de fabrication supérieure, dénotent une ingéniosité inouïe dans l'emploi de la cantre pour multiplier les couleurs. Dans cette catégorie de petits velours rentrent ceux faits spécialement pour la voiture et la chaise à porteurs. La capricieuse fantaisie du moment y mêle les plus divers

1 L'Art de décorer les tissus, pl. CVII, nos 6, 7, 10, 11, 16. 
éléments: fleurs, personnages, armoiries, accessoires de toute sorte, etc., etc ${ }^{1}$.

Une autre innovation d'un aspect particulier sera celle des chinés à la branche. D'une entente théoriquement facile, leur exécution est bien faite pour troubler. Comment ces fils de chaîne, qui produisent le décor, étaient-ils définitivement ourdis pour que le flochetage des formes conserve malgré tout cette précision relative? Il y a là au moins un tour de main d'une habileté qui nous dépasse. De nos jours on imite évidemment ces tissus en imprimant la chaîne; l'industrie, lá, se comprend, mais elle n'arrive pas au charme de l'autre. Les chinés à la branche servent également au costume et à l'ameublement : dans ce dernier cas le rapport est parfois de grande dimension ${ }^{2}$.

Des idées du jour, aidées beaucoup par la découverte des restes d'Herculanum et de Pompéi, naîtra une formule nouvelle du décor. Depuis Louis XIV en effet le détail était complètement réaliste, ce retour à l'antique déterminera l'emploi simultané de l'ornement conventionnel et de liaisons architectoniques. Déjà, à la fin du $\mathbf{x v}^{\mathrm{e}}$ siècle, l'art de Raphaël les avait exploitées dans le décor mural. La compréhension française n'a évidemment pas la haute envolée italienne; elle est plus élégante, plus jolie, car c'est ce mot qui revient toujours à la pensée quand il s'agit de Louis XVI. C'est cette formule, évoquée de l'antique, qui, en s'exaspérant, fera le fond du style suivant. L'ameublement surtout nous fournit ces exemples

1 L'Art de décorer les tissus, pl. CX, nos 1, 2, 3, 4, 5, 6, 7, 8, 9 .

2 Ibidem, pl. CXII, $\mathrm{n}^{\circ} 4$. 


\section{-( 1 1 11 ) -}

de la nouvelle entente ornementale. On lapplique à des damas et à des lampas dans lesquels la composition est à retour ${ }^{1}$ et dans lesquels parfois apparaissent des parties brochées polychromes dont la disposition est pittoresque sur le fond à pointe 2 .

Parmi les réformes auxquelles Louis XVI finit par consentir est celle de la suppression des maitrises et des jurandes. En 1784, le travail devient libre. La Fabrique, délivrée des entraves qui l'enserraient, va produire avec plus de liberté. On ne fera plus, par exemple, de tissus que dans cette largeur de II/24 de l'aune, exigée par les règlements; on pourra se servir de fils plus ténus, faire des tissus mélangés; mais c'est surtout la permission de faire des étoffes imprimées qui révolutionne les idées combattues jusqu'alors. Lyon, qui n'avait cessé de demander contre elles des mesures protectionnistes, se met également à en fabriquer (on en faisait depuis longtemps en Allemagne et en Angleterre). Oberkampf exploitera sur toile ce procédé de décor, avec un rare bonheur, dans sa manufacture de Jouy-en-Josas près de Versailles. A Lyon on imprime seulement sur soie ${ }^{3}$.

Enfin, dans le meuble, signalons l'emploi de larges bandes décorées qui servaient à border les étoffes unies que la mode avaient mises en faveur ${ }^{4}$.

Parmi les principales maisons lyonnaises qui concou-

1 L'Art de décorer les tissus, pl. CXI.

2 Ibidem, pl. CXIII, no 5.

3 Ibidem, pl. CX, nos ro, 14.

4 Ibidem, pl. CIX, nos $1,2,3,6,7,8$. 
rurent à la glorieuse prospérité de la Fabrique au xvıri ${ }^{\mathrm{e}}$ siècle, nous citerons celles des Mathevon, Dutillieu, GalliGallien, Dechazelle, et surtout cette maison Pernon qui vers 1760 s'associe l'homme le plus complet, le plus merveilleux artiste du tissu décoré : Philippe de la Salle.

Philippe de la Salle est à la fois dessinateur, peintre, fabricant, mécanicien. Avec Jean Revel et Bony il est la plus brillante figure dont s'honore l'industrie de la soie à Lyon au xviri siècle, époque où s'éleva au plus haut degré de perfection la science du décor appliqué à l'étoffe.

Philippe de la Salle est né, en $\mathbf{1}_{723} 3$ à Seyssel ; il meurt en $\mathbf{r} 803$. Ses ouvrages portent le cachet du maître, un sentiment décoratif exceptionnel, une imagination vive jointe à un grand charme dans la composition. Le fabricant ne le cède en rien à l'artiste. Il possède aussi une entente merveilleuse de la technique industrielle. Par le jeu des soies de couleur, le mélange du lancé au broché, par un emploi judicieux de la chenille, qu'il fut un des premiers à mettre en œuvre, il obtenait à l'exécution les effets à la fois les plus puissants et les plus délicats. Philippe de la Salle apporta d'utiles modifications au métier. Quelque supérieur que soit le nôtre, nous ne saurions dépasser la perfection de ses tissus, les égaler même. Il fut anobli par Louis XVI, décoré de l'ordre de SaintMichel et pensionnè à 6000 livres. Aprés avoir travaillé pour les maisons souveraines de France et de leétranger, il mourut pauvre, ruiné par la Révolution. Dans les dernières années de sa vie, la ville de Lyon lui accorda un logement au palais Saint-Pierre; il y transporta son cabinet 
de dessin et ses métiers, dont il ne reste malheureusement aucune trace actuellement. Cette collection, qui serait des plus précieuses aujourd'hui pour l'histoire de la Fabrique, a disparu, on ne sait comment, avec tout ce qui formait le fonds de l'ancien Conservatoire des Arts et Métiers de Lyon créé par Napoléon I $^{\mathrm{er}}$. Grâce à des acquisitions successives, le Musée a pu constituer une riche collection des chefs-d'œuvre de Philippe de la Salle ${ }^{1}$. Il s'en dégage une vérité sur laquelle nous ne saurions trop insister : c'est que toute cette production de Philippe de la Salle lui est absolument personnelle, à peine par ci par là un spécimen rentre dans la formule du temps; en général son génie créait de toutes pièces.

A côté de cette prestigieuse figure, Bony mérite lui aussi une mention spéciale. Il est également peintre et fabricant de soieries. Toutefois, c'est surtout dans la broderie qu'il excellera ${ }^{2}$. Comme il travaille plus particulièrement à l'époque napoléonienne, nous reviendrons sur son œurre.

Tout le talent de ces habiles manufacturiers lyonnais ne put empêcher le discrédit du tissu façonné à la fin du $x_{v i 11^{e}}$ siècle. La mode voulut des broderies. La Fabrique lyonnaise produisit en ce genre d'incomparables tours de force, mais, constatons-le toutefois : si, avec la navette, son goût était arrivé au plus haut degré de perfection, ses broderies attestent, sinon une décadence, du moins un art sensiblement moins élevé.

1 L'Arl de décorer les lissus, pI. CVII, $\mathrm{n}^{05} \mathrm{r}, 2,3$; pl. CVIII, etc.

2 Ibidem, pl. CVII, n ${ }^{0} \mathbf{2}$. 


\section{$-\left(\begin{array}{lll}11 & 4\end{array}\right)-$}

Ce que nous venons de dire sur la période française peut se résumer en quelques mots : le Louis XIV est pompeux et donne l'impression du plus grand que nature; le Louis XV est riche et élégant, et, dans le détail, de proportions nature; le Louis XVI enfin, est joli, d une délicalesse toute de charme, et donne l'idée du plus petit que nature. Les trois styles, essentiellement réalistes d'expression, exploitent principalement l'élément floral.

Avec la Révolution nous arrivons à un tournant de l'histoire qui nous conduira à notre organisation moderne. Préparée depuis longtemps par l'émancipation philosophique, l'évolution est normale. La royauté a fait son œuvre, œuvre glorieuse, qui constitue l'unité du territoire, une France unique avec une direction unique. Dans la seconde moitié du xvme siècle, les fautes accumulées de la monarchie de droit divin l'ont réduite à l'impossibilité de gouverner. Poussé par les encyclopédistes, le tiers, jusque-là écarté du pouvoir, en réclame sa part; et de ses revendications naît une société nouvelle toute différente de l'autre.

Avant $\mathbf{1 7}_{\mathbf{7}}$, la France comprenait trois classes d'individus: la noblesse, le clergé, le tiers. Dans l'ensemble, chacune avait son rôle, la noblesse donnait son sang, le clergé ses prières, le tiers son travail d'où dépendait la fortune publique. Or le clergé de cour et de salon ne priait plus guère, la noblesse ne formait plus exclusivement l'armée, seul le tiers restait fidèle à ses fonctions : il travaillait, aussi payait, et chaque année davantage. Les philosophes du $x v n^{e}$ siècle se chargèrent de lui faire comprendre la duperie de son rôle; il la comprendra d'autant mieux que, 
grâce à son activité, son importance a grandi, tandis que diminuait l'influence de la noblesse, l'œuvre de Louis XIV couronnant les efforts tentés dès Louis XI. Les travailleurs réclament contre les dépenses excessives qu'ils sont obligés de solder ; ils veulent aussi l'abolition des privilèges, une plus juste répartition des impôts, une part, qu'ils ont achetée cher, dans la direction des affaires publiques. Par suite du développement considérable de l'industrie, de la division de la fortune, des progrès de la science en général, le tiers, qui en avait été le principal ouvrier, exige pour lui le droit de se mêler au gouvernement, ce qui allait entraîner une réorganisation du pouvoir.

Malheureusement la théorie nouvelle ne put remplacer pacifiquement l'ancienne, et la Révolution éclata. Nous n’avons pas à nous occuper de son histoire; c'est une période éclatante et tragique qui marque la fin du moncle des privilèges, des abus de l'autorité confiée à une caste fermée, et qui prépare l'avenir avec une économie nouvelle et la possibilité pour tous d'être au nombre des dirigeants.

La Révolution isole la France du reste du monde, et, de cet isolement, naîtra un sentiment désormais inséparable de nos aspirations : l'idée de Patrie.

\section{PÉRIODE CONTEMPORAINE}

Le monde né de la Révolution inaugure une économie spéciale. La consommation change de bénéficiaires et le travail s'en trouve profondément modifié. Pour mieux sai- 
sir à quelles exigences l'industrie artistique que nous étudions va être obligée de se soumettre, il nous paraît indispensable de nous édifier d'abord sur le caractère de la nouvelle clientèle comparée à l'ancienne, et sur les différences d'organisation du travail avant et après $\mathbf{1 7 8 9}$. Lintérêt des monuments contemporains n'a pas à être amoindri par cette comparaison; le progrès existe, le génie du $\mathrm{xix}^{\mathrm{e}}$ siècle fait partie désormais de l'Histoire, et nier son activité créatrice serait une inutile folie et en même temps une désertion.

Les clients de l'ancien régime avaient tous les affinements des fins de race et l'insouciante prodigalité des classes privilégiées, riches par droit de naissance. Quelle différence entre la situation du fabricant au $x^{\prime}{ }^{\ominus}$ siècle, alors que les encouragements lui venaient de cette société raffinée dont le goût ne marchandait pas, et celle qui lui est faite par le monde nouveau sans éducation préalable, et lui imposant, par ailleurs, la terrible préoccupation du bon marché.

Parallèlement, les producteurs d'antan avaient avant tout l'orgueil de la bonne façon et du beau; la fabrication supérieure était entretenue à Lyon par une législation sévère du travail. Maîtrises et jurandes veillaient à l'observation stricte des règlements, interdisant sous peine de déchéance, d'amendes considérables, du carcan même, toute malfaçon. Il n'en est plus ainsi après r 79r : à partir de cette époque le travail est libre, la clientèle tout autre, la concurrence acharnée.

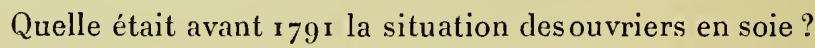


On en distinguait deux catégrories : l'une, appelée la «communauté ", comprenait l'apprenti, le compagnon et le mâ̂tre-ouvrier ; deux maîtres-gardes élus par eux étaient chargés de leurs intérêts, de la surveillance des productions et de juger les différends s'élevant entre les membres de la communauté; l'autre catégorie groupait les employés subalternes, domestiques au service des premiers (tireurs de lacs, dévideuses, liseuses, etc.) qui, en aucun cas, ne pouvaient arriver à la maìtrise.

L'apprentissage, commencé vers quatorze ans, durait en moyenne cinq ans, passés chez le même maître, à des conditions stipulées à l'avance dans un contrat. Un examen sur les ressources du métier, l'exécution d'un chefd'œuvre (une aune d'étoffe de sa spécialité) et le paiement d'un droit qui varie suivant les époques faisaient admettre l'apprenti au grade de compagnon.

Le compagnonnage durait deux ans, que l'intéressé pouvait passer chez différents maîtres. Pour changer d'atelier, le compagnon devait terminer la pièce commencée, régler les avances qu'on avait pu lui faire et prévenir un mois à l'avance. Un examen analogue à celui de l'apprentissage et le paiement d'un nouveau droit lui permettaient d'obtenir sa lettre de maîtrise et alors de monter un atelier.

Les droits élevés, une fois payés, faisaient que l'ouvrier restait à Lyon pour en bénéficier, et là était le but de ces droits successifs.

Au $x \mathrm{xu}^{\mathrm{e}}$ et au $\mathrm{xvm}^{\mathrm{e}}$ siècle pouvaient seuls faire partie de la communauté les Lyonnais d'origine. Les enfants des 
maîtres bénéficiaient de privilèges particuliers : durée moindre de l'apprentissage et du compagnonnage, exonération d'une partie des droits de passage d'une classe dans une autre, etc. Les maîtres, qui ne pouvaient avoir qu'un seul apprenti, avaient en plus le droit de faire l'éducation de leurs enfants. Les filles apportaient en dot à leur mari les avantages dont jouissaient leurs frères.

Le nombre de métiers autorisé pour un même maître était de quatre; on obtenait ainsi une égalité presque absolue, tous les maîtres étant passés par les mêmes épreuves et ayant un atelier de même importance. Le roi accordait pourtant parfois aux inventeurs le privilège de monter plus de quatre méliers, pour exploiter eux-mêmes leur découverte; mais c'était là une exception.

Quand une pièce était terminée, elle était portée au Bureau; les maîtres-gardes l'examinaient, contrôlaient sa bonne façon. En queue et en tête de la pièce étaient tissées deux tirelles portant les initiales de l'ouvrier, son surnom de compagnonnage en toutes lettres, avec sa marque particulière; au dessous : le nom et la qualité de l'étoffe, le nombre de portées dont la chaîne était composée. Le maître-marchand y ajoutait d'autres mentions. Enfin, les maîtres-gardes apposaient l'empreinte : “ Bureau de visite des étoffes de soie de la manufacture de Lyon. »

Il était interdit aux maîtres-ouvriers de s'associer entre eux, de même aux marchands de s'associer aux maîtres ouvriers. On empêchait ainsi le canut en général de sortir de sa situation.

Pour soutenir le bon renom de la manufacture lyonnaise, 
perpétuer la perfection du travail, rester industrie de luxe, de dures obligations étaient imposées à la Fabrique : telle la défense absolue de tout mélange à la soie, de se servir d'or faux, de tisser les étoffes sur une autre largeur que celle réglementaire de 1 1/24 de l'aune, de fabriquer un tissu autre que celui de sa spécialité, etc., etc.

En $\mathbf{r}_{79}$, le travail devient libre; il n'est plus soumis aux réglementations des maîtrises. Quant à la clientèle, elle s'est démocratisée. Les ressources dont elle dispose, étant moindres, ne permettront plus au producteur la richesse de l'ancien décor. La manufacture va donc s'ingénier à produire à bon marché.

Il est à peine besoin de dire que, pendant la tourmente révolutionnaire, la production s'arrête presque complètement. Le nombre des métiers à Lyon tombe à 2000, de $\mathbf{1 8 . 0 0 0}$ qu'il était en ${ }_{17} \mathbf{8}_{7}$, et il en sera ainsi jusquau Consulat.

On dit généralement que le $\mathrm{x}_{1} \mathrm{x}^{\mathrm{e}}$ siècle a été peu inventif en art décoratif, et qu'il n'a pas eu de style caractérisé, exception faite toutefois pour la période de l'Empire. Peut-être serait-il plus juste de dire que l'éloignement n'est pas encore suffisant pour que nous puissions dégager, de l'immense production du siècle, son côté génial? Pour nous, nous envisageons la question sous un autre jour. Nous voyons dans l'œuvre du $\mathrm{xrx}^{\mathrm{e}}$ siècle les manifestations normales et progressives de l'état de choses consécutif à la Révolution. La Révolution a créé un monde nouveau. L'art de ce monde et, plus particulièrement, son industrie artistique devaient passer par les phases habituelles d'imi- 
tation, d'éducation et d'affranchissement, avant d'arriver à sa forme particulière définitive. Nous avons vu que c'était la loi commune à toutes les époques de transition : l'art arabe rayonne au moyen âge, l'art italien le copie pour satisfaire les goûts de luxe que les croisés avaient pris chez les Orientaux pendant les guerres saintes, et, tandis que l'intransigeance religieuse des continuateurs de Mahomet arrête l'essor de la brillante fantaisie arabe, l'Italie s'affranchit de son influence, puis, retrempant son inspiration dans l'antique, évolue vers une conception artistique, plus conforme à son propre génie, et enfin crée à son tour. De même, la Renaissance française est la transition éducative qui prépare l'essor français. Le $x_{1} x^{\dot{e}}$ siècle nous permet de constater des phases analogues de copie et d'adaptation marquant la marche en avant du monde de la Révolution vers sa période d'affranchissement et de création, période à laquelle il nous paraît que nous sommes arrivés actuellement.

A l'époque du Consulat, toute recherche tend vers la tradition antique des républiques grecque et romaine. Les fouilles faites à Herculanum et à Pompéi, dont nous avions déjà signalé l'influence sur les artistes à l'époque de Louis XVI, vont aider encore" davantage ceux de la République. La tendance s'affirme d'autant plus que l'art trouve en David un chef d'école autoritaire imposant sa manière de voir. Cette direction presque unique des arts donne à l'ensemble une homogénéité très caractérisée, si bienque le style en est absolument classé. En quelques mots on peut le définir : c'est une copie, ou mieux une adaptation 
des ressources décoratives de l'antique. Lans le tissu on s inspirera du décor mural gréco-romain, mélange de lignes d'architecture, d'ornements conventionnels et d'éléments réalistes.

Au point de vue industriel, par suite de la division de la fortune, du nivellement des conditions, il s agira moins de créer des produits somptueux que d'arriver à les mettre à la portée du plus grand nombre. Une des conséquences de cette préoccupation sera l'usage de plus en plus fréquent de la broderie. La raison en est facile à discerner: le montage d'un métier de façonné entraîne une mise de fonds souvent considérable et nécessite un métrage suffisant pour récupérer les frais; la broderie au contraire permet de les limiter. On s'en sert dans le costume autant que dans l'ameublement. A aucune époque le métier, sinon l'art du brodeur, n’a été poussé à cette perfection. La variété de la matière employée est inouïe à côté de l'extrême délicatesse de l'exécution même ${ }^{1}$. La virtuosité du brodeur se sert de tout: soies et métaux précieux sous toutes les formes, application de tissus unis, façonués, imprimés, peints; application de dentelles, plus ou moins surbrodées, application de plumes et de peaux, etc., etc.

Les tissus unis, pour la même raison de bon marché, sont également en faveur; des bordures plus ou moins riches, tissées ou brodées, les accompagnent.

Par suite de la liberté du travail et de la suppression des règlements de l'ancienne fabrique, on fail à Lyon beau-

1 'Art de décorer les tissus, pl. C.VI, nos $1,2,3,4,5, \&, 9$, 10, II, $12,13,14$. 
coup de tissus jusque-là prohibés : tissus imprimés, mélangés, de largeur variable, tissés d'or faux, etc. Le fil étant plus ténu, le décor prend une apparence plus sèche, l'étoffe elle-même a moins de main.

En ameublement on fabrique quantité de damas et de lampas à composition plus ou moins pompéienne. La coloration en est plus éteinte sous le Consulat ${ }^{1}$, plus montée de ton sous l'Empire?

Dans les ameublements officiels, le chêne et le laurier figurent généralement; on y trouve également la fretillaire ou couronne impériale, la rose, le lierre, l'abeille, etc. L'ordonnance architecturale losangée est surtout employée $^{3}$. Il serait injuste de ne pas citer ici les noms de deux associés architectes: Percier et Fontaine, chargés de la décoration des palais impériaux. On retrouve leur art dans toutes les manifestations de l'époque.

Le Musée de Lyon possède une riche collection de ces étoffes de l'époque napoléonienne; beaucoup sont d'autant plus précieuses que les ameublements eux-mêmes. ont disparu ou ont été dispersés dans les tristes circonstances que l'on sait ${ }^{4}$.

Nous ne pourons signaler toutes les tentatives faites en fabrication: l'une d'elles pourtant mérite d'autant plus d'être mentionnée que l'on crut un moment à son succès durable, et que la direction des Beaux-Arts s'en émut

1 L'Art de décorer les tissus, pl. CXVII, nos 2, Io.

2 Ibidem, pl. CXVII, nos 11, 13, 14, 15, I6, 17, 8 .

3 Ibidem, pl. CxVII, nos $15,16$.

4 Ibidem, pl. CIVII, nos 2, 10, 14, 15, 16, 18, etc. 
fortement; nous voulons parler des velours Grégoire. Le secret de leur exécution a malheureusement été perdu, ne survivant pas à l'inventeur qui, lui-même, n'arriva jamais à rendre son invention industriellement pratique. Théoriquement, la technique en paraît simple en somme, mais le tour de main, indispensable à sa réussite, est resté mystérieux. Sur un satin initial, sept ou huit fois plus grand que le velours final, était peint le sujet à représenter; on parfilait alors ce satin et l'on tissait en velours sept ou huit spécimens du motif en prenant un fil sur sept ou sur huit suivant la proportion de l'embuvage. Le charme précieux des tissus ainsi obtenus est extrême ${ }^{1}$.

A côté de ces velours tissés, d'autres, ayant évidemment la prétention de les imiter, eurent également un moment de faveur; tels les velours Richard, et ces velours imprimés fabriqués surtout dans le Nord.

Au commencement du xixe siècle, la Fabrique lyonnaise se ressaisit et reconstitue son industrie. En 18 I 1 on compte déjà $\mathbf{1} 3.000$ métiers. Toutefois, malgré ce regain de prospérité, le rendement des affaires est peu brillant, à ce point que l'on se demande si le changement des conditions du travail a bien été un réel progrès. Un haut sentiment d'honneur commercial hante aussi les esprits, il répugne aux Lyonnais de fabriquer des tissus de second ordre. Ils ont dans le sang l'orgueil du bien faire, et nous avons parlé plus haut de ces règlements sévères peu à peu établis pour satisfaire ces beaux sentiments. Les exagérations

1 L'Art de décorer les tissus, pl. CXX. 


\section{$-(124)-$}

même de cette législation n'avaient-elles pas été une des causes de la prospérité de la Fabrique au xvin siècle, entretenant son bon renom, sa réputation d'industrie de luxe? La liberté du travail a donné lieu aux tromperies, aux malfaçons, résultant d'une concurrence étrangère de plus en plus acharnée. Aussi, peu à peu reviendra-t-on à quelques mesures d'ordre intime, revendiquées parl'opinion.

Dès 1806 , une loi rétablit le principe d'une hiérarchie: la direction de la communauté est confiée au maître-marchand; la direction de l'atelier est laissée au maîtreouvrier, propriétaire des métiers, dont le nombre n'est plus limité. L'atelier reste familial. La matière première est fournie par le fabricant. Par ailleurs, on institue le livret d'acquit, comme moyen de crédit pour le chef-ouvrier, et le Conseil des prud'hommes, réminiscence de l'ancien Bureau des Gardes.

La lutte pour le bon marché persiste quand même; les fabricants demandent des mesures protectionnistes de toutes sortes; il est difficile de savoir ce que serait devenue la glorieuse Fabrique lyonnaise sans l'heureux événement qui, à cette époque, révolutionne son industrie et va lui permettre de lutter efficacement contre la concurrence.

La mécanique Jacquard, réalisant une économie considérable de main-d'œuvre, rendra possible la remise à la mode des tissus façonnés, en les produisant à des prix jusqu'alors inconnus. A un attirail compliqué de pédales et de cordages, Jacquard substitue un mécanisme aussi simple qu'ingénieux, au moyen duquel un seul ouvrier peut exécuter les étoffes les plus somptueuses. 
Jacquard est né à Lyon en $\mathbf{1 7} 52$. Fils d’un maîtreouvrier, pendant son enfance il tire le lacs. A celte dure besogne, sa santé s'altère au point qu'il est obligé de quitter le métier, pour ne le reprendre qu'à la mort de son père auquel il succède. Seul, il s'instruit, hanté de l'espoir d'améliorer un jour le sort des malheureux tireurs de lacs. Ses recherches, autant que son inexpérience commerciale, amènent en peu de temps sa ruine. Malgré ses déboires, la mécanique le préoccupe toujours et, en r8or, il expose une première machine qui lui vaut d'être appelé à Paris, par Carnot, et d'obtenir, grâce à cette haute protection, une petite situation au Conservatoire des Arts et Métiers. Là, il pourra achever son œuvre, réaliser sa mécanique, application ingénieuse des inventions de Vaucanson et de Bouchon.

Incompris d'abord, persécuté même, Jacquard triomphe enfin. Sa découverte convenait trop bien aux besoins de l'époque, pour qu'il en fût autrement. Outre l'économie énorme qu'elle permettait dans le prix de revient, elle délivrait des milliers d'hommes, de femmes, d'enfants du supplice d'un métier extrêmement pénible où tous contractaient des infirmités, voire même des difformités physiques. Déjà, en 1813 , on compte un grand nombre de mécaniques Jacquard à Lyon; cependant ce n'est que sous la Restauration que son emploi se généralisera. En i $8 \mathbf{9} 9$, Jacquard est décoré. Disons, à sa louange, que constamment il refuse d'aller monter ses métiers à l'étranger. Il meurt à quatre-vingt-deux ans à Oullins, dans la banlieue lyonnaise où il avait acheté une petite maison et où 


\section{$-(126)-$}

il avait été nommé conseiller municipal par ordonnance de Charles X.

"Jacquard n’a entrepris les recherches qui ont amené sa merveilleuse découverte que stimulé par l'émotion douloureuse que lui causaient la vue et le souvenir des fatigues imposées a l'ouvrier par le lourd métier d'autrefois; sa science est issue de sa conscience, son génie est sorti de son cocur ». Ainsi s'exprime M. Ed. Aynard, président d'honneur de la Chambre de commerce de Lyon, et il nous excusera, nous n'en doutons pas, de lui emprunter ces derniers mots qui résument si éloquemment la vie d'un homme modeste par l'origine et le caractère, un des plus grands par les conséquences économiques de son œuvre. A Lyon, elles sont le principe d'une prospérité inouie, dont nous trouvons la preuve dans l'accroissement constant du nombre des métiers. En I 8 I , on en comptait 12.700 dans la région lyonnaise, et ce nombre sera porté à 120.000 en 1872 . A partir de cette époque, le tissage mécanique prend de l'extension. La production ne diminue pas, bien au contraire, mais elle ne peut être évaluée par le nombre des métiers.

En possession d'un instrument inconiparable, la Fabrique lyonnaise retrouve donc sa prospérité industrielle et commerciale.

Au point de vue de l'art, la Restauration marque une nouvelle phase de cette période d'imitation des arts disparus. Bien entendu, on ne veut plus rien qui rappelle l'Empire; le rêve serait de reprendre les choses où les avaient lajssées les émigrés au moment de la Révolution; 
mais la Fabrique s'est déshabituée des formules qui avaient fait la gloire des $\mathrm{xvII}^{\mathrm{e}}$ et $\mathrm{xvm}^{\mathrm{e}}$ siècles. L'école davidienne depuis un quart de siècle a travaillé dans une tout autre voie; aussi ce brusque retour en arrière ne trouve-t-il plus d'artistes préparés à satisfaire les tendances du jour. D'autre part, la Restauration n'a pas la bonne fortune de trouver son grand artiste dirigeant, son David ou son Le Brun, chargé de régler le luxe dont voudrait s'entourer le trône.

Par ailleurs le monde a marché.

La clientèle nouvelle se divise en deux classes: le grand monde, celui de la cour, et le beau monde, celui des parvenus de la fortune. Le grand monde, c'est la noblesse retour d'exil, où elle a subi vingt-cinq ans de cruelles privations. Rappelons que la constitution de la société est changée. Grâce à la Révolution, il n'y a plus de classes privilégiées, ayant, par atavisme, cet affinement du goût et cette désinvolture dans la dépense, qui provenaientjustement de ces privilèges acquis par les seuls droits de la naissance. Lorsque la royauté est rétablie, elle l'est sur de nouvelles bases. Elle n'est plus absolue. Le roi gouverne avec le contrôle d'un parlement, il n'a plus le droit de puiser indéfiniment dans les caisses de l'Etat: partant, ceux qui vivaient des générosités royales n’ont plus à compter sur elles.

Le beau monde, celui des parvenus de la finance et du commerce, n'a pas encore l'éducation raffinée indispensable au goût; il n'a pas perdu non plus l'habitude de compter, et puis, il a les yeux tournés vers la cour. Tous les désirs 
d'un roi, vieux et malade, de revenir à l'art charmant de sa jeunesse, n'aboutiront qu'à mêler à la gracilité de certains détails le besoin d'asseoir sa fatigue dans le solide meuble d'acajou. Dans la décoration des tissus, le mélange de choses trop lourdes et de motifs trop minces caractérise les quelques manifestations spéciales de cette époque $e^{1}$.

Mieux que des goûts de la clientèle, le mouvement artistique reçoit son impulsion de cette poussée particulière désignée sous le nom de romantisme. Le romantisme est une transformation complète de la compréhension du beau. Jusque-là, le beau résidait dans la perfection de la forme, dans l'élévation des sentiments surhumains avec son expression la plus complète dans l'art et la littérature désignés sous le nom de classiques. La nouvelle école se demande si la vérité scientifique et historique, l'étude des passions livrées à linfluence des milieux, le réalisme, ne créent pas une forme d'art autrement intéressante que la forme allégorique. Par suite, on n'étudiera plus exclusivement le classique, mais toutes les manifestations de l'esprit humain sous toutes ses formes, à toutes les époques et dans tous les pays. Une des conséquences les plus immédiates sera l'étude approfondie de l'histoire, non plus aux seuls points de vue dynastique et politique, mais aussi au point de vue des progrès intellectuels et scientifiques. De cette nouvelle orientation des études naitra le désir de reconstitution du passé.

Ce mouvement se fait sentir dès Louis XVIII. La duchesse

1 L'Art de décorer les tissus, pl. CXXIV. 
de Berry qui, avec sa jeunesse et sa grâce, apporte un peu de joie à la cour, cherche, dans les fêtes qu'elle donne, à suivre les idées des artistes et des littérateurs contemporains. Aux bergerades de Trianon, aux ballets symboliques des $\mathrm{xvil}^{\mathrm{e}}$ et $\mathrm{xv}^{\mathrm{e}}{ }^{\mathrm{e}}$ siècles, elle fait succéder des mascarades historiques. Telle par exemple, cette reconstitution du mariage de Marie Stuart et de François II, où elle distribue tous les rôles aux plus grands seigneurs de la cour. Chacun devait y composer son personnage avec recommandation expresse de s'appuyer sur les documents les plus authentiques. Elle-même représente Marie Stuart d'après le portrait appartenant au duc d'Orléans, actuellement dans les collections de Chantilly. Il est assez piquant d'ailleurs de dire quelle particularité avait décidé du choix du programme : c'est simplement la forme des manches qui se rapprochaient de celle des fameuses manches à gigot alors à la mode.

Tel est le point de départ pour l'art qui nous occupe de cette ère de reconstitution de tous les styles du passé, traités avec les nouveaux moyens économiques dont dispose la Fabrique.

Les théories romantiques donneront donc au goût du jours sa vraie direction, continuant l'évolution normale de la civilisation créée par la Révolution. Le romantisme sera la vraie période d'arlaptation aux besoins de ce monde nouveau. Sans copier précisément, transposant plutôt, il ira chercher ses modèles dans les arts disparus, surtout ceux de la période dite française. Ses essais seront d'abord maladroits et lourds, il ne comprendra pas non plus quion 
n’augmente pas impunément les dimensions du détail décoratif sans en changer absolument le caractère. Nous avons dit que le Louis XIV était pompeux, qu'il donnait l'impression du plus grand que nature, que le Louis XV revient à des proportions plus humaines, que le Louis XVI est menu, plus petit que nature. Là sont les vraies caractéristiques de ces différents styles; vouloir donner des proportions énormes au décor du second tiers du xvill ${ }^{e}$ siècle, c'est l'interpréter faussement et faire tout autre chose. C'est pourtant une erreur dans laquelle tomberont souvent les artistes industriels de la Restauration et de Louis-Philippe.

Quand sous Napoléon III on continuera à s'inspirer du passé, on le fera du moins avec une éducation plus sûre. Beaucoup d'étoffes d'ameublement de cette époque sont incontestablement belles de composition, évoquant les arts disparus, mais sans les copier, allant généralement prendre dans une autre branche de la décoration certains éléments inexploités jadis. C'est ainsi, par exemple, que le décor dit: "Bérain ", dont on trouve si peu d'exemples dans les tissus du temps, devient, sous Napoléon III, l'expression la plus courante de ce que les tapissiers nous donneront comme pur style Louis XIV. De même sous Louis $\mathrm{XV}$, la rocaille était restée principalement du domaine de la sculpture; sous Napoléon III, elle fait le fond du décor tissé, dénommé Louis XV par le marchand de meubles ${ }^{1}$. Il mélangera aussi peu heureusement des

1 L'Art de décorer les tissus, pl. CXXV. 
styles tout différents, le Louis XV et le Louis XVI principalement ${ }^{1}$.

De l'époque de Napoléon III date également une interprétation curieuse des colorations cles tissus anciens. S'en rapportant à des matériaux décolorés par le temps, bien des gens, même éclairés, s'imaginèrent que ces étoffes avaient été fabriquées ainsi, et cette idée s'était accréditée au point de rendre obligatoire cette décoloration pour İes reproductions de tissus, surtout de ceux de Louis XVI. Depuis, dans de nombreuses collections, on ne manque pas d'échantillons ayant conservé leur premier coloris dont l'intensité, souvent extrême, n'a rien à voir avec les couleurs anémiées des reproductions. Mais c'est là encore une des idées faisant loi chez le marchand de meubles et faisant partie de sa science si spéciale. Qui sait? peut-être sera-t-elle dans l'avenir l'expression vraie des styles du $\mathrm{xxx}^{\theta}$ siècle.

Il nous reste à parler de l'évolution qui nous précède immédiatement.

En 1878 , les Japonais exposèrent une suite inoubliable de produits de leurs industries artistiques, parmi lesquels des tissus et des broderies. Le succès près des artistes fut inouï. Jusque-là, toutes ces manifestations de l'Extrême Orient élaient restées du domaine de la curiosité. Pour la première fois, il nous était permis d'en étudier, sur un grand nombre de spécimens, le charme imprévu, la saveur réaliste, l'exécution spirituelle et 
savante. Ce fut une révélation d'autant plus suggestive, que le Japon nous livrait la forme spéciale de sa compréhension artistique, indemne encore de toute préoccupation d'exportation et de mélange de procédés européens. Depuis, quelques grands magasins sont allés en Chine et au Japon, charger des navires entiers, et ce fut un envahissement de productions désormais inférieures qui calma l'engouement légitime issu de la merveilleuse exposition des Japonais, en 1878 . Il n'en est pas moins vrai qu'alors cet engouement a eu une influence incontestable sur notre art. Au commencement du xrmI ${ }^{\mathrm{e}}$ siècle, l'Extrême Orient avait également impressionné notre goût. Mais alors, ce fut principalement par son côté fantaisiste et baroque. A la fin du $x_{1 \times}{ }^{e}$ siècle, au contraire, c'est l'exactitude réaliste des Japonais dans leur interprétation de la nature qui nous charmera et nous retiendra. Depuis lors, l'étude approfondie, la représentation scientifique du modèle présideront aux conceptions nouvelles. L'emploi simultané de l'ornement conventionnel et de l'ornement réaliste, constant jusque-là, fait place à un nouveau genre de composition qui ne se sert que de détails nature, sans liaison architectonique.

Ainsi donc, le $\mathrm{xxx}^{\mathrm{e}}$ siècle se sera inspiré alternativement des arts de toutes les époques et de tous les pays. La période napoléonienne exploite les formules décoratives de l'antiquité; la Restauration copie maladroitement l'art de l'ancien régime, le Napoléon III adapte et transpose, avec une science incontestable, les mêmes arts disparus; l'Extrême Orient enfin impressionne les artistes, les rame- 


\section{$-(133)-$}

nant à l'étude pénétrante de la nature dans le troisième tiers du siècle. Jusqu'à ces dernières années, la recherche tend presque toujours à la reconstitution, cette suggestion de réminiscence et d'évocation a été iilconsciemment la grande préoccupation. Non moins inconscient est ce besoin impérieux de créer de toutes pièces, qui est le propre très caractéristique de la jeune école contemporaine.

C'est ce qui nous faisait dire que le $\mathrm{xrx}^{\mathrm{c}}$ siècle pouvait être considéré comme l'évolution normale et progressive de l'état de choses consécutif à la Révolution. Après la revue lente, qui lui sert de préparation, des arts des civilisations disparues, la civilisation moderne arrive enfin à sa forme définitive, à son ère de création. Jamais l'industrie n'a été en possession de moyens d'action aussi puissants, jamais, grâce à l'initiative généreuse de nos maîtres et de nos dirigeants, l'enseignement n'a mis à la disposition des travailleurs autant de facilités. L'avenir nous dira si cet effort d'enfantement qui, d'individuel, s'est généralisé ces dernières années, restera stérile.

L'art de décorer les tissus est une gloire nationale incontestée depuis trois siècles. Il a fait la fortune et la prospérité lyonnaises. Tous nos efforts ne doivent-ils pas tendre à conserver à notre cité la place d'honneur qu'elle doit occuper! 
Nous avons cru devoir parler spécialement de la dentelle, dégager du moins des collections du Musée quelques indications pouvant aider à une première initiation. Il arrive souvent, quand on parle de ces délicieuses manifestations de l'industrie artistique, même entre connaisseurs, que l'entente est pénible sur le nom et l'origine à donner à un spécimen; nous voudrions d'abord dire pourquoi.

Suivant l'époque et suivant le pays les dénominations changent, et c'est là une première cause de désaccord. Le mot dentelle lui-même ne se généralise qu'au xvıı ${ }^{\mathrm{e}}$ siècle ; avant on disait passement, appellation complètement abandonnée aujourd'hui. Sous ce nom, on désignait tout ce qui était du domaine de la broderie à fond clair. De tout temps on en a fabriqué; au Musée nous pouvons en voir qui remontent aux époques de Thèbes et de Memphis ${ }^{1}$. Au moyen âge, les chevaliers envoyaient leurs filles chez la châtelaine apprendre à "broder, tapisser". Toutefois, ces passements n'étaient pas, à proprement parler, ce que nous désignons, nous, sous la rubrique dentelle; c'étaient des broderies ajourées demandant pour être exécutées un support initial. Il y en avait de trois sortes:

1 L'Art de décorer les tissus, pl. LXXXVI, n 4. 
Dans une toile on découpait certaines parties, les bords étaient alors festonnés, brodés au point de boutonnière. On obtenait ainsi le point coupé ${ }^{1}$.

Parfois, de cette même toile, on retirait des fils, laissant seulement ceux qui devaient relier ou soutenir les différentes parties du dessin. Cette broderie s'appelait à fils tirés ${ }^{2}$.

On se servait aussi d'une toile claire, un quintin (du nom de la petite ville de Bretagne où elle se fabriquait), et aussi d'un véritable filet: le lacis; on remplissait certaines mailles, suivant le décor à exécuter, au point de reprise ou de marque, et l'on obtenait le filet brodé ${ }^{3}$.

Tous les documents antérieurs au $\mathrm{xv}^{\ominus}$ siècle, livres de patrons, miniatures, gravures, portraits, etc., nous prouvent que seules alors ces broderies étaient connues; et voilà un premier point établi .

A la fin du $x^{e}$ siècle, à Venise, ont eut l'idée d'adjoindre à ces passements un bord, à découpures aiguës, indépendant du support initial, et ces passements s'appelaient passements " dantelés ${ }^{4}$ ". (Peut-être faut-il voir là l'origine du mot dentelle.) D'après le même principe on s'ingénia à faire tout le passement "en l'air ", c'est-à-dire sans avoir recours au support de toile ou de lacis.

Disons de suite que l'art charmant qui en dériva se perdit presque complètement au commencement du

1 L'Art de décorer les tissus, pl, LXXXV1I, $n^{\circ}$ I

2 Ibidem, pl. LxxxVIII, nos 12,16 .

3 Ibidem, pl. LXXXVIII, nus 2, 4, 5 .

4 Ibidem, pl. LXXXVIII, no 8. 


\section{$-(136)-$}

$\mathrm{xlx}^{\mathrm{e}}$ siècle, après trois siècles d'existence. Des raisons de prix et aussi les progrès de la mécanique en sont la cause, et nous ajouterons de hautes raisons de morale : presque toutes les malheureuses dentelières devenaient aveugles avant trente ans. Péniblement elles gagnaient quelques sous en quinze heures de travail, et encore le plus souvent devaient-elles exécuter ce travail dans des caves humides où le fil restait plus souple, mais où leur santé s'altérait rapidement. La mécanique se substituera à elles. Désormais il manque aux dentelles ce charme inexprimable des cuvres originales, fabriquées de toutes pièces de la main de fée d'ouvrières spécialistes. Les dentelles contemporaines sont le produit de la collaboration de l'artiste et de l'ingénieur; loin de nous la pensée d'en amoindrir la réelle valeur, considérons plutôt que c'est un art nouveau qui a déjà d'ailleurs produit des chefs-d'œuvre.

Il semblerait que, d'aprés ce que nous venons de dire, la simple conscience eût dû faire conserver le langage usité au xvine siècle pour désigner les différents types de dentelle, mais déjà on faisait des imitations en dehors des lieux d'origine. De cette tromperie commerciale certainement excusable, est née une première confusion. De proche en proche se pénètrent tous les procédés. Les imitateurs, butinant à clroite et à gauche dans les différents genres, amenèrent la confusion des mots. Aujourd'hui, nous le savons. Ne serait-il pas de toute justice de revenir pourtant aux appellations du xvine siècle?

Toutefois, il se présente encore d'autres inconvénients. On désignait alors les dentelles de deux façons: soit en 


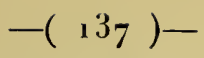

les baptisant du nom d'origine, soit en leur donnant celui de la consommation. C'est ainsi que, quoique fabriqué à Bruxelles, le point d'Angleterre tient son nom du pays consommateur et cela jusqu'à la Restauration. Seulement à ce moment, on commence à parler de Bruxelles, pays d'origine. En général, les points dits d'Espagne, sont fabriqués à Venise, tandis qu'on imite un peu partout le vrai point de Venise.

Malgré ces confusions, la vérité peut se dégager aujourd'hui. Ayons le courage de considérer d'abord la dentelle comme un art disparu, et tâchons de consacrer le terme définitif à la gloire du pays producteur; ainsi cesseront beaucoup de ces discussions où tout le monde est d'accord et où personne ne s'entend. Nous allons essayer une classification simple pour arriver à cette entente.

En réalité, il n'y a que cinq types de dentelle : trois à l'aiguille, deux au fuseau. Nous n'apprendrons rien à personne en disant que toutes les dentelles rentrent dans ces deux modes d'exécution.

Pour l'aiguille, les trois types sont: le Venise, l'Alençon et le Bruxelles.

Pour le fuseau : la Valenciennes et la Malines.

Toutes les autres dentelles ne sont que des succédanés, empruntant ici et là quelques détails d'industrie, les combinant ou les compliquant. 


\section{$-($ І 38$)-$}

Primitivement, la guipure était une dentelle faite d'un ou plusieurs fils enroulés autour d'un cordonnet appelé guipure; d'où son nom ${ }^{1}$. Depuis, on désigne ainsi certaines dentelles communes. La blonde est une dentelle de soie.

Dans toute dentelle entrent deux éléments: le fond et le dessin ou fleur; c'est leur étude qui permet de classer les différents genres.

Le fond est à bricle ou à réseau. La bride est un fil plus ou moins recouvert, simple ou non, enrichi souvent d'un ornement appelé picot (presque généralement fait à l'aiguille) qui relie entre eux les différents détails de la fleur. Le réseau est un filet régulier sur lequel la fleur paraît comme appliquée. La fleur, elle, varie à l'infini.

Dans le point, ou dentelle à l'aiguille, l'ornement est d'un aspect comparativement robuste; la dentelle au fuseau paraît plus délicate.

Comparant les deux genres, Charles Blane dit: “ Le caractere dominant des dentelles au fuseau est le fondu des contours; l'aiguille est au fuseau ce que le crayon est à l'estompe. Le dessin que le fuseau adoucit, l'aiguille le précise, en quelque sorte le burine. "

Les réseaux à l'aiguille, peu variés, sont bouclés, travail relativement facile avec l'aiguille, presque impossible au fuseau. Dans les réseaux au fuseau, les fils s'entre-croisent, se cordent les uns sur les autres. A la loupe, il est facile de se rendre compte par là même de quel genre est un réseau.

1 Les passementiers en font encore usage. 
Suivant l'origine, la fleur et le fond s'exécutent simultanément ou à part.

D'une façon générale, le décor est conventionnel en Italie, réaliste en Flandre. En France, conventionnel dabord, aussi longtemps qu'on imite le point de Venise, il devient réaliste dès la fin du $\mathrm{xvu}^{e}$ siècle, jusqu'à se rapprocher de la nature avec une fidélité, une exactitude qui feraient honneur au peintre le plus méticuleux.

Nous allons présenter au lecteur les cinq types fondamentaux de la dentelle et, s'il veutbien examiner les modèles eux-mêmes, s’imprégner de leur aspect et de leur technique particulière, ce sera pour lui un grand pas fait dans la connaissance de ces merveilles.

Venise [Dentelle à l'aiguille]. - Les " passements dantelés " de Venise remontent àla fin du xve siècle. Après ce dernier essai de point fait en l'air, on fabriqua tout le passement de la même manière. Les plus vieux points rappellent les anciennes compositions imaginées pour les points coupés, fils tirés, filets brodés ${ }^{1}$. En général ce sont des ornements géométriques, carrés, triangles, rosaces, polygones étoilés, etc., fait par bandes reliées entre elles après coup ${ }^{2}$. Jusquà la fin du $\mathrm{xrr}^{\mathrm{e}}$ siècle le dessin est traité sans relief, c'est le Venise plat.

Peu à peu le décor à ramages a succédé au dessin pure-

1 De nos jours on appelle souvent ces passements: dentelle de Cluny; parce que, quand on les copia, il $y$ a une trentaine d'années, les modéles furent pris au musće rle Cluny.

2 L'Art de décorer les lissus, pl. LXXXVIII, nos 10, โ2, I6. 


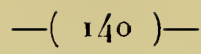

ment géométrique, et nous retrouvons cette parlicularité si caractéristique que nous signalions dans les tissus de la même époque : nous voulons parler de l'interprétation des parties courbes en général qui se brisent en sections polygonales. Cette constatation pourrait affirmer ce que nous avancions plus haut, que nous sommes en face d'une recherche de forme spéciale à l'époque. Ajoutons que souvent les spécialistes donnent à ces passements le nom de points d'Espagne. Dans ces points le fond est à brides. Les beaux points à rinceaux et feuillages gothiques rappelant le décor oriental sont de cette époque.

Au commencement $d u^{\prime} x^{\prime} u^{e}$ siècle la composition se ressent de l'évolution artistique. De rinceaux qui s'enlacent et se pénètrent partent des ramages à robuste flore conventionnelle, festonnés, rebrodés en reliefs parfois très haut ${ }^{1}$. La mode a fait succéder aux fraises gaudronnées le rabat et le col plat; ces hauts reliefs leur donnent une opulence incomparable. Les hommes surtout en portaient un peu partout dans le costume : cols, manchettes, jarretières, embouchures de bottes, rosettes de chaussures, etc. On fabriquait également de ces dentelles pour le meuble: lingerie de table, de literie, équipage de bain, etc.

A la fin du xvir ${ }^{\mathbf{e}}$ siècle les goûts changent : la mode veut des dentelles plus légères, le point se porte encore, mais l'hiver seulement. Aussi au $\mathrm{xvmi}^{\mathrm{e}}$ siècle, pour soutenir la concurrence des dentelles au fuseau, Venise imagine des points plus menus : parmi ceux-ci le point de rose ${ }^{2}$ où,

1 L'Art de décorer les tissus, pl. XCI, $\mathrm{n}^{0 \mathrm{~s}} \mathrm{I}, 2,3,4 \cdots$

2 Ibidem, pl. XCII, nos $\mathrm{I}, 2$. 
sur un fond de petites barrettes à picots, se déroulent de minces rinceaux enrichis de rosettes, de bouclettes en relief picotées et superposées.

On fait également à Venise de la dentelle au fuseau, mais nous ne devons pas voir là un point original.

Alençon [Dentelle à l'aiguille]. - Le point d'Alençon est une suite du point de France qui dérivait luimême du point de Venise. Dès le $\mathrm{xv}^{\mathrm{e}}{ }^{\mathrm{e}}$ siècle on fait de la dentelle en France. La gravure a vulgarisé les modèles de passements, et on les copie, sans arriver toutefois à la perfection italienne. C'est encore Colbert qui délivrera le pays de la dépendance étrangère. Il s'informe des villes productrices qui ont la plus sérieuse réputation d'habileté, et $\mathrm{y}$ installe des ouvriers vénitiens et flamands chargés d'enseigner leurs secrets. La production en tant que détails devient donc identique. Bientôt le génie national apporte sa note particulière, la composition tend à devenir plus nature. Les principaux centres sont Aurillac, Sédan, Reims, Arras, Lyon, Loudun, Alençon, etc. Colbert décrète que toutes les dentelles qu'on y fabriquera désormais porteront le nom de point de France. A Alençon les résultats sont reconnus rapidement supérieurs. L'habile ministre de Louis XIV y crée une manufacture spéciale, à la tête de laquelle il place une femme d'intelligente initiative : $\mathbf{M}^{\mathrm{me}}$ de Laperrière. D’elle-même elle arait trouvé les secrets vénitiens; elle $\mathrm{y}$ ajoutera le bon goût français, allégeant les formes un peu lourdes de l'Italie, par une grande variété de détails délicats que la virtuo- 


\section{- ( I 12 ) -}

sité de ses ouvrières invente. On prend à Alençon l'habitude de préciser la forme des contours en les festonnant sur un crin, voire même un cheven pour les pièces plus précieuses. Cet usage se conservera au moment oú Alençon deviendra tout à fait original.

Beaucoup d'artistes fournissent des modèles à Alençon : I.e Brun et Bérain, entre autres. Grâce à eux l'allure générale devient toute française. Le point de France se différenciera par une ornementation plus légère, par l’introduction de détails d’architecture idéale, par un équilibrè inconnu de I'Italie. Les compositions se pondèrent, alliant des éléments à reproduction symétrique à des parties pittoresques de gracieux ramages, mode de décor inusité par delà les Alpes. Aussi, croyons-nous devoir insister sur la détermination d'origine française attribuée aux points à l'aiguille de la fin du xvir siècle où apparaît linfluence de l’école de Bérain, laissant au contraire celle d'Italie, d'invention au moins, aux points dont l'ornementation reste à ramages pittoresques. Pour mémoire nous rappelons que, sous la rubrique " composition pittoresque ", nous entendons celle où aucun détail ne se répète symétriquement. Toutefois, toutes ces dentelles dont nous venons de parler sont produites d'après le procédé vénitien. Sur un vélin qui, préalablement, a reçu le dessin à exécuter, sont brodés les détails de la fleur, reliés par des brides plus ou moins picotées. Fond et fleur sont donc ici travaillés simultanément.

L'invention d'Alençon consistera à faire à part tous les détails de la dentelle, assemblés ensuite au point de raccroc. 
Dix-huit mains différentes pouvaient $y$ travailler; nous entrons alors dans la période géniale.

Jusque-là le fond était à bride, et cette bride dans les plus vieux points de France était plutô: une barrette picotée reliant les détails de la fleur, partout où le besoin en paraissait utile pour maintenir l'ensemble. Peu à peu il y aura tendance à ordonnancer cette bride jusqu à arriver à un parti pris de régularité qui nous mènera enfin à un réseau à grandes mailles hexagonales picotées. Nous en avons un très bel exemple au Musée (nous n'avons pas pu le reproduire dans notre ouvrage l'Art de décorer les tissus, son acquisition étant récente). Cette bride régulière sera la dernière étape avant le véritable Alençon dans lequel la fleur se détache sur un réseau. La maille en reste hexagonale; on la rencontre plus ou moins délicate, et elle est faite d'un fil recouvert au point de boutonnière. A la loupe on peut facilement constater ce fait.

La fleur de l'Alençon varie bien entendu suivant les évolutions artistiques du $\mathrm{xvm}^{\mathrm{e}}$ siècle. Sous Louis XV elle ondule en rinceaux gracieux, rubanés, fleuris, foliacés, dans lesquels se mêlent les toilés et les jours les plus variés. Sous Louis XVI, la fleur est à ordonnance de semis : fleurettes, accessoires lyriques et champêtres, bouquets, etc., arec une bordure à découpure souple. D'une façon générale, les détails principaux sont cernés de ce festonnage sur crin qui, si délicatement, en précise les contours.

Pour nous résumer: sous Louis XIV, dessin imité de Venise, évoluant vers la composition dite Bérain. Au commencement du xrü ${ }^{\circ}$ siècle, fleurs et branchages sans solu- 


\section{-(144) -}

tion de continuité avec guirlandes et festons encadrés d'un fin réseau et rehaussés de jours variés; sous Louis XVI, semis de petits bouquets, rosettes, feuilles, fleurons, accessoires, etc. Sous le Directoire, les mêmes semis corrigés par la mode.

Alençon tombe à l'époque de l'Empire.

Alençon n'est pas seul à exploiter son point. Le même genre s'exécute à Argentan, qui prend la spécialité de pièces de grandes dimensions. Notre Musée a la bonne fortune de posséder, un des plus intéressants, le plus beau peut-être, des points d'Argentan'.

Bruxelles [Dentelle à l'aiguille]. - Le point de Bruxelles s'appelait point d'Angleterre, et en voici la raison. $\mathrm{Au} \mathrm{xvil}^{\mathrm{e}}$ siecle, le parlement anglais, protectionniste à outrance, voulut défendre l'importation des points de Bruxelles, mais la mode est une capricieuse personne qui se moque des édits. On fit venir des ouvriers dans l'espoir de créer une industrie similaire. Pour deux causes cette tentative avorta: d'un côté, le sol anglais ne se prêtait pas à la culture de l'espéce de lin indispensable comme matière première, et, d'autre part, l'atmosphère anglaise ne s'accordait pas avec les exigences d'une fabrication aussi délicate. Les produits étaient si inférieurs, que force fut de tourner la loi et de recourir à un expédient. On entra en fraude les points de Bruxelles et on les vendit sous le nom de point d'Angleterre. Ce n'est que sous la

1 L'Arl de décorer les tissus, pl. CVII, n $\mathrm{n}$. 
Restauration que l'usage s'en perdit, jusque-là Bruxelles s'était bien gardé de revendiquer, de crainte d'indisposer sa riche cliente

L'histoire du point de Bruxelles est serisiblement la même que celle du point d'Alençon. C'est à l'origine la copie de Venise avec tendance, qui va en s'accentuant, au réalisme dans le détail. Le fil de Flandre est incomparablement le plus fin. Il est fait d'un lin qui croît dans le Brabant et qu'on préparait uniquement pour la dentelle et la batiste. Pour le réseau principalement, c'est ce fil qui permit de défier toute concurrence. Les plus belles fleurs étaient exécutées à Bruxelles même. Le travail était divisé par fragments sur des morceaux de parchemin où se lisait le dessin, on assemblait ensuite les diverses parties au point de raccroc, comme à Alençon. L'extrême ténuité des fils rendait long le travail; par suite, les dentelières salissaient leur ouvrage au point qu'on devait le blanchir à la céruse avant d'assembler les morceaux. Pour livrer la marchandise à la consommation, on la frappait à la main, opération terrible dans ses effets pour la santé des ouvrières. Malgré cette précaution, ces points jaunissaient à la chaleur d'un salon, à l'air de la mer, a u roisinage d'un tissu blanchi au soufre. Aussi, pour éviter de dispendieux et fâcheux lavages, mit-on à la mode le port de dentelles si jaunes qu'on finit par leur donner artificiellement cette couleur.

Dans les vieux points de Bruxelles la fleur et le fond étaient travaillés ensemble, par petits morceaux, comme nous le disons plus haut. Pour les relier on ajoutait quelques détails de tiges fleuries et feuillées, et les fonds sont 
alors à brides. Le réseau n'apparait qu'au xrmi siècle. Souvent alors bricles et réseaux voisinent dans la même pièce; de mème qu'il est fréquent de voir l'aiguille et le fuseau concourir au même ensemble. Après les anciens dessins de style gothique, le décor est à ordonnance de lignes sinueuses qui elles-mêmes font place aux semis, aux assemblages de fleurs, de branches, de colonnettes, de guirlandes, etc., avec pois, étoiles, fleurettes; enfin, au moment de la Révolution, il est aux pyramides et aux palmettes.

A Bruxelles, comme dans toutes les Flandres, on fabrique aussi beaucoup de deritelles au fuseau.

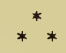

On donne a la dentelle au fuseau une origine flamande, à peu près contemporaine de linvention de l'aiguille à Venise. La dentelle au fuseau se fait sur un mélier appelé carreau, oreiller. C'estune boîte, en général de forme carrée, rembourrée intérieurement. Un cylindre rembourré également, tourne sur un axe dans une ouverture ménagée au centre du carreau ; sur ce cylindre est fixé un parchemin piqué de trous d'épingles, qui suivent le dessin du modèle à reproduire. Des fuseaux souvent très nombreux contiennent les fils de la dentelle. Les épingles plantées dans les trous au fur el à mesure de l'avancement du travail, servent de jalon et maintiennent le point.

Valenciennes [Dentelle au fuseau]. — Dès le commen- 


\section{$-(1 / 17)-$}

cement du $\mathrm{Xv1}^{\mathrm{e}}$ siècle on fait à Valenciennes de la dentelle au fuseau; les motifs sont alors les mêmes que ceux des passements à fils tirés, à point coupé, puis à l'aiguille. Déjà renommée sous Louis XIV, la Valenciennes est surtout en faveur au xrmi siècle jusqu'à la Révolution.

La Valenciennes se fait avec le même fil, fleur et fond, ce qui lui donne un peu l'aspect de papier découpé. Le fond est à réseau; le toilé de la fleur ressemble à de la fine batiste. C'est la dentelle la plus longue et la plus délicate à exécuter; il fallait dix mois, à quinze heures de travail par jour, pour achever une paire de manchettes.

Elle devait s'exécuter à Valenciennes même. Finie hors les murs, la même pièce présentait une différence notable, bien que faite sur le même carreau par la même ouvrière.

A la ville, la dentellière travaillait dans des caves humicles, aux environs au contraire en plein air; le fil s'y séchait et rendait le travail difficile. Le décor de la Valenciennes est surtout floral, et le répertoire de ses modèles limité (tulipes, œillets, iris, anémones). La grande caractéristique c'est que la fleur n'est jamais cernée d'un cordonnet.

Malines [Dentelle au fuseau]. - Ce qui caractérise au contraire la Malines, c'est un gros fil plat cernant la fleur. Le toilé de celle-ci est encore plus lin que celui de la Valenciennes, ce qui nécessite justement cette bordure du dessin. Le réseau est une petite treille ronde excessivement légère. La Malines fut surtout à la mode sous 
Louis XV et la rocaille apparaît dans la composition. Sous Louis XVI on exécute principalement des guirlandes et des enlacements ajourés.

Toutes les autres dentelles rentrent dans ces cinq types que nous venons d'étudier : le Bruges, par exemple, est une espèce de Malines robuste où le réseau est à grandes mailles, ou à brides; la Binche est une Valenciennes où le réseau est remplacé par une infinité de jours reliant la fleur. A Gênes, à Milan, à Venise, les dentelles au fuseau moins fines de matière se reconnaissent surtout aux détails de la composition. L'ornement y reste plus conventionnel et, lorsque les personnages et les animaux y apparaissent, ils sont d'expression allégorique. Le même genre de dentelle au fuseau fabriqué à Bruxelles ou en France contiendra des détails plus réalistes, les personnages y porteront le costume contemporain, les animaux y seront représentés sous la forme active.

Nous n'avons pas la prétention d'avoir tout dit sur la dentelle, nous n'avons cherché qu'à éclairer un peu les premières études. Il est bien entendu aussi que, lorsque nous disons que la dentelle est un art disparu, nous ne voulons parler que de ces merveilles industriellement impossibles à refaire aujourd'hui : le fil de nos mécaniques ne remplacera jamais celui filé jadis à la main dans le Brabant; hélas! aussi les durs soucis de la vie quotidienne, les nouvelles conditions du travail, ne comportent plus celte joie fière du bien faire qui soutenait l'ouvrier des corporations. La clientèle même n'a plus la désinvolture dépensière des privilégiés de l'ancien régime. Rési- 


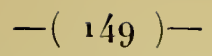

gnons-nous donc à ne voir dans ces chefs-d'œuvre du passé que des joyaux de collection.

Des dentelles plus communes, on en fait toujours et partout.

Si notre Musée historique des tissus possède une belle collection de dentelles, nous ne saurions omettre de dire qu'il le doit en grande partie aux générosités de $\mathrm{I}^{\mathrm{me}} \mathrm{Ed}$. Aynard et de M. Aug. Isaac, actuellement président de la Chambre de commerce de Lyon. Enfin le Musée bénéficie actuellement du legs Guitton-Teillard, qui comprend entre autres choses une remarquable collection de dentelles anciennes.

Nous nous sommes efforcés de résumer dans ces notes les théories que nous développons dans les conférences dont la Chambre de commerce nous a fait l'honneur de nous charger. Leur but est le même: la mise en valeur de son Musée historique des tissus. La riche bibliothèque qui $\mathrm{y}$ est adjointe a été précieuse pour nous dans nos recherches, et nous voulons signaler aux travailleurs les principaux ouvrages auxquels nous avons puisé.

Parmi ceux qui s'occupent de théorie artistique, nous citerons: dans la collection de la bibliothèque des: Beaux-Arts, l'Art byzantin de Bayet, l'Art. 


\section{$-(150)-$}

arabe et l'Art persan de Gayet; la Peinture italienne de Lafenestre; la Peinture française d'Olivier Merson; les Styles français de Lechevalier-Chevignard; la Composition décorative de Mayeux, etc., etc.; les livres de Viollet-le-Duc, les Arts arabes de Jules Bourgoin, etc.; les ouvrages qui ont plus directement rapport à l'industrie des tissus décorés : Tableaux historiques de l'Asie de Klaproth; Recherches sur la fabrication des étoffes de soie de Francisque Michel; les rapports de M. Natalis Rondot; les ouvrages de M. Pariset, du chanoine Bock, de Dupont-Auberville, Fischbach, R. Forrer, Lessing, de Farcy, BuryPalisser, etc., etc.

La bibliothèque du Musée renferme d'inépuisables documents, tant anciens que modernes, pouvant aider l'éducation et les recherches artistiques. Le travailleur $\mathrm{y}$ trouve également quantité de dessins originaux des maitres de la décoration en général et aussi de la Fabrique. D'autre part, les spécimens exposés ne sont qu'une faible partie des trésors du Musée, tous sont at la disposition des chercheurs.

Puissent ces renseignements aider la jeune génération qui, plus que jamais, a besoin de s'armer pour la lutte. Si son ardeur orgueilleuse la pousse à s'affranchir du passé, elle doit avant tout le connaître. 


\section{$-(15 i)$}

L'expérience des siècles lui évitera bien des déboires: ce serait folie et lâcheté de sa part de se la refuser.

L'histoire est lì pour nous dire combien lentement se préparent les évolutions des manifestations de l'esprit. Les époques vraiment créatrices ont été précédées par une longue suite d'efforts dont quelque génie finit par trouver la résultante. Si l'on étudie l'œuvre de ce génie, on reste confondu de l'étendue de sa science; englobant toutes les connaissances conlemporaines, elle lui fait pressentir, aider et exprimer la nouvelle formule. De nos jours nos connaissances sont si multiples que leur conquête pourrait faire hésiter les plus courageux. La préroyance généreuse de nos dirigeants s'est acharnée heureusement à faciliter l'enseignement en créant des écoles et des laboratoires, des bibliothèques et des musées. Chaque spécialité y trouve rassemblés les éléments indispensables pour compléter son éducation. L'œuvre du Musée historique des tissus est justement une de ces institutions préparatoires de l'avenir.

Raymond Cox. 


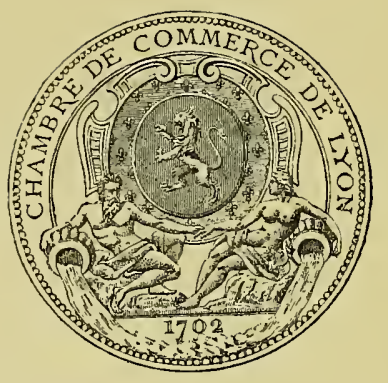






\section{PRINGIPAUX DONATEURS}

MIM. BROSSET AINÉ, ancien Président de la Chambre de commerce.

Oscar GaLLINE, ancien Président de la Chambre de commerce.

PARISET, ancien Vice-Président de la Chambre de commerce.

ED. AYNARD, Président d'honneur de la Chambre de commerce.

Aug. ISAAC, Président de la Chambre de commerce.

Ime ED. AYNARD.

MM. Antonin TERME, Directeur du Musée.

MONVENOUX, Conservateur du Palais du commerce.

EGHERNIER, architecte.

CHAMPAGNE ET ROUGIER.

RONZE.

ZUBER de Mulhouse.

BOUVARD.

CHATEL ET TASSINARI.

J.-A. HENRY.

LAMY Père et Fils.

GIRAUD.

E. SCHULZ.

GUITTON-TEILLARD.

Ime GUITTON-TEILLARD. 
PLACE DES CORDELIERS

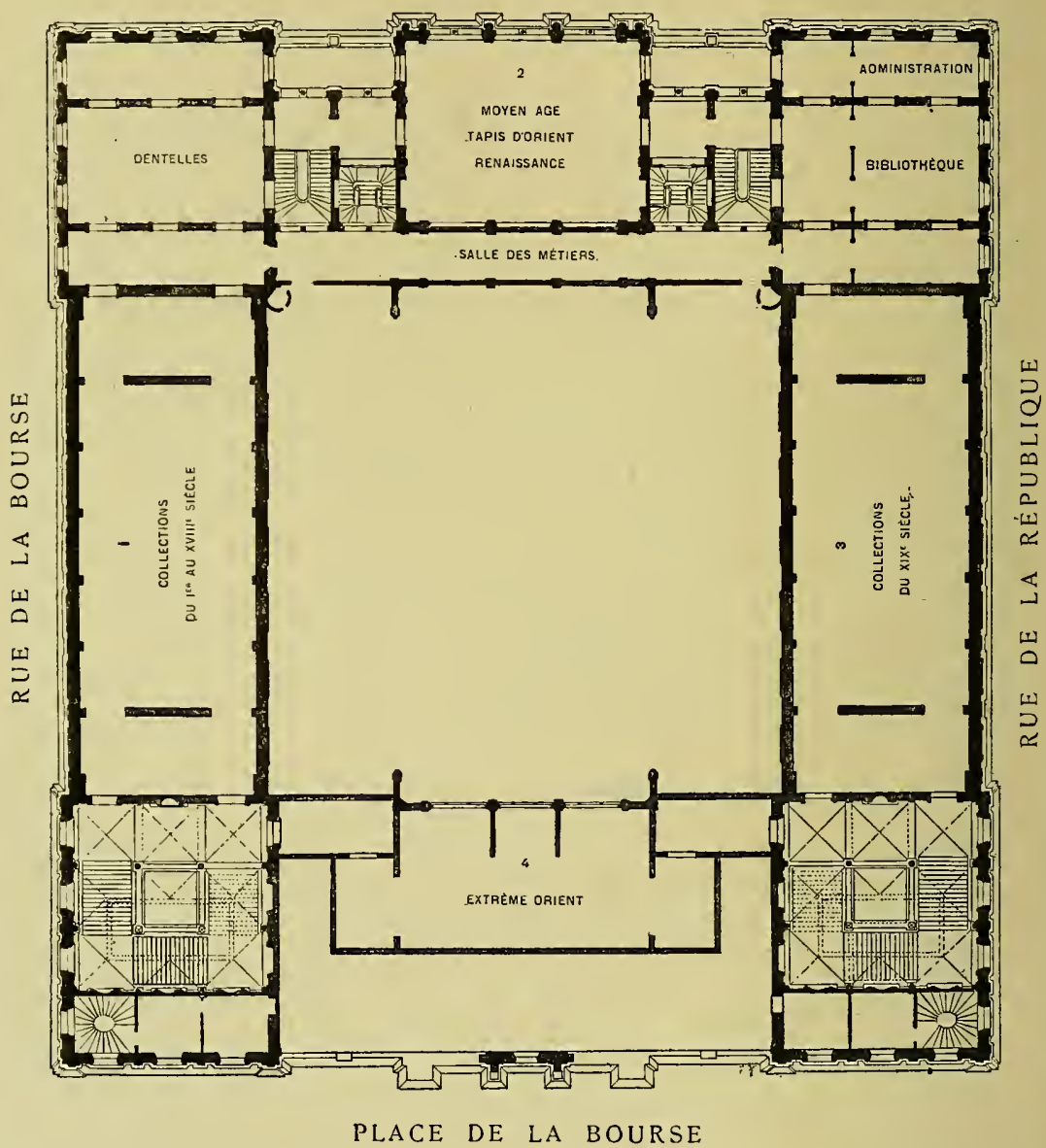


Le Musée historique des Tissus est ouvert au public le Jeudi et le Dimanche de $1 /$ heures à 4 heures. Tous les autres jours, les visiteurs peuvent être admis à en voir les collections. L'entrée du Musée est place de la Bourse, et l'on y accède par l'escalier de gauche qui conduit directement au deuxième étage, entièrement consacré à l'institulion du Musée.

Les travailleurs que leurs recherehes amènent spécialement à la Bibliothèque peuvent également entrer par la place des Cordeliers et gagner le deuxième étage par l'escalier de gauche. A partir du mois d'octobre jusqu'à fin avril, la Bibliothèque est ouverte le soir : les Mardi, Mercredi, Vendredi et Samedi de chaque semaine.

La visite du Musée doil se faire en eommençant par le côté Sud :

I $^{0}$ Galerie $n^{0} I$ (rue de la Bourse). Exposition chronologique des spécimens de tissus et broderies antérieurs au xix siecle;

$2^{0}$ Salle des dentelles (angle de la rue de la Bourse et de la place des Cordeliers);

3o Galerie $n^{\circ}$ II (place des Cordeliers). Exposition de pièces importantes du moyen âge et de la Renaissance et collection de tapis d'Orient;

$4^{\circ}$ Bibliothèque (angle de la place des Cordeliers et de la rue de la République). Dans eette partie sont également situés les bureaux du Directeur et de l'Administration ;

$5^{\circ}$ Couloir intérieur. Exposition de petits modèles de métiers et collection d'ustensiles pour la fabrique;

$6^{\circ}$ Galerie $n^{0}$ III (rue de la République), exposition chronologique de la production du $\mathrm{x}_{1 \mathrm{x}} \mathrm{e}^{\mathrm{e}}$ siccle;

$7^{0}$ Galerie $n^{0}$ IV (pląee de la Bourse). Collection de tissus et broderies d'Orient et d'Extrème Orient. 



\title{
CATALOGUE SOMMAIRE
}

\author{
DES GOLLEGTIONS
}

\section{TISSUS DE HAUTE ANTIQUITÉ}

1 Collection d'échantillons provenant des nécropoles de Thèbes, de Memphis et de Baggar. Collection Beseriani, donnée par M. Raoul-Duval, en 1887 .

2 Étoffes égyptiennes de la XVIII à la XXe dynastie (2000 ans avant J.-C.). Collection Graff.

3 Bandelettes décorées d'inscriptions, de momie égyptienne. Collection Denon.

\section{PÉRIODE DITE BYZANTINE}

La période dite byzantine comprend les huit premiers siècles de notre ère. Les tissus coptes permettent de l'étudier. Ceux du Musée proviennent de deux sources principales : la collection Graff, les fouilles d'Antinoë.

Ceux de la collection Graff ont été rassemblés à Akmin, à El-Fayoun, à Erment et à Menchieb. Les autres ont pour origine les nécropoles d'Antinoë. L'initiative des premières recherches entreprises à Antinoë appartient au Musée Guimet. En I 885 , des sondages préliminaires furent exécutés sous la conduite de M. Gayet, qui est resté, depuis cette époque, le 
savant directeur des travaux. En ${ }_{1896}$, la Chambre de commerce de Lyon, les ayant subventionnés, devait bénéficier, en retour, de toutes les découvertes faites ayant trait à l'histoire du tissu.

Toutes les étoffes exposées provenant de ces différents centres sont, ou des pièces de costume, ou des suaires et coussins funéraires. Les plus anciennes remontent au commencement de notre ère. Jusqu'au $\mathrm{vi}^{\mathrm{e}}$ siècle, elles ne contiennent pas de soie.

Le costume. - $\Lambda \mathrm{u}$ moment où l'Egypte était devenue colonie romaine, le costume se composait principalement d'une tunique et d'un manteau. La tunıque, courte, était généralement de lin. Divers empiècements décorés l'enrichissaient qui, jusqu'au IV siècle surtout, furent distinctifs de caste et de grrade. (Les femmes portaient sous ce vêtement une autre tunique longue.) Le manteau était un véritable châle, dont les angles supérieurs, fixés sur l'épaule droite au moyen de fibules ou d'agrafes, laissaient le bras droit libre, le gauche étant au contraire dissimulé sous la draperie. Divers empiècements le décoraient également.

Ces différents motifs d'ornement rentrent dans quatre catégories que nous désignons sous les rubriques : tabulx, clavi, parag udes et galons. Ils sont en général tissés, parfois brodés. Ceux qui sont tissés ont été fabriqués sur des métiers analogues à ceux dont se servent encore nos tapissiers de haute et basse lisse; d'où le nom qu'on leur a donné de gobelins coptes. Quelquefois les ornements font partie intégrante de l'étoffe de fond, mais le plus souvent ils y sont appliqués. L'encolure, les manches et souvent la base de la tunique sont bordés de galons. De chaque côté du cou pendent les paragaudes; sur les épaules et sur les cuisses apparaissent des clavi; entre les paragaudes enfin, sur la poitrine et dans le dos, se placent les tabulæ. A partir du Iv ${ }^{\circledR}$ siècle le fond du tissu sera parfois tout couvert d'ornements, jusqu'à la profusion 
même et, par suite, le décor devient moins distinctif de caste et de grade.

4 Fragments de tuniques, $\mathrm{I}^{\mathrm{er}} \mathrm{el} \mathrm{II}^{\mathrm{e}}$ siècles.

5 Fragments de tuniques, in et re siècles.

6 Fragments de tuniques, ${ }^{\mathrm{e} e}, \mathrm{ri}^{\mathrm{e}}$ et $\mathrm{rr}^{\mathrm{e}}$ siècles.

7 Fragments de tuniques à décor d'art copte indigène.

Le manteau. - Le manteau est dérivé de la chlamyde et du peplum antiques. Sa forme est généralement rectangulaire comme un châle. On l'ornait de galons et de tabulæ. Le fond est de tissus divers piormi lesquels il convient de signaler celui à grands bouclés qui donnent à l'ensemble l'aspect de fourrure. Les ornements sont, comme pour la tunique, brodés ou tissés genre gobelins.

Suivant les époques et suivant les centres, le manteau varie considérablement. Il atteint jusqu'à 8 mètres de longueur, entourant tout le corps de la tête aux pieds. "Pris sous l'aisselle droite, il passe sur le dos, revient à l'épaule, remonte de biais enveloppant la tête pour, une fois encore, faire le tour du corps, se draper définitivement sur l'épaule gauche et relomber en longs plis sur le dos ". (Gayet, fouilles d'Antinoë.)

8 Fragments de manteaux.

9 Suaires funéraires. (Fouilles d'Antinoë, VII $^{\circ}$ et rinle siècles.)

Goussins funéraires. - Ces coussins se plaçaient sous la tête et parfois sous les pieds du mort. Tous sont faits d'un empiècement carré de gobelins coptes, le plus souvent encadrés de tissu bouclé.

Io Coussins funéraires d'art copte indigène.

I Coussins funéraires de gobelins coptes inspirés de l'antique, $1^{\mathrm{er}}, 1 \mathrm{I}^{\mathrm{e}}$, nII et ive siècles. 


\section{$-(162)-$}

12 Coussins funéraires de gobelins coptes inspirés de byzantin, ve, Vie, vire et vire siècles.

13 Coussins funéraires de gobelins coptes inspirés d'art sassanide, $\vee^{\circ}$, vie, vile et ville siècles.

Tabulæ. - Nous désignons sous le nom de tabula (tableau) les empiècements carrés de gobelins coptes ornant la tunique entre les paragaudes. En général, leur décor comprend un motif principal qui varie suivant les époques et qui s'encadre dans une figure géométrique, carré, cercle, losange, étoile, etc., donnant souvent lieu elle-même à un encadrement plus ou moins orné.

14 Type de tabula copte indigène. Décor de méandres ot d'entrelacs se détachant en écru sur un fond de pourpre. Le dessin y est obtenu à la broche volante, en ressauts, et non brodé. On retrouve ce type jusqu'aux Croisades, et nous retrouverions son origine dans l'ancien art phénicien.

15 Divers échantillons du même genre.

16 Type de tabula d'art copte indigène. Décor foliacé dérivé de l'art antique phénicien.

17 Divers échantillons du même genre.

I8 Typo de tabula de gobelins coptes à décor inspiré de l'antique. Sujet mythologique rappelant le culte de Bacchus, $\mathrm{e}^{\text {er }}$ et ${ }_{11}$ sieccles. Fragment remarquable de finesse. Le tissu de fond sur lequel est appliqué l'empiècement présente lui-même un intérèt particulier. C'est un véritable façonné. Dans les gobelins coptes des rer et rie siècles, à inspiration antique, l'ornement rappelle celui des vases gréco-romains. Le dessin relativement correct est d'une sobriété extrême de coloration. Les détails décoratifs ne se reproduisent pas symétriquement de chaque côté des axes.

I9 Divers échantillons du mèma genre.

2o Type de tabula de gobelins coptes à décor inspiré de l'antique, 


\section{$-(\mathbf{1} 63)-$}

II: et IV $^{e}$ sièeles. A cette époque on introduit dans le décor quelques taches épisodiques de couleur. En général, le dessin s'enlève en foncé sur le fond.

2 I Divers échantillons du même genre.

22. Type de tabula de gobelins coptes à décor d'inspiration byzantine, rve et $v^{\circ}$ siècles. Les tissus coptes d'inspiration byzantine perdent la correction du dessin qu'ils devaient à l'antique. Le byzantin leur fournit sa riche palette. La forme générale reste architecturale avec une tenclance à la symétric dans le détail décoratif.

\section{Divers échantillons du même genre.}

24 Type de tabula de gobelins coptes à décor d'inspiration byzantine, $v^{e}$ et vil $^{c}$ siècles. A cette époque le dessin est devenu barbare et la coloration éclatante. De plus en plus les détails décoratifs tendent à se reproduire symétriquement de chaque cùté des axes.

25 Divers échantillons du même type.

26 Type de tabula de gobelins coptes à décor d'inspiration sassanide, $\mathrm{re}, \mathrm{v}_{1} \mathrm{e}$ et vile siceles. (Guerrier's scythes de chaque côté d'un homa.) L'influence de la Perse de la dynastie des sassanides semanifeste par l'apparition, dans le décor, de homas (arbre de vie) et de pyrées (autel du feu), figures symbo. liques, souvenir de l'ancienne religion de Zoroastre. En général, les détails décoratifs se reproduisent symétriquement de chaque côté de ces figures.

27 Divers échantillons du même genre.

Glavi. - Nous désignons sous le nom de clavi (clavus, clou, ornements en forme de tête de clou) les empic̀cements de gobelins coptes ornant la tunique aux épaules, aux cuisses, etc., plus petits que les tabulæ.

28 Type de clavus d'art copte indigène. Décor de méandres et entrelacs, de détails symétriques très simples, se détachant en clair 


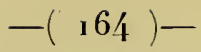

sur un fond plus ou moins foncé. On retrouvera ce type jusquaux croisades, et son origine remonte à l'art antique phénicien.

29 Divers échantillons du même genre.

3o Type de clavus de gobelins coptes à décor inspiré de l'antique, , ${ } I^{\mathrm{c}}, \mathrm{III}^{\mathrm{e}}$ et $\mathrm{IV}^{\mathrm{c}}$ siècles.

3 I Divers échantillons du même genre.

32 Type de clavus de gobelins coptes à décor inspiré de l'art byzantin, $1 \mathrm{v}^{\mathrm{e}}$, ve, vie et vire siècles.

33 Divers échantillons du même genre.

34 Type de clavus de gobelins coptes à décor inspiré de l'art sassanide, $v^{e}, v^{e}$ et vire siècles.

35 Divers échantillons du même genre.

Paragaudes. - Nous désignons sous le nom de paragaudes les empiècements, en bande de gobelins coptes, ornant la tunique de chaque côté de l'encolure. Elles représentent les courroies ou chainettes qui maintenaient la cuirasse sur les épaules. Elles seront le principe des bandes d'orfroi de la chape liturgique.

36 Type de paragaude d'art copte indi gène, décor de méandres, d'entrelacs, de détails symétriques très simples se détachant en clair sur le fond plus ou moins foncé. On retrouvera ce type jusqu'aux Croisades et son origine remonte à l'art antique phénicien.

37 Divers échantillons du môme genre.

38 Type de paragaude de gobelins coptes à décor d'inspiration antique, $\mathrm{I}^{\mathrm{e}} \mathrm{r}, 1 \mathrm{I}^{\mathrm{e}}, \mathrm{III}^{\mathrm{e}}$ et $\mathrm{IV}^{\mathrm{e}}$ siècles.

39 Divers échantillons du même genre. 


\section{$-(165)-$}

40 Type de paragaude de gobelins coptes à décor d'inspiration byzantine, $\mathrm{r}^{\mathrm{e}}, \mathrm{v}^{\mathrm{c}}, \mathrm{vl}^{\mathrm{e}}$ et $\mathrm{vil}^{\mathrm{e}}$ siècles.

4. Divers échantillons du même genre.

42 Type de paragaude de gobelins coptes à décor d'inspiration sassanide, $v^{\circ}, v^{e}$ et $v^{\circ} 1^{\circ}$ siècles.

43 Divers échantillons du même genre.

Galons. - Nouṣ désignons sous ce nom les bandes de gobelins coptes qui ornent la tunique au cou, aux manches, au bord inférieur.

44 Type de galon d'art copte indigène, décor de méandres, d'entrelacs, de détails très simples et symétriques se détachant en clair sur un fond plus ou moins foncé. On retrouve ce type jusqu'aux Croisades, son origine remonte à l'art antique phénicien.

45 Divers échantillons du même genre.

46 Type de galon de gobelins coptes à décor inspiré d'art antique, $\mathrm{I}^{\mathrm{e}}, \mathrm{Il}^{\mathrm{e}}, \mathrm{In}^{\mathrm{e}}$ et $\mathrm{Iv}^{\mathrm{e}}$ siècles.

47 Divers échantillons du même genre.

48 Type de galon de gobelins coptes à décor inspiré du byzantin, ve, $\mathrm{vl}^{\mathrm{e}}$ et $\mathrm{vII}^{\mathrm{c}}$ siècles.

49 Divers échantillons du même genre.

5o Type de galon de gobelins coptes inspiré d'art sassanide, $\mathrm{r}^{\mathrm{c}}, \mathrm{vI}^{\mathrm{c}}$, vil ${ }^{e}$ et vilı ${ }^{e}$ siècles.

5ı Divers échantillons du même genre.

Broderies coptes. - L'art des broderies coptes rentre en général dans le genre d'ornement dit géométrique, même lorsque l'artiste représente des figures animées. On y rencontre parfois la soie que sa valeur élevée empêchait d'employer pour les tissus. 


\section{$-\left({ }_{1} 66\right)-$}

52535455 Collection de tissus brodés antérieurs au vine siècle. Fragments de tissus dits gobelins coptes.

56 Type de tissus dit gobelins coptes à semis de feuilles.

$5_{7}$ Divers échantillons du même genre.

58 Typo de tissu dit gobelins coptes à semis de yases fleuris.

59 Divers échantillons du même genre.

6o Type de tissu dit gobelins coptes à bandes.

6. Divers échantillons du mẻme genre.

62 Type de tissu dit gobelins coptes à décor d'inspiration antique, $\mathrm{I}^{\mathrm{e}}, 1 \mathrm{1}^{\mathrm{e}}, 1 \mathrm{11}^{\mathrm{e}}$ et $1 \mathrm{~V}^{\mathrm{e}}$ siècles..

63 Divers échantillons du même genre.

64 Type de tissu dit gobelins coptes à décor d'inspiration byzantine, ive et $v^{e}$ siècles.

65 Divers échantillons du même genre.

66 Type de tissu dit gobelins coptes à décor d'inspiration byzantine, $v_{1}{ }^{e}$, vije et vilie siècles.

67 Divers échantillons du même genre.

68 Type de tissu dit gobelins coptes à décor d'inspiration sassanide, $v^{e}, v^{e}, v^{e}$ et $v_{111^{e}}$ siècles.

69 Divers échantillons du même genre.

70 Type de tissu dit gobelins coptes, décor à ordonnance de lignes horizontales, inspiration byzantine, $\mathrm{v}^{\mathrm{e}}, \mathrm{vl}^{\mathrm{e}}, \mathrm{v}_{11^{\mathrm{e}}}$ et $\mathrm{v}_{111^{\mathrm{e}}}$ siècles.

7 I Divers échantillons du me̊me genre.

72 Type de tissu dit gobelins coptes, décor à ordonnance de lignes horizontales, inspiration sassanide, $\mathrm{v}^{\mathrm{e}}, \mathrm{v}^{\mathrm{e}}$, $\mathrm{vil}^{\mathrm{e}}$ et $\mathrm{vm}^{\mathrm{e}}$ siècles.

73 Divers échantillons du même genre. 


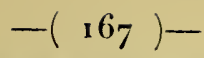

74 Type de tissu dit gobelins coptes, décor à ordonnance de cercles ou de roues isolées, inspiration byzantine, ${ }_{{ }^{2}}{ }^{\mathrm{e}} \mathrm{vil}^{\mathrm{e}}$ et $\mathrm{v}_{11} \mathrm{e}$ siècles.

$7^{5}$ Divers échantillons du même genre.

76 Type de tissu dit gobelins coptes, décor à ordonnance de roues tangentes, inspiration byzantine, $\mathrm{vi}^{\mathrm{e}}, \mathrm{vir}^{\mathrm{e}}$ et viri ${ }^{\mathrm{e}}$ siècles.

77 Divers échantillons du me̊me genre.

78 Type de tissu dit gobelins coptes, décor à ordonnance de cercles ou de roues isolées, inspiration sassanide, ví, vile et vIII ${ }^{\mathrm{e}}$ siccles.

79 Divers échantillons du même genre.

8o Type de tissu dit gobelins coptes, décor à ordonnance de roues tangentes, inspiration sassanide, $\mathrm{vi}^{\theta}, \mathrm{v}^{\mathrm{e}}{ }^{\mathrm{e}}$ et $\mathrm{v}_{11 \mathrm{I}^{\mathrm{e}}}$ siècles.

8 I Divers échantillons du même genre.

82 Type de tissu dit gobelins coptes, décor de compartiments géométriques décorés, inspiration byzantine, $\mathrm{VI}^{\mathrm{e}}{ }, \mathrm{vII}^{\mathrm{e}}$ et $\mathrm{vill}^{\mathrm{e}}$ siècles.

83 Divers échantillons du même genre.

84 Type de tissu dit gobelins coptes, décor de compartiments géométriques décorés, inspiration sassanide, $\mathrm{Vr}^{\mathrm{e}}$, vir et $\mathrm{viII}^{\mathrm{e}}$ siècles.

85 Divers échantillons du même genre.

86 Type de tissu dit gobelins coptes, semis sans division architectonique, inspiration byzantine, vile et vill siècles.

87 Divers échantillons du même genre.

88 Type de tissu dit gobelin's coptes, semis sans division architectonique, inspiration sassanide, vile et vine siècles.

89 Divers échantillons du même genre.

Tissus coptes de soie. $-\Lambda$ partir du ville siècle apparaît, de façon courante, l'emploi de la soie dans les tissus. C'est 
sous Justinien que l'on connut, à Constantinople, le secret du ver à soie, du mûrier, que la Chine seule détenait depuis des siècles. En même temps, on dut pouvoir s'initier à ses procédés de tissage. Les premières étoffes de soie sont en effet, de suite, de fabrication supérieure, relativement à ce qu'était jusque-là celle de ces gobelins coptes uniquement ouvrés sur métier de tapissicr.

Quant au décor lui-même, il se réduit à quelques types principaux également exploités par les Byzantins et les Perses, ordonnance de cercles ou de roues isolés ou tangents, ordonnance de lignes horizontales, ordonnance losangée, ordonnance de compartiments géométriques décorés, ordonnance de semis.

9o Type de tissu copte, de soie, à ordonnance de cercles isolés, inspiration byzantine, $\mathrm{vI}^{\mathrm{e}}$, $\mathrm{VI}^{\mathrm{e}}$ et $\mathrm{V}^{\mathrm{e}}{ }^{\mathrm{e}}$ siècles.

9r Divers échantillons du même genre.

92 Type de tissu copte, de soie à ordonnance de roues tangentes, inspiration byzantine, $\mathrm{VI}^{\mathrm{e}}$, $\mathrm{viI}^{\mathrm{e}}$ et $\mathrm{vil}^{\mathrm{e}}$ siècles.

$9^{3}$ Divers échantillons du même genre.

94 Type de tissu copte, de soie à ordonnance de cercles isolés, inspiration persane, $\mathrm{VI}^{\mathrm{e}}, \mathrm{vir}^{\mathrm{e}}$ et $\mathrm{vm}^{\mathrm{e}}$ siècles.

$9^{5}$ Divers échantillons du même genre.

$9^{6}$ Type de tissu copte, de soie à ordonnance de roues tangentes, inspiration persane, $\mathrm{vi}^{\mathrm{c}}$, vile et $\mathrm{vur}^{\mathrm{c}}$ siècles.

97 Divers échantillons du même genre.

$9^{8}$ Type de tissu copte de soie, à ordonnance de lignes horizontales décorées, inspiration byzantine, $\mathrm{vl}^{\mathrm{e}}$, vile et rill ${ }^{\mathrm{e}}$ siècles.

99 Divers échantillons du même genre.

Ioo Type de tissu copte de soie, à ordonnance de lignes horizontales décorées, inspiration persane, $\mathrm{v}^{\mathrm{e}}$, vile et vire siècles. 


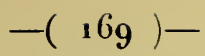

10I Divers échantillons du même genre.

102 Type de tissu copte de soie, à ordonnance de compartiments géométriques décorés, inspiration byzantine, $\mathrm{Vi}^{\mathrm{e}}$, $\mathrm{vi}^{\mathrm{e}}$ et viri ${ }^{\mathrm{e}}$ sićcles.

ro3 Divers échantillons du même genre.

ro4 Type de tissu copte de soie, à ordonnance de compartiments géométriques décorés, inspiration persane, $\mathrm{vi}^{e}, \mathrm{vir}^{\circ}$ et vine siècles.

ıõ̃ Divers échantillons du me̊me genre.

Io6 Type de tissu copte de soie, à ordonnance losangèe, inspiration byzantine, vie, vil et vir ${ }^{\mathrm{e}}$ siècles.

107 Divers échantillons du même genre.

Io8 Type de tissu copte de soie, à ordonnance losangée, inspiration persane, vi', vile et vilro siècles.

rog Divers échantillons du même genre.

1 Io Type de tissu copte de soie, à ordonnance de semis, inspiration byzantine, vie, $\mathrm{vI}^{\circ}$ et ril' ${ }^{\circ}$ siècles.

I I Divers échantillons du même genre.

Ir 2 Type de tissu copte de soie, à ordonnance de semis, inspiration persane, $\mathrm{vi}^{\circ}$, vir${ }^{\bullet}$ et $\mathrm{vin}^{\bullet}$ siècles.

113 Divers échantillons du même genre.

I 4 Sandales de cuir à décor doré, fouilles d'Antinö̈, vie, viı ${ }^{\mathrm{e}}$ siècles.

115 Vêtement avec empiècenıent au cou, décor géométrique copte, Antinoë, vıre sičcle.

ı16 Tunique avec empiècement de gobelins coptes, Antinö̈, vic, vire siècles.

I 7 Vêtement à longues manches, avec col et revers ornés de galons jaunes; brodé de décors méandriques et de galons rouges brodés de motifs crucifères inscrits, Antinö̈, vie, vile siccles. 


\section{$-(170)-$}

118 Vêtement à longues manches, tissu de bourre de soie pourpre avec bandes de soie polychrome, type à ordonnance losangée, Antinoë, v11 ${ }^{\mathrm{e}}$ siècle.

119 Manteau en drap feutré vert avec bande de soie, semis de cœurs rouges sur fond jaune, art byzantin, Antinoë, vıe siècle.

120 Vêtement à longues manches en bourre de soie pourpre, avec galon brodé laine et bande de soie à semis de paons, art sassanide, Antinoë, vue siècle.

12I Tunique de lin à rayures verticales brodées de pois rouges, bleus et blancs, et ornée de vase de fleurs de gobelins coptes, Antinoë, $\mathrm{r}^{\mathrm{e}}, \mathrm{v}^{\mathrm{e}}$ siècles.

122 Fragment de tunique drap feutré jaune, décoré de clavi et de paragaudes de gobelins coptes, Antinoë, vi ${ }^{\mathrm{e}}$ siècle.

123 Bourrelet de tour de cou, Antinoë, vi ${ }^{\mathrm{e}}$, vile siècles.

124 Manteau en bourre de soie pourpre avec bande de soie polychrome à petits semis, art sassanide, Antinoë, vire siècle.

125 Manteau bourre de soie verte, avec bande de soie rouge à semis de compartiments géométriques, décorés de croix, de roses mystiques, etc., art byzantin, Antinoë, viı siècle.

126 Manteau bourre de soie pourpre avec bande de soie à semis de figures géométriques décorées, art byzantin, Antinoë, vire siècle.

127 Fragment de vêtement de laine, décoré de divers ornements gobelins coptes, Antinoë, $\mathrm{vl}^{\circ}$, viı siècles.

I28 Fragment de costume de laine vert foncé, décoré de bandes verticales pourpres et blanches, avec large galon de gobelins coptes d'inspiration byzantine, Antinoë, v1e, vıle siècles.

J29 Divers fragments de costumes, Antinoë, vı, vil ${ }^{\mathrm{e}}$ siècles. 


\section{PÉRIODE ARABE}

La période dite arabe va du vin ${ }^{e}$ siècle au $x_{1 v^{0}}$ siècle.

Les tissus coptes nous permettent d'en étudier la phase qui précède le $x^{e}$ siècle, phase pendant laquelle l'art musulman subit encore souvent l'influence plus ou moins directe de l'art byzantin ou de l'art persan de l'époque sassanide. Les collections Graff et d'Antinoë, celles aussi acquises du chanoine Bock sont les trois sources principales d'où viennent les échantillons du Musée. Ce ne sont plus seulement les nécropoles égyptiennes, mais encore nos cimetières occidentaux qui les fournissent. Quelques-uns sont des souvenirs, des cadeaux diplomatiques enroyés par des califes, d'autres, enfin, de précieuses reliques rapportées jadis par les pieux pèlerins de la Terre Sainte.

A partir du vine siècle, de l'Himalaya à l'Atlantique, l'empire musulman est en même temps principal producteur et principal consommateur; les Grecs, toutefois, continuent à fabriquer, mais leur art s'est immobilisé dans le formalisme rituel byzantin.

Nous avons classé les échantillons de la période arabe en quatre grandes catégories : art primitif musulman, art du Califat du Caire, art du Califat de Bagdad, art du Califat de Cordoue. L'arl siculo-arabe, que nous désignions sous le nom d'école palermitaine des $x_{11}{ }^{e}$ et $x_{1} v^{e}$ siècles, nous servira de transition pour arriver à la période italienne.

Par art primitif musulman, nous entendons celui que l'Islam emprunte aux Coptes devenus leur's fournisseurs. En haine des chrétiens, ils regrettent tout ce qui peut les rappeler. C'est un art essentiellement géométrique dont les détails sont surtout des combinaisons de lignes.

L'art du Califat du Caire conservera longtemps les formes architectoniques de la période byzantine combinant la repré- 


\section{$-\left(7^{2}\right)-$}

sentation hiératique des animaux, affrontés, adossés ou isolés, a vec les différents éléments décoratifs de l'art primitif musulman. Les tissus y sont, en général, mélangés.

L'art du Califat de Bagdad semble l'origine de la vraie forme du décor arabe, affranchi de toute réminiscence de l'art Lyzantin. La composition y est touffue et enchevêtrée, avec une flore, ou plutòt floraison irréelle. L'architecture en est proscrite. Les tissus sont de soie pure.

L'art du Califat de Cordoue est l'utilisation la plus complète, en nềme temps que la plus scientifique, des formules de la géométrie esthétique.

13o Type de composition à ordonnance de dessins géométriques, art primitif musulman.

13. Divers échantillons du même genre.

132 Fragments de tissus, composition à ordonnance de lignes horizontales décorées de figures, de personnages saints à représentation symétrique, art byzantin de l'époque carlovingienne.

133 Fragments de sandales brodées or sur satin, de l'époque carlovingienne.

13. Collection de galons à décor géométrique, de l'époque carlovingienne.

I35 Type de damas, composition à ordonnance de roues tangentes décorées, art byzantin de l'époque carlovingienne.

136 Divers échantillons du même genre.

I37 Divers échantillons gazes brodées décor méandrique, art musulman, $1 x^{e}, x^{e}$ siècles.

138 Velours à semis de lions et d'oiseaux affrontés, époque des fatimites, califat du Caire, $x^{\mathrm{e}}$ siècle.

${ }_{139}$ Satin bleu brodé d'or, travail français du $\mathbf{x i}^{\mathrm{e}}$ siècle. 
140 Broderie d'or sur satin rouge, semis d'animaux fantastiques, art arabe des $\mathrm{XI}^{\mathrm{e}}$ et $\mathrm{xII}^{\mathrm{e}}$ siècles. (Collection Dupont-Auberville.)

I4r Fragments de brocart or du $\mathrm{xI}^{\mathrm{c}}$ siècle.

142 Type à composition à meneaux d'arcs lancéolés décorés d'animaux affrontés ou adossés, d'arabesques et de croix, art arabe interprété par les Grecs, $\mathrm{xI}^{\mathrm{e}}, \mathrm{x}_{1}{ }^{\mathrm{e}}$ sic̀cles.

143 Type de composition à ordonnance de figures géométriques décorées d'animaux, de croix et de croissants, fabrication palermitaine du $x ! 1^{\circ}$ siècle.

I44 Divers échantillons du même genre.

I45 Type de tissu à ordonnance de semis d'animaux à représentation hiératique, art arabe antérieur au xir siècle.

I 46 Divers échantillons du même genre.

I47 Type de composition à ordonnance de lignes horizontales décorées d'animaux et de homas, art persan du xiı ${ }^{e}$ siècle.

I 48 Divers échantillons du mème genre.

I 49 Type de petit décor à lettres arabes décoratives, mèlées de figures géométriques, fabrication palermitaine du xire siècle.

I5o Divers échantillons du même genre.

r5r Type de composition à compartiments géométriques décorés d'animaux hiératiques (tissu mélangé), art arabe, califat du Caire antérieur au $\mathrm{x}_{1} \mathrm{I}^{\mathrm{e}}$ siècle.

152 Collection de galons à décor géométrique de méandres et d'entrelacs, fabrications byzantine et palermitaine antérieures au xure siecle.

I53 Ancienne chasuble provenant d'une abbaye d'Auvergne, type de brocart arabe du califat du Caire, ordonnance de roues tangentes décorées d'animaux affrontés ou adossés. - Au bas, une inscription tissée nous apprend que ce drap d'or a été fabriqué au pays de Roum pour le sultan'Ala Eddlin Kë̈lobad 
le Victorieux, qui monta sur le trone des Seldjoucides, l'an 6 i 6 de l'hégire.

154 Tiraz à décor épigraphique exclusif. Cette forme commune à tout l'Islam s'est'perpétuée jusqu'aux temps modernes; les plus anciens se reconnaissent pourtant à la forme carrée de leur épigraphie. (Lettres cuffiques.)

155 Divers échantillons du même genre.

156 Grand tiraz à compartiments géométriques isolés, décorés d'arabesques, d'entrelacs et d'inscriptions arabes. Ce genre de composition, commun à lout l'Islam, s'est perpétué jusqu'aux temps modernes sans changements appréciables, les plus anciens se reconnaissent pourtant à la forme carrée de leur épigraphie. (Lettres cuffiques.)

I57 Divers échantillons du même genre.

158 Chape brodée. Le haut décoré de l'aigle de saint Jean, du lion de saint Marc, du bœuf de saint Luc et de l'ange de saint Mathieu; le bas à décor de méandres et d'entrelacs géométriques, art du mont Athos, xme siecle.

I59 Chasuble velours rouge avec croix brodée or et couleurs sur satin vert; saints personnages dans compartiments quadrilobés, art du mont Athos, xule siècle et suivants.

I6o Broderie d'or "Mise au tombeau ", école du mont Athos, xin1 ${ }^{\mathrm{e}}$ siecle.

161 Fragment de chape, broderie de saints personnages dans des architectures rayonnantes, travail français de la fin du $\mathrm{x}{ }_{111^{\mathrm{e}}}$ siécle.

162 Bande brodée sur toile, arbre de Jessé se détachant en couleur sur un fond d'or de compartiments quadrilobés décorés de léopards passants, travail anglais, xile siècle. (Collection Spitzer.)

I 63 Divers petits manipules brodés, travail anglais du XIII ${ }^{\complement}$ siècle. ${ }_{16} 6$ Type de composition à ordonnance de roues tangentes, décorées 


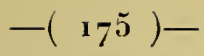

d'animaux affrontés ou adossés et d'arabesques. Tissu particulier composé de deux chaînes et de deux trames, arec quelques points brochés or, art du califat de Bagdad, $\mathbf{x} 111^{\mathrm{e}}$ siècle.

I65 Chasuble, type caractéristique de composition symétrique très enchevêtrée, à animaux affrontés ou adossés de chaque côté de homas rigides, tissu particulier à combinaison de deux trames et de deux chaînes, arec quelques points brochés or, art arabe du califat de Bagdad, $x_{111^{e}}$ siècle.

I66 Divers échantillons du même genre de tissu.

I67 Dalmatique, tissu persan, type à ordonnance de lignes horizontales décorées d'animaux affrontés ou adossés et de homas, art arabe du califat de Bagdad, xüe siècle.

I68 Divers fragments de tissus hispano-mauresques, de fabrication antérieure au $\mathrm{x}_{11}{ }^{\mathrm{C}}$ siècle.

I69 Grand tiraz, composition à ordonnance de lignes horizontales décorées d'entrelacs, d'arabesques et d'inscriptions arabes, fabrique d'Alméria, xm ${ }^{e}$ siècle.

170 Divers échantillons du même genre.

I I Type de tissu décoré d'entrelacs géométriques scientifiques, art arabe, califat de Cordoue, $x \mathrm{III}^{\mathrm{c}}$, xive siècles.

I 72 Divers échantillons du même genre.

I 73 Type caractéristique de décor hispano-mauresque à combinaisons géométriques savantes, mêlées d'arabesques et d'inscriptions, art hispano-mauresque, $\mathrm{x} \mathrm{II}^{\mathrm{e}}$ siecle.

I 74 Divers échantillons du même genre, xı11", xıve siècles.

Le $X I I^{e}$ siecle. - Le répertoire des détails décoratifs d'invention persane du $x^{\circ}{ }^{\circ}$ siècle est assez limité. La variété du décor vient de leur utilisation. Les animaux et la flore y apparaissent. Les animaux sont plus près de la nature que dans la période précédente. Les principaux sont: le lion, la 


\section{$-\left(17^{6}\right)-$}

gazelle, le guépard, l'aigle, la colombe, le paon, l'oie, etc. auxquels nous devons ajouter les animaux fabuleux, tels que le griffon, le dragon, etc. La flore est fantaisiste : les fleurs sont plutôt floraisons irréelles rentrant dans le genre Aster, ou dans celui des palmettes; les feuillages sont dentelés et découpés, les tiges grêles et effilées. La composition ellemême, toujours très touffue, est ou symétrique ou pittoresque et sans lignes architecturales.

L'école palermitaine utilisera les mêmes formules, avec une tendance marquée à une interprétation plus réaliste. L'aspect des tissus siculo-arabes sera moins déchiqueté, et la gracilité persane fera place à une expression plus trapue. La juxtaposition des motifs constituant le rapport, est plus lisible chez les Palermitains qui y introduiront parfois quelques lignes d'architecture clairement définies. Enfin, dans un décor tout persan, l'apparition de pièces héraldiques ou de symboles chrétiens dénotera l'origine oecidentale de l'étoffe.

$L e x I V^{e}$ siècle. - $\mathrm{Au} \mathrm{xIV}^{\mathrm{e}}$ siècle, la eonsommation est devenue surtout occidentale. Consécutivement, l'Orient resté producteur important subira l'influence des aspirations de sa nouvelle clientèle. Pour celle-ci, Venise importera des tissus d'Asie Mineure, où plus de clarté dans l'ordonnance, plus de réalisme dans le détail sont manifestement le reflet des exigences occidentales. Le répertoire des nouveaux motifs décoratifs, où rarement l'animal apparaît, se réduira d'ailleurs à l'interprétation étrangement schématique de quatre fleurs principales : la tulipe, l'œillet, la jacinthe et l'églantier.

De son côté, l'Italie continue à fabriquer des tissus dont le décor reste influencé par l'Orient, tout en devenant plus nature dans le détail. Les ouvriers de l'école palermitaine ont émigré en partie après les Vêpres Siciliennes et ont fondé, dans les divers centres italiens qui les ont recueillis, des fabriques rivales où l'on continue d'abord à fabriquer suivant les mêmes traditions; peu à peu, d'aucuns prendront une spécialité : 


\section{$-(177)-$}

Florence fait des damas à petits décors avec quelques points brochés or ou couleur dans lesquels la flore devient très réaliste. Lucques fait des damas à décor de personnages saints; Sienne tisse des étoffes particulic̀res destinées à remplacer les broderies d'orfroi des costumes liturgiques, et reproduisant des scènes du Nouveau Testament. Venise prend la spécialité des velours coupés, Gênes celle des velours ciselés. Jusqu'à la fin duxiv ${ }^{\mathrm{e}}$ siècle, le dessin reste petit d'échelle; vers le $x^{e}$, en même temps que le vêtement devient plus ample, le décor prendra des proportions plus considérables.

175 Type de tissus à décor de palmettes avec animaux affrontés à disposition symétrique rectiligne, art persan, xul ${ }^{\mathrm{e}}$ siècle.

176 Divers échantillons du même genre.

177 Type de tissu à décor de palmette persane avec animaux affrontés à disposition symétrique rectiligne, école palermitaine, xuI siècle.

I 78 Divers échantillons du même genre.

r 79 Type de tissu à décor de palmette avec animaux affrontés à disposition symétrique sinueuse formant meneau, art persan du xil1 ${ }^{\mathrm{e}}$ siècle.

180 Divers échantillons du même genre.

18r Type de tissu à décor de palmette persane avec animaux affrontés, disposition symétrique sinueuse formant meneau, école palermitaine, xm1 $1^{\mathrm{e}}$ siècle.

182 Divers échantillons du même genre.

r83 Type de tissu à compartiments losangés décorés d'inscriptions arabes et d'entrelacs avec palmette centrale, art persan du xIII siècle.

x84 Divers échantillons du même genre.

I85 Type de tissu à compartiments losangés décorés d'inscriptions 


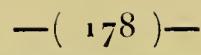

arabes et d'entrelacs, avec palmette centrale dans le goût persan, école palermitaine du xiıe siècle.

r 86 Divers échantillons du même genre.

r 87 Type de composition à disposition symétrique et à ordonnance de semis sur lignes horizontales sans liaison architectonique, animaux et floraisons dans le goût persan, école palermitaine des $\mathrm{XIII}^{\mathrm{e}}, \mathrm{x} \mathrm{x}^{\mathrm{e}}$ siècles.

187 bis Divers échantillons du même genre.

x88 Type de composition à disposition symétrique et à ordonnance de rayures horizontales décorées d'animaux, de floraisons irréelles et d'inscriptions arabes dans le goût persan, ćcole palernitaine, $\mathrm{x}^{\mathrm{e}}$ siècle.

r 89 Divers échantillons du même genre.

rgo Type de composition à disposition pittoresque et à ordonnance de rayures horizontales, décorées d'animaux, de floraisons irréelles et d'inscriptions arabes dans le goût persan, école palermitaine du xinte siècle.

19I Divers échantillons du même genre.

r92 Type de tissu à ordonnance de lignes verticales sinueuses, de tiges grêles fleuries de palmettes et d'asters, Perse, $\mathrm{x}_{111^{\mathrm{e}}}$ siécle.

r93 Divers échantillons du même genre.

r94 Type de tissu à ordonnance de lignes verticales sinueuses, de branchages vigoureux fleuris de palmettes et d'asters dans le goût persan, école palermitaine du xı1 ${ }^{\mathrm{e}}$ siècle.

ı 95 Divers échantillons du même genre.

196 Type de composition pittoresque à animaux et arabesques dans le goût persan, avec croix, écussons on couronnes, école palermitaine, $\mathrm{x}^{\mathrm{e}}$ et $\mathrm{xiv}$ siècles.

197 Divers échantillons du même genre. 


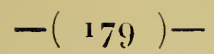

I 98 Types de composition à disposition sur lignes diagonales d'entrelacs ou d'arabesques décorées d'animaux passants, école palermitaine, $\mathrm{x}_{11} \mathrm{I}^{\mathrm{C}}$ et $\mathrm{x}_{\mathrm{I}} \mathrm{v}^{\mathrm{e}}$ siecles.

199 Divers échantillons du même genre.

200 Type de composition à ordonnance de rayures verticales décorées d'animaux, de floraisons irréelles, d'entrelacs et d'inscriptions arabes, école palermitaine du xıı siècle.

2or Divers échantillons du même genre.

202 Type de composition pittoresque à ordonnance de floraisons irréelles et d'animaux sur disposition horizontale, art persan du xive siècle.

203 Divers échantillons du même genre.

204 Type de composition pittoresque à ordonnance de floraisons irréelles et d'animaux sur disposition horizontale dans le goût persan, école palermitaine du xıve siècle.

205 Divers ėchantillons du même genre.

206 Type de composition à disposition de meneaux décorés d'animaux, d'arabesques et de floraisons irréelles, art persan du $\mathrm{x} \mathrm{V}^{\mathrm{e}}$ siècle.

207 Divers échantillons du même genre.

208 Type de composition à disposition de meneaux décorés d'animaux, d'arabesques et de floraisons irréelles dans le goût persan, école palermitaine, $x^{\prime} v^{c}$ siècle.

209 Divers échantillons du même genre.

210 Type de composition à semis de compartiments arabescaux et d'animaux affrontés, école palermitaine, xıve siècle.

2I I Divers échantillons du même genre.

212 Semis de fleurs de lis. Palerme, xnn siècle.

2) 3 Semis d'étoiles florancées. Palerme, xi11 ${ }^{\circ}$ siccle. 
214 Écharpe de tournoi, voile de soie brodé or et couleur, décor d'animaux chimériques et de végétations dans le goût persan, avec semis de pièces de blason, Halerme, xrve sićele.

2 İ 2 Mitres avec galon tissé à décor géométrique. Palerme, $\mathrm{xur}^{\mathrm{e}}$ siècle. Acquises sur les fonds légués par M. Oscar Galline, ancien président de la Chambre de commerce. (Collection Simonetti.)

216 Bande brodée sur toile, arbre de Jessé se détachant, en couleur, sur un fond d'or à compartiments quadrilobés décorés de léo. pards passants, travai، anglais, xum siècle (Collection Spitzer.)

2 I Frontal d'autel. Diverses scènes de la Passion, broderie italienne, xive siècle.

218 Broderie or et soie, ordonnance de bandes horizontales avec compartiments géométriques décorés de fleurs de lis et de méandres, Palerme, $\mathbf{x} \mathrm{m}^{\mathrm{C}}$ sièclc.

2 I9 Chasuble velours rouge avec croix brodée or et couleur sur satin vert, école du mont Athos, xin et xiv ${ }^{\mathrm{e}}$ siècles.

220 Velours coupé genre ferronnerie, avec palmettes brochées or et argent, Perse, fin xiv sičcle.

22) Velours coupé sur fond tramé or, type à personnages et fleurs souples, Perse, xiv siècle.

222 Velours coupé, type à personnages et fleurs souples avec boucles or et argent, Perse, $\mathrm{xv}^{\mathrm{c}}$ siècle.

223 Velours coupé, décor à ordonnance de lignes verticales sinueuses de branches feuillées et fleuries, Perse, $x v^{c}$ siècle.

224 Brocart or sur fond velours coupé, composition à ordonnance de grands meneaux à rosaces décorés de tulipes, Asic Mineure, fin xive siecle.

225 Divers échantillons du même genre.

226 Brocart d'or sur fond velours coupé, composition de grands meneaux couronnés, décorés de tulipes, Asie Mineure, fin xrve siècle. 


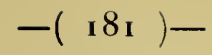

PÉRIODE ITALIEXYE

La période dite italienne va du $x_{10}{ }^{\mathrm{a}}$ au xvirc siècle, le xiv ${ }^{\mathrm{e}}$ siècle lui servant de phase éducative. La consommation et la production deviennent occidentales. L'étude approfondic que les artistes font de la nature au $x_{1 v^{e}}$ siècle en Italie inaugure le premier effort d'émancipation de l'influence orientale. L'art devient réaliste. La production se localise dans différents centres qui prennent chacun une spécialité.

Auxve siècle, l'étude de l'antique fera évoluer la décoration vers la forme définitive de la Renaissance, qui s'en adaptera le principe d'ornementation. L'industrie est alors en pleine possession de procédés supérieurs de fabrication que l'extension commerciale a vulgarisés; si bien que, si lïnvention reste italienne, il est incontestable que chaque spécialité n'est plus le monopole de tel ou tel centre; on fait de tout un peu partout, même à l'étranger, sous la conduite toutefois d'ouvriers italiens qui y ont été appelés.

La clarté sobre, la pondération architectonique caractérisent les productions du commencement de la Renaissance; des progrès de métier, l'introduction de procédés nouveaux donneront au commencement du xvie siècle le maximum d'éclat et de richesse. A la fin, l'ivresse de la science, l'habileté manuelle, prédominant le goût, amèneront le vertige en exaspérant la composition par une infinité de détails dans lesquels sombreront la perfection et la clarté de la phase précédente.

227 Type de tissu décoré de feuillages réalistes et d'animaux à petite échelle, Florence, xive siècle.

228 Divers échantillons du même genre.

229 Type de semis de chérubins à ailes rayonnantes, fabrication de Lucques, xıve siècle. 
23o Divers échantillons du même genre.

23r Type de semis d'anges et accessoires religieux, Lucques, xive siècle.

232 Divers échantillons du même genre.

233 Type de tissu décoré de scènes du Nouveau Testament, Lucques, xıve siècle.

234 Divers échantillons du même genre.

235 Dalmatique, type de tissu à ordonnance lorizontale avec personnages du Nouveau Testament (le Christ et la Madeleine), fabrication du Nord de l'Italie, xive siècle.

236 Divers échantillons du même genre de tissu.

237 Collection d'échantillons de tissus de Sienne, xıve siècle et suivants. Sienne a la spécialité de bandes et panneaux tissés décorés de saints personnages, en général du Nouveau Testament et destinés à remplacer les broderies d'orfroi des costumes liturgiques. Dans les plus anciens, le dessin se détache en clair sur le fond foncé, et parfois la composition est polychrome. Sienne conserve la spécialité de ces tissus jusquau xviı siècle. Le dessin est alor's le plus souvent foncé sur le fond clair et indiqué parlois par un serti de velours coupé.

238 Dalmatique de satin rouge avec application de panneaux tissés, représentant « l'Assomption", Sienne, $\mathrm{xvI}^{\mathrm{e}}$ siècle.

239 Petit brocart d'argent décoré de personnages pittoresques, d'animaux nature et de végétations souples, type caractéristique d'art persan du xie siècle.

240 Satin à décor sergé polychrome, type de composition et scènes épisodiques, personnages et animaux an naturel, flore fantaisiste, Perse, fin $x v^{\circ}$ sićcle.

24r Satin à décor sergé polychrome, type de composition de scènes de la vie orientale, personnages au naturel et flore fantaisiste, art persan, fin $x v^{e}$ siècle. 
242 Velours coupé, deux corps sur fond tramé or, semis de tulipes et de papillons, Perse, fin xıve siècle.

243 Divers échantillons du même genre, xıve et $\mathrm{xV}^{\mathrm{c}}$ siècles.

244 Brocarts sur fond velours et satin, composition de grands meneaux cordelière, décorés de grenades, $\mathrm{xv}^{\mathrm{c}}$ et $\mathrm{xvi}^{\mathrm{c}}$ sićcles. Velours dits d'Asie Mineure, importés par Venise.

245 Brocarts sur fond velours et satin, composition de grands meneaux décorés de tulipes et de jacinthes, velours dits d'Asie Mineure, importés par Venise, $\mathrm{xv}^{\mathrm{c}}$ siècle.

246 Velours coupé, type à grands meneaux, décorés de tulipes, de jacinthes et d'œillets, velours dits d'Asie Mineure, importés par Venise, xve siècle.

247 Divers échantillons du même genre d'importation ou de fabrication vénitienne, $\mathrm{xIv}^{\mathrm{e}}, \mathrm{x}^{\mathrm{e}}$ et $\mathrm{xvI}^{\mathrm{e}}$ siècles.

248 Velours coupé polychrome, type de branches d'asters, sur fond clouté, deux hauteurs de velours, Venise, xıve siccle.

249 Velours coupé polychrome, type de branches d'asters sur fond tramé or, Venise, xiv siècle.

250 Dalmatique, satin vert broché or et soie rose, décor de grandes floraisons irréelles souples, à découpures dentelées, à ordonnance de lignes diagonales sinueuses, fabrication vénitieune inspirée d'art persan, fin xrve siècle.

25 r Type de velours coupé polychrome à décor imité de l'0rient, Venise, fin $x v^{e}$ siecle.

252 Divers échantillons du même genre.

253 Velours coupé polychrome à deux liauteurs, type à semis d'asters dans le goût persan, Venise, $x r^{\cdot e}$ siccle.

254 Divers échantillons du même genre, xıve et $\mathrm{xv}^{0}$ siecle.

255 Type de velours coupé dit à ferronnerie, décor de feuilles lobées 
avec fleurons indépendants se détachant on satin sur le fond de velours, Venise, commencement du $x^{c}$ siècle.

256 Divers échantillons du même genre.

${ }_{257}$ Type de velours coupé dit à ferronnerie, décor de feuilles lobées satin sur le fond de velours avec grenade ou fleuron indépen. dant broché or, Venise, xve siècle.

258 Divers échantillons du même genre.

259 Type de velours coupé dit à ferronnerie, décor de feuilles lobées, de cordelières et de fleurons reliés, Venise, fin xve siecle.

260 Divers échantillons du même genre, fin xve et xvie siècles.

26r Velours coupé sur fond satin, type de grand meneau de branchages feuillés et entrelacés, Venise, fin du moyen âge.

262 Divers échantillons du même genre.

263 Velours coupé sur fond satin, décor de grands meneaux de branchages entrelacés avec fleuron indépendant, Venise, fin du moyen âge.

264 Divers échantillons du même genre.

265 Velours deux corps, décor de petits meneaux, Venise, xve siècle.

266 Divers échantillons du même genre, $x^{e}$ et $x_{v i}{ }^{e}$ siècles.

${ }_{26} 6$ Velours coupé, deux corps avec broché or, type au meneau couronné, Venise, fin xve siècle.

268 Divers échantillons du même genre.

269 Damas décor de meneaux de branchages feuillés avec fleuron indépendant, Venise, fin xve siècle.

$27^{\circ}$ Divers échantillons du même genre.

27 I Damas broché or, décor de meneaux de branches feuillées, avec fleuron indépendant (grenade dans une forme ovoïde découpée en accolade), Venise, Renaissance. 
272 Divers échantillons du même genre.

273 Brocart décor velours coupé, enrichi de bouclés, type à la bande verticale sinueuse, décorée de grenades sur feuilles lobées et de cordelières ornées, Venise, Renaissance.

274 Divers échantillons du même genre.

275 Divers fragments de velours bouclés or et argent de l'époque cle la Renaissance.

276 Chasuble, velours coupé et tramé or, décor à ordonnance de lignes horizontales décorées de la devise «Espérance» et du collier de l'ordre de la Cosse de Genet, fait pour le duc de Bourbon, archevèque de Lyon, $\mathbf{1}\left\{3_{7}-\mathbf{1} 488\right.$, fabrication de Venise.

277 Chasuble, velours coupé et tramé or, dit clouté, Venise, $\mathrm{XV} \mathrm{v}^{\mathrm{e}}$ sic̀cle.

278 Chasuble, velours vénitien dit à ferronnerie avec bande d'orfroi de Cologne, $x v^{e}$ siècle.

279 Chape, velours dit à ferronnerie, Venise, XVe siècle, avec orfroi brodé de saints personnages, travail français du $\mathrm{xv}^{\circ}{ }^{\circ}$ siècle.

280 Chasuble, velours vénitien dit à ferronnerie de la fin du XVIc siècle, avec croix brodée « Dieu le Père, Christ en croix et Bon Pasteur ». Au bas, armoiries des provinces des Pays-Bas, travail flamand de la fin du $x^{c}{ }^{c}$ siecele.

28r Chape, velours coupé broché or avec bouclés, type à la bande verticale sinueuse décorée, Venise fin du XVc siècle, avec orfroi et chaperon brodés, travail allemand de la fin clu $\mathrm{xV}^{\mathrm{c}}$ siècle.

282 Chasuble, velours coupé sur fond satin, décor de meneaux, cordelières entrelacées et nouées, avec fleurons couronnés indépendants, type caractéristique de la fin du moyen âge, fabrication vénitienne.

283 Chasuble, brocart d'or avec bouclés, dessin serti de velours, type 
à la bande verticale sinueuse décorée, Venise, xvi siècle, avec bande d'orfroi brodé.

284 Chasuble, velours vert, coupé à deux hauteurs et un seul corps, décor de meneaux et volutes de branchages feuillés et fruités, Venise, fin $x v^{e}$ siecle, avec croix brodée de l'école du mont Athos, Irve siecle.

285 Petit velours ciselé sur fond satin, décol de branches fleuries, d'animaux passants et d'oiseaux perchés, Gênes, xie siècle.

286 Divers échantillons du même genre, $\mathrm{x}^{\mathrm{e}} \mathrm{v}^{\mathrm{e}}$ et $\mathrm{xv}^{\mathrm{e}}$ sićcles.

287. Petit velours ciselé sur fond satin, semis de fleurons et de flammes du Saint-Esprit, Gênes, $\mathrm{XT}^{\mathrm{e}}$ siecle.

288 Divers échantillons velours ciselé sur fond satin à petits décors, Gênes, époque de la Renaissance.

289 Petit velours, décor coupé sur fond épinglé, animaux et branches fleuries, Nord de l'italic, xive et xve siècles.

290 Divers échantillons du mêne genre.

29 I Petit velours coupé sur fond satin; décor symétrique d'abeilles et de fleurs de lis, Florence, $x v^{e}$ siecle.

292 Divers échantillons du même genre.

$29^{3}$ Grand velours ciselé sur fond satin, type au vase de fleurs avec tiges formant meneaux et volutes, Gênes, fin xve siècle.

294 Type de velours ciselé sur fond satin décor de grands meneaux et fleurons reliés, Gènes, fin xve siècle.

295 Divers échantillons du même genre.

296 Type de velours ciselé sur fond satin, décor de fleurons moyens isolés, Gènes; fin xve siècle.

297 Divers échantillons du même genre, Gênes, xvo et xvie sićcles.

298 Type de velours ciselé polychrome sur fond satin, décor de grands fleurons isolés, Gênes, fin $x^{e}{ }^{e}$ siècle. 


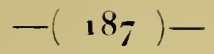

299 Divers échantillons du même genre, Gênes, xre et $x r^{\mathrm{e}}$ siecles.

3 oo Damas à grands meneaux entrelacés à un seul chemin, Italie, xre siccle.

3or Tissu satin et trame liée, décor de grands meneaux double cordelière avec vases fleuris, $x v^{\text {ve }}$ siècle.

302 Divers échantillons du même genre, xre et $x r^{\circ}$ siècles.

303 Type de tissu à grands meneaux et arabesques, décor velours ciselé avec bouclés or et argent sur fond lamé argent. Espagne, fin $x v^{e}$ siècle.

304 Divers óchantillons du même genre.

305 Divers fragments de bouclés d'or et d'argent, Espagne, xre et xric siècles.

306 Tissu tramé fil et soie, décor de branches de chêne formant meneaux et fleurons indépendants, fin du moyen àge.

307 Divers échantillons du même genre.

308 Divers échantillons tramés fil et soie à décor de compartiments et d'arabesques, Espagne, Xve et $\mathrm{XVI}^{\mathrm{e}}$ siècles.

309 Divers échantillons de tissus à décor dit gothique, $\mathrm{xv}^{\mathrm{re}}$ et $\mathrm{x} \mathrm{vi}^{\mathrm{e}}$ siccles.

3 1o Divers échantillons de tissus imprimés, Allemagne, $x I v^{-e}, x v^{e}$ et $\mathrm{xvI} \mathrm{I}^{\mathrm{e}}$ siècles.

3 r collection d'échantillons, Cologne, xrve siècle et suivants. Cologne fabriquait des tissus spéciaux espoulinés dans lesquels certaines parties ètaient destinées à recevoir des broderies. Ces étoffes remplaçaient les orfrois brodés des costumes liturgiques.

3 r2 Bande de tissu espouliné, de liurre de Cologne, xre siècle.

3r3 Parements de brancard pour procession : tissu vénitien bouclé or à trois hauteurs avec application de panneaux brodés soie 
et or nué; $a$ : la Résurrection; $b$ : Translation de l'Arche, Italie, fin $\mathrm{xv}^{\mathrm{e}}$ siècle.

314 Chasuble damas vert décoré de meneaux réticulés avec fleurons et rinceaux de branches feuillées et fruitées. Nord de l'Italie. Bande de velours brodé d'ontiales et de cordelières nouées et campanées, travail français de la fin du $x v^{e}$ siècle.

315 Chape : velours ciselé dit de Gênes, type de meneau cordelière avec fleuron indépendant, $x v^{e}$ siècle, orfroi et chaperon de l'œuvre de Cologne, datés de ${ }_{1} 4^{3} 7$.

3 I 6 Chasuble : velours ciselé sur fond lamé, décor de petits meneaux et fleurons indépendants, Italie, fin xve sieccle.

317 Mitre brodée de portraits de saints personnages dans des compartiments quadrilobés, Palerme, xive siècle.

31 8 Panoeau de broderie représentant " le Bon Pasteur ", travail français de la fin du xive siècle.

3 r9 Diverses bandes brodées, travail français de la Renaissance.

320 Diverses bandes brodées, travail anglais de la Renaissance.

321 Diverses bandesbrodées de fleurons, travail flamand de la Renaissance.

322 Diverses bandes brodées de fleurons, travail espagnol de la Renaissance.

323 Divers chaperons brodés, travail français de la Renaissance.

324 Divers chaperons brodés, travail flamand de la Renaissance.

325 Divers chaperons brodés, travail espagnol de la Renaissance.

$3_{26}$ Collection de bandes d'orfrois décorées de saints personnages dans des architectures, France, $\mathrm{xv}^{\circ}$ et $\mathrm{xvi}^{\mathrm{e}}$ siècles.

327 Collection de bandes d'orfrois décorées de saints personnages dans des architectures, Flandre, $\mathrm{xv}^{\mathrm{e}}$ et $\mathrm{xvi}^{\circ}$ siècles. 


\section{$-(189)-$}

328 Collection de bandes d'orfrois décorées de saints personnages dans des architectures, Espagne, $\mathrm{xv}^{\mathrm{e}}$ et $\mathrm{xvI}^{\mathrm{e}}$ siècles.

329 Collection de bandes d'orfrois décorées de saints personnages dans des architectures, Italie, $x v^{e}$ et $x v{ }^{e}$ siècles.

33o Collection de bandes d'orfrois décorées de saints personnages dans des architectures, Allemagne, $x^{\circ}$ et $x v{ }^{\circ}$ siécles.

33r Collection de saints personnages brodés pour orfrois de costumes liturgiques, $\mathrm{xv}^{\mathrm{e}}$ et $\mathrm{xvI}^{\mathrm{e}}$ siècles.

332 Chaperon broderie soie et or "Annonciation ", travail flamand du $\mathrm{xy}$ siècle.

333 Chaperon brodé or et soie polychromes «l'Adoration des bergers », travail flamand de la fin du $x^{e}$ siècle.

334 Croix de chasuble à bras obliques, broderie d'or nué et soies polychromes, comprenant trois sujets : l'Adoration des Mages, la Circoncision et la Présentation. Un petit écusson porte un monogramme, un autre les armoiries d'Amsterdam. Ecole de Bruges, fin du $x v^{\circ}$ siècle. (Collection Spitzer.)

335 Six médaillons broderie d'or unie, soies polychromes, représentant diverses scènes de la Passion, d'après Kranack. Eeole de Bruges, fin du $x v^{\mathrm{e}}$ siècle.

336 Petit tableau brodé or et soie « la Cène », travail français de la fin du $x v^{e}$ siècle.

337 Petit tableau brodé soies polychromes et serti or « Mère de pitié assistée de saint Jean et de Marie-Magdeleine », travail français de la fin du xve siècle.

338 Petit panneau brodé soie et or sur velours rouge décor de rinceaux et d'oiseaux, Italie, fin du xve siècle.

339 Petit panneau de broderie soie et or à armoiries, travail espagnol de la fin du $\mathrm{xv}^{\circ}$ siècle.

340 Chape velours rouge brodé de fleurons et de figures : « Vierge et 


\section{$-(190)-$}

anges ", travail anglais avec orfroi et chaperon flamands, fin $\mathrm{xv}^{\mathrm{e}}$ siècle.

34 I Chasuble velours rouge brodé de chérubins, travail anglais de la fin $d u x^{e}$ siècle.

342 Fragments de broderie or sur velours, école de Cologne du $\mathrm{xv}^{\mathrm{t}}$ siècle.

34. Petit coffret recouvert d'une étoffe de soie brodée or : Rinceaux et animaux avec applications velours, écussons aux armes d'Aragon, Espagne, xve siecle.

34. Brocart décor de feuilles courbées en meneaux avec vase de fleurs au centre, Italic, $x_{v i}{ }^{\circ}$ siccle.

Divers échantillons du même genre.

345 Brocart à grand décor de bandes verticales sinueuses, ornées de branches feuillées et fruitées à dessin serti soie, xvie siècle.

346 Divers échantillons du même genre.

347 Velours dit à ferronnerie, décor satin et or de rinceaux et de volutes sur fond de velours coupé, Venise, xvi siècle.

3.48 Divers échantillons du même genre.

3 亿́9 Brocart décor à compartiments de petits meneaux de branches feuillées avec vase de fleurs central, Venise, $\mathrm{xvI}^{\mathrm{e}}$ siècle.

35 o Divers échantillons du même genre.

3亏̃ Tissu broché, décor de meneaux de branchages fleuris contournés en rinceaux, Venise, xvio siècle.

352 Divers échantillons du même genre.

353 Collection de tissus décor satin sur fond tramé, composition dite grotesque, $\mathrm{xvi}^{\mathrm{e}}$ siècle.

354 Tissu à décor lamé or et argent, ordonnance de petites bandes verticales rigides, entourées de rubans sinueux formant meneaux avec petit fleuron central, fin $\mathrm{xv}^{\mathrm{e}}$ sièclc. 


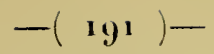

355 Petit velours ciselé sur fond satin, décor de meneaux et fleurons, Gìnes, xvie siècle.

355 Divers échantillons du même genre.

$35_{7}$ Petit velours frisé sur fond côtelé, semis de branches fleuries, Xvic sieccle.

358 Petit velours ciselé deux corps sur fond satin, décor de feuilles formant arc lancéolé avec sommet épanoui, Gènes, xvic siècle.

35 ğ Divers échantillons du même genre.

360 jetit velours ciselé sur fond satin, décor de branches de chêne formant meneaux et fleurons, Gênes, $\mathrm{XVI}^{\mathrm{C}}$ siècle.

30 I $_{1}$ Grand velours ciselé sur fond satin, type à tiges fleuries et fruitées formant fleurons et meneaux à large couronne, Gênes, fin $\mathrm{XvI}^{\mathrm{e}}$ siècle.

362 ¿Dalmatique, tissu de soie façonné et velours de Gênes à grand décor, fin $\mathrm{XVI}^{\mathrm{C}}$ siècle.

363 Tissu broché à décor rappelant l'0rient, Venise, xvi e siècle.

364 Divers échantillons du même genre.

365 Type de velours coupé polychrome à décor imité de l'0rient, Venise, $\mathrm{XvI}^{\mathrm{e}}$ siècle.

366 Divers échantillons du même genre.

367 Brocart à ordonnance de petits meneaux fleuris de tulipes, d'œillets et de jacinthes, Pcrse, $\mathrm{xvi}^{\mathrm{e}}$ siècle.

368 Divers échantillons du même genre.

369 Tissu à petit décor à ordonnance de semis, Persc, xivie et IvII $^{\mathrm{e}}$ siècles.

37o Divers échantillons du même genre.

37 I Dalmatique, tissu persan, type à ordonnance de petits meneaux décorés d'œillets, Persc, Xríc siècle. 


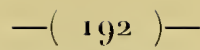

372 Velours coupé sur fond satin, à deux chemins, décor de meneaux ornés d'œillets, de tulipes et de jacinthes, Per'se, Xvic siècle.

373 Divers échantillons du même genre.

374 Brocart or et soie, décor de palmettes, tulipes, jacinthes, églantines et œillets, Perse, Xvic siècle.

${ }_{3}^{7} 5$ Divers échantillons du même genre, xvı et $x^{\mathrm{x}} \mathrm{II}^{\circ}$ siècles.

${ }_{37} 6$ Velours coupé plusieurs corps sur fond tramé or, décor de fleurs et feuillages, Perse, xvie siccle.

$3_{77}$ Divers échantillons du même genre, xv1e et $x{ }^{\mathrm{e}} \mathrm{II}^{\mathrm{e}}$ siècles.

378 Velours ciselé, deux chemins, décor de bandes verticales à feuilles lobées contournées et bordées de rayures verticales ornées, Italie, XVI ${ }^{\circ}$ siccle.

$3_{79}$ Divers échantillons du même genre.

38o Velours ciselé à petit décor géométrique, xvi ${ }^{\mathrm{e}}$ siècle.

381 Divers échantillons du même genre.

382 Type de velours ciselé dit de Gênes, décor de semis de petites floraisons fantaisistes, fin $\mathrm{XVI}^{\mathrm{e}}$ siècle.

383 Divers échantillons du même genre, $\mathrm{xvI}^{\mathrm{e}}$ et $\mathrm{xvII^{ \textrm {e } }}$ siècles.

384 Type de velours à deux hauteurs, décor de floraisons fantaisistes velours ciselé sur fond épinglé, Italie, fin xvie siècle.

385 Divers échantillons du même genre, xvĩ et xvĩ ${ }^{\mathrm{e}}$ siècles.

386 Type de velours ciselé, dit de Gênes, sur fond satin, décor à ordonnance de branchages verticaux sinueux, fleuris et fruités, fin $\mathrm{XVI}^{\circ}$ siicle.

387 Divers échantillons du même genre, $\mathrm{xvI}^{\mathrm{e}}$ et $\mathrm{xv}_{\mathrm{v}} \mathrm{e}^{\mathrm{e}}$ sićcles.

388 Velours ciselé, dit de Gênes, sur fond satin, quatre chemins, décor de branchages feuillés et fleuris à ondulations verticales (la découpure des courbes en sections brisćes est caractéristique de l'époque), fin xvı siècle. 


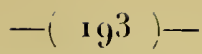

389 Divers échantillons du même genre.

39o Divers échantillons de satin broché à petit décor, semis de branches fleuries et fruitées et de bâtons rompus feuillés, $\mathrm{XvI}^{\mathrm{e}}$ siccle.

39r Collection de tissus satin broché d'or à ordonnance de rayures horizontales décorées, fin de la Renaissance.

392 Collection de tissus, décor à grand meneau et fleuron indépendants, fin xvic siécle.

393 Collection de tissus satin et tramés fil, type de petits meneaux couronnés et fleurons indépendants, fin $\mathrm{Xvi}^{\mathrm{e}}$ sičcle.

394 Tissu tramé or à petit décor vermiculé, fin xvi siècle.

395 Divers échantillons du même genre.

396 Collection de tissus à décor serti sur fond tramé or, type de meneaux enchevêtrés et fleurons, xvie siècle.

397 Tissu satin et trame liée à deux chemins, ordonnance de bandes verticales ornées, $x \mathrm{XI}^{\circ}$ siecle.

398 Divers échantillons du même genre.

399 Tissu satin et trame liée, décor de branches feuillées et fruitées, Xri $I^{e}$ siècle.

400 Divers échantillons du même genre.

4or Type de tissu satin et trame liée, grand décor de meneaux et volutes formant rinceaux, avec bande ornée aux lisières, fin $\mathrm{XvI}^{\mathrm{C}}$ siècle.

402 Divers échantillons du même genre.

403 Tissu satin et trame liée décor de fleurons et d'oiseaux affrontés, fin $\mathrm{Xvi}^{\mathrm{e}}$ siecle.

404 Divers échantillons du même genre.

405 Velours ciselé, dit de Gênes, sur fond satin, décor de branchages 


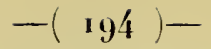

fleuris et fruités formant meneaux couronnés et vase de fleurs au centre, lc tout bordé aux lisières d'une bande ornéc, fin xric siècle.

\{06 Divers échantillons du même genre.

407 Damas décor de tiges feuillées formant meneaux avec vase fleuri au centre, fin $\mathrm{xv}^{\mathrm{e}}$ siècle.

408 Divers échantillons du même genre.

409 Damas deux chemins décor de branchages fleuris formant meneaux avec médaillon silhouetté d'accolades et fleuron central, Italie, xrie siècle.

4 ro Divers échantillons du même genre.

4I Ialmatique grand brocart à boucles d'or, décor à compartiments de velours en accolade, Venise, $x^{\circ} 1^{\circ}$ siècle.

412 Bande satin broché, décor de rinceaux feuillés et fleuris avec personnages au naturel, Italic.

413 Lampas polychromes à grands ramages, Venise, fin $\mathrm{xv}^{\mathrm{e}}$ siècle,

4 I Divers échantillons du même genre.

$4 \times 5$ Chasuble damas, tissu à compartiments décorés et enchevêtrés, fin de la Renaissance.

416 Collection de tissus lattés fil, décor de grands fleurons, fin de la Renaissance.

417 Tissu tramé or avec décor serti, de compartiments mélangés de volutes et d'arabesques, Espagne, $\mathrm{xvI}^{\mathrm{e}}$ siècle.

4 r8 Divers échantillons du même genre.

4 19 Echantillon de velours coupé trois corps à deux hauteurs, décor de branchages fleuris et fruités, formant meneaux avec fleuron central lié d'une banderole à inscription, Espagne, xv1 ${ }^{\mathrm{e}}$ siècle.

420 Bande de velours frisé, décor de meneaux mélangés de volutes avec personnages et animaux au naturel, se détachant sur fond satin. Espagne, xvie siecle. 


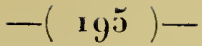

42I Brocart d'or à meneaux d'arabesques, Espagne, Xvı siècle.

422 Collection de brocarts à petits dessins avec parties de longue peluche, Espagne, fin xvie siècle.

423 Divers échantillons de velours ciselé, Espagne, Xvi ${ }^{e}$ siècle.

424 Type de tissu à meneaux, d'arabesques et détails réticulés, Espagne, Xvie siecle.

\{25 Divers échantillons du même genre.

426 Divers échantillons de tissus à petit décor, Espagne, xvie siècle.

427 Divers échantillons de tissus à petit décor mêlé d'armoiries, Espagne, Xrí siècle.

428 Chape et chaperon. La chape de brocart tramé et bouclé or avec dessin serti de velours coupé rouge, décor de meneaux couronnés et armoiries de différentes provinces espagnoles au centre. L'orfroi et le chaperon brodés sur velours cramoisi de figures et d'ornenients en haut relief recouvert de paillettes de vermeil, serrées et liées par des fils de soic. Espagne, xvı siçcle. (Collection Spitzer.)

429 Chape, tissu décor satin jaune sur fond de trame liée crème, type de meneaux à arabesques et de détails réticulés. Les orfrois et le chaperon brodés de saints personnages dans des architectures. Espagne, Xvi ${ }^{\mathrm{e}}$ siecle.

430 Dalmatique, damas à meneaux d'arabesques et bouclés d'or, Espagne, xvi $^{\mathrm{e}}$ siècle.

431 Chasuble, décor à petits dessins de velours frisé avec parties de longue peluche sur fond satin, Espagne, fin xize sicele.

432 Chasuble, décor de meneaux fleuris et fleurons couronnés avec croix brodée de saints personnages, Espagne, fin xrie siècle.

433_Chasuble, velours dit à ferronnerie, décor de rinceaux et de volutes, Venise, xvie siècle, avec croix brodće, travail flamand IVI ${ }^{\mathrm{e}}$ siècle.

431 Chape, décor taffetas crème sur fond sergé, type de grand meneau 


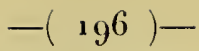

à cordelière et détails réticulés avec le fleuron indépendant, Italie, $\mathrm{Xr}^{\mathrm{e}}$ siècle.

435 Petit manteau d'enfant, tissu lamé or sans envers, décoré d'un semis de petites tiges dentelées dans le goût oriental, fin de la Renaissance.

436 Chasuble, velours ciselé sur fond satin, décor de meneaux et fleurons reliés et couronnés, trois chemins, Gènes, $\mathrm{xv} \mathrm{I}^{\circ}$ siècle.

4337 Chasuble, velours, décor velours coupé sur fond frisé, type de petits meneaux de branchages et d'S enlacés avec le fleuron indépendant surmonté d'une fleur de lis, Florence, commencement du $\mathrm{xvI}^{\mathrm{e}}$ siècle.

438 Chasuble, velours ciselé sur fond lamé or, décor de petits meneaux à fleuron indépendant, Italie avec croix brodéc, travail espagnol, $x_{v i}$ siècle.

439 Collection de tissus fil et soie à grand décor, Allemagne, xv1 ${ }^{\mathrm{e}}$ et $\mathrm{x} v \mathrm{I}^{\mathrm{e}}$ siecles.

440 Collection de tissus fil et soie, décor à meneaux de branches de vigne avec animaux et vase fleuri, $x 1^{\circ}$ siècle.

44r Collection de damassés lattés fil et coton, $x \mathrm{x} 1^{\mathrm{e}}$ sieccle.

$4\{2$ Chape, tissu toile imprimée avec orfroi et chaperon brodés, Allemagne, $\mathrm{xvI}^{\mathrm{e}}$ siècle.

443 Broderie de fils d'or et d'argent sur satin, décor d'S et de volutes formant meneaux enchevêtrés, France, $\mathrm{xvI}^{\mathrm{c}}$ siècle.

444 Broderie application, décor de branches de vigne formant meneau avec animaux adossés et vase fleuri, France, xvıe siècle.

445 Broderie application, décor de rinceaux et d'armoiries, France, xvie siècle.

446 Satin brodé or et soie, France, fin $\mathrm{Xvi}^{\mathrm{e}}$ siècle.

447 Bande brodée or sur velours avec fleur de lis, France, époque de Louis XII. 


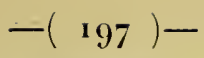

448 Couverture de livre: broderie application sertie d'un cordonnet or sur velours violet avec initiales, France, époque de Henri II.

449 Gouttière de lit, broderie application, décor d'arabesques et de cartouches, France, époque de Henri II.

45o Gouttière de lit, décor application d'arabesques et compartiments, France, Renaissance.

45 I Gouttière de lit, décor, application d'arabesques et de compartiments ornés, France, époque de Henri IV.

452 Panneau de dalmatique, broderie d'or uni, décor à dauphins, France, fin $x \mathrm{xr}^{\mathrm{e}}$ siècle.

453 Bandes brodées à ordonnance de rayures diagonales ornées de rinceaux fleuris, France, ćpoque de Henri II.

454 Deux panneaux de broderie : a) sujet de chasse; b) combat d'animaux sauvages devant la Cour de Henri II (proviennent du château d'Anet, collection Spitzer), France, époque de Henri II.

455 Gouttière de lit, broderie, application velours sur satin, décor d'arabesques et de médaillons. France, Renaissance.

456 Diverses gouttières de lit brodées, $\mathrm{xvI}^{\mathrm{e}}$ et $\mathrm{xvII^{ \textrm {e } }}$ siècles.

457 Diverses broderies application, École française de la Renaissance.

458 Panneau brodé pour dalmatique, représentant « la Cène »; Italie, X're siècle.

459 Broderie fil d'or sur satin, avec fleurs au plumetis, xvic siecle.

46o Bande brodée, application sur velours, Italic, xvıe siécle.

46r Bourse liturgique, broderie au point de satin, rehaussée d'or et d'argent, encadré de satin rose brodé de rinceaux d'or, Florence, $\mathrm{xvI}^{e}$ sieccle. (Don de M. Ed. Aynard.) 


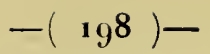

462 Petit chaperon, broderie, application de velours serti or sur drap d'or, Italie, $x v^{c}{ }^{c}$ siècle.

463 Diverses broderies sur satin, décor de rinceaux, Italie, $\mathrm{xvI}^{\mathrm{e}}$ siècle.

464 Panneau de broderie au petit point sur canevas représentant les noces de Cana, travaịl italien de la fin du xvic siècle.

465 Petite enveloppe de livre en tissu espouliné, décor de corbeilles fleuries et d'oiseaux, France, fin xvic siècle.

466 Voile de calice, taffetas rouge, broderie d'application de taffetas crème avec détails au pinceau et serti de fil d'or, France, xvre siècle.

467 Petite enveloppe de boite, brodée d'un cordonnet noué, formant compartiments, décorés de fleurs coupées au plumetis, France, fin $x I^{c}$ siècle.

468 Satin rouge, brodé en or à haut relief, décor de tiges et volutes fleuries formant meneanx, travail anglais de la fin du Xvie siccle.

469 Large bande de velours avec application de satin serti d'un cordonnet, Italie, xvre sićcle.

47o Chaperon, broderie soie et or (Prédication de saint JeanBaptiste), travail flamand du $x^{2} i^{c}$ siècle.

47 Chaperon, broderie soie et or (Prédication de saint Pierre), travail flamand du xrie siècle.

$47^{2}$ Divers échantillons de broderie, Espagne, $\mathrm{xvI}^{\mathrm{C}}$ et $\mathrm{xvII}^{\mathrm{e}}$ sičcles.

473 Diverses bandes velours brodé de fleurons or, Espagne, $\mathrm{xvre}$ siècle.

47ł Mitre, décor représentant diverses scènes de la Passion (curieux travail exécuté en plumes de colibri), Espagne, xvic siècle.

$4\rceil ð$ Parements de brancard de procession, broderie de filigrane d'or sur velours rouge, avec deux panneaux brodés d'or uni, soies polychromes (sujets en l'honneur de saint Jean l'Érangćliste), Espagne, Xvic siècle. 
476 Petit tableau brodé au point de satin rehaussé d'or (le Christ au roseau), travail flamand du xvic siecle.

477 Devant d'autel, broderie d'or uni, soies polychromes avec figures au point de satin, décor de rinceaux et de compartiments encadrant trois sujets représentant : le Baptême, la Prédication et le Martyre de saint Jean-Baptiste, ćcole de Bruges, xrye sičcle. (Don de M. Ed. Aynard.)

478 Velours ciselé sur fond lamé or, décor de rinceaux fleuris et de cornes d'abondance, fin de la Renaissance.

479 Brocatelles tramées fil, fin de la Renaissance.

480 Brocatelles décor de fleurons et volutes avec bandes décorées aux lisières, fin de la Renaissance.

48I Chasuble, tissu tramé fond satin, décor de feuilles contournées. formant meneaux couronnés avec vase fleuri central, (la croix brodée imitation de bouclés vénitiens), fin xrre siècle.

482 Type de damas à grand décor, ramages, amours et fleurs de lis. France, fin de la Renaissance.

483 Voile de calice, taffetas rouge brodé or, France, fin $x_{r y}^{e}$ siécle.

484 Velours ciselé dit de Gênes sur fond satin, quatre chemins, décor de branchages feuilles et fleurs à ondulations verticales (la découpure des courbes en lignes brisées est caractéristique de l'époque), commencement du xvire siècle.

485 Type de tissus tramé. à grandes floraisons ornées de fleurs de lis, France, xvir siècle.

486 Divers échantillons du même genre.

487 Type de velours ciselé dit de Gênes, semis de grandes floraison: fantaisistes sur satin ou fond lamé, commencement du $\mathrm{xrri}^{\mathrm{e}}$ sic̀cle.

488 Divers échantillons du même genre.

489 Tiraz à inscriptions arabes sur ordonnance chevronnée, art arabe, $\mathrm{xvil}^{\mathrm{e}}$ siecle. 
490 Divers échantillons du même genre.

49r Étendard turc en damas de soie, décor exclusif d'inscriptions arabes sur fond bleu et rouge, $\mathrm{xvII}^{\circ}$ siècle.

492 Type de petit damas broché, décor à ordonnance de lignes verticales sinueuses de branchages fleuris et feuillés, commencement du $x \mathrm{xII}^{\mathrm{c}}$ sicele.

$49^{3}$ Divers échantillons du même genre.

494 Type de damas à grand décor surchargé de détails brochés or et argent, à ordonnance de grandes lignes verticales sinueuses, Italie, commencement du xvir siècle.

$49^{5}$ Divers échantillons du même genre.

496 Type de tissu à grand décor surchargé de petits détails fleuris ou conventionnels, mélangé de motifs floraux à grande échelle, dans une ordonnance rappelant le meneau, époque de Louis XIII.

497 Divers échantillons du même genre.

498 Type de velours coupé à décor broché or de petits détails floraux, époque de Louis XIII.

499 Divers échantillons du même genre.

5oo Type broché couleur à grand décor symétrique de branches fleuries, ćpoque de Louis XIII.

5or Divers échantillons du même genre.

502 Taffetas broché à semis de fleurs coupées, époque de Louis XIII.

503 Divers échantillons du même genre.

504 Divers taffetas lattés polychromes à semis de fleurs coupées, époque de Louis XIII.

505 Divers taffetas lisérés, époque de Louis XIII.

506 Diverses brocatelles à grand décor, France, époque de Louis XIII. 


\section{$-(201)-$}

5o7 Bande de velours ciselé dit de Gênes, décor de grands ramages sur fond satin, époque de Louis XIII.

508 Brocart décor à ordonnance de lignes verticales, époque de Louis XIII.

5o9 Divers échantillons du même genre.

5ro Chasuble satin broché or et couleur, décor de feuilles formant meneau avec fleuron indépexdant, Italie, commencement du $\mathrm{XvII}^{\mathrm{e}}$ siècle.

511 Chasuble damas broché argent et couleur du type à ordonnance de lignes verticales sinueuses, surchargées de détails divers, époque de Louis XIII.

512 Chape brocart à ordonnance de lignes verticales sinueuses, surchargées de détails divers, époque de Louis XiII.

5ı3 Type de tissu broché à ordonnance de rayures verticales décorées de branchages fleuris, époque de Louis XIII.

514 Divers échantillons du même genre.

515 Type de satin broché à petit décor de branches fleuries, époque de Louis XIII.

5 6 Divers échantillons du même genre.

$5{ }_{17}$ Divers tissus à petit décor, commencement du $\mathrm{xvII}^{\mathrm{e}}$ siècle.

5 I 8 Divers éshantillons de damassé, commencement du xvir ${ }^{\mathrm{e}}$ siècle.

5ı9 Satin broché couleurs et chenille, décor à personnages et animaux, sujets de chasse et champêtres, Espagne, xvire siècle.

520 Divers échantillons du même genre.

521 Chasuble satin broché or et couleurs à semis de grosses fleurs et rayures verticales sinueuses décorées de branchages fleuris, époque de Louis XIII.

522 Grand panneau brodé soies polychromes et paillettes de l'œuvre 
des anciennes Ursulines d'Amiens, commencement du $\mathrm{x} V \mathrm{II}^{\mathrm{e}}$ siècle.

523 Grand panneau vertical, brodé application satin avec détails au pinceau et serti d'un cordonnet, sur fond taffetas, décor de vases fleuris et de grands ramages de feuilles et volutes encadrantes, France, époque de Louis XIII.

524 Une autre dans le me̊me genre.

525 Voile de calice brodé filigrane décor de fleurs avec monogramme du Christ, Hongrie, commencement du xviı siècle.

526 Chasuble de même travail et faisant partie du même ornement d'église.

527 Chasuble velours rouge brodé or à gros reliefs, Hongrie, époque de Louis XIII.

528 Corporalier broderie de soie et d'or, signé "Pierre Vigier, 1621 ", Ecole lyonnaise.

529 Devant d'autel brodé, décor de grands rinceaux et de compartiments contenant divers tableaux brodés représentant l'Agneau, le Bon Pasteur et la Nativité, travail espagnol, daté de 1618 .

53o Dalmatique: satin blanc avec broderie en haut relief, application satin couleurs sur empreinte estampée de carton, et rehaussé de paillettes et de cordonnet or et argent, Espagne, xvile siècle.

531 Portière de satin bleu brodé, décor de fleurettes, de paons encadrés de rinceaux, le tout dans le goût persan, Venise, xvII ${ }^{\mathrm{e}}$ siècle.

532 Echarpe gaze brodée d'arabesques, Rhodes, xvile siècle.

533 Deux voiles de soie brodés de grandes fleurs fantaisistes, Macédoine, $\mathrm{xvII}^{\circ}$ siècle.

534 Collection de broderies de Karamanie, xvıre et xvıı siècles.

535 Batiste brodée de grandes floraisons fantaisistes, Alger, xvıle siécle.

536 Filet brodé, Rhodes, xvire siècle. 


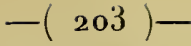

537 Collection d'indiennes imprimées à grandes floraisons fantaisistes, Indes, $\mathrm{xv}_{1 I^{\mathrm{e}}}$ siècle.

538 Deux fragments broderie de soie sur filet et fil tiré, Maroc, $\mathrm{XVII}^{\mathrm{e}}$ siècle.

539 Grande tenture de coton brodée de soie, décor d'arabesques, Indes, $\mathrm{x} v 1 \mathrm{I}^{\mathrm{e}}$ siècle.

54o Grande tenture de coton brodée de soie, fleurs, feuillages et paons, Indes, XvIl ${ }^{\mathrm{e}}$ siècle.

\section{PÉRIODE FRANÇAISE}

La période dite française commence au $\mathrm{xv}^{\mathrm{e}}$ siècle. Elle a été préparée par les efforts successifs de la royauté, soucieuse de la prospérité du pays. Louis XI, François ${ }^{\text {er }}$ et Henri IV sont les principaux promoteurs de lindustrie de la soierie. Dès la fin $d u x{ }^{e}$ siècle, la France, rivale commerciale de l'Italie, subit pourtant encore incontestablement son influence. Il n'en est plus ainsi à partir du moment où Colbert organise définitivement le travail. Désormais la glorieuse Fabrique donnera le ton au reste du monde. La grande innovation qui caractérisera les nouveaux tissus sera l'interprétation réaliste de la flore représentée par le modelé des ombres et des lumières remplaçant les à-plat exclusivement employés jusque-là. Les styles Louis XIV, Louis XV et Louis XVI exploitent principalement la forme florale; l'évolution débute par la recherche du pompeux et du grand, destinés à servir de cadre à la majesté du trône que le Roi-Soleil amènera à son plus haut poinl. Avec Louis XV c'est l'élégance qui prédomine, les proportions des détails décoratifs diminuent. Sous Louis XVI enfin, les mêmes éléments ornementaux deviennent jolis, minces, avec toutefois la plus grande perfection de bon goût et de bonne façon. En résumé, les détails déco- 


\section{$-(204)-$}

ratifs donnent l'impression du plus grand que nature sous Louis XIV, de grandeur nature sous Louis XV, et du plus petit que nature sous Louis XVI. Sous Louis XVI, en outre, aux éléments floraux, tendront à se joindre des ornements conventionnels pris à l'antique, et consécutivement on fera dans la composition une part plus considérable aux lignes architectoniques.

Louis $X I V$. - L'on peut diviser le règne de Louis XIV en trois parties : $x^{\circ}$ pendant sa minorité c'est encore l'art italien qui s'impose; les tissus sont ceux que nous avons classés sous la rubrique Louis XIII. Le décor est surchargé de détails grands et petits amenant la confusion $; 2^{0}$ une fois organisée par Colbert, la Fabrique s'affranchit de toute influence étrangère. A la profusion suceède la clarté dans l'ordonnance, et le réalisme dans l'expression. La flore est presque exclusivement employée. En général, elle se détache sur des fonds unis, énorme, prenant toute l'importance $; 3^{\circ}$ peu à peu le semis s'éclaircira et au commencement du xvir ${ }^{\mathrm{e}}$ siècle les fonds qui s'armurent concourront également à la richesse de l'étoffe, tandis que les détails tendront à des proportions moins volumineuses.

541 Damas grand décor à pointe de motifs foliacés, France, époque de Louis XIV.

5 \2 Divers échantillons du même genre.

5̆33 Damas grand décor à pointe de motifs foliacés mélangés d'ornement conventionnels, France, époque de Louis XIV.

544 Divers échantillons du même genre.

545 Type de brocatelle grand décor à pointe de motifs foliacés, France, époque de Louis XIV.

546 Divers échantillons du même genre.

547 Type de brocatelle grand décor à pointe de motifs foliacés, 


\section{$-(205)-$}

mélangés d'ornements conventionnels, France, époque de Louis XIV.

548 Type de tissu fond coton, décor à pointe de grands motifs foliacés mélangés d'ornements conventionnels, France, époque de Louis XIV.

549 Divers échantillons du même genre.

55o Lampas polychrome, décor dit Berain, France, fin Louis XIV.

55. Divers échantillons du même genre.

552 Damas à grands ramages sans disposition symétrique, France, époque de Louis XIV.

553 Divers échantillons du même genre.

554 Type de lampas polychrome, grand décor à pointe de motifs floraux et fantaisistes, Italie, fin $\mathrm{du} \mathrm{xvII}^{\mathrm{e}}$ siècle.

555 Divers échantillons du même genre.

556 Type de damas broché à grand décor floral, disposition à pointe (tissu dit tissu d'église), France xvir ${ }^{\mathrm{e}}$ siècle.

557 Divers échantillons du même genre.

558 Velours ciselé grand décor à pointe de grosses floraisons sur fond brodé de perles (château de Nancy), Gènes, xviı siècle.

559 Type de velours ciselé grand décor à pointe de motifs foliacés mélangés d'ornements conventionnels, Gênes, $\mathrm{xvII}^{\mathrm{e}}$ siècle,

560 Divers échantillons du même genre.

56r Velours ciselé polychrome, grand décor à pointe de grosses fleurs, Gênes, $\mathrm{xv1I^{ \textrm {e } }}$ siècle.

562 Divers échantillons du même genre.

563 Velours ciselé sur fond satin, décor dit Berain, France, fin du $\mathrm{xv}_{11}^{\mathrm{e}}$ siècle.

564 Divers échantillons du même genre. 


\section{$-(206)-$}

565 Drap d'or broché matelassé sur fond cordonnet, grand décor de bouquet nués, $\mathrm{xvil}{ }^{\mathrm{C}}$ siècle.

566 Type de tissu broché soies polychromes sur fond uni, décor de grandes floraisons réalistes, Lyon, époque de Colbert.

567 Divers échantilions du même genre avec ou sans métal.

568 Type de tissu broché soies polychromes sur fond uni, décor de gros fruits, Lyon, époque de Colbert.

569 Divers échantillons du même genre avec ou sans métal.

570 Type de tissu broché sur fond uni, décor de grosses fleurs et de gros fruits mélangés, Lyon, époque de Colbert.

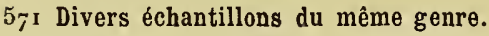

572 Type de tissu broché sur fond uni, décor de grosses floraisons réalistes et de jardins, Lyon, époque de Colbert.

573 Divers échantillons du même genre.

574 Type de tissu broché sur fond uni, décor de grosses floraisons réalistes et de paysages fantaisistes avec ruines, Lyon, époque de Colbert.

$5_{75}$ Divers échantillons du même genre.

$5_{7} 6$ Type de tissu broché sur fond uni, décor de grosses floraisons réalistes avec architectures, Lyon, époque de Colbert.

577 Divers échantillons du même genre.

578 Type de tissu broché sur fond uni, décor de vase surmonté de grosses fleurs, Lyon, époque de Colbert.

579 Divers échantillons du même genre.

580 Type de tissu broché sur fond uni, décor de grosses fleurs ou de gros fruits et de coquillages, Lyon, époque de Colbert.

58I Divers échantillons du même genre.

582 Type de tissu broché sur fond uni, décor de grosses fleurs dans une 


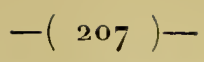

ordonnance de bandes verticales sinueuses ornées de passements figurés. Lyon, époque de Louis XIV.

583 Divers échantillons du même genre.

584 Type de tissu broché sur fond uni, décor de grosses floraisons réalistes reliées par des détails de passements figurés, Lyon, époque de Louis XIV.

585 Divers échantillons du même genre.

586 Type de tissu broché sur fond uni, décor à pointe de grandes floraisons réalistes, Lyon, époque de Colbert.

587 Divers échantillons du même genre.

588 Type de tissu sur fond uni, décor à pointe de gros fruits, Lyon, époque de Colbert.

589 Divers échantillons du même genre.

5go Type de tissu broché sur fond uni, décor à pointe de grosses floraisons et de jardins, Lyon, époque de Colbert.

59 r Divers échantillons du même genre.

592 Type de tissu broché sur fond uni, décor à pointe de grosses floraisons réalistes et de paysages fantaisistes avec ruines, Lyon, époque de Colbert.

593 Divers échantillons du même genre.

594 Type de tissu sur fond uni, décor à pointe de grosses floraisons réalistes avec architectures, Lyon, époque de Colbert.

595 Divers échantillons du même genre.

596 Type de tissu broché sur fond uni, décor à pointe de vases avec bouquets de grosses fleurs, Lyon, époque de Colbert.

$5 y 7$ Divers échantillons du même genre.

598 Type de tissu broché sur fond uni, décor à pointe de grosses fleurs et de gros fruits mélangés, Lyon, époque de Colbert. 
599 Divers échantillons du même genre.

6oo Type de tissu broché sur fond uni, décor à pointe de grosses fleurs dans une ordonnance de bandes verticales sinueuses de passements figurés, Lyon, époque de Louis XIV.

6or Divers échantillons du même genre.

602 Type de tissu broché sur fond uni, décor à pointe de grosses fleurs, de gros fruits et de coquillages, Lyon, époque de Louis XIV.

603 Divers échantillons du même genre.

604 Type de tissu broché sur fond uni, décor à pointe de grosses floraisons réalistes reliées par des détails de passements figurés, Lyon, époque de Louis XIV.

605 Divers échantillons du même genre.

606 Type de tissu broché sur fond armuré, décor de grandes floraisons réalistes, Lyon, fin du règne de Louis XIV.

607 Divers échantillons du même genre.

608 Type de tissu broché sur fond armuré, décor de gros fruits, Lyon, fin du règne de Louis XIV.

609 Divers échantillons du même genre.

61 Type de tissu broché sur fond armuré, décor de grosses floraisons réalistes et de jardins, Lyon, fin du règne de Louis XIV.

6I I Divers échantillons du même genre.

612 Type de tissu broché sur fond armuré, décor de grosses floraisons réalistes et de paysages fantaisistes avec ruines, Lyon, fin du règne de Louis XIV.

6.3 Divers échantillons du même genre.

614 Type de tissu broché sur fond armuré, décor de grosses floraisons réalistes avec architectures, Lyon, fin du règne de Louis XIV. 


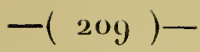

615 Divers échantillons du même genre.

6.6 Type de tissu broché sur fond armuré, décor de vases avec bouquets de grosses fleurs, Lyon, fin du règne de Louis XIV.

$6{ }_{17}$ Divers échantillons du même genre.

618 Type de tissu broché sur fond armuré, décor de grosses fleurs et de gros fruits mélangés, Lyon, fin du règne de Louis XIV.

619 Divers échantillons du même genre.

620 Type de tissu broché sur fond armuré, décor de grosses fleurs dans une ordonnance de bandes verticales sinueuses de passements figurés, Lyon, fin du règne de Louis XIV.

62I Divers échantillons du même genre.

622 Type de tissu broché sur fond armuré, décor de grosses fleurs ou de gros fruits et de coquillages, Lyon, fin du règne de Louis XIV.

623 Divers échantillons du même genre.

624 Type de tissu broché sur fond armuré, décor de grosses floraisons réalistes reliées par des détails de passements figurés, Lyon, fin du règne de Louis XIV.

625 Divers échantillons du même genre.

626 Type de tissu broché sur fond armuré, décor à pointe de grandes floraisons, Lyon, fin du règne de Louis XIV.

627 Divers échantillons du même genre.

628 Type de tissu broché sur fond armuré, décor à pointe de gros fruits, Lyon, fin du règne de Louis XIV.

629 Divers échantillons du même genre.

63o Type de tissu broché sur fond armuré, décor à pointe de grosses floraisons réalistes et de jardins, Lyon, fin du règne de Louis XIV.

63. Divers échantillons du même genre. 


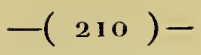

63. Type de tissu broché sur fond armuré, décor à pointe de grosses floraisons réalistes et de paysages fantaisistes avec ruines, Lyon, fin du règne de Louis XIV.

633 Divers échantillons du même genre.

634 Type de tissu broché sur fond armuré, décor à pointe de grosses floraisons réalistes avec architectures, Lyon, fin du règne de Louis XIV.

635 Divers échantillons du même genre.

636 Type de tissu broché sur fond armuré, décor à pointe de vases avec bouquet de grosses fleurs, Lyon, fin du règne de Louis XIV.

637 Divers échantillons du même genre.

638 Type de tissu broché sur fond armuré, décor à pointe de grosses fleurs et gros fruits mélangés, Lyon, fin du règne de Louis XIV.

639 Divers échantillons du même genre.

6 fo Type de tissu broché sur fond armuré, décor à pointe de grosses fleurs dans une ordonnance de bandes verticales sinueuses de passements figurés, Lyon, fin du règne de Louis XIV.

64r Divers échantillons du même genre.

642 Type de tissu broché sur fond armuré, décor à pointe de grosses fleurs ou de gros fruits et de coquillages, Lyon, fin du règne de Louis XIV.

643 Divers échantillons du même genre.

644 Type de tissu broché sur fond armuré, décor à pointe de grosses fleurs réalistes reliées par des détails de passements figurés, Lyon, fin du règne de Louis XIV.

645 Divers échantillons du même genre.

646 Galons de livrée à décor d'armoiries, Espagne, xvIle siècle. 
647 Collection de velours frappés, Flandre, XviI ${ }^{\mathrm{e}}$ siècle.

648 Collection de tissus imprimés, Allemagne, xvı1 ${ }^{\mathrm{e}}$ siècle.

649 Collection de tissus imprimés, Angleterre, xvıre siècle.

650 Collection de tissus à petit décor, Espagne, $\mathrm{xvII}{ }^{\mathrm{e}}$ siècle.

65r Petit lambrequin, fond satin rouge, brodé à haut relief, décor conventionnel avec glands, France, xvire siècle.

652 Bande de drap feutré, brodée à haut relief de rinceaux fantaisistes, France, xvile siècle.

653 Chape, damas blanc lyonnais de l'époque de Louis XIV, avec orfroi brodé de saints personnages et chaperon brodé représentant la Résurrection, travail espagnol du $\mathrm{xvII}^{\mathrm{e}}$ siècle.

654 Chape, tissu broché or et couleurs, décor à pointe de grosses floraisons, Lyon, époque de Louis XIV.

655 Chasuble, tissu laine or, brodée de rinceaux sertis or, avec détails au pinceau et fleurs au plumetis, travail français, époque de Louis XIV.

656 Chasuble, tissu côtelé, brodé de grosses fleurs au plumetis, avec croix brodée à haut relief d'ornements conventionnels, disposition à pointe, travail français, époque de Louis XIV.

657 Chasuble, brocart décor baroque de fabrication italienne, avec croix brodée or et argent à haut relief, décor d'ornements conventionnels, disposition à pointe, travail français, époque de Louis XIV.

658 Chasuble, broderie à haut relief, décor polychrome de fleurs et rinceaux, France, époque de Louis XIV.

659 Bordure de dais, damassé brodé de branches fleuries avec figures découpées et ajustées représentant la Vierge, saint Pierre et saint Paul, travail français du $\mathrm{xvII}^{\mathrm{e}}$ siècle.

66o Pennon de corporation, toile brodée or et soies polychromes, décor d'armoiries à l'écu de France, aux armes du Dauphin et à celles 
de diverses corporations de drapiers, semis de bouquets et invocation au roi, travail français, époque de Louis XIV.

66r Grand panneau brodé de fleurs, d'arabesques et d'oiseaux sur fond quadrillé, travail espagnol du xvir ${ }^{\mathrm{e}}$ siècle.

662 Baldaquin, broderie laines polychromes sur canevas, travail français, époque de Louis XIV.

663 Diverses broderies du même genre.

664 Deux panneaux de broderie sur canevas, travail rhénan du $\mathrm{XVII}^{\mathrm{e}}$ siècle.

665 Médaillon brodé, cannelé, uni, avec une des figures au point de satin (la Pentecôte), France, époque de Louis XIV.

666 Médaillon brodé or uni couleurs avec nus des figures an point de satin (les disciples à Emmaüs), France, époque de Louis XIV.

667 Médaillon brodé or uni couleurs, avec nus des figures au point de satin (Arrestation de Saint-Pierre), France, époque de Louis XIV.

668 Divers brodequins brodés application, France, époque de Louis XIV.

669 Satin blanc brodé application de velours polychrome serti d'un cordonnet, décor de vases fleuris, couronnés d'un baldaquin, France, fin du règne de Louis XIV.

670 Diverses collections de tissus orientaux du xvII ${ }^{e}$ siècle.

67 I Diverses collections de broderies orientales du $x{ }^{\mathrm{e}}{ }^{\mathrm{e}}$ siècle.

Louis $X \boldsymbol{V}$. Régence. - La régence continue l'évolution : diminution de l'échelle des ornements, richesse des fonds. L'art s'égaie de plus en plus.

672 Type de tissu broché or, argent et soies polychromes sur fond armuré, décor à ordonnance de lignes verticales ornées de 


\section{$-(213)-$}

grosses floraisons réalistes et de petits paysages fantaisistes, Lyon, Régence.

673 Divers échantillons du même genre.

674 Type de tissu à ordonnance de lignes verticales sinueuses à grosse flore réaliste, Régence.

675 Divers échantillons du même genre.

676 Tissu broché or, argent et soies polychromes, semis de vases rocaille, avec semis de grosses fleurs, Lyon, Régence.

677 Divers échantillons du même genre.

678 Type de tissu broché or et soies polychromes, décor à pointe à ordonnance de semis de grosses floraisons réalistes, Lyon, Régence.

679 Divers échantillons du même genre.

68o Type de tissu broché soies polychromes, décor de fleurs et de fruits, Lyon, Régence.

68r Divers échantillons du même genre.

682 Type de tissu broché soies polychromes, décor de flore et de détails d'architecture, Lyon, Régence.

683 Divers échantillons du même genre.

684 Type de tissu broché soies polychromes, décor de vases fleuris, Lyon, Régence.

685 Divers échantillons du même genre.

686 Type de tissu broché soies polychromes, décor de fleurs et coquillages, Lyon, Régence.

687 Divers échantillons du même genre.

688 Type de tissu broché, soies polychromes, décor de fleurs et de détails de passements figurés, Lyon, Régence. 


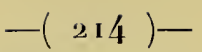

689 Divers échantillons du même genre.

6go Type de lampas polychrome à grand décor floral, Italie, commencement du $\mathrm{XvII}^{\mathrm{e}}$ siècle.

69r Divers échantillons du même genre.

692 Type de damas à grand décor, sans disposition symétrique, Régence.

693 Divers échantillons du même genre.

694 Type de damas à grand décor à pointe, Régence.

695 Divers échantillons du même genre.

696 Type de brocatelle, disposition à pointe, Régence.

697 Divers échantillons du même genre.

698 Divers bas de robe, tissu broché or et couleurs sur fond façonné, Lyon, Régence.

699 Chaise à porteur, décorée de peintures, de l'école de Berain et garnie de velours de Gênes, Régence.

700 Divers petits tissus à personnages dans le goût de Callot, époque de Louis XV.

La majorité de Louis $X V$. - Le détail floral prend des proportions nature. L'ordonnance caractéristique sera la ligne verticale sinueuse indiquée par des éléments divers et semée de bouquets. Pour la reine Marie Leczinska, on introduira des fourrures dans la composition. $\mathbf{M}^{\mathrm{me}}$ de Pompadour mettra les chinoiseries à la mode. A la fin du règne, la ligne verticale sinueuse, au lieu d'être traitée à part, se relie aux bouquets, el la composition ne présente plus que des éléments floraux.

$7^{0}$ I Type de tissu broché sur fond armuré, décor à ordonnance de lignes verticales sinueuses rubanées, semées de bouquets, Lyon, époque de Louis XV. 


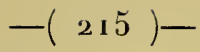

702 Divers échantillons du même genre.

7o3 Type de tissu broché sur fond armuré, décor à ordonnance de lignes verticales sinueuses de dentelles figurées, semées de fleurs, I.yon, époque de Louis XV.

704 Divers échantillons du même genre.

705 Type de tissu broché sur fond armuré, décor à ordonnance de lignes verticales sinueuses de fourrures figurées, semées de fleurs. L'introduction de fourrures dans l'ornement des tissus estun souvenir du pays d'origine de la reine Marie Leczinska, Lyon, époque de Louis XV.

$7^{06}$ Divers échantillons du même genre.

$7^{07}$ Type de tissu broché sur fond armuré, décor à ordonnance de lignes verticales sinueuses de passements or ou argent figurés, semés de fleurs, Lyon, époque de Louis XV.

708 Divers échantillons du même genre.

$7^{\circ 9}$ Type de tissu broché sur fond armuré, décor à ordonnance de lignes verticales sinueuses rubanées et ornées de petits détails floraux, avec bouquets de fleurs au naturel, Lyon, époque de Louis XV.

710 Divers échantillons du même genre.

71 1 Type de tissu broché sur fond armuré, décor à ordonnance de lignes verticales sinueuses et de détails floraux or et argent, Lyon, époque de Louis XV.

712 Divers échantillons du même genre.

713 Type de tissu broché sur fond armuré, décor à ordonnance de lignes verticales sinueuses contrariées et formant compartiments ornés de fleurs, Lyon, époque de Louis XV. (On retrouve dans ce type les mêmes détails de bandes sinueuses que plus haut, dentelles, passements, fourrures, ete.)

714 Divers échantillons, du même genre.

715 Type de tissu broché sur fond armuré, décor à ordonnance de lignes 


\section{$-(2.6)-$}

verticales sinueuses de branches feuillées, fleuries ou fruitées, Lyon, fin Louis XV.

$7_{16}$ Divers échantillons du même genre.

717 Type de tissu broché sur fond armuré, décor à ordonnance de lignes verticales sinueuses de branches feuillées, fleuries ou fruitées, mélangées de bouquets, Lyon, fin Louis XV.

718 Divers échantillons du même genre.

719 Type de tissu broché sur fond armuré, décor floral exclusif, à ordonnance de lignes verticales sinueuses contrariées formant compartiments, Lyon, fin Louis XV.

720 Divers échantillons du même genre

72. Type de tissu broché sur fond armuré, décor à ordonnance de lignes verticales sinueuses avec personnages et paysages fantaisistes, Lyon, fin Louis XV.

722 Divers échantillons du même genre.

723 Type de tissu broché sur fond armuré, décor à ordonnance de lignes verticales sinueuses contrariées et formant compartiments, dispositions à pointe, Lyon, époque de Louis XV.

724 Divers échantillons du même genre.

725 Type de tissu broché sur fond armuré, décor à ordonnance de lignes horizontales sinueuses de tiges fleuries, Lyon, fin Louis XV.

726 Divers échantillons du même genre.

727 Type de tissu broché sur fond armuré avec détails floraux interprétés de l'École de Pillement1, Lyon, époque de Louis XV.

728 Divers échantillons du même genre.

729 Type de tissu broché sur fond armuré, décor à ordonnance de semis de détails floraux, Lyon, époque de Louis XV.

1 Le Musée possède de nonbreux dessins et ètudes des Pillement. 
730 Divers échantillons du même genre.

${ }_{73}$ r Type de tissu broché sur fond uni (on retrouve tous les détails des ordonnances précédentes sur ces fonds unis pour des tissus de moindre valeur), époque de Louis XV.

732 Divers échantillons du même genre.

733 Type de tissu broché sur fond moire (e'est sous Louis XV qu'apparait la moire); Lyon, époque de Louis XV.

734 Divers échantillons du même genre.

735 Tissu broché en grande largeur, décor du type à ordonnance de lignes verticales sinueuses rubanées, avec paysage mythologique (spécimen connu sous le nom de "Voyage à Cythère ", composition de Jean Revel (1684"1 $\left.7^{5} \mathrm{r}\right)$.

736 Tissu de robe pour Madame de Pompadour, drap d'or et d'argent broché soies polychromes, du type à ordonnance de lignes verticales sinueuses contrariées et formant compartiments, ceux-ci décorés aux emblèmes de la favorite, Lyon, époque de Louis XV.

${ }_{73} 7$ Type de tissu broché or et soies polychromes, décor à ordonnance de lignes verticales sinueuses, de feuillages fantaisistes contournés, fabrication italienne de l'ćpoque de Louis XV.

738 Divers échantillons du même genre.

739 Type de tissu broché soie et or à décor chinois, Lyon, époque de Louis XV.

740 Divers échantillons du même genre.

741 Type de tissu broché soies polychromes à décor chinois, Lyon, époque de Louis XV.

7.12 Type de bas de robe tissu broché or et soie, décor de bouquets et de rocailles, Lyon, époque de Louis $\mathrm{XV}$.

743 Divers échantillons du même genre. 


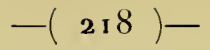

744 Tissu pour robe, décor à ordonnance de semis avec ornement indépendant de la partie inférieure, Lyon, époque de Louis XV.

7/5 Divers échantillons du même genre.

746 Type de bas de robe, tissu broché, décor de détails floraux, Lyon, époque de Louis XV.

747 Divers échantillons du même genre.

748 Type de damas, décor à ordonnance de lignes verticales sinueuses à grosse flore, époque de Louis XV.

749 Divers échantillons du même genre.

75o Type de damas grand décor à pointe de flore mélangée d'ornements conventionnels, époque de Louis XV.

7วัı Divers échantillons du même genre.

7ð̌2 Type de tissu broché or et soie à décor baroque, Italie, époque de Louis XV.

$7_{753}$ Divers échantillons du même genre.

754 Brocart à personnages mythologiques, Venise, époque de Louis XV.

755 Divers échantillons du même genre.

756 Type de tissu broché soies polychromes, décor baroque à détails chinois, Italie, époque de Louis XV.

$7^{5} 7$ Divers échantillons du même genre.

7õ Tissu broché or et argent sur fond lamé argent, décor à ordonnance de lignes verticales sinueuses et personnages rappelant les courses de taureaux, Espagne, époque de Louis XV.

759 Divers échantillons du même genre.

$7^{60}$ Type de tissus lattés apprêtés et cylindrés, décor dans le goût oriental, fabrication polonaise du $\mathrm{xvm}^{\mathrm{C}}$ siccle.

76r Divers échantillons du même genre. 


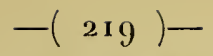

762 Divers échantillons de fabrication espagnole et des Pays-Bas, de l'époque de Louis XV.

763 Divers échantillons de fabrication allemande, de l'époque de Louis XV.

$7_{6} 6$ Divers tissus brochés chenille (la chenille est employée pour la première fois sous Louis XV; on la rencontre seule ou jointe aux autres soies polychromes dans les diverses ordonnances des tissus brochés), Lyon, époque de Louis XV.

765 Satin broché tout chenillé soies polychromes grand décor à chinoiseries (ameublement), Lyon, époque de Louis XV.

$7_{66}$ Diverses collections de tissus à petit décor, époque de Louis $\mathrm{XY}$.

${ }_{767}$ Collection d'échantillons de tissus, de l'époque de Louis $\mathrm{XV}$, de la fabrique Dechazelle (ancien fonds Lemire).

768 Chasuble satin violet broché soies polychromes à décor chinois, époque de Louis XV.

769 Une chape brocart à décor baroque, de fabrication ilalienne, époque de Louis XV.

$77^{\circ}$ Diverses chapes et chasubles en tissu façonné, de l'époque de Louis XV.

77r Diverses collections de tissus orientaux, du commencement du xviri ${ }^{\circ}$ siccle.

$77^{2}$ Diverses collections de broderies orientales, du commencement du xviri ${ }^{e}$ siècle.

Louis XVI. - Sous Louis XVI, le détail décoratif devient plus petit que nature. L'ordonnance caractéristique sera la ligne verticale rigide, semée de fleurettes et d'accessoires divers. Dans l'ameublement, grâce aux fouilles actives de Pompéi et d'Herculanum, certaines compositions s'inspirent de l'antique. Sous Louis XVI, à côté de l'art évideınment 


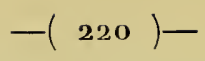

mièvre de l'époque, resplendit l'œuvre de Philippe de la Salle, grand artiste et grand industriel lyonnais dont la production est géniale et personnelle.

773 Type de tissu broché sur fond armuré, décor à ordonnance de lignes verticales rigides, semées de fleurettes, Lyon, époque de Louis XVI.

774 Divers échantillons sur fond uni ou armuré.

$77^{5}$ Type de tissu broché sur fond armuré, décor à ordonnance de lignes verticales rigides avec semis d'accessoires lyriques ou champêtres, Lyon, époque de Louis XVI.

${ }_{776}$ Divers échantillons sur fond uni ou armuré.

777 Type de tissu broclé sur fond armuré, décor à ordonnance de lignes verticales rigides, ornées de médaillons, Lyon, époque de Louis XVI.

$77^{8}$ Divers échantillons sur fond uni ou armuré.

779 Type de tissu broché sur fond armuré, décor à ordonnance de lignes verticales rigides avec bouquets et guirlandes diagonales, Lyon, époque de Louis XVI.

780 Divers échantillons sur fond uni ou armuré.

78، Type de tissu broché sur fond armuré avec semis de bouquets et de guirlandes, Lyon, époque de Louis XVI.

782 Divers échantillons sur fond uni ou armuré.

783 Type de tissu broché sur fond armuré, décor de semis de fleurettes et d'accessoires divers, Lyon, époque de Louis XVI.

784 Divers échantillons du même genre sur fond uni ou armuré.

785 Type de tissu broché sur fond armuré, décor de semis de fleurettes, Lyon, époque de Louis XVI.

786 Divers échantillons sur fond uni ou armurée. 


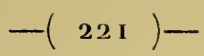

$7^{8} 7$ Type de tissu broché sur fond armuré, décor de rubans noués ou ondulants, Lyon, époque de Louis XVI.

788 Divers échantillons du même genre sur fond uni ou armuré.

789 Collection de tissus brochés sur fonds pékinés, Lyon, époque de Louis XVI.

$79^{\circ}$ Type de tissu broché sur fond armuré, décor de lignes verticales rigides, avec lignes verticales sinueuses, ornées de fleurettes, Lyon, époque de Louis XVI.

791 Divers échantillons du même genre, sur fond uni ou armuré.

792 Diverses collections de velours miniature du type à petit décor velours coupé polychrome, Lyon, époque de Louis XVI.

$79^{3}$ Diverses collections de velours miniature du type à petit décor velours coupé sur fond armuré, Lyon, époque de Louis XVI.

794 Diverses collections de velours miniature du type à petit décor velours frisé polychrome, Lyon, époque de Louis IVI.

$79^{5}$ Diverses collections de velours miniature du type à petit décor velours frisé polychrome sur fond armuré, Lyon, époque de Louis XVI.

$79^{6}$ Diverses collections de velours miniature du type à petit décor velours ciselé polychrome, Lyou, époque de Louis XVI.

797 Diverses collections de velours miniature du type à petit décor ou velours ciselé polychrome sur fond armuré, Lyon, époque de Louis XVI.

$79^{8}$ Diverses collections de velours miniature pour voitures et chaises à porteur, époque de Louis XVI. Dans ces velours, les sujets toujours de petites dimensions, présentent la plus grande fantaisie. On y rencontre également les personnages, les animaux, les accessoires de toutes sortes, les armoiries, la flore réaliste et l'ornement conventionnel.

799 Velours miniature pour voitures et chaises à porteur, fabrication espagnole de l'époque de Louis XVI. 
8 oo Diverses collections de tissus à petit décor sans effet de poil, époque de Louis XVI.

8or Diverses collections de tissus à petit décor avec effet de poil (dit droguet), d'invention lyonnaise, époque de Louis XVI.

802 Type de tissu de soie à décor imprimé, fin Louis XVI. (Jusqu'en I 78 , les tissus imprimés étajent interdits en France.)

803 Divers échantillons du même genre.

804 Diverses collections de toiles de Jouy à décor imprimé de l'époque de Louis XVI.

8o5 Divers échantillons de tissus brochés, soies polychromes sur fond armuré, et fabriqués spécialement pour petits gilets (décor de petits personnages), Lyon, époque de Louis XVI.

806 Type de tissus d'ameublement, à dẻcor broché, mélangé de chiné.

807 Divers échantillons du même genre.

So8 Divers échantillons de tissus de costume à décor broché et chiné.

809 Type de lampas, décor dans le goût de Pompéi, Lyon, époque de Louis XVI.

8ı Divers échantillons du même genre.

8r r Type de lampas, décor imité de Pompéi, disposition à pointe, Lyon, époque de Louis XVI.

8 r2 Divers échantillons du même genre.

8.3 Lampas, décor de chinoiserie avec semis se rapportant au travail de la soie, Lyon, époque de Louis XVI.

814 Types de damas, décor dans le goût de Pompéi, Lyon, époque de Louis XVI.

815 Divers échantillons du même genre.

8 I 6 Type de damas à décor dans le goût de Pompéi, disposition à pointe, Lyon, époque de Louis XVI. 


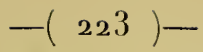

8I 7 Divers échantillons du même genre.

818 Type de lampas avec parties brochées soies polychromes (dans ces tissus d'ameublement, le décor du lampas est généralement à pointe et les parties brochées pittoresques), Lyon, époque de Louis XVI.

8 ıg Divers échantillons du même genre.

820 Type de damas avec parties brochées soies polychromes (dans ces tissus d'ameublement, le décor du damas est généralement à pointe et les parties brochées pittoresques), Lyon, époque de Louis XVI.

82. Divers échantillons du même genre.

822. Type de tissu dit chiné à la branche, grand décor d'ameublement, Lyon, époque de Louis XVI.

823 Divers échantillons du même genre.

824 Collection de tissus de costumes chinés à la branche, Lyon, époque de Louis XVl.

825 Bande de tissus brochés sur fond cannetillé, décor de fleurs réalistes et de gros rinceaux conventionnels (ameublement de la salle de musique du petit Trianon), Lyon, époque de Louis XYI.

826 Diverses bandes de tissu d'ameublement décor de flore réaliste, Lyon, époque de Louis XVI.

${ }_{27}$ Diverses bandes de tissu broché d'ameublement, décor de flore réaliste et d'ornements conventionnels, Lyon, époque de Louis XVI.

828 Diverses bandes de tissus dits chinés à la branche. Lyon, époque de Louis XVI.

829 Collection d'échantillons de tissus, de l'époque de Louis XYI, provenant de l'aneienne maison Dechazelle (fonds Lemire).

83o Tissu décoré aux emblèmes des trois ordres, Lyon, fin Louis X'll. 


\section{$-(224)-$}

83r Une robe de cour, de l'époque de Louis XVI.

832 Diverses chapes en tissu broché, de l'époque de Louis XVI.

833 Dalmatique, tissu broché sur fond armuré du type à ordonnance de lignes verticales rigides avec tiges verticales sinueuses feuillées et fleuries, Lyon, époque de Louis XVI.

834 Philippe de la Salle 1 : Lampas bleu et crème avec petits médaillons brochés soies polychromes, ornés de canards, de coqs et de chiens, Lyon, époque de Louis XVI.

835 Philippe de la Salle : Tissu de siège, décor au panier fleuri broché soies polychromes sur fond cannetillé, Lyon, époque de Louis XVI.

836 Philippe de la Salle : Deux tissus de siège, décor au faisan, $a, b$, Lyon, époque de Louis XVI.

837 Philippe de la Salle : Tissu de siège avec médaillon broché soies polychromes (aux emblèmes de la fidélité), Lyon, époque de Louis XVI.

838 Philippe de la Salle : Satin broché, soies polychromes, décor de ramier et de paniers fleuris, Lyon, époque de Louis XVI.

839 Philippe de la Salle : Satin broché soies polychromes et chenille, décor au paon (panneau alternant aree celui dit au faisan), Lyon, époque de Louis XYr.

840 Lampas polychrome, décor dit aux pandours de Marie-Thérèse, Lyon, époque de Louis IVI.

84r Lampas décoré d'amours et de fleurs dans le goût de Clodion, Lyon, époque de Louis XVI.

S42 Philippe de la Salle : Médaillon pour siège, décor à la perdrix Lyon, époque de Louis XVl.

843 Philippe de la Salle : Gros de Tours broché soies polychromes, décor dans le goût de Pompéi, Lyon, époque de Louis XVI.

1 Voir dans lintroduction la notice sur Philippe de la Salle, p. 12. 


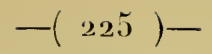

844 Bordure accompagnant le précédent, Lyon, époque de Louis XYI.

845 Philippe de la Salle : Satin jaune à bandes verticales crème, de lignes rigides décorées, avec médaillons décorés de ramiers, broché soies polychromes, Lyon, période de Louis XVI.

846 Philippe de la Salle: Tissu broché soies polychromes sur fond armuré, décor au panier fleuri, avec couronnes, guirlandes et rubans, Lyon, époque de Louis XVI.

847 Philippe de la Salle : Satin broché soies polychromes, composition dite à la perdrix, Lyon, époque de Louis XVI.

848 Philippe de la Salle: Satin broché soies polychromes, avec médaillon de la Grande Catherine, encadré de fleurs, Lyon, époque de Louis XVI.

849 Deux médaillons, portrait de la Cour impériale de Russie, alternant dans le décor précédent, Lyon, époque de Louis XVI.

85o Philippe de la Salle : Satin broché soies polychromes, décor à l'aigle impériale russe avec trophées de guerre; grande écharpe bleue formant compartiments avec cordelières et guirlandes (fait pour la Grande Catherine de Russie), Lyon, époque de Louis XVI.

85̃ ^ Philippe de la Salle : Lampas broché soies polychromes, décor de fruits, de bouquets et de guirlandes, l.yon, époque de Louis XVI.

852 Philippe de la Salle : Gros de Tours broché soies polychromes, décor de ramiers, d'accessoires de musique, de paniers fleuris et de guirlandes, Lyon, époque de Louis XVI.

85.3 Philippe de la Salle : Tissu broché soies polychromes et chenille sur fond serge, décor de lignes verticales sinueuses contrariées de tiges robustes fleuries avec écharpes et cordelières campanées, Lyon époque de Louis XVl.

85.4 Philippe de la Salle: Diverses bandes tissus brochés soies polychromes sur fond armuré, décor de tiges fleuries avec nœuds de rubans, Lyon, époque de Lonis XV!. 


\section{$-(226)-$}

855 Philippe de la Salle: Tissu broché soies polychromes, décor de larges bandes verticales sinueuses de fourrures et de perles avec bouquets de grosses fleurs, Lyon, époque de Louis XVI.

856 Philippe de la Salle: Tissus broché sur fond armuré, décor de bouquets soies polychromes, Lyon, époque de Louis XVI.

857 Divers échantillons du même genre.

858 Philippe de la Salle : Bordure avec tiges fleuries et bande sinueuse de fourrure brochée soies polychromes sur satin crème; autre bande de fourrure aux lisières, Ly on, époque de Louis XVI.

859 Philippe de la Salle: Tissu broché soies polychromes sur fond armuré (fait pour la Grande Catherine de Russie à l'oecasion de la fin des guerres de Crimée). Dans un laurier fleuri, l'aigle impériale foudroie le dernier bateau turc, Lyon, époque de Louis XVI.

86o Philippe de la Salle: Satin broché soies polychromes, décor de vases de fleurs, avec bordures ornées aux lisières, Lyon, époque de Louis XVI.

86 I Philippe de la Salle: Lampas broché soies polychromes, décor de liserons avec médaillon central satin broché (joueur de cornemuse), encadré de roses, Lyon, époque de Louis XVI.

862 Philippe de la Salle: Satin broché soies polychromes, décor à médaillon dit: à la jardinière, encadré de guirlandes de fleurs, Lyon, ćpoque de Louis XVI.

863 Philippe de la Salle: Satin lampassé broché soies polychromes, décor dans le goût de Pompéi, Lyon, époque de Louis XVI.

864 Philippe de la Salle: Velours ciselé polychrome sur fond satin crème, décor de grosses fleurs et de plumes de paon, Lyon, époque de Louis XVI.

865 Philippe de la Salle: Tissu broché soies polychromes sur fond armuré, décor dit: aux perdrix, Lyon, époque de Louis XVI.

866 Philippe de la Salle : Satin broché soies polychromes et chenille, grande composition dite : aux faisans, Lyon,époque de Louis X VI. 


\section{$-(227)-$}

867 Philippe de la Salle: Dessin de tabouret tissu broché, décor de médaillons camaieu: composition dite : aux tourterelles, encadrés d'œillets et de roses, Lyon, époque de Louis XVI.

868 Philippe de la Salle: Bande de satin blanc broché chenille, décor de rinceaux fleuris et d'oiseaux avec bordure ornée, Lyon, époque de Louis XVI.

869 Philippe de la Salle : Lampas broché soies polychromes, décor de liserons, médaillon central : accessoires lyriques et panier fleuri dans un encadrement de roses, Lyon, époque de Louis XVI.

870 Philippe de la Salle: Satin jaune broché soies polychromes, décor de bouquets, guirlandes, semis de roses et bande fleurie aux lisières, Lyon, époque de Louis XVI.

87r Philippe de la Salle: Satin crème broché soies et chenille, décor de bouquets et guirlandes d'œillets, Lyon, époque de Louis XVI.

$8_{72}$ Philippe de la Salle: Tissu de soie broché, avec médaillon; composition dite : au galant jardinier, décor camaieu bleu et rose sur fond satin bleu, Lyon, époque de Louis XVI.

873 Le même sans les effets de broc'łé, Lyon, époque de Louis XVI.

874 Philippe de la Salle: Satin brodé au point de chaînette, décor au panier fleuri, Lyon, ćpoque de Louis XVI.

875 Fhilippe de la Salle: Deux panneaux broderie au point de chaînette (d'après un dessin de Philippe de la Salle), Lyon, époque de Louis XVI.

${ }_{7} 6$ Type de damas à décor dans le goût de Philippe de la Salle, Lyon, époque de Louis XVI.

877 Divers échantillons du même genre.

878 Type de lampas à décor dans le goût de Philippe de la Salle, Lyon, époque de Louis XVI.

879 Divers échantillons du même genre.

88o Taffetas broché soies polychromes, décor de grosses floraisons 


\section{$-(228)-$}

réalistes pittoresques, École de Philippe de la Salle, Lyon. époque de Louis XVI.

88, Divers échantillons du même genre.

882 Lampas, grand décor de paniers fleuris et de bouquets, École de Philippe de la Salle, Lyon, époque de Louis XVI.

883 Divers échantillons du même genre.

884 Bony 1 : Écran brodé au point de chaînette, soies polychromes, décor dans le goût de Pompéi, Lyon, époque de Louis XVI.

885 Bony : Dessus de fauteuil brodé, soies polychromes, Lyon, époque de Louis XVI.

886 Bony : Taffetas brodé au point de chainnette, décor dans le goût de Pompéi, I,yon, époque de Louis XVI.

887 Bony : Satin brodé au point de chaînette, soies polychromes et chenille, décor dans le goût de Pompéi (très caractéristique de l'ornementation de Louis XVI).

888 Collection d'échantillons de broderies pour costumes (paillettes et fils or et argent) sur tissus de soie, Lyon, époque de Lonis XVI.

889 Collection d'échantillons de broderies pour costumes, décor soies polychromes sur tissus de soie, Lyon, époque de Louis XVI.

S9o Collection d'échantillons de broderies paillettes avec fil or et argent sur velours, Lyon, époque de Louis XVI.

89r Collection d'échantillons de broderies, soies polychromes sur velours, Lyon, époque de Louis XVI.

892 Collection d'échantillons de broderies paillettes avec fil or et argent sur drap, Lyon, époque de Louis XVI.

893 Collection d'échantillons de broderies soies polychromes sur drap, Lyon, époque de Louis IVI.

I Bonỵ, dessịnateur et fabricant, émule de Philip̣pe de La Salle, 


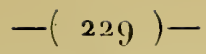

894 Collection d'échantillons de broderies, paillettes et fils d'or et d'argent sur gaze, Lyon, époque de Louis XVI.

895 Collection d'échantillons de broderies soies polychromes sur gaze, Lyon, époque de Louis XVI.

896 Collection de petits gilets brodés, Lyon, époque de Louis XVI.

897 Baldaquin brodé, époque de Louis XVI.

S98 Habit brodé soies polychromes sur velours, époque de Louis XT.

899 Habit brodé soies polychromes et application de dentelle sur taffetas, Lyon, époque de Louis XVI.

goo Habit brodé soies polychromes sur fond taffetas, Lyon, époque du Directoire.

9or Habit brodé soies polychromes sur fond velours, Lyon, époque du Consulat.

\section{NOS CONTEMPORAINS}

Le $x 1 x^{c}$ siècle sert de phase éducative à notre art contemporain : la période napoléonienne s'inspire de l'antique; la Restauration, le Louis-Philippe et le Napoléon III interprètent les styles disparus, surtout ceux français. L'Extrême Orient, enfin, à partir de 1878 , impressionne nos artistes. Jusque-là, tout est à la reconstitution; depuis, l'initiative lend vers l'émancipation affranchie du passé.

902 Type de lampas, décor dans le goût de Pompéi, époque du Directoire.

9o3 Collection de tissus pour sièges, époque du Directoire.

904 Collection de velours pour ameublement, époque du Directoirc. 


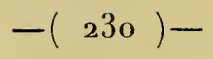

905 Collection de tissus d'ameublement à décor lancé, époque du Directoire.

$9^{06}$ Collection de tissus d'ameublement à décor broché, époque du Directoire.

$9^{07}$ Collection de tissus d'ameublement à décor lancé et broché, époque du Directoire.

908 Suite d'échantillons, tissus transparents à décor broché, époque du Directoire.

909 Suite de tissus soie imprimés, époque du Directoire.

9 ro Suite de toiles imprimées, fabrique de Jouy-en-Josas, époque du Directoire.

91 Suite de petits tapis et écrans, époque du Directoire.

9 I2 Suite de tissus à décor rappelant un événement politique contemporain, époque du Directoire.

913 Grand panneau brodé, application de tulle sur satin bleu rehaussé de broderies soies polychromes avec or et argent, grande composition de Bony, époque du Directoire, ancien fonds Lemire.

914 Suite d'échantillons de broderies sur tissus de soie, époque du Directoire

$9^{15}$ Suite d'échantillons de broderies sur tissus transparents, époque du Directoire.

9ı 6 Suite d'échantillons de broderies sur velours et drap, ćpoque du Directoire.

917 Suite de gilets brodés, époque du Directoire.

918 Suite de bas de robes brodés or et soies, époque du Directoire.

9r9 Type de lampas, décor dans le goût de Pompéi, époque du Consulat.

920 Type de velours ciselé sur fond satin, grand décor de vases et de 


\section{$-(23$ I $)-$}

fontaines jaillissantes, avec étoiles napoléoniennes et palmettes, époque du Consulat.

$9^{2}$ I Divers échantillons du même genre.

$9^{22}$ Collection de tissus d'ameublement, époque du Consulat.

923 Collection de tissus pour sièges, époque du Consulat.

924 Type de lampas d'ameublement, décor dans le goût de Pompéi, époque du Consulat.

925 Divers échantillons du même genre.

926 Diverses bandes d’ameublement, époque du Consulat.

927 Suite de petits tapis et écrans, époque du Consulat.

$9^{28}$ Écran satin bleu, décor blanc ou vase allégorique, dessin de Joseph Picard, époque du Consulat (1801).

929 Collection de bordures tissées, époque du Consulat.

$9^{30}$ Collection de bordures brochées, époque du Consulat.

$9^{31}$ Collection de portraits tissés de Bonaparte Ier, consul, époque du Consulat.

932 Suite de tissus à décor rappelant un evénement politique contemporain, époque du Consulat.

933 Suite de tissus de soie imprimés, ćpoque du Consulat.

$9^{34}$ Suite de toiles imprimées, fabrique de Jouy, époque du Consulat.

935 Petit gilet satin imprimé, décor dans le goût de Percier et Fontaine époque du Consulat.

$9^{36}$ Ėcran fond blanc cotelé, décor velours ciselé vert avec mention : " Fait en présence du premier consul, à Lyon, le 26 nivose, an $\mathrm{X} \%$.

$9^{3} 7$ Satin vieux rose broché cordonnet crème, décor dentelle figurée, 
composition de montants de roses sur un semis d'ètoiles napoléoniennes, avec large soubassement également en dentelle drapée figurée, décorée de guirlandes de laurier et de lierre sur un fond d'œillets, de muguets et d'églantiers, bordé de palmettes et autres ornements conventionnels (ameublements de la Malmaison), ćpoque du Consulat.

$9^{38}$ Tenture à ordonnance de larges bandes verticales jaunes et bleues, décorées de palmettes et de rinceaux foliacés et conventionnels, avec couronnes et étoiles napoléoniennes (commandẻe pour le grand Trianon à Pernon en 1803), époque du Consulat.

939 Panneau de satin blanc lamé, décoré de casques, de faisceaux, de licteurs avec compartiments destinés à recevoir des broderies (ameublements de la Malmaison), fabriqué par Pernon, époque du Consulat.

940 Lampas fond bleu broché or et argent (ameublements de la Malmaison, chambre de Joséphine, 18o3), époque du Consulat.

94 I Tenture fond satin bleu, décor application de velours crème avec détails au pinceau; composition dans le goût de Pompéi, époque du Consulat.

942 Écran fond or brodé soies et chenille polychromes, décoré d'un oiseau perché sur une guirlande de fleurs attachée à deux flambeaux, composition de Bony, époque du Consulat.

943 Écran fond bleu brodé or et soie mêlée de chenille, décoré d'un oiseau dans son nid sur fond d'or à réserves, par Bony, époque du Consulat.

944 Tenture de satin vert à rayures en partie peintes avec broderie au point lancé et chenille soie, décor de palmettes et de lyres, époque du Consulat.

945 Collection de broderies pour le costume, époque du Consulat.

946 Collection de broderies pour le meuble, époque du Consulat.

947 Diverses robes brodées or et soie, époque du Consulal. 


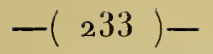

948 Suite de gilets brodés, époque du Consulat.

949 Bas d'une robe de cour brodée pour Maria Federowna (femme de Paul Ier), impératrice de Russie, école lyonnaise, époque du Consulat.

$9^{50}$ Suite de broderies soie sur mousseline, pour garnitures de robes, époque du Consulat.

$9^{5}$ ı Bande brodée au point de chaînette, décor de plumes et de rinceaux, dessin de Bony, époque du Consulat.

9.5̆ Type de lampas, décor dans le goût de Pompéi, époque de l'Empire.

953 Type de lampas d'ameublement, composition de roues décorées de sphinx adossés, dans une ordonnance losangée de guirlandes foliacées et fleuries, époque napoléonienne.

$9^{54}$ Divers échantillons du même genre.

955 Tenture satin bleu avec décor allégorique représentant le Génie de la Fabrique lyonnaise, composé par Dutillien, et tissé avec le régulateur de son invention, époque de l'Empire.

956 Tenture fond cannetillé rouge, décor jaune de sphinx et d'autels, symboliques, époque de l'Empire.

$9^{57}$ Tenture satin noir décorée de satyres dans le goût gréco-romain par Grand frères, époque de l'Empire.

$9^{58}$ Satin noir orné de bacchantes en rouge orangé, par Grand frères, décor dans le goût gréco-romain, époque de l'Empire.

$9^{59}$ Type de tissu pour sièges, décor velours ciselé sur fond satin, époque de l'Empire.

960 Divers échantillons du même genre.

$9^{6}$ r Collection de tissus pour sièges, époque de l'Empire.

$9^{62}$ Collection de tissus d'ameublement, époque de l'Empire.

$9^{63}$ Suite de petits tapis et écrans, époque de l'Empire. 


\section{$-(234)-$}

964 Collection de bordures tissées, époqué de l'Empire.

965 Collection de bordures brodées, époque de l'Empire.

$9^{66}$ Suite d'échantillons gaze tour anglais, broderies soies polychromes, commencement du $\mathrm{x}_{\mathrm{Ix}} \mathrm{e}^{\mathrm{e}}$ siècle.

967 Velours chinés, époque de l'Empire.

968 Collection de portraits tissés de Napoléon empereur, époque de l'Empire.

$9^{69}$ Suite de tissus à décor rappelant un événement politique contemporain, époque de l'Empire.

970 Suite de tissus de soie imprimés, époque de l'Empire.

97I Suite de toiles imprimées fabrique de Jouy, époque de l'Empire.

972 Tenture et bordure velours ciselé vert olive, rehaussée de fleurs brodées soie et chenille couleurs et de vases et ornements à haut relief brodés d'or, par Lemire, époque de l'Empire.

973 Tenture velours ciselé bleu broché d'or, décorée de médaillons à la couronne impériale; bordure satin bleu broché d'or à compartiments avec bande de laurier, par Lemire, époque de l'Empire.

974 Tenture et bordure brocart d'or fond satin blanc, décor aux emblèmes impériaux (aigle impériale, couronne impériale, montants d'épis et guirlandes de lierre), par Lemire, époque de l'Empire.

975 Brocart or, argent et sorbec, sur fond velours cramoisi, décor de palmiers et de branches de chêne et d'olivier entourant l'N impériale et la croix de la Légion d'honneur (pour un salon des Tuileries), par Grand frères, époque de l'Empire.

976 Tenture de lampas fond satin citron avec compartiments violets décorée de branches de timbalier et de fleurs nuancées (pour le petit salon de Joséphine à Versailles), par Grand frères, époque de l'Empire.

977 Lampas fond bleu, décor jaune au sceptre couronné, par Grand frères, époque de l'Empire. 


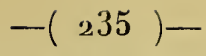

$97^{8}$ Lampas fond bleu, décor de bouclier (pour le palais de Meudon), par Grand frères, époque de l'Empire.

979 Tenture et bordure brocart d'or, d'argent et de sorbec, fond satin cramoisi avec décor d'abeilles (salle du Trône á Versailles), par Grand frères, époque de l'Empire.

$9^{80}$ Panneau et bordure satin blanc broché or, chenille et soies couleurs (chambre à coucher de l'Empereur aux Tuileries), par Grand frères, époqué de l'Empire.

98 I Tenture et bordure satin bleu broché or (pour la salle des Marécháux aux Tuileries), par Grand frères, époque de l'Empire.

982 Bordure fond satin cramoisi broché d'or, décoré de l'N impériale (saile du Trône aux Tuileries, 1805 ), par Grand frères, époque de l'Empire.

$9^{83}$ Large bordure fond satin citron damassé, décor de grands rinceaux chenille rouge, par Lemire père et fils, époque de l'Empire.

984 Velours chiné décoré de branches de laurier fleuri, bordures de palmettes et de roses, par Richard (chambre à coucher de Napoléon Ier à Fontainebleau), époque de l'Empire. (Echantillon d'essai, à Fontainebleau le fond est crème.)

$9^{85}$ Spécimen d'essai de la broderie du manteau du sacre, dessin de Percier et Fontaine, époque de l'Empire.

986 Panneau de satin blanc brodé de chenille et application velours détaillé au pinceau, décor dans le goût de Pompéi, composition de Bony, époque de l'Empire.

$9^{8} 7$ Panneau de satin blanc brodé au point lancé, décor de fleurs abritées d'un voile en application de tulle noir, dessin de Bony, époque de l'Empire.

$9^{88}$ Suite de broderie sur soie ou mousseline, décor dans le goût de Pompéi, fleurs soies couleurs, ornements conventionnels, emblèmes impériaux, époque de l'Empire.

$9^{89}$ Suite de broderies sur divers fonds, pour robes de cour, décor, ar- 


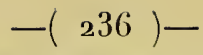

gent ou soies couleurs, de fleurs et d'ornements conventionnels, époque de l'Empire.

$99^{\circ}$ Suite de robes de cour brodées or et soie, époque de l'Empire.

99 I Diverses paires de gants toile brodée, époque de l'Empire.

992 Suite de gilets brodés, époque de l'Empire.

$99^{3}$ Collection de broderies pour le costume, époque de l'Empire.

994 Collection de broderies pour le meuble, époque de l'Empire.

Velours Grégoire. - Le velours Grégoire est théoriquement facile à comprendre, le tour de main seul est resté le secret de l'inventeur. Sur un satin initial sept ou huit fois plus grand que le velours final était peint le sujet à représenter. On parfilait alors le satin et, prenant un fil sur sept ou huit, suivant l'embuvage, on faisait sept ou huit exemplaires de velours.

$99^{5}$ Satin préparé pour exécuter un velours Grégoire, époque de l'Empire.

$99^{6}$ Portrait de Napoléon I ${ }^{\mathrm{er}}$, couronné de laurier, velours Grégoire, époque de l'Empire.

997 Portrait du pape Pie VII, velours Grégoire, époque de l'Empire.

$99^{8}$ Portrait de femme, velours Grégoire, frisé, époque de l'Empire.

999 Divers portraits, velours Grégoire, époque de l'Empire.

ıooo Portrait de Louis XVIII, velours Grégoire, époque de la Restauration.

roor Portrait de la duchesse d'Angoulême, velours Grégoire, époque de la Restauration.

roo2 Portrait de Louis XVI, velours Grégoire, époque de l'Empire.

1003 Suite de velours Grégoire, d'après les Heures de Raphaël, époque de l'Empire. 


\section{$-\left({ }_{23} 3\right)-$}

เ004 Suite de velours Grégoire, sujets religieux, d'après Raphaël (la Vierge à la chaise, la Vierge à l'Enfant, etc.), époque de l'Enspire.

roo5 Suite de velours Grégoire, petits sujets dans le goût de Pompéi, époque de l'Empire.

roo6 Suite de velours Grégoire : personnages d'après Greuze, époque de l'Empire.

I007 Suite de velours Grégoire : sujets champêtres, époque de l'Empire.

I008 Suite de velours Grégoire : bouquets de fleurs, époque de l'Empire.

ı०og Échiquier velours Grégoire, époque de l'Empire.

ro ro Suite d'études d'animaux, de fruits et de fleurs, velours Grégoire, époque de l'Empire.

Ior I Christ en croix, velours Grégoire, époque de I'Empire.

Ior2 Lampas d'ameublement, décor dans le goût de Pompéi, époque de la Restauration.

ı 3 Grand panneau fond cannetillé bleu, décor camaïeu or, avec tableaux tissés soies polychromes (chevaux et taureaux au pâturage), fait par M. Chuard, à Lyon, I8r9; époque de la Restauration.

ro14 Collection de tissus d'ameublement, époque de la Restauration.

ı 5 Collection de tissus pour sièges, époque de la Restauration.

ror 6 Suite de petits tapis et écrans, époque de la Restauration.

1017 Collection de tissus à décor interprété du Louis XIII, époque de la Restauration.

1018 Collection de tissus à décor interprété du Louis XIV, époque de la Restauration. 


\section{$-(238)-$}

ıо 9 Collection de tissus à décor interprété du Louis XV, époque de la Restauration.

1020 Collection de tissus à décor interprété du Louis XVl, époque de la Restauration.

102. Diverses collections de tissus pour gilets, époque de la Restauration.

1022 Diverses collections de tissus de robes, époque de la Restauration.

ro23 Collection de bordures tissées, époque de la Restauration.

1024 Collection de bordures brodées, époque de la Restauration.

1025 Lampas fond satin blanc broché or, chenille et soie (appartements de la duchesse d'Angoulême), par Grand frères, époque de la Restauration.

I026 Tenture satin blanc broché or et soies polychromes (appartements de la duchesse d'Angoulême, par Lemire, époque de la Restauration.

I027 Lampas fond blanc broché soies polychromes (appartements de la duchesse d'Angoulême), par Lemire, époque de la Restauration.

I028 Grand panneau de velours bleu, coupé sur fond frisé avec bordure broché or liseré et rebordé (chambre à coucher de Louis XVIII aux Tuileries), par Grand frères.

I029 Deux stores à décor transparent (tour anglais) aux armes de France et au chiffre de Louis XVIII.

103o Damas fond rouge broché or, décor de vases astragales, fleurs de lis et accessoires avec chiffre de Louis XVIII (ameublement royal), par Lemire.

I03 I Tenture satin rouge broché or avec médaillon fond argent broché soies polychromes (ameublement royal), par Lemire, époque de Louis XVIII.

1 032 Grand panneau fond cannetillé rouge broché or (fait pour la salle 


\section{$-\left(23_{9}\right)-$}

du Trône aux Tuileries), par Grand frères, époque de Louis XVIII.

I033 Petit panneau fond cannetillé rouge broché or (feuille de paravent pour le même ameublement).

I034 Grand panneau fond cannetillé rouge, décor broché camaileu jaune aux armes de la ville de Lyon (salon de l'Hòtel de Ville), par Grand frères, époque de la Restauration.

1035 Gros de Tours, décor tissé imitant l'impression typographique : Testament de Louis XVI, par Maisiat (1827).

Io36 Suite d'écrans, décor en l'honneur des alliés, époque de la Restauration.

Io37 Suite de tissus à décor rappelant un événement politique contemporain, époque de la Restauration.

1038 Collection de tissus de soie imprimés, époque de la Restauration.

ro39 Collection de toiles imprimées, fabrique de Jouy, époque de la Restauration.

ı 040 Collection de broderies pour le costume, époque de la Restauration.

ı041 Collection de broderies pour le meuble, époque de la Restauration.

ı042 Suite de gilets brodés, époque de la Restauration.

1043 Foulard imprimé dans le goût d'Epinal, représentant les armées des alliés quittant la France, époque de la Restauration.

ro44 Collection Teillard, 417 carnets d'échantillons, fabrication de ı 825 à 1835 .

ro45 Collection Larpin, environ r5.0oo échantillons, époque de la Restauration, Louis-Philippe.

ı 046 Collection de tissus d'ameublement, décor imité des styles français des $\mathrm{xvII}^{\mathrm{C}}$ et $\mathrm{xvi{ } ^ { \circ }}$ siècles, époque de Louis-Philippe. 


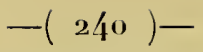

I047 Collection de tissus pour sièges, époque de Louis-Philippe.

Io/8 Collection Baudinot, 75.000 échantillons de tissus pour gilets, fabrication de $\mathbf{8} 833$ à 1867 .

1049 Collection Champagne, environ 8000 échantillons, fabrication de 1830 à 1860 . (Don de M. Champagne.)

ı55o Collection Bergeret, environ $\mathbf{5} 5.000$ échantillons de tissus et 300 mises en carte, de 1845 à 1860 .

ro5 I Collection de tissus de la maison Didier-Petit, époque de LouisPhilippe.

ro52 Diverses collections de tissus de robe, époque de LouisPhilippe.

ı53 Diverses collections de tissus pour gilets, époque de LouisPhilippe.

ro54 Tissu qui recouvrait les cendres de Napoléon Ier, retour de Sainte-Hélène; soie pourpre violette, décor fil de verre jaune, époque de Louis-Philippe.

ro55 Dossier de canapé fond satin écarlate, décoré d'un paysage camaileu bistre, par Gantillon, époque de Louis-Philippe.

ıo56 Taffetas bleu à décor camaïeu blanc, au chiffre de la princesse Clémentine (tissu pour ombrelle), époque de Louis-Philippe.

ro57 Portrait de Napoléon Ier, soies brochées camaïeu sur fond satin rouge, par Gantillon, époque de Louis-Philippe.

Io58 Collection de petits tissus faits à l'occasion du retour des cendres de Napoléon Ier, époque de Louis-Philippe.

I 059 Tissus à décor rappelant un événement contemporain, époque de Louis-Philippe.

ro6o Collection de tissus à décor en l'honneur de l'indépendance des États-Unis, époque de Louis-Philippe.

1061 Divers portraits tissés de Louis-Philippe. 


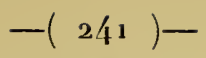

ro62 Tableau tissé : Visite de M. le duc d'Aumale à la Croix-Rousse à l'atelier de M. Carquillat, d'après Bonnefond, par Carquillat, en 1844 .

Io63 Portrait tissé de Jacquard, d'après Bonnefond, par DidierPetit, 1839.

ı064 Divers tableaux tissés, époque de Louis-Philippe.

ı65 Suite de toiles imprimées, fabrique de Jouy, époque de LouisPhilippe.

ı666 Drapeau tricolore pour la Garde nationale, avec mention : République française, $3^{\circ}$ légion, Lyon, 1848.

I 067 Écharpe de Lamartine, conseiller municipal du Bourget (1848).

I068 Manteau de cour fait pour l'Impératrice Eugénie, brocart à décor de roses impériales et d'hortensias en velours frisé et coupé rouge et blanc, exécuté en 1853 par E. Schulz et Cic. (Don de M. E. Schulz.)

1069 Portrait de Bergeon, fond satin broché camaïeu, par Raynaud, Lyon, 1854 .

ro7o Portrait de Philippe de la Salle, fond satin décor broché camaïeu, par Reynaud, Lyon, I854.

Io7 I Portrait de Bony, fond satin broché camaïeu, rehaussé de couleurs, par Reynaud, Lyon, 1855.

r072 Satin blanc broché soies polychromes (bouquet de fleurs) offert à l'Impératrice Eugénie à son passage à Lyon, avec mention "Dédié à Sa Majesté l'Impératrice des Français, Godemard, Meynier et Delacroix, Lyon ", époque de Napoléon III.

1073 Satin blanc broché conleurs, décoré d'oiseaux des îles, exécuté pour la Reine d'Angleterre, par E. Schulz et $C^{i \bullet}$, époque de Napoléon III. (Don de M. E. Schulz.)

1074 Collection de tissus de la maison Ronze, d'après son procédé spécial, époque de Napoléon III. (Don de M. Ronze.) 


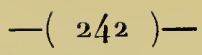

${ }_{1075}$ Suite de bas de robe façonnés et imprimés sur chaîne, par Champagne et Rougier, époque de Napoléon III.

${ }_{107} 6$ Collection Champagne et Rougier, environ 8000 échantillons des $\mathrm{xv}_{11}{ }^{\mathrm{e}}$ et $\mathrm{xIx}^{\mathrm{e}}$ siècles, (de 1750 à 1850 .) (Don de M. Champagne.)

1077 Suite de velours broderie triple corps par Repiquet et Silvan, époque de Napoléon III.

${ }_{10} 8$ Collection de tissus d'ameublement, époque de Napoléon III.

1079 Suite de rubans décorés de scènes militaires ayant rapport à la campagne de Crimée, époque de Napoléon III.

1080 Suite de tissus à décor, imité du Louis XIV, époque de Napoléon III.

ı08I Suite de tissus à décor, imité du Louis XV, époque de Napoléon III.

I 082 Suite de tissus à décor, imité du Louis XVI, époque de NapoIéon III.

1083 Portrait tissé de la famille impériale, fin du xix e siècle.

1084 Tableau tissé d'après la Vierge de Saint-Jean du musée SaintPierre, par A. Lamy et A. Giraud, tissé par Burel, don de MM. Lamy et Giraud, époque de Napoléon III.

1085 Velours ciselé deux corps, décor camaïeu rouge sur fond satin jaune, décor dit Bérain, par Tassinari et Chatel, époque de Napoléon III.

Ј086 Velours ciselé deux corps, décor camaïeu rouge sur fond satin jaune, décor dit Bérain, par L. et A. Emery, époque de Napoléon III.

1087 Grand panneau de broderie application, décor dit Bérain, exécuté pour la maison Tassinari et Chatel, par $\mathrm{M}^{\mathrm{m}_{0}}$ Leroudier, époque de Napoléon III. 


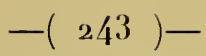

1088 Suite d'échantillons de tissus exposés en 1867 et donnés au Musée par MM. Belliard frères et Cie, Caquet-Vauzelle et Côte, Derbez et Cie, Lamy et Giraud, Poncet, Papillon et Girodon, R. Rouze, Schulz et Béraud, etc.

1089 Lampas satin rouge décor camaïeu (tenture du pavillon de l'Impératrice à l'exposition de 1867 ), par Mathevon et Bouvard, don de MM. Bouvard et Burel, époque de Napoléon III.

rogo Satin vert d'eau, décor de papillons multicolores (tenture du boudoir de l'Impératrice Eugénie aux Tuileries), exécuté par L. et A. Emery, époque de Napoléon III. (Don de M. A. Martin.)

rogr Collection Meynier, environ 8000 échantillons, époque de Napoléon III.

rog2 Collection de tissus de robe, époque de Napoléon III.

rog3 Divers portraits tissés, époque de Napoléon III.

ro94 Robe gros, de Tours, broché, décor de branches fleuries, exécutée en présence de Sa Majesté l'Impératrice lors de sa visite au Palais du Commerce, le 27 août 1869 Fabriquée et donnée par Schulz et Beraud.

rog5 Suite de toiles imprimées, fabrique de Jouy, époque de Napoléon III.

rog6 Suite de tissus exposés en 1878 et donnés au Musée par MM. A. Lamy et A. Giraud, E. Schulz et Cie.

1097 Christ en croix, broderie au point de satin, par $M^{\text {me }}$ Leroudier, exposition de 1878 .

rog8 Panneau brocatelle camaïeu, décor de palmes, de lauriers et d'accessoires lyriques, exécuté pour le foyer du grand Opéra de Paris, par Lamy et Giraud, fir du xix siècle. (Don de MM. Lamy et Giraud.) 


\section{$-(244)-$}

rog9 Grand panneau décoratif dans le goût de la Renaissance française par A. Lamy et A. Giraud, Exposition de 1878 . (Don de M. E. Lamy.)

I roo Suite de tissus exposés en 1894 et donnés au Musée par MM. Atuyer, Bianchini ct Férier, Bachelard et Cie, Bardon et Ritton, Beraud et Cie, C.-J. Bonnet et Cie, Chavent père et fils, Ogier, Duplan et Cie, Poncet père et fils, Schulz et Gourdon, etc.

I ıо Panneau brocatelle camaïeu, décor aux armes de la ville de Paris, tenture du grand salon de l'Hôtel de Ville de Paris, exécuté par J.-A. Henry, fin du xixe siècle. (Don de M. J.-A. Henry.)

1102 Livre entièrement tissé (paroissien) satin façonné, par J.-A. Henry, fin du xixe siècle. (Don de M. J.-A. Henry.)

I 103 Pentes de dais brocart imitant le point de tapisserie: cortège triomphal de saints et de personnages historiques français, par J.-A. Henry, fin du $\mathrm{xIX}^{\circ}$ siècle.

I 104 Suite de poupages tissés velours, par Furnion et Cie, I878.

I 105 Collection E. Schulz. La collection Schulz ne contient pas moins de 20.000 échantillons représentant près de 5o ans de fabrication (de 1842 à $\mathbf{1 8 8 6}$ ). (Don de M. Emile Schulz )

I 106 Suite d'échantillons de tissus exposés en 1889 et donnés au Musée par MM. Atuyer, Bianchini et Férier, L. Audibert et $\mathrm{Cie}$, Bardon, Ritton et Mayen, Bérard et Ferrand, J. Beraud et Cie, Bresson, Agnès et Cie, Brosset-Heckel et Cie, Brunet-Lecomte, Moïse et Cie, Bouvard et Mathevon fils, Chatel et Tassinari, Devaux et Bachelard, Ducoté Caquet-Vauzelle et Cote, L. et A. Emery, L. Gonindard, Jance et Cie, Guivet ef Delaroche; A. Gourd et Cie, J.-A. Henry, Lamy et Giraud, Ogier, Duplan et Cie, J.-M. Piotet et Roque, Roux père et fils, SchuIz, Gourdon et $\mathrm{C}^{\text {ie }}$, Tresca frères et Cie, $\mathrm{M}^{\text {me }}$ Leroudier.

I 107 Suite de tissus façonnés de la maison Sapojnikoff de Moscou. Exposition de Chicago. (Don de M. E. Guimet.) 
I 08 Grand panneau décoratif application et broderie, décor dans le goût de la Renaissance, dessiné par M. Bardey, exécuté par Mlle Bardey, fin du $x^{0} x^{0}$ siècle.

I 109 Portrait au petit point de M. Ed. Aynard, président d'honneur de la Chambre de commerce de Lyon, brodé par Mme Anaïs Favre en 1893 .

I Io Portrait au petit point de Meissonnier, brodé par $\mathrm{M}^{\mathrm{me}}$ Anails Favre en 1892 .

I I Couverture et garde de livre, d'après les dessins de A. Giraldon, tissées par Chatel et Tassinari, fin du xix ${ }^{\mathrm{e}}$ siècle. (Don de MM. A. Giraldon et Hachette, éditeur.)

11 I2 Petite garde de livre tissée pour un album, offert par ses élèves à M. Pascal, architecte, à l'occasion de sa vingt-einquième année de professorat à l'École des Beaux-Arts dc Paris, dessin de M. R. Cox, exécuté par Lamy et Bornet, fin du xixe siècle. (Don de MM. Lamy et Gautier.)

I I3 Suite de tissus façonnés de la maison Kolokolinkoff de Moscou, fin du $\mathrm{XIX}^{\mathrm{e}}$ siècle. (Don de MM. Sitoff et Kolokolinkoff.)

II 14 Suite de portraits tissés de la fin du $x_{1 X}{ }^{e}$ siècle.

I I5 Suite de tableaux tissés de la fin du $x_{1 x}{ }^{e}$ siècle.

I 16 Grande tenture brocatelle lampassée grenat brochée d'or, dessin de M. Claudius Ducrot ayant obtenu le premier prix au Concours de la Chambre de commerce en 1899 , exécuté et donné par M. J.-A. Henry, fin du xixe siècle.

1117 Grande tenture velours ciselé, décor de montants de laurier sur fond au chiffre de la République, exécutće par Chatel et Tassinari, d'après les dessins de A. Giraldon, Exposition de r $9^{\circ o .}$

I 18 Grande tenture brocatelle, décor de corbeilles fleuries et de couronnes, exécuté par Chatel et Tassinari, d'après les dessins de Karbousky, Exposition de 1900. 


$$
-(246)-
$$

I I9 Grand panneau d'ameublement dans le goût du Directoire, satin crème broché, soies polychromes, exécuté par Albert Martin sur les dessins d'Ant. Martin, Exposition de 1900.

1120 Suite de tissus exposés en 1900 et donnés au Musée par MM. Algoud frères, Arquische Ravier et Grospeillier, L. Audibert et Cie, Bachelard et Cie, Bardon et Ritton, J. Béraud et $\mathrm{C}^{\mathrm{i} i}$, C.-J. Bonnet et Cie, Boucharlat et Pelet, Bouvard et Burel, Chatel et Tassinari, Chavent père et fils, Duplan et $\mathrm{C}^{t_{e}}$, Gourd et $\mathrm{C}^{\mathrm{ie}}$, Ollagnier Fructus et Descher, Poncet père et fils, Piotet et Roque, etc. 


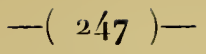

T APISSER IES

I121 Fragment très ancien de tapisserie orientale, décor d'animaux symboliques dans une ordonnance de roues tangentes (ce précieux fragment faisait partie d'un devant d'autel autrefois conservé à l'église de Saint-Géréon de Cologne), type de composition antérieure au $\mathrm{x}^{\mathrm{e}}$ siècle.

I 22 Grande tapisserie en deux parties, dans le genre des tapisseries considérées comme ayant appartenu au chevalier Bayard et illustrant la vie des grands généraux de l'antiquité, France, xve siècle.

I 23 Grande tapisserie représentant Ambroise de Ravenne (probablement le donateur) offrant un fruit à l'Enfant Jésus sur les genoux de la Vierge. Le groupe principal est surmonté de trois anges et d'assistants vêtus de riches costumes avec parties tissées d'or, bordure d'églantiers et de rubans, Flandre, fin du $\mathrm{Xv}^{\mathrm{e}}$ siècle.

1124 Grande tapisserie, décor paraphrasant la vie et la mort du chevalier, Flandre, commencement du $\mathrm{XvI}^{\mathrm{e}}$ siècle.

I 25 Tentures à semis de fleurs de lis et d'L couronnés, France, époque de Louis XII.

I 26 Devant d'autel représentant l'adoration des mages, France, époque de François Ier.

1127 Fragment de tapisserie allemande du $x v I^{e}$ siècle.

1128 Deux fragments de tapisserie de l'École de Fontainebleau, décor dans le goût de Ducerceau, avec médaillons d'après le Primatice, $\mathrm{xvI}^{\mathrm{e}}$ siècle (collection Peyre). 
II29 Fragment de tapisserie, décor à personnages, Flandre, commencement du $x v^{e}$ siècle.

I 3 o Petit tapis en tissu espouliné, sujet de chasse, Inde, $\mathrm{xvII}^{\mathrm{e}}$ siècle.

I 3 I Grande tapisserie faisant partie de la série dite des éléments (l'Air), carton de Le Brun, Gobelins, époque de Louis XIV (envoi du garde-meuble national).

I132 Petits panneaux de tapisserie, décor de bouquets, ćcole de Monnoyer, Gobelins, époque de Louis XIV.

I 33 Grande tapisserie : conquête de la Toison d'or, d'après un carton de de Troy. Gobelins, époque de Louis XV (envoi du garde-meuble national).

I 134 Suite de tapisseries pour sièges, décor de personnages et danimaux, Beauvais, époque de Louis XV.

I 35 Diverses savonneries pour sièges, Gobelins, époque de la Restauration.

1 I36 Portrait en savonnerie, époque de Napolćon III.

1137 Trois panneaux de tapisserie à décor de fleurs pour canapé, manufacture de Beauvais, Exposition de 1878.

Tapis d'Orient. - L'histoire des tapis d'Orient est restée obscure, et il serait extrêmement délicat d'assigner une date et une origine certaines à ces monuments dans la plus grande majorité des cas. L'invention industrielle s'en perd dans la nuit des temps.

Ici nous ne nous occupons que des tapis bouclés, connus sous le nom de tapis persans ou d'Orient. Au moyen âge et à la Renaissance se sont établies certaines traditions de composition qui nous présentent de curieuses pénétrations des formules décoratives d'Orient et d'Extrême Orient. Les spécialistes les plus autorisés s'accordent à reconnaître deux époques plus particulièrement supérieures : la fin $d u x^{e}$ siè- 


\section{$-(249)-$}

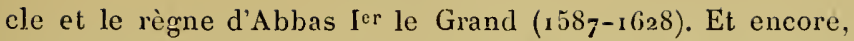
étant donné la lenteur avec laquelle se renouvellent les formules décoratives en Orient, il convient d'entendre plutôt par là : fabrication plus active. L'ornementation, elle, est en quelque sorte immobilisée. Ilélas! depuis quelque temps l'Occident est venu troubler la quiétude rêveuse des producteurs, leur apportant nos procédés scientifiques modernes et motre fièvre dévorante. Désormais l'atelier, dirigé par l'Européen, s'inspire bien des anciens modèles, mais la mécanique et le laboratoire ont tué la tradition. Cette merveilleuse industrie, dont les produits défiaient le temps et évoquaient hier encore les splendeurs orientales des Mille et une Nuits, u'en est plus que le pâle reflet, éphémère même.

La Chine, la Perse, l'Inde el en général le pays musulman fournissent les éléments décoratifs des anciens tapis d'Orient. Les différents arts de ces centres s'y pénètrent intimement, si bien que nous pensons devoir placer l'origine de ces décors tissés au moment des invasions mongoles. Le répertoire ornemental est relativement restreint. La Chine apporte /quelques-uns de ses monstres et de ses animaux symboliques: le dragon, le phénix, la grue, la chauve-souris, le poisson, etc. Elle donne aussi ses masques, et surtout son fameux ruban dentelé, représentation du ciel : le $t c h i$.

De la Perse, on exploite les palmetles conventionnelles, les animaux d'une si délicate justesse d'expression, et cette flore que nous avons signalée en parlant du tissu persan : l'œillet, la tulipe, la jacinthe et l'églantier. Les personnages réels ou irréels sont aussi persans.

A l'Inde le tapissier emprunte sa palme et ses feuillages allongés.

L'art musulman, lui, se reconnaît dans les arabesques et l'épigraphie et au parli-pris géométrique de certaines compositions, tant pour l'ensemble que pour le détail.

ll est presque constant de voir réunis simultanćment quelques-uns de ces éléments. Dans les plus anciens tapis, 
la composition est plus touffue, elle s'éclaircit à partir du $\mathrm{xvII}^{\mathrm{C}}$ siècle.

I 38 Grand tapis de laine, décor à compartiments rappelant le meneau d'arc lancéolé. Dans le champ, diverses scènes relatives à la culture d'un arbre fruitier, probablement le pêcher. Des djinns plantent l'arbuste dans la forêt ou apprennent à le greffer dans le verger; d'autres oflrent ses fruits à un personnage entouré de sa cour et de musiciens. Les lignes du mencau s'ornent de flore conventionnelle et d'animaux. Dans lencadrement, un large ruban ondulé semé de fleurs et d'animaux alterne avec des compartinents lobés où reparaissent les djinns. Ėnfin, l'encadrement lui-mème est bordé d'un rinceau d'arabesques, petites têtes d'animaux et de masques dans le goût chinois. Perse, $\mathrm{xIv}^{c}$ et $\mathrm{xv}^{\mathrm{c}}$ siecles. (Provient dit-on de la cathédrale de Tours.)

1 39 Tapis de laine à rehauts d'or et d'argent. Ce beau spécimen est caractéristique du type à animaux et personnages. Sa composition se divise en quatre parties : au milieu, un compartiment circulaire lobé, où sont représentés quatre canards et oú nous n'hésitons pas à voir symbolisée l'idée de la maison. C'est la vasque dont l'eau rafraîchit la partic centrale de toute habitation orientale. Autour, dans une nouvelle enceinte bordée d'accolades, le jardin oú les djinns (génies bienfaisants) s'empressent de servir le maitre, lui offrant à boire, l'éventant, etc. Jusqu'ici, règne une symétrie voulue, évoquant l'idée d'ordre dans l'habitation. Elle fera contraste avec le parti pris de pittoresque du compartiment suivant, représentation de la forch avec son inextricable enchevêtrement floral et sa faune multiple. Dans cette troisième partie, tous ces détails petits et grands qui, au premier aspect, sembleraient placés au hasard de la fantaisie la plus libre, sont au contraire autant de taches décoratives s'équilibrant sur des données architectoniques, dont nous trouvons la trace dans les fines tiges de rinceaux qui se reproduisent symétriquement de chaque côté des axes. Enfin, délimitant le tout, un cadre où ondule une large bande rubanée où reparaissent faune et flore. Peut-être la présence de gre- 


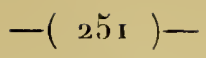

nouilles sur ces ondulations nous amènerait-elle à voir l'idée de flots cernant la forêt. Rien ne manque à cette composition pour être bien persane: le symbole, la complication du détail, l'impression de l'indéfini. La flore se réduit aux différentes palmettes et asters. La faune est plus varićc. Très juste de silhouette, nous signalerons même un détail qui dénote de cette curieuse recherche dans l'interprétation du modèle : i'artiste, pour mieux rendre la nature de la robe de ses bêtes, s'ingénie à préciser dans la crinière d'un lion son aspect flottant, tandis que le flanc reste lisse. Dans ce beau modèle, ce qui nous frappe surtout, c'est la science incomparable avec laquelle s'ćquilibre l'ensemble, pour arriver au plus chatoyant imprévu. Perse, xve siécle.

I 140 Tapis de laine rehaussé de parties d'argent. Composition du type à animaux, de la même famille que le précédent; l'épigraphie et le tchi y jouent un rôle important. Les fonds des diverses parties de la composition sont rouge, noir et crème, Perse, $\mathbf{x} v^{c}$ et $x v^{c}$ siëcles. (Provient de la collection Goupil.)

I I 1 Tapis de laine de la même famille que le précédent, Perse, $\mathrm{xv}^{\mathrm{e}}$ et $\mathrm{XVI}^{\mathrm{c}}$ siccles.

1142 Tapis de soie fond rouge à bordure verte, décor à ordonnance de semis de tiges fleuries, d'œillets, de jacinthes et d'églantiers rappelant l'ancien homa, avec oiseaux perchés et affrontés. Dans ce tapis apparaissent également quelques nuages chinois, Perse, xve et xvil ${ }^{\mathrm{c}}$ siécles. (Provient de la collection Goupil.) Ce beau spécimen est malheureusement incomplet; toutefois un hasard inouï avait fait trouver à Goupil son complément, que le Musée possèdc également (ce dernier morceau est très détérioré.) La pičce principale a ćté trouvée au Cairc, le petit fragment à Madrid dans l'atelier de Fortuny.

I 43 Grand tapis dit de Bagdad, décor à nombreux compartiments à fonds et à forme divers, cernés du même ruban continu bistre. Le détail ornemental est presque exclusivement chinois. Dans des compartiments fond bleu : lutte du dragon et du phénix; dans des compartiments fond rouge; rinceaux d'ara- 


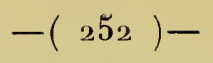

besques avec palmettes, asters et grues (symbole chinois de longue vie). Dans des compartiments fond vert: arabesques symétriques de tchi. Le fond crème, sur lequel se détachent les compartiments, s'ornc lui-même d'arabesques à palmettes, de rinceaux et de tchi. Autour, une large bande fond rouge décorée d'arabesques, de rinceaux et de grues, avec compartiments à reproduction symétrique et à décor d'arabesques et de tchi, alternant avec des compartiments polylobćs réguliers, décorés de la même lutte du phénix et du dragon. L'encadrement se borde lui-même de bandes jaunes à décor d'arabesques et de tchi. Ce type nous parait originaire des fronticeres chinoises de la Perse et son invention contemporaine de la dynastie mongole, $x_{1}{ }^{e}$ et $x^{e}$ siècles.

I 144 Tapis de laine bouclé à deux hauteurs avec parties lisses. Le clamp principal, partagé en nombreux compartiments cernés d'un ruban déchiqueté dans le goût chinois, se décore de palmettes, de palmes, d'arabesques et d'asters avec quelques oiseaux. Aux angles du champ principal des caravelles porturaises rojuent sur une mer où apparaissent des poissons et des naufragés; autour un encadrement à large ruban formant compartiments, dans lesquels réapparaissent palmettes et rinceaux. Cetapis, dont nous ne connaissons pas de similaire, dut être fait sur commande au moment des grancles découvertes géographiques de la Renaissance. Nous le pensons originaire des confins de, la Perse, de Samarkande peut-être.

I145 Tapis de laine, décor sur fond rouge avec bordure sur fond bleu foncé, semis de larges palmettes et de tiges fleuries établis sur un fin ruban rappelant le tchi qui divise la composition en compartiments losangés. Dans la bordure se superposent de belles tiges fleuries à reproduction symétrique, est de la Perse, $\mathrm{x} v^{\circ}$ siècle.

I 46 Grand tapis de laine, à composition très chargée, du type à animaux, décor de tiges fleuries à parti pris symétrique et de palmettes et d'arabesques, divers compartiments, rappelle le genre de composition du no ${ }_{1} 39$, Perse, xvie sićcle.

1147 Petit tapis à décor persan, du $\mathrm{xvi}^{\mathrm{c}}$ siècle. 


\section{$-(253)-$}

1148 Tapis de laine sur fond quadrillé or, avec bordure sur fond quadrillé argent, décor de fines arabesques, Indes, xvir ${ }^{\mathrm{e}}$ siècle.

I 49 Tapis de laine fond rouge à bordure vert foncé, décor exclusivement conventionnel de palmettes et de tchi, Purse, xvrre sičcle.

I 5 o Tapis de laine, décor de palmes, palmettes et arabesques sur fond rouge, Afghanistan, $\mathrm{xvr}^{\mathrm{e}}$ et $\mathrm{xvI}^{\mathrm{e}}$ siècles.

I 5 I Tapis (dit polonais) bouclé soie, lamé or et argent, décor de rinceaux et d'arabesques, $x^{2} I^{e}$ siècle. On ne s'accorde pas sur l'origine de ces tapis. Sous le régne de Sobieski, roi de Pologne (1629-1696), on les connut en Europe, soit qu'il les rapportât comme butin de guerre lors de ses expéditions dans le Caucase et la Tartarie, soit que ces tapis aient été réellement exécutés en Pologne par des ouvriers orientaux.

I 52 Tapis (dit polonais), même genre que le précédent.

1 53 Fragment de tapis (dit polonais), du xvi1 ${ }^{e}$ siècle.

I 54 Tapis de laine, décor de palmettes, rinceaux et tchi sur fond rouge avec bordure fond vert, Perse, $x_{v i{ }^{e}}$ siècle.

I 55 Petit tapis de laine fond rouge avec encadrement sur fond bistre, décor exclusif d'arabesques et de tchi avec tendance à la représentation géométrique, Perse, $\mathrm{xvir}^{\mathrm{e}}$ siècle.

¿156 Tapis bouclé soie sur fond or à ordonnance de semis d'animaux, Perse, xvir ${ }^{\mathrm{e}}$ siècle.

I 157 Tapis à décor géométrique, Maroc, $\mathrm{xv}^{\mathrm{e}}$ et $\mathrm{xvr}^{\mathrm{e}}$ siècles.

\158 Divers tapis de selle à décor, dans le goût persan, de tulipes, d'œillets et de jacinthes, Asie Mineure, xvir ${ }^{e}$ et xirr ${ }^{e}$ sićcles.

I 159 Divers fragments de tapis anciens, d'Asic Mineure.

I6o Grand tapis dans le goût persan, $\mathrm{xvII}^{\mathrm{e}}$ siècle.

I 61 Petit barda de Karamanie, $\mathrm{x}_{\mathrm{r}} \mathrm{I}^{\mathrm{e}}$ siècle.

I 62 Tapis à décor de trois couronnes dont le champ s'orne d'arabesques, travail espagnol, $\mathrm{xvI}^{\mathrm{e}}$ siècle. 


\section{PASSEMENTS ET DENTELLES}

I 63 Fragment de broderie soie sur toile à fond réservé, décor de rinceaux et de figures d'enfants, travail anglais, $x v^{e}$ siècle.

I 164 Broderie soie sur toile à fond réservé, fin $\mathrm{xv}^{\mathrm{e}}$ siècle.

1 I 65 Suite de nappes et napperons à décor de filet brodé, Italie? $\mathrm{xvI}^{\mathrm{e}}$ siècle.

I 66 Filet brodé, décor conventionnel symétrique, Italie, $\mathrm{xvI}^{\mathrm{e}}$ siècle.

I167 Filet brodé, décor de grands personnages (chasseurs entourant une princesse, le faucon au poing), France, époque de Henri IV.

1 I 68 Divers filets brodés orientaux anciens.

1169 Suite de carrés en filet brodé.

1170 Broderie à point coupé, décor à la tulipe, Espagne, fin du $\mathrm{xvI}^{\mathrm{e}}$ siècle.

$117 \mathrm{I}$ Divers spécimens point coupé, $\mathrm{xVI}{ }^{\mathrm{e}}$ siècle et suivants.

$17^{2}$ Suite de passements à fil tiré, Venise, $\mathrm{xv}^{\mathrm{e}}$ et $\mathrm{xvI} \mathrm{I}^{\mathrm{e}}$ siècles.

${ }_{11} 73$ Passement à fil tiré rehaussé de broderie d'or, Venise, $\mathrm{xvI}^{\mathrm{e}}$ siècle. (Don de Mme Ed. Aynard.)

I174 Echantillon de fil tiré rebrodé soie, décor de sirènes et d'animaux, travail italien, $\mathrm{xvl}^{\mathrm{e}}$ siècle.

1 I 75 Divers échantillons fil tiré, Italie, $\mathrm{x} v 1^{\mathrm{e}}$ siècle,

${ }_{11} 7^{6}$ Curielix échantillonnage de divers points à fil tiré, Venise $\mathrm{xvI}^{\mathrm{e}}$ siècle. 
177 Large bande de passementerie à fil tiré, décor de rinceaux et de fleurons conventionnels, Italie, fin du Xvi ${ }^{e}$ siècle. (Don de $M^{\mathrm{me}}$ Ed. Aynard.)

I $7_{7} 8$ Bande dentelée et campanée au point noué, Espagne, xviI sičcle. (Don de Mme Ed. Aynard.)

1'79 Suite de passements dantelés, Venise, commencement du $\mathrm{xvi}{ }^{\mathrm{e}}$ siècle.

1180 Bande dentelée, dentelle à fil tiré sur linon, Danemark, xviJie sic̀cle.

I18I Courte-pointe passement dit de Cluny, Venise, $\mathrm{xr}^{\circ}$ siècle.

I 182 Point ${ }^{1}$ de Venise à rinceaux dans le goût arabe, Venise, fin du $\mathrm{xvI}^{\mathrm{e}}$ siecle.

I 83 Type de point de Venise plat, ramages sur fond de brides, dentelle dite point d'Espagne, époque de Louis XIII.

I 84 Grand col plat, point de Venise à reliefs, ramages sur fond de brides, époque de Louis XIII. (Don de $\mathbf{M}^{\mathrm{m}}$ Ed. Aynard.)

1185 Grand col plat à décor rayonnant, point noué dit d'Espagne, Venise, époque de Louis XIII.

I 86 Divers échantillons du même genre.

${ }_{1187}$ Divers échantillons de points de Venise à grands ramages à reliefs sur fond de brides, Venise, $\mathrm{XvI}^{\mathrm{e}}$ et $\mathrm{Xv}^{\mathrm{v} I I^{c}}$ siècles.

1188 Fragment de volant point de rose, décor sur fond de brides régulières, Venise, époque de Louis XV. (Don de $\mathrm{M}^{\mathrm{me}} \mathrm{Ed}$. Aynard.)

I 89 Col et manchettes point de rose, Venise, époque de Louis XV.

I rgo Petit volant au point de rose, Venise, époque de Louis $\mathrm{Xr}$.

1 Le nom de "point" est réservé à la seule dentelle à l'aiguille. 


\section{$-(256)-$}

19. Divers petits volants, décor imité de Venise au point de France, époque de Colbert.

r $9^{2}$ Col point de France, époque de Colbert.

I $9^{3}$ Beau point de France, décor influencé par l'école de Bérain, époque de Louis XIV.

I 94 Petit volant point d'Alençon, décor de tiges fleuries sur réseau à mailles hexagonales avec bordure sinueuse enrichie de jours divers, Alençon, époque de Louis XV.

1 ig Divers échantillons du même genre, Alençon ou Argentan, époque de Louis XV.

$119^{6}$ Petit volant point d'Alençon à semis de fleurettes, de pois, etc., époque de Louis XVI.

I 97 Divers échantillons du même genre, Alençon ou Argentan, époque de Louis XVI.

I $9^{8}$ Petit volant point d'Alençon, décor à semis, fin du $x_{v i l I^{c}}$ sic̀cle.

I 99 Divers échantillons du même genre, Alençon ou Argentan, de la fin du xvin ${ }^{e}$ siècle.

1200 Rochet d'évêque, médaillons avec bouquets, guirlandes et rubans d'expression très réaliste, sur réseaux à mailles changeant dans les différentes parties du décor; pièce de premier ordre passant pour avoir appartenu a Marie-Antoinetle, Argentan, époque de Louis XVI.

120 I Trois échantillons dentelle de Bruxelles, fin du rigne de Louis XIV. (Don de M. Aug. Isaac.)

1202 Barbe de dentelle dite d'Angleterre, à décor de lignes ondulées, époque de Louis XV.

I 203 Divers échantillons point de Bruxelles des xvil et $x^{e}{ }^{e}{ }^{e}$ sieccles.

I 204 Fond de bonnet, dentelle de Bruxelles, époque de Louis XVI.

1205 Barbs point de Bruxelles, sujet de chasse, commencement du xvin ${ }^{\mathrm{e}}$ siècle. 
1206 Point à l'aiguille, Bruges, $\mathrm{xvII}^{\mathrm{e}}$ siècle.

1207 Guipure de Gênes, $\mathrm{xvI}^{\mathrm{e}}$ siècle.

1208 Petit bonnet au point de Malte, $\mathrm{XvII}^{\mathrm{e}}$ siècle.

1209 Bande de broderie ajourée pour linge d'autel, décor de rinceaux

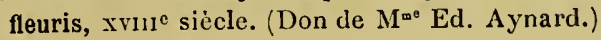

\2 ro Col point régence, Bedfort, xviII siècle.

1211 Broderie soie sur batiste, bordée de passementerie de soie, sujet religieux, travail italien du $\mathrm{xvI}^{\circ}$ siècle.

1212 Dentelle au point noué, décor rayonnant, Paraguay, Xvili ${ }^{\mathrm{C}}$ siècle.

1213 Bonnet vénitien brodé or et soies polychromes sur taffetas vert, Venise, $\mathrm{xvII}^{\mathrm{e}}$ siècle.

1214 Dentelle au fuseau, barbe de Valenciennes, époque de Louis XV.

1215 Divers échantillons du même genre.

1216 Dentelle au fuseau, barbe de Malines, décor à grands ramages

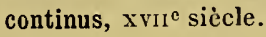

1217 Divers échantillons du même genre.

1218 Dentelle au fuseau, barbe de Malines, décor de lignes sinueuses ornées, époque de Louis XV.

1219 Divers échantillons du même genre.

1220 Dentelle au fuseau, une paire de manchettes Malines, époque de Louis XV.

1221 Dentelle au fuseau, petit volant de Malines, de l'époque de Louis XVI.

1222 Divers échantillons du même genre.

1223 Dentelle au fuseau, col de Malines, commencement du xviII $^{c}$ siècle.

1224 Dentelle au fuseau, un col, Binche, ${\mathrm{x} v \mathrm{I}^{\mathrm{C}}}$ siécle. 


\section{$-(258)-$}

1225 Dentelle au fuseau, petit volant, Binche, époque de Louis XV.

I 226 Dentelle au fuseau, un fond de bonnet, Binche, $x v r^{e}$ siècle.

I227 Dentelle au fuseau, barbe, Binche, xvire siècle.

1228 Dentelle d'ameublement au fuseau, décor de grands ramages symétriques avec personnages et animaux (sujets de chasse), Flandre, $\mathrm{xvrl}^{\mathrm{e}}$ siècle.

I229 Dentelle au fuseau, deux échantillons, Flandre, xvirre siècle.

123o Grand volant de Bruxelles, mélange d'aiguille et de fuseau, xvire siècle. (Don de $\mathrm{M}^{\mathrm{m}}$ Aynard.)

123 I Dentelle au fuseau. Fragment, sujet religieux, Bruxelles, xvire siècle.

1232 Devant de robe guipure de Flandre, xvrr ${ }^{e}$ siècle.

1233 Suite d'échantillons de guipure ordinaire, du $\mathrm{xvII}^{\mathrm{e}}$ siècle et suivants.

1234 Devant d'autel guipure, décor de rinceaux, d'armoiries et d'accessoires religieux, Flandre, $x$ rr $^{\mathrm{e}}$ siècle.

г23ã Dentelle d'ameublement au fuseau, décor d'animaux et de cartouches avec personnages allégoriques, Italie, xvrre siècle. (Don de $\mathbf{M}^{\mathrm{m}} \mathrm{E}$ Ed. Aynard.)

I236 Barbe de dentelle dite d'Angleterre, époque de Louis XVI. (Don de M. Aug. Isaac.)

I237 Dentelle au fuseau. Petit volant à décor de rinceaux, d'accessoires religieux et de saints personnages, Brabant, époque de Louis XIlI. (Don de M. Aug. Isaac.)

I238 Suite d'échantillons de passementerie d'or et d'argent, Espagne, $\mathrm{x}$ vire siècle.

I239 Dentelle au fuseau, Espagne, xvire siècle.

1240 Divers échantillons dentelle de Lille, xvirı siècle.

I24 I Divers échantillons dentelle de Chantilly (blondes), xvin ${ }^{\circ}$ siècle. 


$$
-(259)-
$$

$12 / 2$ Voile de soie broderie or et soies polychromes, sans envers, Indes orientales, $\mathrm{xvin}^{\mathrm{e}}$ siècle. (Don de $\mathrm{M}^{\mathrm{me}}$ Ed. Aynard.)

1243 Gants avec manchettes, brodés soie or et perles fines, travail français du xviI ${ }^{e}$ siècle. (Vente Spitzer.)

1244 Suite de broderies arméniennes. (Don de Mme Ernest Chantre.)

1245 Mouchoir brodé, époque de Napoléon III. (Don de M. Dumond.)

I246 Col brodé, époque dé Napoléon III. (Don de Mme la comtesse de Renéville.)

1247 Suite de broderies à fil tiré de fabrication scandinave moderne.

1248 Suite d'échantillons de dentelles modernes de la maison Dognin et Cie. (Don de M. Aug. Isaac.) 


\section{EXTRÊME ORIENT}

I249 Broderie sur satin, application sertie, décor de canards et de nénuphars, Chine, époque du haut moyen âge.

1250 Collection de tissus chinois anciens, $\mathrm{xv}^{\mathrm{e}}$ siècle et suivants.

I25̃ Tableau de haute lisse représentant le dieu Fô (Boudha) dans sa gloire, vénéré par deux bonzes, Chine, fabrique de Ke-seu, premières annies du ${\mathrm{x} v 1^{\mathrm{e}}}$ sićcle. (Collection Callery.)

1252 Panneau de haute lisse en soie (chrysanthèmes et insectes), fabrique de Ke-seu, Chine, xve, xvic siècles.

1253 Deux plastrons de mandarins tissu espouliné, particulier à la fabrique de Sou-Tchou, Chine, xv $\mathrm{I}^{\mathrm{e}}$ siècle.

1254 Robe impériale brodée soie et or, décor au dragon à cinq griffes des manufactures impériales chinoises, $\mathrm{xvI}^{\mathrm{e}}$ siècle.

1255 Suite de robes impériales avec dragon à cinq griffes, tissu Ke-seu. (Gobelins chinois), des $\mathrm{XVI}^{\mathrm{e}}$, $\mathrm{xVII}^{\mathrm{e}}$ et $\mathrm{xVIII}^{\mathrm{c}}$ siècles.

1256 Grand panneau broderie soies polychromes sur toile de soie, décor de fleurs et d'animaux, Chine, $\mathrm{xv}^{\mathrm{e}}$ et $\mathrm{xvI}^{\mathrm{e}}$ siècles.

1257 Divers tissus de soie peints pour tenture décorés de branches fleuries et d'oiseaux, Chine, $\mathrm{XvII}^{\mathrm{e}}$ et $\mathrm{xvII} \mathrm{I}^{\mathrm{c}}$ siccles.

r258 Fragment de tapis, peinture sur satin, sujet de guerre, Chine, XviII ${ }^{\mathrm{C}}$ siècle.

I 259 Grand tapis chinois, décor de lions, de phénix et d'accessoires divers, des fabriques impériales de Pékin, $\mathrm{xvI}^{\mathrm{e}}$ et $\mathrm{xvII}^{\mathrm{e}}$ siè- 


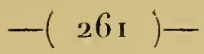

cles. (Donné par Napoléon Ier au Conservatoire des Arts et Métiers de Lyon.)

1260 Grand tapis brodé soies polychromes à grand décor floral sur fond satin grenat, Chine, xvile siècle.

1261 Grand panneau brodé soies polychromes, décor de fleurs et d'oiseaux sur fond drap jaune impérial (provient du Palais d'Été), Chine, xvir siècle. (Don du maréchal de Palikao.)

${ }_{12} \mathrm{G}_{2}$ Grand paravent vieux laqué d'or du Japon, décor de sujets de chasse, $\mathrm{xvIl}^{\mathrm{e}}$ siècle. (Collection Rougier.)

1263 Foukoussa ${ }^{1}$, décor de hérons sur l'eau, broderie soie et or sur fond satin rayé de rouge, de bleu et de gris, Japon, $\mathrm{xvil1}{ }^{\circ}$ siècle. (Vente de Goncourt.)

I 264 Foukoussa, pivoines roses et blanches brodées soies polychromes et or sur velours rouge, Japon, $\mathrm{xvII}^{\mathrm{e}}$ siecle. (Vente de Goncourt.)

I 265 Foukoussa, décor peint et rehaussé de broderie, décor de personnages au bord de la mer par un soleil couchant, Japon, xvil ${ }^{\mathrm{e}}$ sićcle. (Vente de Goncourt.)

I 260 Foukoussa, coq, poule et poussins, broderies soies polychromes sur satin bleu, Japon, XviI ${ }^{\mathrm{e}}$ siècle. (Vente de Goncourt.)

I267 Collection de foukoussas japonais peints et brodés, Japon, $\mathrm{xv}^{\mathrm{e}}$ siècle et suivants.

I268 Robe japonaise ancienne brodée d'éventails sur satin, xril et $\mathrm{xvIII}^{\mathrm{e}}$ siècles.

1269 Collection d'étamines brochées pour robes, Japon, xrile et xvire siècles. (Vente Hayashi.)

1270 Collection de petits sacs pour masques de théâtre, tissus anciens du Japon, XVII ${ }^{\mathrm{e}}$ et $\mathrm{Xvil}^{\mathrm{e}}$ siecles. (Vente IIayashi.)

1 lílolfe japonaise pour envelopper les présents. 
1271 Collection de tissus anciens de soie du Japon, xvile siécle et suivants. (Vente Hayashi.)

I272 Étoffe de Java, coton imprimé en trois couleurs (noir, rouge et bleu), représentant un épisode du Mahabarata sur la guerre de Rama, secondé par les sages, xvie siècle (?)

${ }_{1273}$ Tunique siamoise, broderie de métal ajourée avec dentelle d'or rehaussśe de paillettes, Siam, xvire siècle.

1274 Divers échantillons de crépons japonais modernes, donnés par l'Impératrice Eugénie.

I275 Foukoussa, décor de grues dans des branches fleuries, broderie moderne de líioto.

1276 Grande tenture japonaise velours épinglé rouge décoré d'éventails peints avec parties découpées, Exposition de i889.

1277 Grande tenture japonaise, broderie sur fond bleu, décor de cailles dans des plantes de marais, Exposition de 1889 .

1278 Grande tenture japonaise sur fond mais, décor de chrysanthèmes et d'oiseaux, Exposition de 1889.

1279 Grande tenture japonaise, broderie à reliefs sur fond rouge rayé d'or, d'un paysage d'hiver, Exposition de 1889 .

1280 Grande tenture japonaise moderne, broderie sur fond mais, décor de chrysanthèmes et d'oiseaux, Exposition de $\mathbf{1 8 8 9}$.

128I Collection de tissus japonais moderne de l'Exposition de Chicago, (Don de M. E. Guimet.)

1282 Divers échantillons de tissus de soie façonnés, de fabrication moderne japonaise. (Don de M. A. Chabrières.) 


\section{MISES EN CARTE}

On appelle mise en-carte le transport, sur un papier quadrillé spécial, du dessin d'une étoffe; chaque petit carré y représente un eroisement de fils. La mise en carte sert au montage du métier.

I283 Deux grandes mises en carte, tableaux de fleurs de Jean van Huysum, datées de 1722 et 1723 .

1284 Diverses collections de mises en carte, époque de Louis $\mathrm{XV}$.

t285 Collection de mises en carte de la maison Galli-Galien, époques de Louis XV et Louis XVI.

I286 Mise en carte pour une tenture commandée par la grande Catherine de Russie pour le Kremlin (voir au Musée l'exécution), dessin de Philippe de la Salle, époque de Louis XVI.

I287 Mises en carte pour portraits de la grande Catherine et de grands personnages de la cour de Russie, commandées pour les ameublements du Kremlin, dessin de Philippe de la Salle, époque de Louis XVI.

I 288 Mise en carte pour la chambre de Marie-Antoinette à Fontainebleau, dessin de Philippe de la Salle, époque de Louis XVI.

I 89 Diverses mises en carte de dessins de tenture de Philippe de la Salle, époque de Louis XVI.

I29o Mises en carte des portraits de Louis XVI et Marie-Antoinette pour les tableaux tissés des testaments de Louis XVI et MarieAntoinette, par Maisiat (1827). 


$$
-(264)-
$$

1291 Mise en carte du portrait tissé de Jacquard, daprès Bonnefond exécutée par Didier-Petit, époque de Louis-Philippe.

1292 Diverses mises en carte de dessins de tenture, époque du Consulat.

1293 Diverses collections de mises en carte, époque du premier Empire.

r 294 Diverses collections de mises en carte, époque de la Restauration.

$129^{5}$ Diverses mises en carte, époque de Louis-Philippe. 
COLLECTION DE PETITS MODÉLES DE MÉTIERS

\section{POUR LE TISSAGE DES ÉTOFFES}

I 296 Métier égypto-grec.

I297 Métier chinois pour étoffes façonnées.

I 298 Métier de Jean Calabrais, importé en France sous Louis XI.

1299 Métier dit à la grande tire, inventé à Lyon par Claude Dangon, tisseur, vers 1605 .

¡30\% Métier à bouton, dit à la petite tire, inventé à Lyon par Galantier et Blache, en 6 $687_{7}$.

13or Premier métier mécanique, inventé par Degenne, officier de marine, en 1677 .

1302 Métier pour petit façonné, inventé en $\mathbf{7 2 5}$, par Basil e Bouchon ouvrier passementier.

1303 Métier pour grand façonné dérivant du précédant. invention des griffes et crochets, par Falcon, de ${ }_{172} 8$ a ${ }_{17} 34$.

ı304 Métier à cylindre rond, inventé par Vaucanson, en 1744 .

₹ 305 Métiers pour faire plusieurs armures dites accrochages, inventé a Lyon par Ponson, ourrior tisseur, en 1766 .

I306 Métier de petit façonné dit ligature, inventé à Lyon par Verrier, ourrier tourneur sur bois, en 1790 .

1307 Métier dit à la Jacquard, métier de Vaucansol perfectionné, invention du cylindre carré, par Jacquard, en $\mathbf{1 8 0 4}$. 


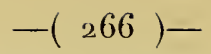

1308 Fac-similé de la mécanique Jacquard, dont l'original est aı Conservatoire des Arts et Métiers à Paris.

13 og Métier de velours coupé façonné à cantre. (Collection Gautier.)

I3 ı Métier pour gaze façonnée à corps anglais. (Collection Gautier.)

ı3ı Métier pour damas satin monté à pointe. (Collection Gautier.)

1312 Métier avec application d'un nouveau mode de presse et pièce coudée, pour opérer le dégriffement de la mécanique Jacquard, par Jacques Matheron (1862). Modèle reproduit par Marin. (Don de MM. Mathevon et Bouvard.)

13ı3 Métier pour châles, fond et bordure. (Collection Gautier.)

1314 Métier de droguet. (Collection Gautier.)

ז3.5 Métier de meuble genre taille-douce et à pointe. (Collection Gau(ier.)

13,6 Métier à la barre pour la fabrication des rubans et passementeries (Emile Fleuret, chef d'atelier, Lyon, I $89^{2}$ ).

13 i 7 Petit métier mécanique pour fabriquer l'armure tricot, inventé et exécuté par François Aubert, en 1804.

1318 Appareils pour le lisage et la confection des cartons pour la mécanique Jacquard.

13 r9 Echantillons et appareils cochinchinois, relatifs au travail de la soie.

${ }_{1320}$ Collection de navettes et autres ustensiles de tissage, par M. Orelle. (Don de M. Orelle.)

1321 Collection de peignes pour tissus spéciaux, gaze tour anglais, tissus perlés, toile métallique, etc.

1322 Machine à coudre au point de chainette, essai de r829 par Thimonnier de Lyon, inventeur de la couture mécanique. (Donnée par les héritiers de l'auteur.) 


$$
-\left({ }_{26} 6_{7}\right)-
$$

1323 Couso-brodeur, système Thimonnier, perfectionné par Magnin, médaille de première classe à l'Exposition de I855. (Donné par l'auteur.)

1324 Collections de cocons de vers à soie.

1325 Collections de papillons de vers à soie.

ז326 Collections Duseigneur-Kléber; a) Histoire des transformations du cocon du ver à soie du $\mathrm{Xvi}^{\mathrm{e}}$ au $\mathrm{xix}^{\mathrm{e}}$ siècles. Monographie du coeon; $b$ ) Maladies du ver à soie.

1327 Planisphères et statistiques pour l'industrie et le commerce des soieries à la fin du $\mathrm{xIx}^{\mathrm{c}}$ siècle, dressées, à l'occasion des Expositions de 1889 et de 1900 , sous la direction de M. Marius Morand, secrétaire de la chambre de Commeree de Lyon, par MM. Larbitray et Tortel. 



\section{T A B LE}

INTRODUCTION . . . . . . . . . . . . . . . . 9

PRÉCIS HISTORIQUE DE L'ART DE DÉCORER LES

TISSUS. . . . . . . . . . . . . . . $2 \mathrm{r}$

Période byzantine . . . . . . . . . . . . . 34

Art copte proprement dit . . . . . . . . 42

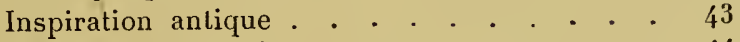

Inspiration byzantine . . . . . . . . . . 44

Inspiration sassanide . . . . . . . . . . 45

Période arabe

Califat du Caire . . . . . . . . . . . . 54

Califat de Bagdad. : . . . . . . . . 56

Califat de Cordoue . . . . . . . . . . . 63

L'art siculo-arabe. . . . . . . . . . 65

Période italienne . . . . . . . . . . . . . . 70

L.e $\mathrm{xv}^{\mathrm{e}}$ siècle . . . . . . . . . . . . . 78

Le $x{ }^{\mathrm{e}}$ siècle . . . . . . . . . . . . 87

PÉRIOde françaISE . . . . . . . . . . . . . $99^{0}$

Louis XV . . . . . . . . . . . . . 101

Louis XVI . . . . . . . . . . . . 106

Période contemporaine . . . . . . . . . 115

La Dentelle . . . . . . . . . . . . . . . 134

Dentelle à l'aiguille : Venise . . . . . . . . 139

- Alençon. . . . . . . . . . . . 141

- Bruxelles . . . . . . . . . . 144

Dentelle au fuseau : Valenciennes . . . . $144^{\circ}$

- Malines . . . . . . . . . . . 147 
Catalogue sommaire des Colllections . . . i 153

Principaux donateurs. . . . . . . . . . 155

Plan du Musée. . . . . . . . . . . . . ${ }^{156}$

Tissus de haute antiquité . . . . . . . . . 159

Période dite byzantine . . . . . . . . . . 159

Le costume . . . . . . . . . . . . . 160

Le manteau. . . . . . . . . . . . . 161

Coussins funéraires . . . . . . . . . 161

Tabulæ . . . . . . . . . . . . . . 162

Clavi . . . . . . . . . . . . . 163

Paragaudes . . . . . . . . . . . . . 164

Broderies coptes . . . . . . . . . . 165

Tissus coptes de soie . . . . . . . . . 167

Pémiode arabe . . . . . . . . . . . . . . I7I

Le $\mathrm{xiI}^{\mathrm{e}}$ siècle . . . . . . . . . . . . ${ }_{175}$

I.e $x_{1} v^{e}$ siècle . . . . . . . . . ${ }_{176}$

Période italienne . . . . . . . . . . . . . $\mathbf{I} 8 \mathbf{I}$

Période française. . . . . . . . . . . . 203

Louis XIV . . . . . . . . . . . . . 204

Louis XV, Régence . . . . . . . . . . 212

La majorité de Louis XV . . . . . . . . 214

Louis XVI . . . . . . . . . . . . . 219

Nos Contemporatns

Velours Grégoire . . . . . . . . . . . 236

Tapisseries . . . . . . . . . . . . . . 247

Tapis d'Orient. . . . . . . . . . 248

Passements et Dentelles . . . . . . . . . . 254

Extrême Orient. . . . . . . . . . . . . 260

Mise en Carte . . . . . . . . . . . . . . 263

Collection de petits modèles de Mútiers pour le

TISSAGE DES ÉTOFFES . . . . . . . . . 265

Lyon. - Imp. A. REY, 4, rue Gentil. - 30364 
, 

. 





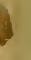


$a^{2} \times 18$

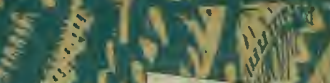
and

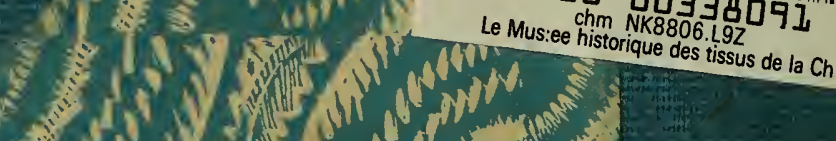

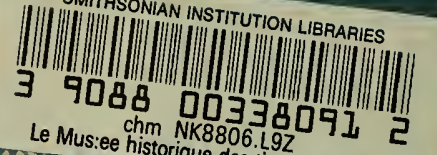

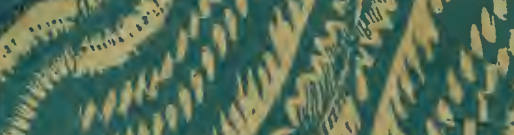

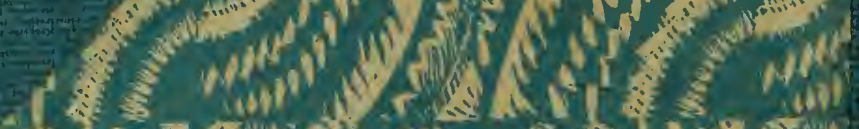

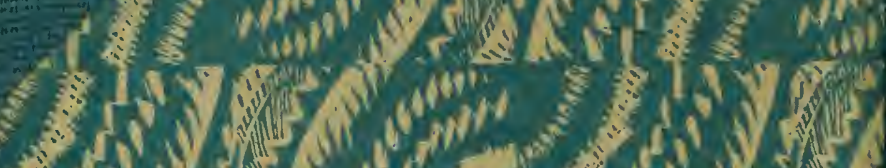

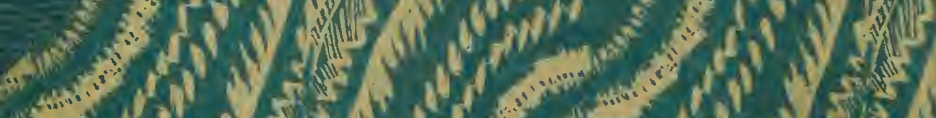

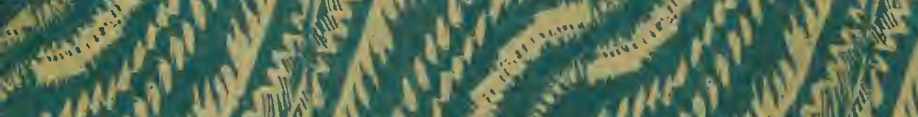

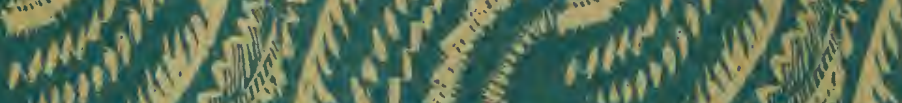

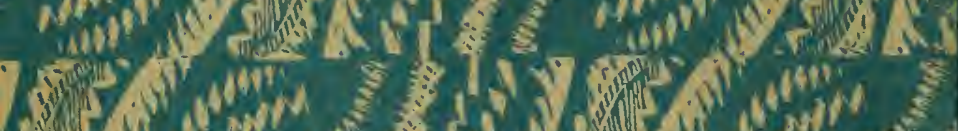

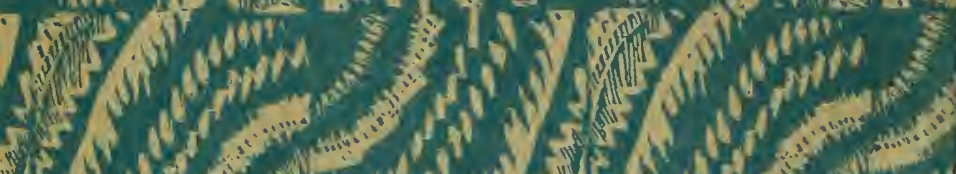

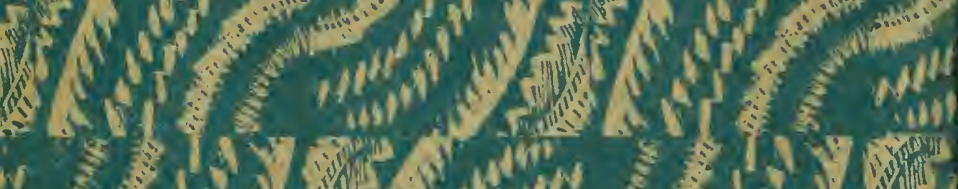

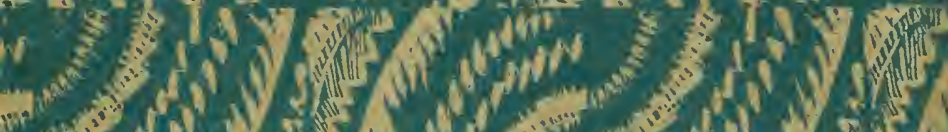

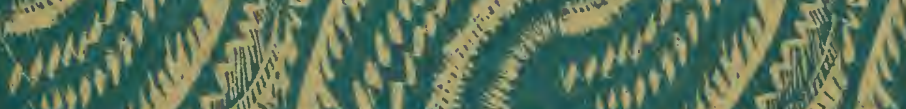

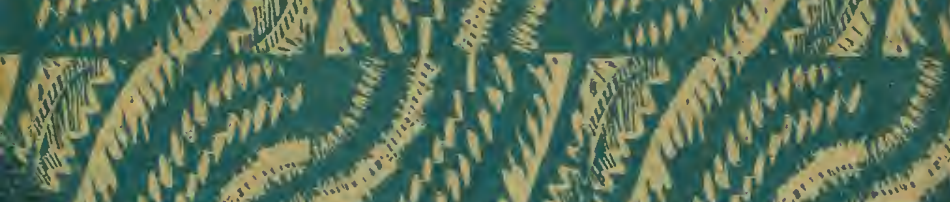

Q1:

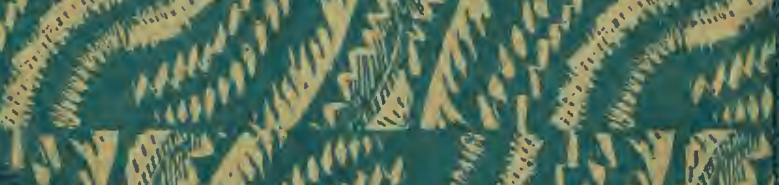

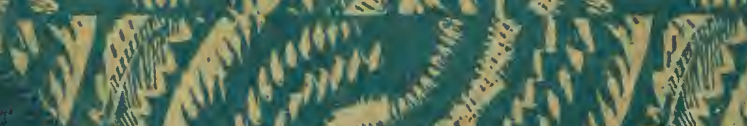

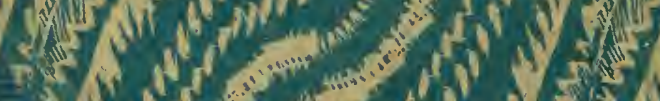

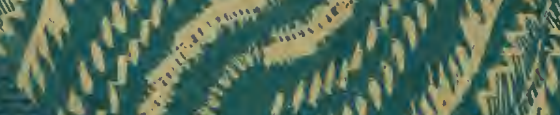

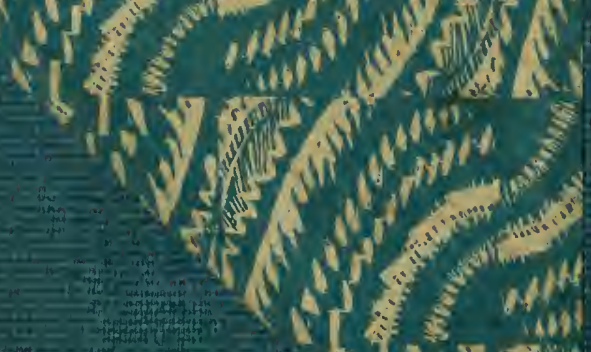

